Prepared for the U.S. Department of Energy

Under Contract DE-AC05-76RL01830

\title{
EFRT M-12 Issue Resolution: \\ Caustic-Leach Rate Constants from \\ PEP and Laboratory-Scale Tests
}

LA Mahoney

SD Rassat

PW Eslinger

RL Aaberg

PM Aker

EC Golovich

BD Hanson
TS Hausmann

JL Huckaby

DE Kurath

MJ Minette

SK Sundaram

ST Yokuda

January 2010

Pacific Northwest

NATIONAL LABORATORY

Proudly Operated by Battelle Since 1965 


\title{
DISCLAIMER
}

This report was prepared as an account of work sponsored by an agency of the United States Government. Neither the United States Government nor any agency thereof, nor Battelle Memorial Institute, nor any of their employees, makes any warranty, express or implied, or assumes any legal liability or responsibility for the accuracy, completeness, or usefulness of any information, apparatus, product, or process disclosed, or represents that its use would not infringe privately owned rights. Reference herein to any specific commercial product, process, or service by trade name, trademark, manufacturer, or otherwise does not necessarily constitute or imply its endorsement, recommendation, or favoring by the United States Government or any agency thereof, or Battelle Memorial Institute. The views and opinions of authors expressed herein do not necessarily state or reflect those of the United States Government or any agency thereof.

\author{
PACIFIC NORTHWEST NATIONAL LABORATORY \\ operated by \\ BATTELLE \\ for the

\section{UNITED STATES DEPARTMENT OF ENERGY} \\ under Contract DE-AC05-76RL01830
}

Printed in the United States of America

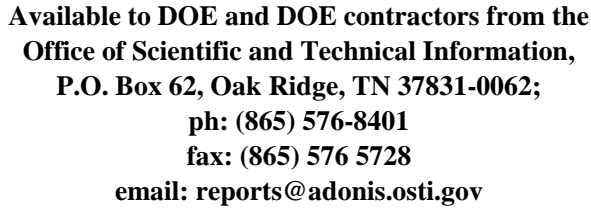

email: reports@adonis.osti.gov

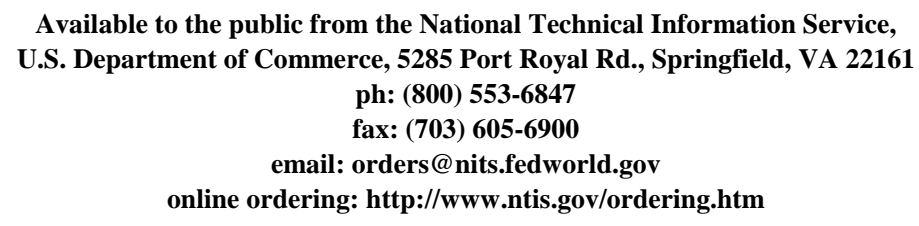




\section{EFRT M-12 Issue Resolution: Caustic-Leach Rate Constants from PEP and Laboratory-Scale Tests}

$\begin{array}{ll}\text { LA Mahoney } & \text { TS Hausmann } \\ \text { SD Rassat } & \text { JL Huckaby } \\ \text { PW Eslinger } & \text { DE Kurath } \\ \text { RL Aaberg } & \text { MJ Minette } \\ \text { PM Aker } & \text { SK Sundaram } \\ \text { EC Golovich } & \text { ST Yokuda } \\ \text { BD Hanson } & \end{array}$

January 2010

Test Specification: 24590-PTF-TSP-RT-07-001 Rev 2

Work Authorization: WA\# 2007-024

Test Plan: TP-RPP-WTP-506, Rev. 0.4; TP-WTP-PEP-044, Rev 0.2

Test Exceptions: 24590-PTF-TEF-RT-08-00002

24590-WTP-TEF-RT-09-00003

24590-PTF-TEF-RT-09-00001

24590-WTP-TEF-RT-09-00002 Rev 0

24590-WTP-TEF-RT-09-00001 Rev 1

R\&T focus area: Pretreatment

Test Scoping Statement(s): NA

Prepared for

the U.S. Department of Energy

Under Contract DE-AC05-76RL01830

Pacific Northwest National Laboratory

Richland, Washington 99352 


\section{COMPLETENESS OF TESTING}

This report describes the results of work and testing specified by Test Specification 24590-PTF-TSP-RT-07-001 Rev 2 "Pretreatment Engineering Platform (PEP) Testing (Phase 1)" and Test Plans TP-RPP-WTP-506 Rev 0.4 "Pretreatment Engineering Platform (PEP) Testing (Phase 1) and TP-WTP-PEP-044 Rev 0.2 "Test Plan for the PEP Parallel Laboratory Testing." The work and any associated testing followed the quality assurance requirements outlined in the Test Specification/Plan. The descriptions provided in this test report are an accurate account of both the conduct of the work and the data collected. Test Plan results are reported. Also reported are any unusual or anomalous occurrences that are different from expected results. The test results and this report have been reviewed and verified.

\section{Approved:}

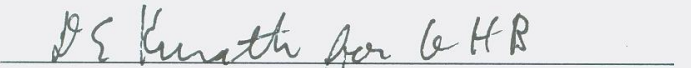

Gordon H. Beeman, Manager

WTP R\&T Support Project

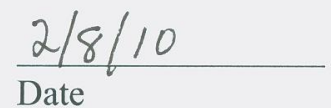




\section{REVISION HISTORY}

\begin{tabular}{|c|c|c|c|}
\hline $\begin{array}{l}\text { Revision } \\
\text { Number }\end{array}$ & $\begin{array}{c}\text { Interim } \\
\text { Change No. }\end{array}$ & Effective Date & Description of Change \\
\hline 0 & 0 & $8 / 14 / 09$ & Initial issue. \\
\hline 1 & 0 & When issued & $\begin{array}{l}\text { Throughout: Corrected "thermocouple" to the more general term } \\
\text { "temperature sensor." } \\
\text { Testing Summary: Made small changes in probability estimates and } \\
\text { the Integrated Test A scale-up factor for consistency with the } \\
\text { estimation methods used in the final report. Corrected a } \\
\text { typographical error in pump name. Updated QA section to reference } \\
\text { HDI instead of SBMS. } \\
\text { Section 2: Updated to reference HDI instead of SBMS. } \\
\text { Tables 3.9, 3.10, 3.11, 3.15, 3.18, 3.19, 4.1, 4.2: Reduced number of } \\
\text { significant figures in standard deviations. } \\
\text { Tables 4.3, 4.9: Made small changes in kinetic rate constants for } \\
\text { consistency with the estimation methods used in the final report. } \\
\text { Tables 4.5, 4.11: Corrected round-off for consistency with the final } \\
\text { report. } \\
\text { Section 5: As a response to a September } 2009 \text { CRESP review } \\
\text { comment, added recommendations for future laboratory-scale } \\
\text { parallel tests. Made small changes in probability estimates, the } \\
\text { Integrated Test A scale-up factor, and kinetic rate constants for } \\
\text { consistency with the estimation methods used in the final report. } \\
\text { Table B.1: Table heading corrected. } \\
\text { Table B.3: Reduced number of significant figures in standard } \\
\text { deviations. } \\
\text { Appendix C: Corrected a typographical error in Equation (C.1). As } \\
\text { a response to a September } 2009 \text { CRESP review comment, revised } \\
\text { the appendix to further explain the way in which the Monte Carlo } \\
\text { method was applied and to reference information on the technical } \\
\text { basis of the analytical uncertainties that were used. }\end{array}$ \\
\hline
\end{tabular}





\section{Contents}

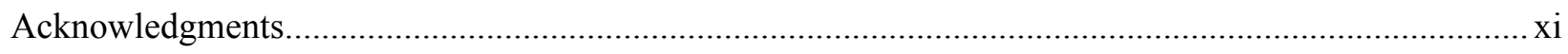

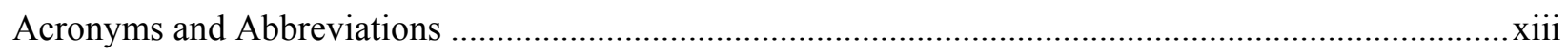

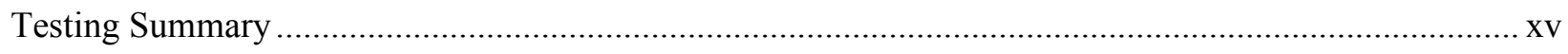

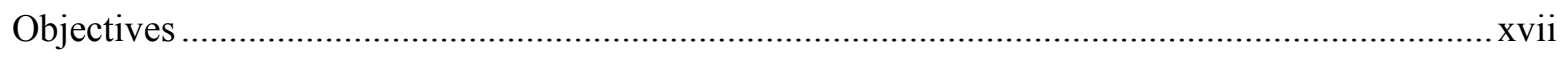

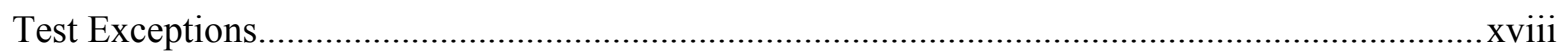

Results and Performance Against Success Criteria ..................................................................... xxiii

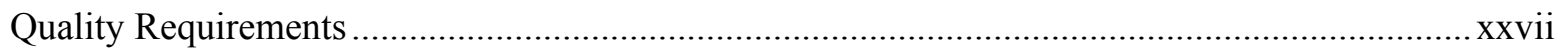

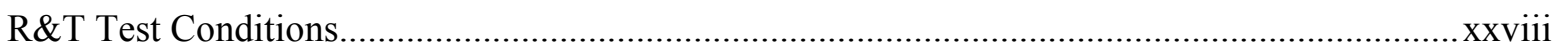

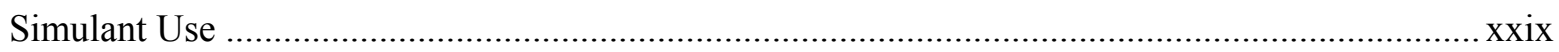

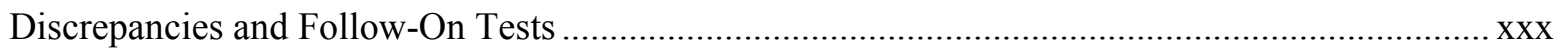

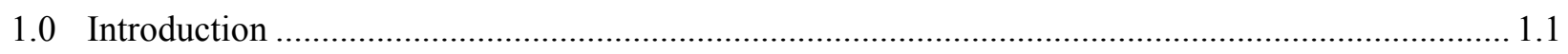

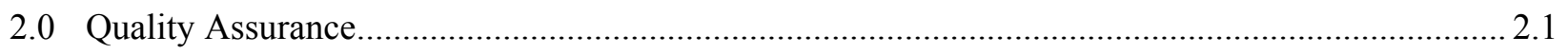

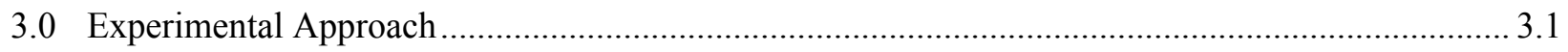

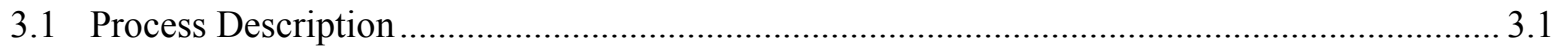

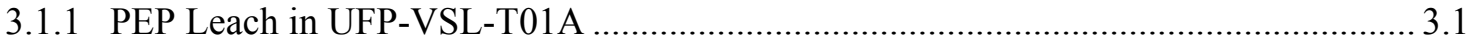

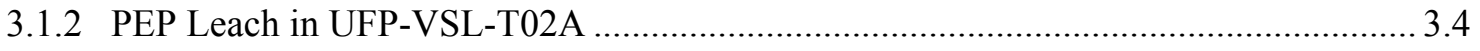

3.1.3 Laboratory-Scale Test Process …....................................................................... 3.13

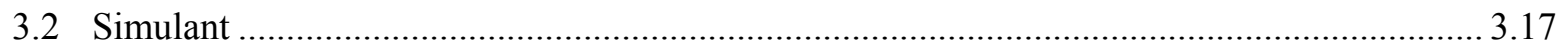

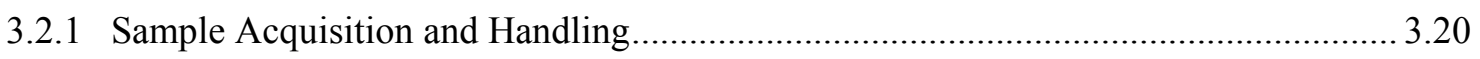

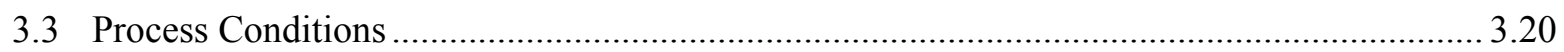

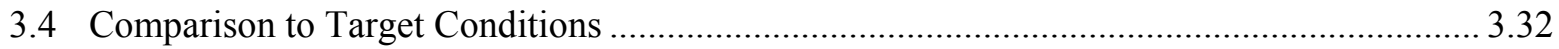

3.4.1 Comparison to Target Condensate Accumulation....................................................... 3.33

3.4.2 Comparison to Target Temperature-Time Profile ..................................................... 3.40

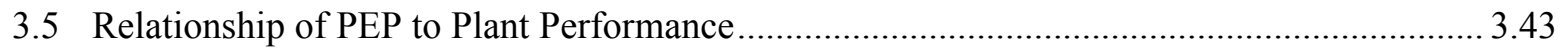

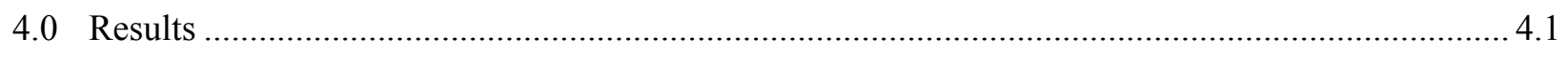

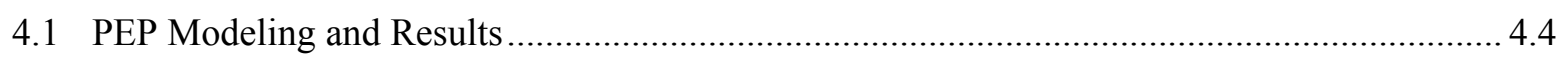

4.1.1 Initial Conditions for Kinetic Modeling of PEP Tests ............................................. 4.10

4.1.2 Results of Kinetic Modeling of PEP Tests .............................................................. 4.12

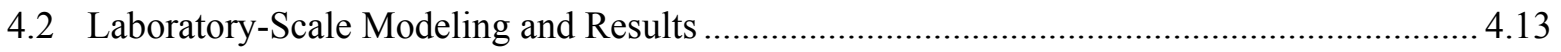

4.2.1 Initial Conditions for Kinetic Modeling of Laboratory-Scale Tests............................ 4.20

4.2.2 Results of Kinetic Modeling of Laboratory-Scale Tests .......................................... 4.24

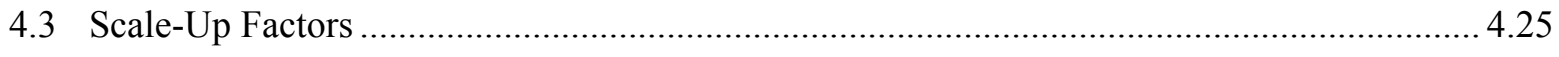

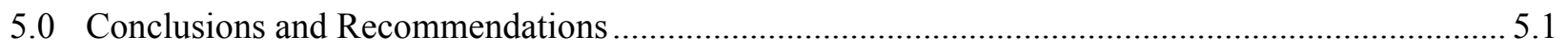

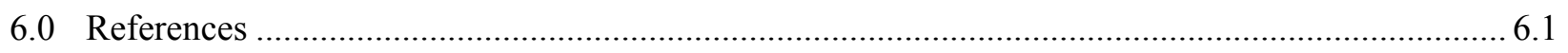


Appendix A Derivation of Equations Used in Leach Calculations..................................................... A.1

Appendix B Auxiliary Data Used in Leach Calculations ....................................................................

Appendix C Uncertainty Inputs to Monte Carlo Calculations and Uncertainties in Tabulations .............C.1

\section{Figures}

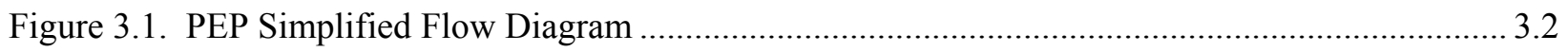

Figure 3.2. Caustic- and Oxidative-Leach and Ultrafilter Operations ................................................... 3.3

Figure 3.3. UFP-T02A In-Tank Sampling Showing the Three Radial Positions at Three Heights and Sampling Flow Loop

Figure 3.4. Volumes in UFP-T01A Associated with Direct Steam Injection During the Heat-Up and Caustic-Leach Periods of Integrated Test A Batch 1

Figure 3.5. Volumes in UFP-T02A Associated with Direct Steam Injection During the Heat-Up and Caustic-Leach Periods of Integrated Test B Batch 2

Figure 3.6. Temperature Measured at the "Prototypic" Sensor in PEP Vessel UFP-T01A During TI-065 Integrated Test A, Batch \#1.....

Figure 3.7. Temperature Measured at the "Prototypic" Sensor in PEP Vessel UFP-T02A During TI-066 Integrated Test B, Batch \#2.

Figure 4.1. Dilution Factors with 95\% Confidence Intervals During PEP Integrated Test A (caustic leaching in UFP-T01A).

Figure 4.2. Dilution Factors with 95\% Confidence Intervals During PEP Integrated Test B (caustic leaching in UFP-T02A).

Figure 4.3. Dilution Factors with 95\% Confidence Intervals for Laboratory-Scale Tests Paralleling Test A (caustic leaching in UFP-T01A).

Figure 4.4. Dilution Factors with 95\% Confidence Intervals for Laboratory-Scale Tests Paralleling Test B (caustic leaching in UFP-T02A)

Figure 4.5. Normalized Dissolved Al with 95\% Confidence Intervals During PEP Integrated Test A and Laboratory-Scale Tests A-1 and A-2 (caustic leaching in UFP-T01A)

Figure 4.6. Normalized Dissolved Al with 95\% Confidence Intervals During PEP Integrated Test B and Laboratory-Scale Tests B-1 and B-2 (caustic leaching in UFP-T02A). 


\section{Tables}

Table S.1. Summary of Test Objectives and Results ..............................................................................

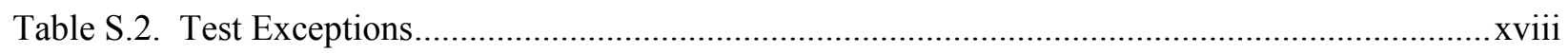

Table S.3. Deviations from Test Specification ................................................................................ xxi

Table S.4. Results and Performance Against Success Criteria ..........................................................xxiii

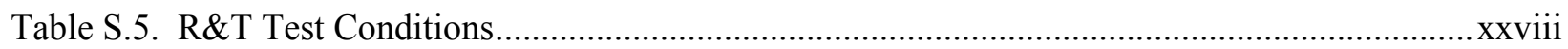

Table 3.1. Nominal Parameter Values for Integrated Test A (UFP-VSL-T01A leaching)...................... 3.5

Table 3.2. Caustic-Leach Batch Component Masses for PEP Integrated Test A Batch 1 ........................ 3.8

Table 3.3. Nominal Parameter Values for Integrated Test B (UFP-VSL-T02A leaching) .................... 3.10

Table 3.4. Caustic-Leach Batch Component Masses for PEP Integrated Test B Batch 2 .................... 3.14

Table 3.5. Experimental Parameters for Laboratory-Scale Versions of Test A.................................... 3.17

Table 3.6. Experimental Parameters for Laboratory-Scale Versions of Test B ................................... 3.17

Table 3.7. Simulant Feed Composition............................................................................................... 3.19

Table 3.8. Mass Concentration of Dissolved Aluminum During Caustic-Leach Tests ........................ 3.22

Table 3.9. Molal Concentration of Dissolved Aluminum During PEP Caustic-Leach Tests ................ 3.23

Table 3.10. Molar Concentration of Free Hydroxide During Caustic-Leach Tests ............................... 3.24

Table 3.11. Molal Concentration of Free Hydroxide During PEP Caustic-Leach Tests ....................... 3.25

Table 3.12. Water in Liquid Phase During PEP Caustic-Leach Tests ................................................. 3.25

Table 3.13. Liquid Density During PEP Caustic-Leach Tests........................................................ 3.26

Table 3.14. Mass Concentration of Aluminum in Bulk Slurry During Caustic-Leach Tests ................ 3.27

Table 3.15. Weight Fraction UDS During Caustic-Leach Tests........................................................ 3.28

Table 3.16. Slurry Density During PEP Caustic-Leach Tests ........................................................... 3.29

Table 3.17. Sample Timing During Caustic-Leach Tests .................................................................. 3.30

Table 3.18. Temperatures During Digestion Period For Caustic-Leach Tests ..................................... 3.31

Table 3.19. Temperatures for Each Sampling Period for PEP Caustic-Leach Tests ............................. 3.32

Table 3.20. Dilution of Liquid Phase During PEP Caustic-Leach Integrated Test A, Batch 1.............. 3.37

Table 3.21. Dilution of Liquid Phase During PEP Caustic-Leach Integrated Test B, Batch 2 .............. 3.41

Table 4.1. Aluminum and Boehmite Leach Factors for PEP Integrated Tests ..................................... 4.9

Table 4.2. Initial Conditions for Kinetic Modeling of PEP Integrated Tests....................................... 4.12

Table 4.3. Kinetic Model Results for PEP Integrated Tests ............................................................. 4.12

Table 4.4. Dilution Factors for Laboratory-Scale Tests ......................................................................... 4.16

Table 4.5. Boehmite Leach Factors for Laboratory-Scale Tests Parallel to PEP Integrated Test A....... 4.19

Table 4.6. Boehmite Leach Factors for Laboratory-Scale Tests Parallel to PEP Integrated Test B....... 4.20

Table 4.7. Total Al Concentration in the Initial Diluted Slurry in Laboratory-Scale Tests................... 4.21

Table 4.8. Initial Conditions for Kinetic Modeling of Laboratory-Scale Tests ................................... 4.24 
Table 4.9. Kinetic Model Results for Laboratory-Scale Tests.

Table 4.10. Scale-Up Factors and Their Basis Inputs for PEP Integrated Test A and Associated Lab Tests

Table 4.11. Scale-Up Factors and Their Basis Inputs for PEP Integrated Test B and Associated Lab Tests

Table 4.12. Sources of Uncertainty in Kinetic Rate Constants ....................................................... 4.28

Table 4.13. Comparison of Boehmite Leach Factors....................................................................... 4.30

Table 5.1. Scale-Up Factors and Kinetic Rate Constants for PEP Integrated and Laboratory-Scale Tests 


\section{Acknowledgments}

The authors would like to thank Wayne Cosby for valuable editorial support, Dave MacPherson and Kirsten Meier for Quality Assurance support throughout the project, and Reid Peterson, Gary Josephson, Evan Dresel, John Geeting, Phil Schonewill, and Gregg Lumetta for their careful and thorough technical reviews and discussions.

In addition to the authors, this report was supported by many dedicated staff involved in laboratory experiments, sampling, data acquisition, data processing, data-quality confirmation, technical reviews, and data analysis.

$\begin{array}{lll}\text { JM Alzheimer } & \text { CA Burns } & \text { RD Scheele } \\ \text { C Arimescu } & \text { JM Cuta } & \text { GJ Sevigny } \\ \text { DD Bachand } & \text { MS Fountain } & \text { SV Shoemaker } \\ \text { EBK Baer } & \text { CE Guzman-Leong } & \text { DM Smith } \\ \text { S Barnes } & \text { RE Hohimer } & \text { PS Sundar } \\ \text { AW Baumann } & \text { ML Kimura } & \text { JJ Toth } \\ \text { GH Beeman } & \text { WL Kuhn } & \text { JC Tucker } \\ \text { DL Blanchard Jr } & \text { WE Lawrence } & \text { MW Urie } \\ \text { JC Bower } & \text { S Lehrman } & \text { BE Wells } \\ \text { OP Bredt } & \text { RP Pires } & \text { JK Young } \\ \text { GN Brown } & \text { DE Rinehart } & \\ \text { SA Bryan } & \text { RL Russell } & \end{array}$

These individuals and the rest of the operations and sampling crew are especially recognized for supporting the Pretreatment Engineering Platform Project by working unpredictable, long, and off-hour shifts for the better part of a year. The tests and reports could not have gotten this far without their extraordinary effort. 



\section{Acronyms and Abbreviations}

AFA

ASME

ASO

$\mathrm{BNI}$

CD

CFR

CUF

DAS

DB

DIW

DOE

EFRT

HDI

IC

ICP

JTG

LCS

$\mathrm{M}$

$\mathrm{NaOH}$

ODE

PEP

PJM

PLM

PNNL

PTF

QA

QAM

QAP

QARD

RPP

RTD

$R \& T$

SwRI antifoam agent

American Society of Mechanical Engineers

Analytical Support Operations

Bechtel National Inc.

Coriolis densitometer

Code of Federal Regulations

Cells Unit Filter

data acquisition system

DrexelBrook (capacitance probe)

deionized water

U.S. Department of Energy

External Flowsheet Review Team

"How Do I...?" (PNNL requirements, policies, and procedures system)

ion chromatography

inductively coupled plasma

Joint Test Group

laboratory control sample

meter or molal

sodium hydroxide

ordinary differential equation

Pretreatment Engineering Platform

pulse jet mixer

polarized light microscopy

Pacific Northwest National Laboratory

Pretreatment Facility

quality assurance

Quality Assurance Manual

Quality Assurance Plan

Quality Assurance Requirements and Descriptions

River Protection Project

resistance temperature detector

Research and Technology

Southwest Research Institute 
TIC

UDS

UFP

WTP total inorganic carbon

undissolved solids

ultrafiltration process

Waste Treatment and Immobilization Plant 


\section{Testing Summary}

Pacific Northwest National Laboratory (PNNL) has been tasked by Bechtel National Inc. (BNI) on the River Protection Project-Hanford Tank Waste Treatment and Immobilization Plant (RPP-WTP) project to perform research and development activities to resolve technical issues identified for the Pretreatment Facility (PTF). The Pretreatment Engineering Platform (PEP) was designed, constructed and operated as part of a plan to respond to issue M12, "Undemonstrated Leaching Processes" of the External Flowsheet Review Team (EFRT) issue response plan. ${ }^{(a)}$ The PEP is a $1 / 4.5$-scale test platform designed to simulate the WTP pretreatment caustic leaching, oxidative leaching, ultrafiltration solids concentration, and slurry washing processes. The PEP replicates the WTP leaching processes using prototypic equipment and control strategies. The PEP also includes non-prototypic ancillary equipment to support the core processing.

Two operating scenarios are currently being evaluated for the ultrafiltration process (UFP) and leaching operations. The first scenario has caustic leaching performed in the UFP-2 ultrafiltration feed vessels (i.e., vessel UFP-VSL-T02A in the PEP and vessels UFP-VSL-00002A and B in the WTP PTF). The second scenario has caustic leaching conducted in the UFP-1 ultrafiltration feed preparation vessels (i.e., vessels UFP-VSL-T01A and B in the PEP; vessels UFP-VSL-00001A and B in the WTP PTF).

In both scenarios, $19 \mathrm{M}$ sodium hydroxide solution ( $\mathrm{NaOH}$, caustic) is added to the waste slurry in the vessels to leach solid aluminum compounds (e.g., gibbsite, boehmite). Caustic addition is followed by a heating step that uses direct injection of steam to accelerate the leaching process. Following the caustic-leach, the vessel contents are cooled using vessel cooling jackets and/or external heat exchangers. The main difference between the two scenarios is that for leaching in UFP-1, the $19 \mathrm{M} \mathrm{NaOH}$ is added to unconcentrated waste slurry (3- to 8 -wt $\%$ solids), while for leaching in UFP-2, the slurry is concentrated to nominally 20 -wt $\%$ solids using cross-flow ultrafiltration before adding caustic.

The PEP testing program was conducted under Test Plan TP-RPP-WTP-506 $6^{(\mathrm{b})}$ using a waste simulant that was developed in response to Task 5 from the M-12 External Flowsheet Review Team (EFRT) issue response plan. ${ }^{(a)}$ The testing included the following tests with simulated Hanford tank waste:

- Shakedown/Functional testing: Tested process operations (e.g., slurry transfers, steam heating of the vessels and the accumulation of condensate, filter backpulsing and flushing), process controls (e.g., transmembrane pressure and axial flow velocity in the filter-loop), certain test functions (e.g., in-line slurry sampling accuracy and precision).

- Integrated Test A: Demonstrated integrated processing when caustic leaching $\left(98^{\circ} \mathrm{C}\right)$ is performed in UFP-VSL-00001A/B with the Cr simulant component added after the post-caustic-leach washing step.

(a) SM Barnes, and R Voke. 2006. "Issue Response Plan for Implementation of External Flowsheet Review Team (EFRT) Recommendations - M12: Undemonstrated Leaching Process.” 24590-WTP-PL-ENG-06-0024 Rev. 0, Bechtel National Inc., Richland, Washington.

(b) GB Josephson, OP Bredt, JK Young, and DE Kurath. 2009. Test Plan for Pretreatment Engineering Platform (PEP) Testing (Phase I). TP-RPP-WTP-506, Rev. 0.4, Pacific Northwest National Laboratory, Richland, Washington. 
- Integrated Test B: Demonstrated integrated processing when the caustic leaching $\left(98^{\circ} \mathrm{C}\right)$ is performed in UFP-VSL-00002A with the Cr simulant component added after the post-caustic-leach washing step.

- Integrated Test D: Demonstrated integrated processing when the caustic leaching is performed at a lower temperature $\left(85^{\circ} \mathrm{C}\right)$ in UFP-VSL-00002A and with the $\mathrm{Cr}$ simulant component added to the initial batch of simulant.

Integrated Test $\mathrm{C}$ was deleted from the scope of the testing (ICN-TP-RPP-WTP-506_R0.2).

The work described in this report addresses caustic leaching under WTP conditions, based on tests performed with a Hanford waste simulant. Because gibbsite leaching kinetics are rapid (gibbsite is expected to be dissolved by the time the final leach temperature is reached), boehmite leach kinetics are the main focus of the caustic-leach tests. The tests were completed at the laboratory-scale and in the PEP, which is a $1 / 4.5$-scale mock-up of key PTF process equipment. Two laboratory-scale caustic-leach tests were performed for each of the PEP runs. For each PEP run, unleached slurry was taken from the PEP caustic-leach vessel for one batch and used as feed for both of the corresponding laboratory-scale tests.

The purpose of this report is to summarize the results from both scales that are related to caustic-leach chemistry to support development of a scale-up factor for the submodels to be used in the G2 model, which predicts WTP operating performance. The scale-up factor takes the form of an adjustment factor for the rate constant in the boehmite leach kinetic equation in the G2 model. These factors provide scale-up from laboratory-scale to PEP-scale and therefore, effectively, to the PTF-scale, since the PEP caustic-leach is considered to be prototypic of PTF leach.

The mixing system design for PEP was expected to produce thorough mixing; scale-up factors of unity for UFP-1 and UFP-2 caustic-leach were therefore expected. However, it was considered possible that spatial variations in temperature and, less importantly, in solids distribution could affect the conversion in PEP and thereby cause scale-up factors to vary from unity (Kuhn et al. 2008).

For caustic leaching in UFP-VSL-T01A, the median estimate of the scale-up factor was 0.79 , based on the first laboratory test, or 0.95 , based on the second. The average of the median scale-up factors is 0.88 . The $95 \%$ confidence interval around the median extended from about 0.4 to 1.6. For caustic leaching in UFP-VSL-T02A, the median estimate of the scale-up factor was 1.51, based on the first laboratory test, or 1.26, based on the second. The average of the median scale-up factors is 1.38 . The $95 \%$ confidence interval around the median extended from 0.8 to 2.6 .

The uncertainties of the scale-up factors were calculated using a Monte Carlo approach and were found to be strongly sensitive to the uncertainties in the initial condition concentration of boehmite as well as the concentrations of liquid tracer species (such as nitrate and chloride) and dissolved aluminum. The rate constants from the six PEP and laboratory-scale tests were not statistically distinguishable from each other at a $95 \%$ confidence level. It is possible that the scale-up factor is unity or greater both for caustic leaching in UFP-VSL-T01A and in UFP-VSL-T02A. The probability of this hypothesis is about $21 \%$ for Test A/Test A-1, 43\% for Test A/Test A-2, 93\% for Test B/Test B- 1 , and $77 \%$ for Test $\mathrm{B} /$ Test $\mathrm{B}-2$. These probabilities were calculated on the assumption that no systematic biases were introduced by experimental, sampling, or analytical laboratory methods.

The PEP test data included in this report are limited to those from the first batch of simulant leached in vessel UFP-VSL-T01A in Integrated Test A and from the second batch leached in vessel 
UFP-VSL-T02A in Integrated Test B. The scope of this report is limited to the boehmite leach rate constants determined for these batches and the associated laboratory-scale tests as well as to information required to assess the extent to which the tests met the run criteria. Results from other caustic-leach batches are provided in WTP-RPT-197.

\section{Objectives}

Table S.1 summarizes the objectives and results of this testing along with a discussion of how the objectives were met. The objectives for the entire PEP testing program are provided with discussion limited to those objectives met by the scope of this report. Objectives not met by the scope of this report are shaded in gray.

Table S.1. Summary of Test Objectives and Results

\begin{tabular}{|c|c|c|}
\hline Test Objective & $\begin{array}{c}\text { Objective } \\
\text { Met? }\end{array}$ & Discussion \\
\hline $\begin{array}{l}\text { Caustic-leach process: Compare } \\
\text { engineering- and laboratory-scale } \\
\text { results to determine impact of } \\
\text { scale-up. }\end{array}$ & $\mathrm{Y}$ & $\begin{array}{l}\text { The caustic-leach results for the PEP and the laboratory-scale results are } \\
\text { compared, and scale-up factors have been calculated for the kinetic rate } \\
\text { constant as discussed in Section } 4.3 \text {. Uncertainties were calculated } \\
\text { using a Monte Carlo approach. The uncertainties in the scale-up factors } \\
\text { were found to be strongly sensitive to the uncertainties in the } \\
\text { concentrations used to calculate them. } \\
\text { For caustic leaching in UFP-VSL-T01A, the median estimate of the } \\
\text { scale-up factor was } 0.79 \text {, based on the first laboratory test, or } 0.95 \text {, } \\
\text { based on the second. The average of the median scale-up factors is } \\
\text { 0.88. The } 95 \% \text { confidence interval around the median extended from } \\
\text { about } 0.4 \text { to } 1.6 \text {. } \\
\text { For caustic leaching in UFP-VSL-T02A, the median estimate of the } \\
\text { scale-up factor was } 1.51 \text {, based on the first laboratory test, or } 1.26 \text {, } \\
\text { based on the second. The average of the median scale-up factors is } \\
1.38 . \text { The } 95 \% \text { confidence interval around the median extended from } \\
0.8 \text { to } 2.6 \text {. } \\
\text { The rate constants from the six PEP and laboratory-scale tests were not } \\
\text { statistically distinguishable from each other at a 95\% confidence level. } \\
\text { It is possible that the scale-up factor is unity or greater both for caustic } \\
\text { leaching in UFP-VSL-T01A and in UFP-VSL-T02A. The probability } \\
\text { of this hypothesis is about } 21 \% \text { for Test A/Test A-1, } 43 \% \text { for Test } \\
\text { A/Test A-2, 93\% for Test B/Test B-1, and } 77 \% \text { for Test B/Test B-2. } \\
\text { These results are based on those from the first batch of simulant leached } \\
\text { in vessel UFP-VSL-T01A in Integrated Test A and from the second } \\
\text { batch leached in vessel UFP-VSL-T02A in Integrated Test B. } \\
\text { Additional results are reported in WTP-RPT-197. }\end{array}$ \\
\hline \begin{tabular}{|l|} 
Oxidative-leach process: \\
Compare engineering- and \\
laboratory-scale results to \\
determine impact of scale-up.
\end{tabular} & NA & $\begin{array}{l}\text { Results to meet this objective are discussed in reports WTP-RPT-188 } \\
\text { and WTP-RPT-197. }\end{array}$ \\
\hline
\end{tabular}


Table S.1. Summary of Test Objectives and Results

\begin{tabular}{|l|c|l||}
\hline \multicolumn{1}{|c|}{ Test Objective } & $\begin{array}{c}\text { Objective } \\
\text { Met? }\end{array}$ & \multicolumn{1}{|c||}{ Discussion } \\
\hline $\begin{array}{l}\text { Cross-flow ultrafiltration: } \\
\text { performance at engineering- and } \\
\text { laboratory-scale to determine } \\
\text { scale-up. }\end{array}$ & NA & $\begin{array}{l}\text { Results to meet this objective are discussed in reports WTP-RPT-185 } \\
\text { and WTP-RPT-197. }\end{array}$ \\
\hline $\begin{array}{l}\text { Slurry wash process: Determine } \\
\text { the post-caustic and oxidative } \\
\text { leaching slurry wash efficiencies. }\end{array}$ & NA & $\begin{array}{l}\text { Results to meet this objective are discussed in report WTP-RPT-187 } \\
\text { and WTP-RPT-197. }\end{array}$ \\
\hline $\begin{array}{l}\text { Process integration: Evaluate the } \\
\text { chemical addition, filter operation } \\
\text { cycle performance, and pressure } \\
\text { pot operations. Also perform } \\
\text { mass balances for aluminum, } \\
\text { chromium, manganese, sodium, } \\
\text { hydroxide, oxalate, phosphate, } \\
\text { sulfate, and water and monitor } \\
\text { permeates for post filtration } \\
\text { precipitation. }\end{array}$ & NA & Results to meet this objective are discussed in report WTP-RPT-197. \\
$\begin{array}{l}\text { Monitor the performance of the } \\
\text { recirculation system pumps, } \\
\text { filters, and heat exchanger to } \\
\text { support Engineering fabrication } \\
\text { decisions for these components. }\end{array}$ & NA & $\begin{array}{l}\text { The data required to meet this objective were provided on compact } \\
\text { disks transmitted in the following reference: Letter from GH Beeman to } \\
\text { H Hazen, "Subcontract No. 24590-QL-HC9-WA49-00001, Project } \\
\text { No. 53569 (WA-024) Engineering Ties Data Transmittal: The } \\
\text { Electronic File Enclosed With This letter Has Been Reviewed For } \\
\text { Technical Accuracy Per the QA Program," } \\
\text { WTP/RPP-MOA-PNNL-00392, dated 4/10/09. }\end{array}$ \\
\hline
\end{tabular}

\section{Test Exceptions}

A summary description of the Test Exceptions applied to these tests is shown in Table S.2.

Table S.2. Test Exceptions

\begin{tabular}{|c|c|}
\hline Test Exceptions & Description of Test Exceptions \\
\hline $\begin{array}{l}\text { 1) 24590-PTF-TEF-RT-08- } \\
\text { 00002, incorporated into ICN1 } \\
\text { to Test Plan TP-RPP-WTP-506. }\end{array}$ & $\begin{array}{l}\text { This Test Exception: } \\
\text { 1. Added a stage during the filter conditioning section of the Functional Test } \\
\text { where the simulant slurry is concentrated from approximately } 5-\mathrm{wt} \% \text { solids to } \\
20 \text {-wt\% solids in one operation. This is in addition to the previously } \\
\text { specified low-solids filter and high-solids filter testing. } \\
\text { 2. Documented the Joint Test Group (JTG) decision regarding the number of } \\
\text { replicate samples to be collected at various processing times. } \\
\text { 3. Revised the terminology specifying the Coriolis densitometer (CD) sample } \\
\text { locations changed to be consistent with PEP operating procedures. Renamed } \\
\text { the "center" array to "inner." } \\
\text { 4. The sampling specified in the low-solids filtration test over specifies the } \\
\text { sample collection timing required. The technical requirement is to get } \\
30 \text { unique samples. The sampling schedule specified is not required to } \\
\text { achieve this test objective. }\end{array}$ \\
\hline
\end{tabular}


Table S.2. Test Exceptions

\begin{tabular}{|c|c|}
\hline Test Exceptions & Description of Test Exceptions \\
\hline \multirow[t]{14}{*}{$\begin{array}{l}\text { 2) } 24590-P T F-T E F-R T-09- \\
\text { 00001 incorporated into ICN-2 } \\
\text { and ICN-3 to Test Plan } \\
\text { TP-RPP-WTP-506. }\end{array}$} & $\begin{array}{l}\text { 1. In several steps, the sampling location was changed from the filter-loop } \\
\text { in-line location to a middle-low CD sample loop location in the } \\
\text { UFP-VSL-T02A vessel. This change impacted sampling in the Functional } \\
\text { and all Integrated tests (ref CCN 187749). }\end{array}$ \\
\hline & $\begin{array}{l}\text { 2. Added a step to the Shakedown/Functional Test (step A.1.31) to add sodium } \\
\text { permanganate to UFP-VSL-T02A to assess possible foaming issue (ref CCN } \\
\text { 187749). }\end{array}$ \\
\hline & $\begin{array}{l}\text { 3. Changed location of second sample for laboratory-scale Cells Unit Filter } \\
\text { (CUF) testing from the in-line filter-loop to the middle-low CD port in the } \\
\text { UFP-VSL-T02A (step A.1.10; Functional Test) (ref CCN 187749). }\end{array}$ \\
\hline & $\begin{array}{l}\text { 4. Collected samples for laboratory-scale laboratory leaching test before and } \\
\text { after caustic addition in UFP-VSL-T01A (A.1.20; Functional Test) and } \\
\text { UFP-VSL-T02A (step A.1.15; Functional Test), and in the Integrated test } \\
\text { steps (B1.2; Integrated Test A, B2.6; Integrated Tests B/D) (ref CCN } \\
\text { 192734). }\end{array}$ \\
\hline & $\begin{array}{l}\text { 5. Deleted reconfiguration of the filter-loop to bypass UFP-VSL-T02A and } \\
\text { circulate flush water with UFP-PMP-T42A and/or UFP-PMP-43A to allow } \\
\text { collection of a representative in-line sample. This step (step A.1.17; } \\
\text { Functional Test) could not be done under the operating restrictions in place } \\
\text { on the operation of the filter-loop (ref CCN 192734). }\end{array}$ \\
\hline & $\begin{array}{l}\text { 6. Eliminated step A.1.25 (filter-loop bypass test with tracer) from the } \\
\text { Functional Test. This test was conducted after the completion of Integrated } \\
\text { Test B (ref CCN 187753). }\end{array}$ \\
\hline & $\begin{array}{l}\text { 7. Modified step A.1.29 (Functional Test) to eliminate the removal of solids } \\
\text { from UFP-VSL-T02A before the high-solids filter test. This step was not } \\
\text { needed as the amount of solids is less than anticipated (ref CCN 187752). }\end{array}$ \\
\hline & $\begin{array}{l}\text { 8. Modified step A.1.30 (Functional Test) to include five filter backpulses } \\
\text { before starting the high-solids filter test (ref CCN 187752). }\end{array}$ \\
\hline & $\begin{array}{l}\text { 9. Modify step B.1.8 (Integrated Test A) to allow } 80 \% \text { of caustic to be added } \\
\text { during in-line simulant transfers to UFP-VSL-T01B and } 20 \% \text { to be added } \\
\text { directly to UFP-VSL-T01B (ref CCN } 187748 \text { ). }\end{array}$ \\
\hline & $\begin{array}{l}\text { 10. Added a high-solids filter test to the end of Integrated Test B to replace the } \\
\text { high-solids filter test from the simulant Shakedown/Functional Test. The test } \\
\text { conducted during the Functional Test was hampered by pump cavitation, and } \\
\text { the target solids concentration was not met (ref CCN 192734). }\end{array}$ \\
\hline & 11. Eliminated Integrated Test C from the Test Plan (ref CCN 192735). \\
\hline & $\begin{array}{l}\text { 12. The requirement to record density using the CDs on the samplers in } \\
\text { UFP-VSL-T02A was eliminated. The density function was not useable due } \\
\text { to entrained air in the simulant. }\end{array}$ \\
\hline & $\begin{array}{l}\text { 13. Modified step B. } 2.6 \text { (caustic addition in Integrated Tests B/D) temperature } \\
\text { limit to change from } 60^{\circ} \mathrm{C} \text { to "as specified in run sheet." This temperature is } \\
\text { calculated based on various other run parameters and specified in the run } \\
\text { sheet. }\end{array}$ \\
\hline & 14. Eliminated the monitoring of Integrated Test $\mathrm{D}$ permeate samples for 30 days \\
\hline
\end{tabular}


Table S.2. Test Exceptions

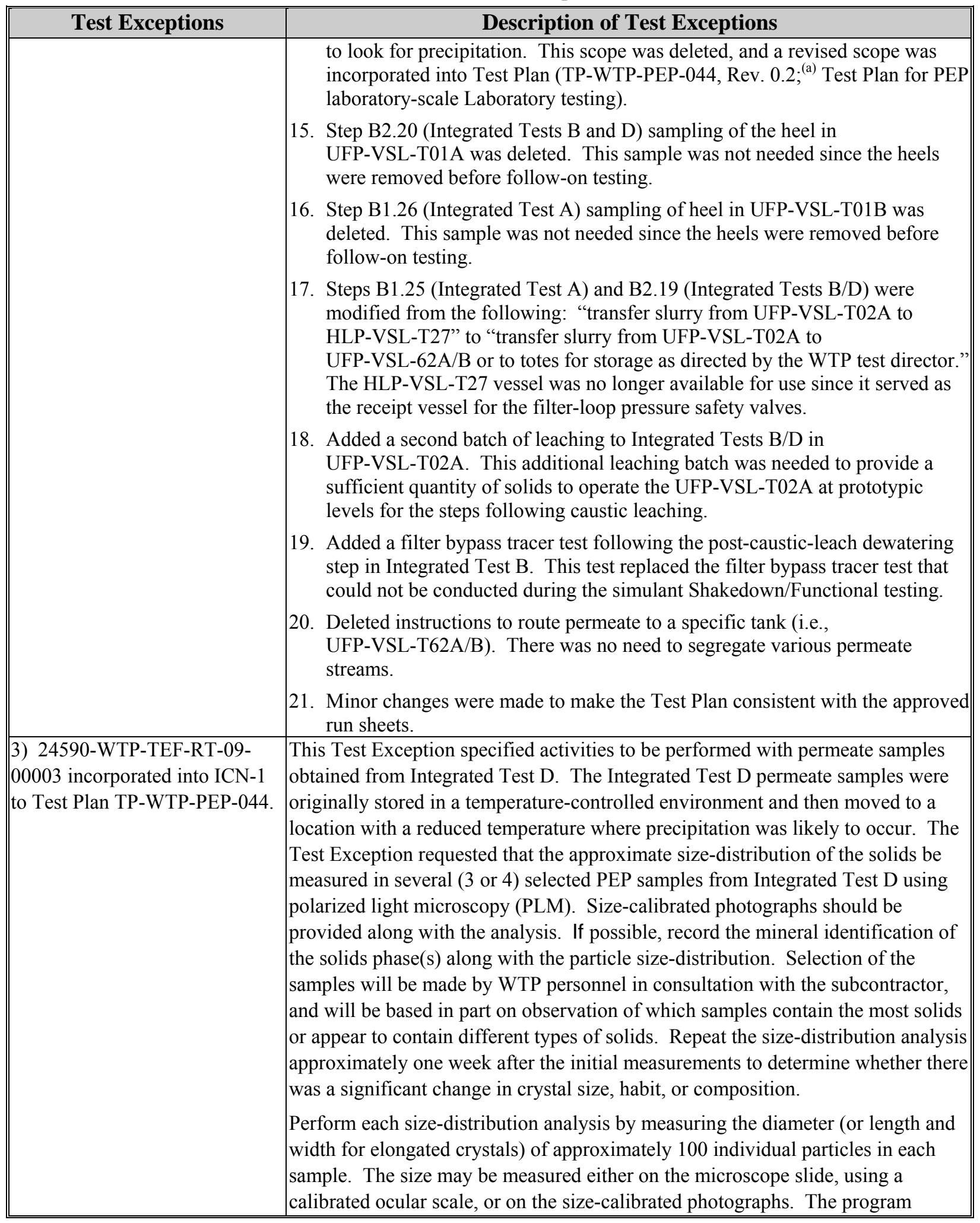

(a) RL Russell. 2008. "Test Plan for the PEP Parallel Laboratory Testing." TP-WTP-PEP-044, Rev. 0.2, Pacific Northwest National Laboratory, Richland, Washington. 
Table S.2. Test Exceptions

\begin{tabular}{|c|c|}
\hline Test Exceptions & Description of Test Exceptions \\
\hline & $\begin{array}{l}\text { recognizes the limitations of the statistical significance of a size-distribution } \\
\text { measurement based on such a small population. This Test Exception did not } \\
\text { affect any of the existing Test Plan objectives. }\end{array}$ \\
\hline \multirow{5}{*}{$\begin{array}{l}\text { 4) } 24590 \text {-WTP-TEF-RT-09- } \\
\text { 00002 Rev 0, incorporated into } \\
\text { ICN-4 to Test Plan } \\
\text { TP-RPP-WTP-506. }\end{array}$} & This Test Exception: \\
\hline & $\begin{array}{l}\text { 1. Requests a report summarizing the lessons learned during scale-up, } \\
\text { manufacture, and transport of the PEP simulant. }\end{array}$ \\
\hline & $\begin{array}{l}\text { 2. Specifies the sampling and analysis scope to be performed to complete the } \\
\text { prototypic nitric acid PEP filter cleaning process. }\end{array}$ \\
\hline & 3. Deletes the Engineering Ties report scope. \\
\hline & $\begin{array}{l}\text { 4. Specifies additional experimental and analytical work required to estimate the } \\
\text { amount of excess caustic in caustic-leachate samples and post-caustic-leach } \\
\text { wash solutions containing } \approx 3.5 \mathrm{M} \mathrm{Na} \text {. }\end{array}$ \\
\hline \multirow{7}{*}{$\begin{array}{l}\text { 5) } 24590-\text { WTP-TEF-RT-09- } \\
\text { 00001 Rev } 1 \text { incorporated into } \\
\text { ICN-2 to Test Plan } \\
\text { TP-WTP-PEP-044. }\end{array}$} & $\begin{array}{l}\text { This Test Exception specifies additional work to be conducted with caustic-leach } \\
\text { solutions and post-caustic-leach washing permeate samples obtained from PEP } \\
\text { Integrated Tests A, B and D. It contains the following tasks: }\end{array}$ \\
\hline & $\begin{array}{l}\text { 1) Determination of precipitate mineralogy, precipitate phase compositions and } \\
\text { solution saturation composition. }\end{array}$ \\
\hline & 2) Determination of rate of approach to saturation concentrations. \\
\hline & $\begin{array}{l}\text { 3) Identification and characterization of precipitates formed in } \\
\text { post-caustic-leach filtrate. }\end{array}$ \\
\hline & 4) Determination of the dilution required to redissolve the precipitate. \\
\hline & $\begin{array}{l}\text { 5) Determination of super-saturation in post-caustic-leach filtrates from } \\
\text { Integrated Test B in the PEP. }\end{array}$ \\
\hline & $\begin{array}{l}\text { 6) Determine the effects of blending during the post-caustic-leach dewatering } \\
\text { and wash cycle. }\end{array}$ \\
\hline
\end{tabular}

As documented in the PEP Test Plan, the deviations from the Test Specification are provided in Table S.3.

Table S.3. Deviations from Test Specification

\begin{tabular}{|c|c|}
\hline Test Specification Reference & Exception Taken \\
\hline $\begin{array}{l}\text { Section } 6.4 .4 \text { "Analytical measurements will be } \\
\text { made in conformance to the Guidelines for } \\
\text { Performing Chemical Physical, and Rheological } \\
\text { Properties Measurements (a) as applicable." }\end{array}$ & $\begin{array}{l}\text { Three method exceptions are required under this Test Plan: } \\
\text { 1. Caustic-leach and oxidative-leach samples taken during this } \\
\text { testing must be separated more quickly than the standard } \\
\text { method using syringes. This testing will use a modified } \\
\text { method using a shorter centrifuge time and applying higher } \\
g \text { forces (e.g. } 4000 \mathrm{~g} \text { vs. } 1000 \mathrm{~g}) \text {. } \\
\text { Impact on results: If the standard method were used the } \\
\text { longer time could very well lead to greater precipitation and } \\
\text { inaccurate results. Laboratory testing will be conducted } \\
\text { with simulants to confirm that this method of sample }\end{array}$ \\
\hline
\end{tabular}

(a) GL Smith and K Prindiville. May 20, 2002. Guidelines for Performing Chemical, Physical, and Rheological Properties Measurements. 24590-WTP-GPG-RTD-001, Rev 0, Bechtel National, Inc., Richland, Washington. 


\begin{tabular}{|c|c|c|}
\hline & & $\begin{array}{l}\text { 2. handling is adequate. } \\
\text { Densities of samples smaller than } 10 \mathrm{~mL} \text { can only be } \\
\text { established within } 2 \text { significant figures of accuracy. Density } \\
\text { measurements for this Test Plan require greater accuracy. } \\
\text { Therefore, a more accurate method employing a pycnometer } \\
\text { will be utilized. } \\
\text { Impact on results: The change to a pycnometer will } \\
\text { generate more precise results than the standard method. The } \\
\text { main impact is expected to be on analysis time. The } \\
\text { pycnometer method will be slower. } \\
\text { The process for determining the wt } \% \text { UDS content of the } \\
\text { slurries will in some cases be determined with the use of a } \\
\text { moisture analyzer. In addition, the method of drying } \\
\text { samples will be modified to allow the use of glass fiber } \\
\text { filters to aid in drying the samples. } \\
\text { Impact on results: Both modifications are intended to } \\
\text { decrease the time required to obtain results. }\end{array}$ \\
\hline
\end{tabular}




\section{Results and Performance Against Success Criteria}

The PEP system tests were designed to generate the data necessary to:

- Provide engineering-scale system performance data. This information is used to support the WTP computer process models projections of the waste processing campaign.

- Confirm the operability and functionality of UFP system components.

The Research and Technology (R\&T) success criteria for achieving these objectives are discussed in Table S.4. The success criteria for the entire PEP testing program are provided with discussion limited to the success criteria covered by the scope of this report. The success criteria not addressed in this report are shaded in gray.

Table S.4. Results and Performance Against Success Criteria

\begin{tabular}{|c|c|}
\hline Success Criteria & How Testing Did or Did Not Meet Success Criteria \\
\hline \multicolumn{2}{|l|}{ UFP System Process Performance } \\
\hline $\begin{array}{l}\text { Measure the aluminum leaching } \\
\text { performance of the PEP and } \\
\text { laboratory systems as a function of } \\
\text { time under WTP UFP-1 and UFP-2 } \\
\text { projected leaching conditions at } \\
\text { bounding high and low process } \\
\text { temperatures (nominally } 100^{\circ} \mathrm{C} \text { and } \\
80^{\circ} \mathrm{C} \text { ). }\end{array}$ & $\begin{array}{l}\text { Aluminum leaching performance was measured at } 98^{\circ} \mathrm{C} \text { for } 16 \text { hours in } \\
\text { Integrated Tests A and B and at } 85^{\circ} \mathrm{C} \text { for } 24 \text { hours in Integrated Test D. Only } \\
\text { results for batch } 1 \text { of Integrated Test A and batch } 2 \text { of Integrated Test B are } \\
\text { included in this report. The remaining results are reported in WTP-RPT- } 197 .\end{array}$ \\
\hline $\begin{array}{l}\text { Compare aluminum leach } \\
\text { performance in UFP-1 where all of } \\
\text { the } \mathrm{NaOH} \text { is added in-line to the } \\
\text { case where a fraction of the total } \\
\mathrm{NaOH} \text { is added directly to the tank. }\end{array}$ & Results to meet this success criterion are discussed in report WTP-RPT- 197. \\
\hline $\begin{array}{l}\text { Measure chromium leaching } \\
\text { performance in the PEP and } \\
\text { laboratory systems as a function of } \\
\text { time at the WTP projected } \\
\text { conditions in UFP-2 for both the } \\
\text { UFP-1 and UFP-2 aluminum } \\
\text { leaching flowsheets. }\end{array}$ & $\begin{array}{l}\text { Results to meet this success criterion are discussed in reports WTP-RPT-188 } \\
\text { and WTP-RPT-197. }\end{array}$ \\
\hline $\begin{array}{l}\text { Evaluate the process control } \\
\text { strategy for specification of } \\
\text { required reagent additions including } \\
\mathrm{NaOH}, \mathrm{NaMnO}_{4} \text {, and wash } \\
\text { solutions provided in the PEP } \\
\text { Phase } 1 \text { Testing Process } \\
\text { Description. }\end{array}$ & $\begin{array}{l}\text { A comparison of targeted and delivered reagent additions is provided in } \\
\text { report WTP-RPT-188 for Integrated Tests A and B. Additional discussion } \\
\text { and results for Integrated Test D are provided in report WTP-RPT- } 197 .\end{array}$ \\
\hline
\end{tabular}


Table S.4. Results and Performance Against Success Criteria

\begin{tabular}{|c|c|}
\hline Success Criteria & How Testing Did or Did Not Meet Success Criteria \\
\hline $\begin{array}{l}\text { Measure the filter system } \\
\text { performance at the nominal flow } \\
\text { velocity and transmembrane } \\
\text { pressures for the solids } \\
\text { concentration and washing stages } \\
\text { for the UFP-1 and UFP-2 aluminum } \\
\text { leaching flowsheets. }\end{array}$ & Results to meet this success criterion are discussed in report WTP-RPT- 197. \\
\hline $\begin{array}{l}\text { Evaluate the control strategy for } \\
\text { make-up additions from } \\
\text { UFP-VSL-00001A/B to } \\
\text { UFP-VSL-00002A/B during initial } \\
\text { dewatering process. }\end{array}$ & Results to meet this success criterion are discussed in report WTP-RPT-197. \\
\hline $\begin{array}{l}\text { Measure the wash-water volumes } \\
\text { required to remove or reduce the } \\
\text { free hydroxide following the } \\
\text { aluminum leaching stage and } \\
\text { dissolved chromium after the } \\
\text { oxidative leaching process to the } \\
\text { specified concentrations. }\end{array}$ & $\begin{array}{l}\text { Results to meet this success criterion are discussed in reports WTP-RPT-187 } \\
\text { and WTP-RPT-197. }\end{array}$ \\
\hline $\begin{array}{l}\text { Perform mass balances for selected } \\
\text { constituents, including aluminum, } \\
\text { chromium, manganese, sodium, } \\
\text { hydroxide, oxalate, phosphate, } \\
\text { sulfate, and water to evaluate } \\
\text { leaching and washing process } \\
\text { performance. }\end{array}$ & $\begin{array}{l}\text { Results to meet this success criterion are discussed for Cr in the oxidative } \\
\text { leaching process for Integrated Tests A and B in report WTP-RPT-188 and } \\
\text { are fully discussed for all constituents in report WTP-RPT-197. }\end{array}$ \\
\hline \begin{tabular}{|l|} 
Measure solids distribution under \\
scaled mixing conditions before and \\
after caustic leaching evolutions.
\end{tabular} & Results to meet this success criterion are discussed in report WTP-RPT-197. \\
\hline $\begin{array}{l}\text { Measure the rheology of the slurry } \\
\text { simulant and shear strength of the } \\
\text { settled solids before and after each } \\
\text { leaching and washing unit operation } \\
\text { and following final concentration. }\end{array}$ & Results to meet this success criterion are discussed in report WTP-RPT-197. \\
\hline $\begin{array}{l}\text { Estimate the quantity of excess } \\
\text { hydroxide added in the process that } \\
\text { may not be needed to keep } \\
\text { aluminate in solution following } \\
\text { filtration. }\end{array}$ & Results to meet this success criterion are discussed in report WTP-RPT-197. \\
\hline $\begin{array}{l}\text { Collect and retain permeate samples } \\
\text { for extended precipitation studies } \\
\text { (including permeate/simulated } \\
\text { supernatant blended cases) from } \\
\text { each concentration cycle. }\end{array}$ & $\begin{array}{l}\text { Samples were collected and retained for extended precipitation studies. The } \\
\text { results of the precipitation studies are discussed in WTP-RPT-197, } \\
\text { WTP-RPT-200 and WTP-RPT-205. }\end{array}$ \\
\hline
\end{tabular}


Table S.4. Results and Performance Against Success Criteria

\begin{tabular}{|c|c|}
\hline Success Criteria & How Testing Did or Did Not Meet Success Criteria \\
\hline \multicolumn{2}{|c|}{ UFP System Operability and Functionality } \\
\hline $\begin{array}{l}\text { Verify that the dual, in-series pump } \\
\text { configuration is controllable and } \\
\text { maintains the required slurry } \\
\text { velocity and pressures for ultrafilter } \\
\text { operation. }\end{array}$ & $\begin{array}{l}\text { The data required to meet this success criterion were provided on compact } \\
\text { disks transmitted in the following reference: Letter from GH Beeman to } \\
\text { H Hazen, "Subcontract No. 24590-QL-HC9-WA49-00001, Project } \\
\text { No. 53569 (WA-024) Engineering Ties Data Transmittal: The Electronic } \\
\text { File Enclosed With This letter Has Been Reviewed For Technical Accuracy } \\
\text { Per the Quality Assurance (QA) Program," WTP/RPP-MOA-PNNL-00392, } \\
\text { dated 4/10/09. }\end{array}$ \\
\hline $\begin{array}{l}\text { Measure the operating } \\
\text { characteristics for the cooling heat } \\
\text { exchanger for the UFP-VSL-00002 } \\
\text { filter recirculation loop } \\
\text { (temperature changes as a function } \\
\text { of flow to determine how to achieve } \\
\text { the desired performance in the PTF } \\
\text { analog). }\end{array}$ & $\begin{array}{l}\text { The data required to meet this success criterion were provided on compact } \\
\text { disks transmitted in the following reference: Letter from GH Beeman to } \\
\text { H Hazen, "Subcontract No. 24590-QL-HC9-WA49-00001, Project } \\
\text { No. } 53569 \text { (WA-024) Engineering Ties Data Transmittal: The Electronic } \\
\text { File Enclosed With This letter Has Been Reviewed For Technical Accuracy } \\
\text { Per the QA Program," WTP/RPP-MOA-PNNL-00392, dated 4/10/09. }\end{array}$ \\
\hline $\begin{array}{l}\text { Confirm whether the WTP process } \\
\text { control strategies for ultrafilter } \\
\text { system filling, operating, } \\
\text { backpulsing, draining, flushing, and } \\
\text { cleaning are adequate for stable } \\
\text { operation. Provide to WTP data to } \\
\text { determine whether backpulsing is a } \\
\text { required and effective means of } \\
\text { restoring the filter permeate rates to } \\
\text { make certain that production } \\
\text { throughput is maintained and to } \\
\text { determine whether operation of the } \\
\text { backpulse system induces any } \\
\text { process or equipment operations } \\
\text { issues. }\end{array}$ & Results to meet this success criterion are discussed in report WTP-RPT-197. \\
\hline $\begin{array}{l}\text { Use only the process information } \\
\text { and data available to the WTP PTF } \\
\text { operating staff during WTP } \\
\text { operations (e.g., caustic and } \\
\text { permanganate addition volumes, } \\
\text { permeate mass balances for solids } \\
\text { concentration) to operate the PEP. }\end{array}$ & Results to meet this success criterion are discussed in report WTP-RPT-197. \\
\hline $\begin{array}{l}\text { Confirm whether the elevated } \\
\text { temperature pulse jet mixer (PJM) } \\
\text { operating strategy is adequate for } \\
\text { stable PEP and WTP operation. }\end{array}$ & Results to meet this success criterion are discussed in report WTP-RPT-197. \\
\hline
\end{tabular}


Table S.4. Results and Performance Against Success Criteria

\begin{tabular}{|c|c|}
\hline Success Criteria & How Testing Did or Did Not Meet Success Criteria \\
\hline $\begin{array}{l}\text { Measure the heat-up rate and } \\
\text { controllability of the PEP } \\
\text { UFP-VSL-00001 and } \\
\text { UFP-VSL-00002 vessels and the } \\
\text { cooling performance for UFP } \\
\text { vessels. }\end{array}$ & Results to meet this success criterion are discussed in report WTP-RPT-197. \\
\hline $\begin{array}{l}\text { Measure the performance of the } \\
\text { in-line addition of process } \\
\text { chemicals into the simulated wastes } \\
\text { and determine the extent of } \\
\text { blending in the process vessels. }\end{array}$ & Results to meet this success criterion are discussed in report WTP-RPT-197. \\
\hline $\begin{array}{l}\text { Monitor ultrafilter performance (to } \\
\text { include visual inspection of the } \\
\text { filter tubes, tube sheets, and heads } \\
\text { from an ultrafilter for any evidence } \\
\text { of flow mal-distribution and/or } \\
\text { solids buildup at least once during } \\
\text { Phase 1). }\end{array}$ & Results to meet this success criterion are discussed in report WTP-RPT-197. \\
\hline $\begin{array}{l}\text { Measure, record, and control } \\
\text { ultrafiltration temperature, } \\
\text { transmembrane pressure, and slurry } \\
\text { flow during filter-loop operations. }\end{array}$ & $\begin{array}{l}\text { Data to meet this success criterion are discussed in WTP-RPT- } 185 \text { for the } \\
\text { low- and high-solids tests and are discussed for the remaining tests in the run } \\
\text { reports for each of the Integrated tests. }\end{array}$ \\
\hline $\begin{array}{l}\text { Record any solids accumulations } \\
\text { observed during any operating stage } \\
\text { or maintenance evolution. }\end{array}$ & Results to meet this success criterion are discussed in report WTP-RPT-197. \\
\hline $\begin{array}{l}\text { Monitor the permeate production } \\
\text { rate of each ultrafilter assembly in } \\
\text { operation. }\end{array}$ & $\begin{array}{l}\text { Results to meet this success criterion are discussed in WTP-RPT- } 185 \text { for the } \\
\text { low- and high-solids tests and are discussed for the remaining tests in report } \\
\text { WTP-RPT-197. }\end{array}$ \\
\hline $\begin{array}{l}\text { Record operating time of each } \\
\text { ultrafilter assembly. }\end{array}$ & Results to meet this success criterion are discussed in report WTP-RPT-197. \\
\hline $\begin{array}{l}\text { Record each ultrafilter assembly } \\
\text { cleaning event (backpulse, flush, } \\
\text { chemical cleaning, etc.). }\end{array}$ & Results to meet this success criterion are discussed in report WTP-RPT-197. \\
\hline \begin{tabular}{|l|} 
Evaluation of the pulse-pot \\
operation and backpulse operation \\
strategies contained in PEP Phase 1 \\
Testing Process Description.
\end{tabular} & Results to meet this success criterion are discussed in report WTP-RPT-197. \\
\hline $\begin{array}{l}\text { Evaluate permeate and permeate } \\
\text { blends for precipitation of solids, } \\
\text { particularly aluminum and oxalate } \\
\text { solids. }\end{array}$ & $\begin{array}{l}\text { Results to meet this success criterion are discussed in reports WTP-RPT-197, } \\
\text { WTP-RPT-200, and WTP-RPT-205. }\end{array}$ \\
\hline
\end{tabular}




\section{Quality Requirements}

The PNNL QA program is based upon the requirements as defined in the U.S. Department of Energy (DOE) Order 414.1C, Quality Assurance and 10 CFR 830, Energy/Nuclear Safety Management, Subpart A-Quality Assurance Requirements (a.k.a. the Quality Rule). PNNL has chosen to implement the following consensus standards in a graded approach:

- ASME NQA-1-2000, Quality Assurance Requirements for Nuclear Facility Applications, Part 1, Requirements for Quality Assurance Programs for Nuclear Facilities.

- ASME NQA-1-2000, Part II, Subpart 2.7, Quality Assurance Requirements for Computer Software for Nuclear Facility Applications.

- ASME NQA-1-2000, Part IV, Subpart 4.2, Graded Approach Application of Quality Assurance Requirements for Research and Development.

The procedures necessary to implement the requirements are documented through PNNL's "How Do I...?" (HDI) system. ${ }^{\text {(a) }}$

PNNL implements the RPP-WTP quality requirements by performing work in accordance with the River Protection Project-Waste Treatment Plant Support Program (RPP-WTP) Quality Assurance Plan (RPP-WTP-QA-001, QAP). Work was performed to the quality requirements of NQA-1-1989 Part I, Basic and Supplementary Requirements, NQA-2a-1990, Part 2.7, and DOE/RW-0333P, Rev 13, Quality Assurance Requirements and Descriptions $(Q A R D)$ as applicable. These quality requirements are implemented through the River Protection Project-Waste Treatment Plant Support Program (RPP-WTP) Quality Assurance Manual (RPP-WTP-QA-003, QAM). The requirements of DOE/RW-0333P Rev 13, Quality Assurance Requirements and Descriptions (QARD) and 10 CFR 830 Subpart A were not required for this work.

RPP-WTP addresses internal verification and validation activities by conducting an independent technical review of the final data report in accordance with RPP-WTP's procedure QA-RPP-WTP-604. This review procedure is part of PNNL's RPP-WTP Quality Assurance Manual (RPP-WTP-QA-003). Following this procedure, a technical review would verify that the reported results are traceable, that inferences and conclusions are soundly based, and the reported work satisfies the objectives.

Key analytes in the laboratory control sample (LCS) and PEP control sample were plotted over time to look for anomalies. The PEP control sample is a project provided material generated from material very similar to the initial simulant feed. In general, the plots constructed to-date associated with the inductively coupled plasma (ICP) and ion chromatography (IC) analysis of solutions shows recovery within limits of $80 \%$ to $120 \%$.

Limited data reported for the upper and lower sparger air flowmeters in UFP-VSL-T02A (FT-1901 and FT-1977, respectively) are impacted by NCR 38767.1. The flowmeter vendor, Micro-Motion, identifies a minimum flow rate $(0.090 \mathrm{~kg} / \mathrm{min})$ where the Coriolis flow uncertainty increases above $0.5 \%$. For the lowest flow rate reported $(0.012 \mathrm{~kg} / \mathrm{min}$ on FT-1977), the estimated uncertainty is $\sim 4 \%$. Since these instruments are used primarily to indicate the approximate air flow rates, higher uncertainty in these data is not considered significant.

(a) PNNL's system for managing the delivery of laboratory-level policies, requirements, and procedures. 


\section{R\&T Test Conditions}

The R\&T test conditions as defined in the Test Specification are summarized in Table S.5. The R\&T test conditions for the entire PEP testing program are provided with discussion limited to the R\&T test conditions covered by the scope of this report. R\&T test conditions not addressed in this report are shaded in gray.

Table S.5. R\&T Test Conditions

\begin{tabular}{|c|c|}
\hline List R\&T Test Conditions & Were Test Conditions Followed? \\
\hline \multicolumn{2}{|l|}{ General Requirements } \\
\hline $\begin{array}{l}\text { Perform mass balances for selected constituents; } \\
\text { including aluminum, chromium, manganese, sodium, } \\
\text { hydroxide, oxalate, phosphate, sulfate, and water to } \\
\text { evaluate leaching and washing process performance. }\end{array}$ & $\begin{array}{l}\text { This R\&T test condition is discussed for Cr in the } \\
\text { oxidative-leach process in Integrated Tests A and B } \\
\text { in WTP-RPT-188 and is fully discussed in report } \\
\text { WTP-RPT-197. }\end{array}$ \\
\hline $\begin{array}{l}\text { Evaluate ultrafilter performance (to include visual } \\
\text { inspection of the filter tubes, tube sheets, and heads } \\
\text { from an ultrafilter for any evidence of flow } \\
\text { mal-distribution and/or solids buildup or evidence of } \\
\text { potential failure). }\end{array}$ & $\begin{array}{l}\text { This R\&T test condition is discussed in report } \\
\text { WTP-RPT- } 197 .\end{array}$ \\
\hline $\begin{array}{l}\text { Assess the blending achieved during in-line additions } \\
\text { of leaching and washing solutions. }\end{array}$ & $\begin{array}{l}\text { In-line addition of wash-water during Integrated } \\
\text { Tests A and B is discussed in WTP-RPT-187 and is } \\
\text { fully discussed in report WTP-RPT-197. }\end{array}$ \\
\hline $\begin{array}{l}\text { Record any solids accumulations observed during } \\
\text { any operating stage or maintenance evolution } \\
\text { (e.g., photography, particle size-distribution). }\end{array}$ & $\begin{array}{l}\text { This R\&T test condition is discussed in report } \\
\text { WTP-RPT-197. }\end{array}$ \\
\hline \multicolumn{2}{|l|}{ Leaching Operations } \\
\hline $\begin{array}{l}\text { Maintain caustic leaching temperature at the required } \\
\text { setpoint and record steam usage to remain in the } \\
\text { temperature range. }\end{array}$ & $\begin{array}{l}\text { Yes. This R\&T test condition was met for the } \\
\text { leaching tests discussed in this report. The } \\
\text { conditions for the remaining tests are discussed in } \\
\text { WTP-RPT-197. }\end{array}$ \\
\hline $\begin{array}{l}\text { Maintain oxidative leaching temperature at the } \\
\text { required setpoint. }\end{array}$ & $\begin{array}{l}\text { This R\&T test condition is discussed in reports } \\
\text { WTP-RPT-188 and WTP-RPT-197. }\end{array}$ \\
\hline $\begin{array}{l}\text { Obtain periodic samples during the leaching } \\
\text { operations to monitor the amount of aluminum or } \\
\text { chromium that has dissolved and concentrations of } \\
\text { the reactants and products in the liquid fraction in the } \\
\text { vessel. }\end{array}$ & $\begin{array}{l}\text { Yes. This R\&T condition was met for the caustic } \\
\text { leaching tests discussed in this report. Additional } \\
\text { discussion of this R\&T condition is provided in } \\
\text { WTP-RPT- } 188 \text { and WTP-RPT-197. }\end{array}$ \\
\hline $\begin{array}{l}\text { Provide data to demonstrate the WTP process control } \\
\text { strategy for the caustic and permanganate addition. }\end{array}$ & $\begin{array}{l}\text { This R\&T test condition is discussed in report } \\
\text { WTP-RPT-197. }\end{array}$ \\
\hline $\begin{array}{l}\text { Measure the rheology of the slurry simulant and } \\
\text { shear strength of the settled solids before and } \\
\text { following each leaching unit operation. }\end{array}$ & $\begin{array}{l}\text { This R\&T test condition is discussed in report } \\
\text { WTP-RPT-197. }\end{array}$ \\
\hline \multicolumn{2}{|l|}{ Concentration Operations } \\
\hline $\begin{array}{l}\text { Monitor the permeate production rate of each } \\
\text { ultrafilter assembly in operation. }\end{array}$ & $\begin{array}{l}\text { This R\&T test condition is discussed in report } \\
\text { WTP-RPT-185, the run reports for the individual } \\
\text { tests, and WTP-RPT- } 197 \text {. }\end{array}$ \\
\hline Record ope & $\begin{array}{l}\text { This R\&T test condition is discussed in report } \\
\text { WTP-RPT-197. }\end{array}$ \\
\hline
\end{tabular}


Table S.5. R\&T Test Conditions

\begin{tabular}{||l|l||}
\hline List R\&T Test Conditions & Were Test Conditions Followed? \\
\hline $\begin{array}{l}\text { Record each ultrafilter assembly "cleaning" event } \\
\text { (backpulse, flush, chemical cleaning, etc.). }\end{array}$ & $\begin{array}{l}\text { This R\&T test condition is discussed in report } \\
\text { WTP-RPT-197. }\end{array}$ \\
\hline $\begin{array}{l}\text { Confirm pulse-pot operation and backpulse operation } \\
\text { strategies. }\end{array}$ & $\begin{array}{l}\text { This R\&T test condition is discussed in report } \\
\text { WTP-RPT-197. }\end{array}$ \\
\hline $\begin{array}{l}\text { Control ultrafiltration temperature, transmembrane } \\
\text { pressure, and slurry flow as specified in test specific } \\
\text { run sheets. }\end{array}$ & $\begin{array}{l}\text { This R\&T test condition is discussed in report } \\
\text { WTP-RPT-185, the run reports for the individual } \\
\text { tests, and WTP-RPT-197. }\end{array}$ \\
\hline $\begin{array}{l}\text { Collect and retain permeate samples for extended } \\
\text { precipitation studies (including permeate/simulated } \\
\text { supernatant blended cases) from each concentration } \\
\text { cycle. }\end{array}$ & $\begin{array}{l}\text { Samples were collected and retained for extended } \\
\text { precipitation studies. The results of the } \\
\text { precipitation studies are discussed in } \\
\text { WTP-RPT-197, WTP-RPT-200, and } \\
\text { WTP-RPT-205. }\end{array}$ \\
\hline $\begin{array}{l}\text { Demonstrate WTP ultrafiltration system control } \\
\text { scheme in normal operating modes (e.g., fill and } \\
\text { startup, operation, backpulsing, flush and drain, } \\
\text { cleaning and return to service). }\end{array}$ & $\begin{array}{l}\text { This R\&T test condition is discussed in report } \\
\text { WTP-RPT-197. }\end{array}$ \\
\hline Washing Operations & \multicolumn{2}{|l|}{} \\
\hline $\begin{array}{l}\text { Wash slurries using a washing protocol to be } \\
\text { specified in test specific run sheets. }\end{array}$ & $\begin{array}{l}\text { This R\&T test condition is discussed in reports } \\
\text { WTP-RPT-187 and WTP-RPT-197. }\end{array}$ \\
\hline $\begin{array}{l}\text { Sample permeate immediately before each wash } \\
\text { solution addition to monitor washing } \\
\text { performance/efficiency. }\end{array}$ & $\begin{array}{l}\text { This R\&T test condition is discussed in reports } \\
\text { WTP-RPT-187 and WTP-RPT-197. }\end{array}$ \\
\hline $\begin{array}{l}\text { Measure rheology of the washed solids. } \\
\text { This R\&T test condition is discussed in reports } \\
\text { WTP-RPT-187 and WTP-RPT-197. }\end{array}$ \\
\hline
\end{tabular}

\section{Simulant Use}

PEP process testing was performed with a nonradioactive aqueous slurry of simulant waste chemicals and solids. The simulant composition and make-up recipe were provided by WTP as documented in Simulant Recommendation for Phase 1 Testing in the Pretreatment Engineering Platform. ${ }^{\text {(a) }}$ Aqueous chemical concentrations were within ranges expected for waste feeds to the PTF except for the hydroxide, oxalate, and phosphate anions. The hydroxide concentration was approximately one standard deviation from the average concentration expected in the feeds to the plant. The oxalate and phosphate components were at their respective solubility limits. The solids components and blend were selected to obtain targeted solids mass loss (aluminum and chromium leaching and oxalate washing) and treatment time. The simulant was not selected to represent any particular Hanford tank waste type.

The simulant was blended from the components listed below. The basis for selecting the individual components and the comparison to actual waste behavior is provided where applicable in the indicated references.

- Boehmite (for Al) (Russell et al. 2009a)

- Gibbsite (for Al) (Russell et al. 2009b)

(a) PS Sundar. 2008. Simulant Recommendation for Phase I Testing in the Pretreatment Engineering Platform. 24590-PTF-RPT-RT-08-006, Rev. 0, Bechtel National, Inc., Richland Washington. 
- Chromium oxyhydroxide (CrOOH) slurry (Rapko et al. 2007)

- Sodium oxalate

- Filtration simulant (Russell et al. 2009c)

- Supernate.

Because the high-temperature caustic leaching process was found to dissolve significant amounts of the $\mathrm{CrOOH}$ solids, a separate chromium solids simulant was prepared and added to the PEP process after post-caustic-leach washing (a non-prototypic addition) in Integrated Tests A and B. In Integrated Test D, the chromium solids component of the simulant was added to the feed to demonstrate the PTF permanganate addition strategy.

Simulant was procured from NOAH Technologies Corporation (San Antonio, TX). Samples of each simulant batch were characterized to make certain that chemical and physical properties requirements were met. Batches of the simulant were procured as follows:

- A 15-gallon trial batch of the blended simulant for laboratory testing to demonstrate the efficacy of the simulant fabrication procedure.

- A 250-gallon scale-up batch of the blended simulant to demonstrate scale-up of the simulant fabrication procedure to an intermediate scale.

- Batches 0, 1, and 2, each nominally 3500 gallons, of blended simulant for the Shakedown/Functional Tests and Integrated Tests A and B. These batches did not contain the $\mathrm{CrOOH}$ component.

- Batch 3, nominally 1200 gal, for Integrated Test D. This batch contained the $\mathrm{CrOOH}$ solids component.

- The CrOOH solids slurry for the Shakedown/Functional Test and Integrated Tests A and B was obtained in two separate batches containing nominally 18 and $36 \mathrm{~kg}$ of $\mathrm{Cr}$ as $\mathrm{CrOOH}$.

\section{Discrepancies and Follow-On Tests}

There are no identified discrepancies or follow-on tests. 


\subsection{Introduction}

Pacific Northwest National Laboratory (PNNL) has been tasked by Bechtel National Inc. (BNI) on the River Protection Project-Hanford Tank Waste Treatment and Immobilization Plant (RPP-WTP) project to perform research and development activities to resolve technical issues identified for the Pretreatment Facility (PTF). The Pretreatment Engineering Platform (PEP) was designed, constructed, and operated as part of a plan to respond to issue M12, "Undemonstrated Leaching Processes," of the External Flowsheet Review Team (EFRT) issue response plan. ${ }^{\text {(a) }}$ The PEP is a $1 / 4.5$--scale test platform designed to simulate the WTP pretreatment caustic leaching, oxidative leaching, ultrafiltration solids concentration, and slurry washing processes. The PEP replicates the WTP leaching processes using prototypic equipment and control strategies. The PEP also includes non-prototypic ancillary equipment to support the core processing.

Two operating scenarios are currently being evaluated for the ultrafiltration process (UFP) and leaching operations. The first scenario has caustic leaching performed in the UFP-2 ultrafiltration feed vessels (i.e., vessel UFP-VSL-T02A in the PEP; and vessels UFP-VSL-00002A and B in the WTP PTF). The second scenario has caustic leaching conducted in the UFP-1 ultrafiltration feed preparation vessels (i.e., vessels UFP-VSL-T01A and B in the PEP; vessels UFP-VSL-00001A and B in the WTP PTF).

In both scenarios, $19 \mathrm{M}$ sodium hydroxide solution ( $\mathrm{NaOH}$, caustic) is added to the waste slurry in the vessels to leach solid aluminum compounds (e.g., gibbsite, boehmite). Caustic addition is followed by a heating step that uses direct injection of steam to accelerate the leach process. Following the caustic-leach, the vessel contents are cooled using vessel cooling jackets and/or external heat exchangers. The main difference between the two scenarios is that for leaching in UFP-1, the $19 \mathrm{M} \mathrm{NaOH}$ is added to unconcentrated waste slurry (3- to 8-wt\% solids), while for leaching in UFP-2, the slurry is concentrated to nominally $20-\mathrm{wt} \%$ solids using cross-flow ultrafiltration before the addition of caustic.

The PEP testing program was conducted under Test Plan TP-RPP-WTP-506 $6^{(\mathrm{b})}$ using a waste simulant, which was developed in response to Task 5 from the M-12 EFRT issue response plan. ${ }^{(a)}$ The testing included the following tests with simulated Hanford tank waste:

- Shakedown/Functional testing: Tested process operations (e.g., slurry transfers, steam heating of the vessels and the accumulation of condensate, filter backpulsing, and flushing), process controls (e.g., transmembrane pressure and axial flow velocity in the filter-loop), certain test functions (e.g., in-line slurry sampling accuracy and precision).

- Integrated Test A: Demonstrated integrated processing when caustic leaching $\left(98^{\circ} \mathrm{C}\right)$ is performed in UFP-VSL-00001A/B with the Cr simulant component added after the post-caustic-leach washing step.

- Integrated Test B: Demonstrated integrated processing when the caustic leaching $\left(98^{\circ} \mathrm{C}\right)$ is performed in UFP-VSL-00002A with the Cr simulant component added after the post caustic-leach washing step.

(a) SM Barnes and R Voke. 2006. "Issue Response Plan for Implementation of External Flowsheet Review Team (EFRT) Recommendations - M12: Undemonstrated Leaching Process.” 24590-WTP-PL-ENG-06-0024 Rev. 0, Bechtel National Inc, Richland, Washington.

(b) GB Josephson, OP Bredt, JK Young, and DE Kurath. 2009. Test Plan for Pretreatment Engineering Platform (PEP) Testing (Phase I). TP-RPP-WTP-506, Rev. 0.4, Pacific Northwest National Laboratory, Richland, Washington. 
- Integrated Test D: Demonstrated integrated processing when the caustic leaching is performed at a lower temperature $\left(85^{\circ} \mathrm{C}\right)$ in UFP-VSL-00002A and with the $\mathrm{Cr}$ simulant component added to the initial batch of simulant.

Integrated Test $\mathrm{C}$ was deleted from the scope of the testing (ICN-TP-RPP-WTP-506_R0.2).

The work described in this report addresses the caustic-leach under Hanford Tank Waste Treatment and Immobilization Plant (WTP) conditions, based on tests performed with a simulant of Hanford waste. Because gibbsite kinetics are rapid (gibbsite is expected to be dissolved by the time the final leach temperature is reached), boehmite leach kinetics are the main focus of the caustic-leach tests. In partial fulfillment of the testing requirements outlined in TP-RPP-WTP-506 Rev 0.4 (see Table S.1), ${ }^{(a)}$ the tests were made at laboratory-scale and in the Pretreatment Engineering Platform (PEP), which is a $1 / 4.5$-scale mock-up of key Pretreatment Facility (PTF) process equipment. Two laboratory-scale caustic-leach tests were performed for each of the PEP runs. Unleached slurry was taken from the PEP caustic-leach vessel for one batch (for each PEP run) and used as feed for the laboratory-scale tests.

The purpose of this report is to summarize the results from both scales that are related to caustic-leach chemistry to support development of a scale-up factor for the submodels to be used in the G2 model, which predicts WTP operating performance. The scale-up factor takes the form of an adjustment factor for the rate constant in the boehmite leach kinetic equation in the G2 model.

The PEP test data included in this report are limited to those from the first batch of simulant leached in vessel UFP-VSL-T01A in Integrated Test A and from the second batch leached in vessel UFP-VSL-T02A in Integrated Test B. The scope of this report is limited to the boehmite leach rate constants determined for these batches and the associated laboratory-scale tests as well as to information required to assess the extent to which the tests met the run criteria.

Quality Assurance (QA) requirements are summarized in Section 2. Section 3 describes the experimental approach and the measurements. The kinetics model predictions and their correlation to data, which are used to determine the rate constant scaling adjustment, are laid out in Section 4. Conclusions are summarized in Section 5.

(a) GB Josephson, OP Bredt, JK Young, and DE Kurath. 2009. Test Plan for Pretreatment Engineering Platform (PEP) Testing (Phase I). TP-RPP-WTP-506, Rev. 0.4, Pacific Northwest National Laboratory, Richland, Washington. 


\subsection{Quality Assurance}

The PNNL QA program is based upon the requirements as defined in the U.S. Department of Energy (DOE) Order 414.1C, Quality Assurance, and 10 CFR 830, Energy/Nuclear Safety Management, Subpart A-Quality Assurance Requirements (a.k.a. the Quality Rule). PNNL has chosen to implement the following consensus standards in a graded approach:

- ASME NQA-1-2000, Quality Assurance Requirements for Nuclear Facility Applications, Part 1, Requirements for Quality Assurance Programs for Nuclear Facilities.

- ASME NQA-1-2000, Part II, Subpart 2.7, Quality Assurance Requirements for Computer Software for Nuclear Facility Applications.

- ASME NQA-1-2000, Part IV, Subpart 4.2, Graded Approach Application of Quality Assurance Requirements for Research and Development.

The procedures necessary to implement the requirements are documented through PNNL's "How Do I...?" (HDI) system. ${ }^{\text {(a) }}$

PNNL implements the RPP-WTP quality requirements by performing work in accordance with the River Protection Project-Hanford Tank Waste Treatment and Immobilization Plant Support Program (RPP-WTP) Quality Assurance Plan (RPP-WTP-QA-001, QAP). Work was performed to the quality requirements of NQA-1-1989 Part I, Basic and Supplementary Requirements, NQA-2a-1990, Part 2.7, and DOE/RW-0333P, Rev 13, Quality Assurance Requirements and Descriptions (QARD), as applicable. These quality requirements are implemented through the River Protection Project-Waste Treatment Plant Support Program (RPP-WTP) Quality Assurance Manual (RPP-WTP-QA-003, QAM). The requirements of DOE/RW-0333P Rev 13, Quality Assurance Requirements and Descriptions (QARD) and 10 CFR 830 Subpart A were not required for this work.

The RPP-WTP addresses internal verification and validation activities by conducting an independent technical review of the final data report in accordance with RPP-WTP's procedure QA-RPP-WTP-604. This review procedure is part of PNNL's RPP-WTP Quality Assurance Manual (RPP-WTP-QA-003). Following this procedure, a technical review would verify that the reported results are traceable, that inferences and conclusions are soundly based, and the reported work satisfies the objectives.

Key analytes in the laboratory control sample (LCS) and PEP control sample were plotted over time to look for anomalies. The PEP control sample is a project-provided material generated from material very similar to the initial simulant feed. In general, the plots of concentrations associated with the inductively coupled plasma (ICP) and ion chromatography (IC) analysis of solutions show recovery within limits of $80 \%$ to $120 \%$.

Limited data reported for the upper and lower sparger air flowmeters in UFP-VSL-T02A (FT-1901 and FT-1977, respectively) are impacted by NCR 38767.1. The flowmeter vendor, Micro-Motion, identifies a minimum flow rate $(0.090 \mathrm{~kg} / \mathrm{min})$ where the Coriolis flow uncertainty increases above $0.5 \%$.

(a) PNNL's system for managing the delivery of laboratory-level policies, requirements, and procedures. 
For the lowest flow rate reported $(0.012 \mathrm{~kg} / \mathrm{min}$ on FT-1977), the estimated uncertainty is $\sim 4 \%$. Since these instruments are used primarily to indicate the approximate air flow rates, higher uncertainty in these data is not considered significant. 


\subsection{Experimental Approach}

The data given in this report are derived from three different processes that represent two different scales. The larger scale data come from the first two PEP facility tests, both of which were conducted at the same caustic-leach digestion temperature. The smaller scale data come from laboratory-scale tests. For each of the PEP tests, two laboratory-scale tests were conducted on slurry taken from the PEP process either before or after $\mathrm{NaOH}$ reagent had been added.

The processes, both PEP and laboratory-scale, are described in Section 3.1. The chemical composition of the simulant is given in Section 3.2. Section 3.3 describes sample acquisition and handling, and Section 3.4 gives the process conditions.

\subsection{Process Description}

The PEP was designed to perform an engineering-scale demonstration of the WTP slurry wash, caustic leaching, oxidative leaching, and ultrafiltration processes. The unit operations tested included solids washing, chemical reagent addition and blending, heating, cooling, leaching, cross-flow ultrafiltration, and filter cleaning. Figure 3.1 shows a simplified flow diagram of the PEP.

Two operating scenarios are currently being evaluated for the UFP system. One scenario has the caustic leaching performed in the ultrafiltration feed vessel (UFP-VSL-T02A). Integrated Tests B and D were conducted under this scenario. The other scenario has caustic leaching conducted in the ultrafiltration feed preparation vessels (UFP-VSL-T01A/B), as in Integrated Test A. The different flowsheets for these two scenarios are shown in Figure 3.2. Within each scenario, the caustic leaching step may be performed at a higher temperature $\left(\sim 98^{\circ} \mathrm{C}\right)$, which enhances leaching kinetics, as for Integrated Tests $\mathrm{A}$ and $\mathrm{B}$, or at a lower temperature $\left(\sim 85^{\circ} \mathrm{C}\right)$ that limits vessel corrosion, as in Integrated Test D.

\subsubsection{PEP Leach in UFP-VSL-T01A}

In Integrated Test A, which was conducted under Test Instruction TI-WTP-PEP-065 (TI-065), simulant stored in HLP-VSL-T22 was transferred into vessel UFP-VSL-T01A together with caustic reagent (nominally $19 \mathrm{M} \mathrm{NaOH}$ ) that was injected into the feed transfer line at the prototypic ratio of caustic/slurry flow rates. A sample of the feed slurry (without added caustic) was taken by grab sample from HLP-VSL-T22 for use in the laboratory-scale testing. (Hereafter, vessel UFP-VSL-T01A is typically referred to as UFP-T01A and HLP-VSL-T22 as HLP-T22.) 


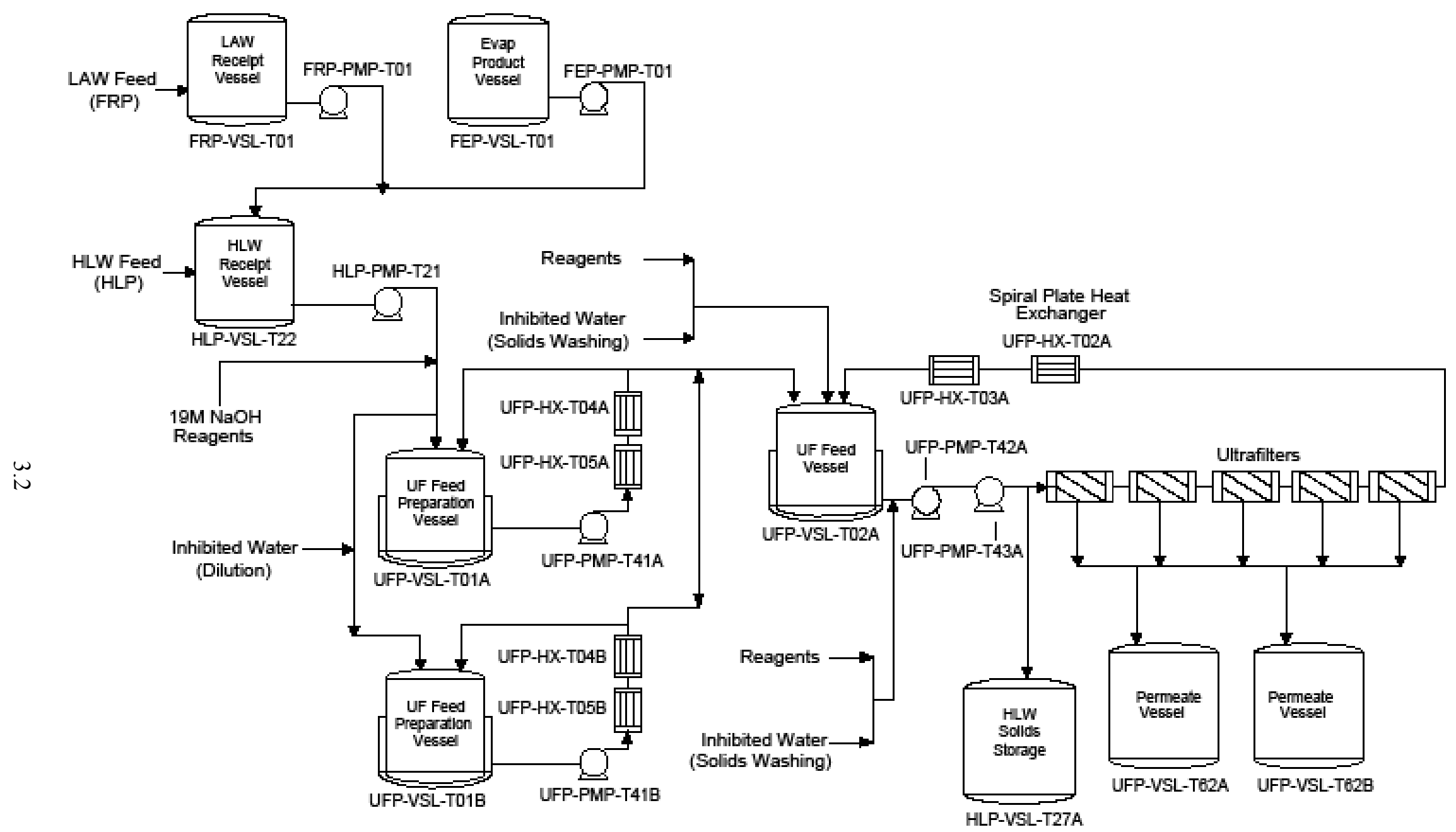

Figure 3.1. PEP Simplified Flow Diagram 


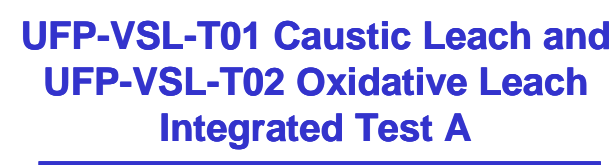

Caustic Addition
Caustic Leach in UFP-VSL-T01
Transfer to UFP-VSL-T02
Cool Down
Concentrate Solids, Post-Caustic Leach
Post-Caustic Leach Wash
Permanganate Addition
$\sqrt[\Omega]{\Omega}$
Oxidative Leach
$\sqrt{\Omega}$
Post-Oxidative Leach Wash
$\sqrt{\Omega}$
Concentrate Solids, Post-Oxidative Leach

\section{UFP-VSL-T02 Caustic Leach and Oxidative Leach Integrated Test B}

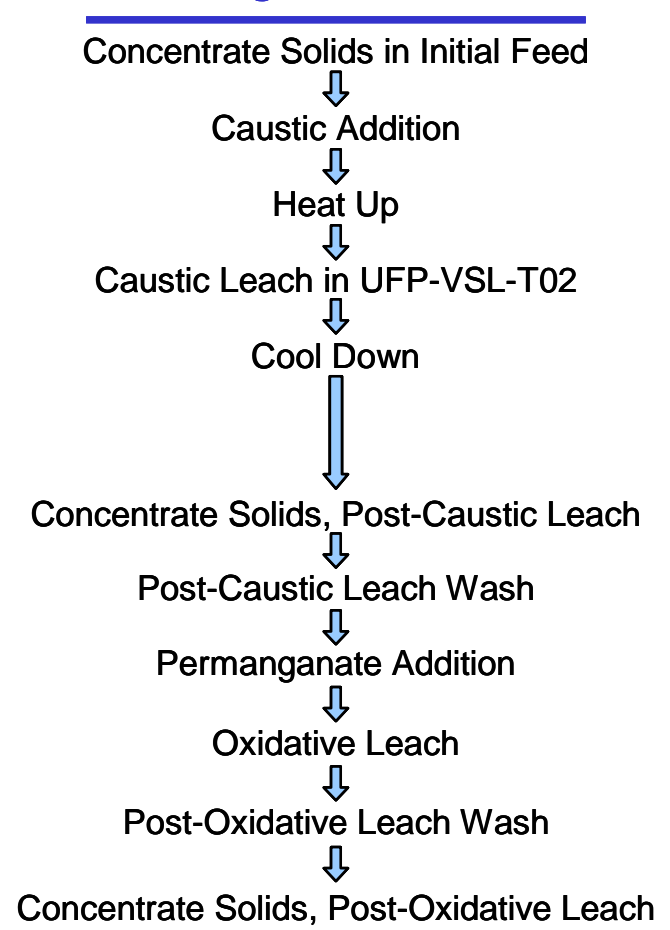

Figure 3.2. Caustic- and Oxidative-Leach and Ultrafilter Operations

PJMs were operated to match the power/volume ratio of the PTF throughout the test. This should achieve prototypic Newtonian slurry mixing and off-bottom suspension of particles. ${ }^{(a)}$ An antifoaming agent (AFA), Dow Corning Q2-3183A, was added directly to UFP-T01A in a quantity expected to produce a nominal concentration of $350 \mathrm{ppm}$ in the slurry. After this addition, another sample of slurry (comprised of feed plus caustic and AFA) was taken from the inner Coriolis densitometer (CD) sample loop at the middle-elevation port in UFP-T01A for use as feed in the laboratory-scale caustic-leach tests. The caustic slurry in UFP-T01A was then heated to about $57^{\circ} \mathrm{C}$ using an external steam heat exchanger, UFP-HX-T04A. This initial heating was accomplished without direct steam injection, unlike the PTF, but this deviation from prototypic operation was necessary to avoid excessive steam condensate accumulation. Because boehmite dissolution is negligible at lower temperatures, the non-prototypic initial heating should have no impact on this scale-up study. After the external heating had been turned off, the UFP-T01A vessel was isolated from its heat exchange recirculation loop and the UFP-T01A slurry was further heated to the leach target of about $98^{\circ} \mathrm{C}$ with direct steam injection through a steam distributor ring ("steam ring") in the vessel. The slurry was maintained at the target temperature for about $16 \mathrm{hr}$ by cycling the steam supply on and off as is planned for the PTF. When steam was not being injected, an air purge was applied to the steam ring at a flow rate chosen to achieve power/volume mixing in the upper region of UFP-T01A. ${ }^{(b)}$ Some of the injected steam accumulated in UFP-T01A as

(a) GB Josephson, OP Bredt, JK Young, and DE Kurath. 2009. Test Plan for Pretreatment Engineering Platform (PEP) Testing (Phase I). TP-RPP-WTP-506, Rev. 0.4, Pacific Northwest National Laboratory, Richland, Washington.

(b) GB Josephson, OP Bredt, JK Young, and DE Kurath. 2009. Test Plan for Pretreatment Engineering Platform (PEP) Testing (Phase I). TP-RPP-WTP-506, Rev. 0.4, Pacific Northwest National Laboratory, Richland, Washington. 
condensate, diluting the slurry, while a significant fraction of the added steam was ultimately evaporated and vented from the vessel in air streams (see Section 3.4.1). The leach was terminated by turning off the steam and recirculating the slurry through an external chiller (UFP-HX-T05A); the temperature of the slurry in UFP-T01A was lowered at a prototypic rate to $\sim 60^{\circ} \mathrm{C}$. At this point the leached slurry was transferred through the UFP-HX-T05A chiller to vessel UFP-VSL-T02A, cooling the slurry to $\sim 25^{\circ} \mathrm{C}$.

Processing continued, alternating caustic-leach batches between vessels UFP-VSL-T01B (UFP-T01B) and UFP-T01A. The UFP-T01A and UFP-T01B vessels alternately took simulant feed from HLP-VSL-T22, leaching and cooling it as described above, and transferring leached slurry to UFP-VSL-T02A for solids concentration. Six batches were leached in the UFP-T01A/B vessels in Integrated Test A, three each in UFP-T01A and UFP-T01B.

The target caustic-leach and vessel operating parameters, as set in the run sheet for Integrated Test A, batch 1, and actual values can be found in Table 3.1. The masses of caustic-leach batch components in the UFP-T01A vessel (i.e., initial simulant, added caustic, and accumulated steam condensate at the end of the 16-hr leach) are summarized in Table 3.2.

The leach batch was processed in UFP-T01A on January 31 to February 1, 2009. A simplified timeline for the batch is provided below. All times are given in local clock time (Pacific Standard Time) using the military convention.

\begin{tabular}{|c|c|c|}
\hline $1 / 31 / 09$ & 09:53 & $\begin{array}{l}\text { 1-L sample taken as grab sample from middle elevation in HLP-T22 to provide } \\
\text { feed for laboratory-scale Test A-2. }\end{array}$ \\
\hline • & $11: 13-12: 02$ & Transfer of simulant, with in-line $\mathrm{NaOH}$ addition, from HLP-T22 to UFP-T01A. \\
\hline • & $11: 41$ & dd AFA to UFP-T01A. \\
\hline • & $13: 26$ & ng with external heater. \\
\hline • & $13: 30$ & $\begin{array}{l}\text { le taken from inner-middle CD port of UFP-T01A to provide feed for } \\
\text { y-scale Test A-1. }\end{array}$ \\
\hline • & $15: 05$ & $\begin{array}{l}57^{\circ} \mathrm{C} \text { reached in UFP-T01A at prototypic temperature sensor; stop heating with } \\
\text { external heater. }\end{array}$ \\
\hline$\bullet$ & $15: 15$ & Begin direct steam injection into UFP-T01A. \\
\hline • & $19: 40$ & $98^{\circ} \mathrm{C}$ reached in UFP-T01A at prototypic tem \\
\hline 1 & $11: 56$ & egin flow through external chiller (leach has been completed). \\
\hline
\end{tabular}

\subsubsection{PEP Leach in UFP-VSL-T02A}

Two leach batches were completed in UFP-VSL-T02A (UFP-T02A) during Integrated Test B, which was conducted under Test Instruction TI-WTP-PEP-066 (TI-066). After the first was complete, the leached slurry in the vessel was cooled and transferred by heel pump to vessel UFP-T01B. A heel of leached cooled slurry was left behind. Based on readings of level instrumentation during the slurry filling process of Integrated Test B, batch 2, the batch 1 heel elevation was $<2.7$ inches above tank bottom center, and the heel volume was $\sim 3$ gal or less.

The caustic-leach process in UFP-T02A was completed as follows. Feed stored in HLP-T22 was transferred into vessel UFP-T01A. PJMs were operated to match the power/volume ratio of the PTF throughout the test. This should achieve prototypic Newtonian slurry mixing and off-bottom suspension 
of particles. ${ }^{(a)}$ AFA was added directly to UFP-T01A in a quantity expected to produce a nominal concentration of $350 \mathrm{ppm}$ in the slurry. The slurry was then transferred from the UFP-T01A feed tank to UFP-T02A, and permeate was removed from UFP-T02A through the first ultrafilter bundle to increase the solids concentration of the slurry. As permeate was removed, the volume (and level) in UFP-T02A fell, triggering the transfer of small refill batches (i.e., $11 \mathrm{gal}$ ) of fresh simulant from UFP-T01A. The filtering and refill process continued, leaving a target quantity of slurry at about $20-\mathrm{wt} \%$ undissolved solids (UDS) in the UFP-T02A vessel and filter-loop. When the solids concentration process was complete, the permeate valves were closed on the filter system, caustic reagent was introduced upstream of the filter-loop pumps at the prototypic ratio of caustic/slurry flow rates, and more AFA was added to maintain the $350 \mathrm{ppm}$ target concentration.

Table 3.1. Nominal Parameter Values for Integrated Test A (UFP-VSL-T01A leaching)

\begin{tabular}{|c|c|c|c|c|}
\hline \multicolumn{2}{|c|}{ Run Sheet Data } & $\begin{array}{c}\text { Expected } \\
\text { Value } \\
\text { UFP-T01A } \\
\text { Leach }\end{array}$ & $\begin{array}{l}\text { Measured } \\
\text { Values } \\
\text { Integrated } \\
\text { Test A }\end{array}$ & Comments \\
\hline \multirow[t]{6}{*}{$\begin{array}{l}1^{\text {st }} \text { UFP-T01A } \\
\text { batch: } \\
\text { Transfer from } \\
\text { HLP-T22 to } \\
\text { UFP-T01A w/ } \\
\text { in-line NaOH } \\
\text { addition }\end{array}$} & $\begin{array}{l}\text { Total transfer volume, } \\
\text { simulant }+\mathrm{NaOH} \text { (gal) }\end{array}$ & $501 \pm 5$ & $\begin{array}{l}\text { Flowmeter: } 498 \\
\text { Vessel level: } \\
\text { i) } 491 \\
\text { ii) } 491 \\
\text { iii) } 481 \\
\text { iv) } 497\end{array}$ & $\begin{array}{l}\text { Flowmeter FT-0119; the } \\
\text { measured value does not correct } \\
\text { for line volume from the meter to } \\
\text { the vessel, which is estimated to } \\
\text { be on the order of } 5 \text { gal. } \\
\text { Based on slurry level in vessel at } \\
\sim 57^{\circ} \mathrm{C} \text { before direct steam } \\
\text { injection: i) measured density } \\
\text { corrected bubbler; ii) as-is } \\
\text { bubbler (uncorrected); iii) vessel } \\
\text { DrexelBrook (DB) (LT-0311); } \\
\text { iv) laser (LT-0320). }\end{array}$ \\
\hline & $\begin{array}{l}\text { Time-averaged transfer rate, } \\
\text { simulant }+\mathrm{NaOH}(\mathrm{gpm})\end{array}$ & $9.6 \pm 1$ & 10.1 & 49.3 minutes \\
\hline & $\begin{array}{l}\text { Concentration of } \mathrm{NaOH} \\
\text { reagent }(\mathrm{M})\end{array}$ & 17.9 & 19.2 & $\begin{array}{l}17.9 \mathrm{M} \text { was the basis for run sheet } \\
\text { calculations per a preliminary } \\
\text { analysis. The reported measured } \\
\text { value is the average of two caustic } \\
\text { samples analyzed by the } \\
\text { Analytical Support Operations } \\
\text { (ASO). }\end{array}$ \\
\hline & $\begin{array}{l}\text { Time-averaged inline caustic } \\
\text { addition flow rate }(\mathrm{kg} / \mathrm{min})\end{array}$ & $12.7-1 /+3$ & 14 & $\begin{array}{l}\text { 23-sec difference between } \\
\text { flowmeters FT-1421 and } \\
\text { FT-0101. }\end{array}$ \\
\hline & Caustic added to vessel $(\mathrm{kg})$ & $639 \pm 10$ & $\begin{array}{l}637 \\
636\end{array}$ & $\begin{array}{l}\text { FT-0101 and FT-1421, } \\
\text { respectively }\end{array}$ \\
\hline & $\begin{array}{l}\text { UFP-T01A initial slurry } \\
\text { volume, heel (gal) }\end{array}$ & 0 & $<2$ & $\begin{array}{l}\text { Zero heel was assumed in run } \\
\text { sheet calculations. The actual } \\
\text { value is based on the minimum } \\
\text { level of the lower bubbler leg, } \\
\text { which indicated no liquid pressure } \\
\text { (assuming water). }\end{array}$ \\
\hline
\end{tabular}

(a) GB Josephson, OP Bredt, JK Young, and DE Kurath. 2009. Test Plan for Pretreatment Engineering Platform (PEP) Testing (Phase I). TP-RPP-WTP-506, Rev. 0.4, Pacific Northwest National Laboratory, Richland, Washington. 
Table 3.1. Nominal Parameter Values for Integrated Test A (UFP-VSL-T01A leaching)

\begin{tabular}{|c|c|c|c|c|}
\hline \multicolumn{2}{|c|}{ Run Sheet Data } & $\begin{array}{l}\text { Expected } \\
\text { Value } \\
\text { UFP-T01A } \\
\text { Leach }\end{array}$ & $\begin{array}{l}\text { Measured } \\
\text { Values } \\
\text { Integrated } \\
\text { Test A }\end{array}$ & \multirow{6}{*}{ 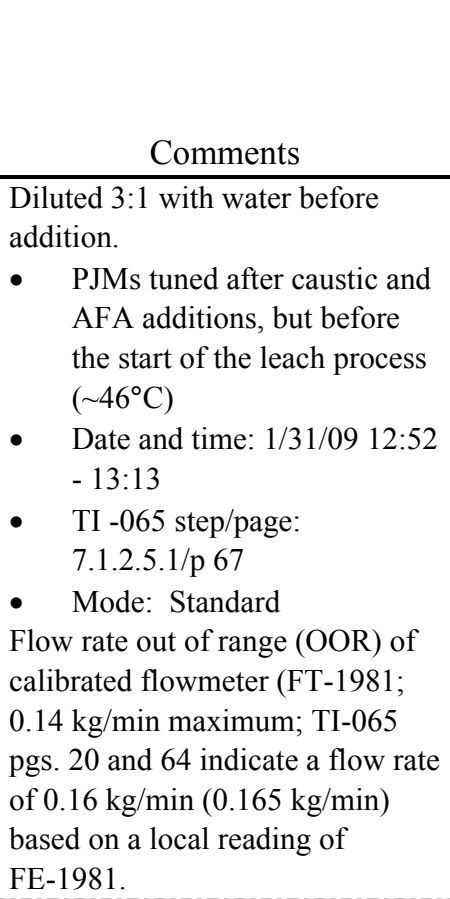 } \\
\hline & $\begin{array}{l}\text { Volume of antifoam (AFA) } \\
\text { concentrate to add (mL) }\end{array}$ & $1000 \pm 20$ & 1000 & \\
\hline & $\begin{array}{l}\text { Pulse jet mixer (PJM) jet } \\
\text { velocity }(\mathrm{m} / \mathrm{s})\end{array}$ & $4.8 \pm 0.3$ & 5.3 & \\
\hline & $\begin{array}{l}\text { PJM stroke, } 80 \% \text { nominal } \\
\text { (in. }\left[\mathrm{xx}_{0}\right] \text { ) }\end{array}$ & $29 \pm 2$ & $29.8(85 \%)$ & \\
\hline & PJM cycle time (s) & $35 \pm 1$ & 35.3 & \\
\hline & $\begin{array}{l}\text { Steam ring purge air flow rate } \\
(\mathrm{kg} / \mathrm{min})\end{array}$ & $0.20 \pm 0.02$ & $\begin{array}{l}>0.14 \text { (DAS); } \\
\text { "0.16 max" } \\
\text { (TI-065 entry) }\end{array}$ & \\
\hline $\begin{array}{l}1^{\text {st }} \text { UFP-T01A } \\
\text { batch: } \\
\text { Initial heat-up } \\
\text { provided by } \mathrm{NaOH}\end{array}$ & $\begin{array}{l}\text { Endpoint temperature for } \\
\text { initial heat-up }\left({ }^{\circ} \mathrm{C}\right)\end{array}$ & $57-1 /+3$ & $\begin{array}{l}57.5 \text { (end of } \\
\text { pre-heat); } \\
57.3 \text { (start direct } \\
\text { steam injection) }\end{array}$ & Prototypic sensor, TTK-0325 \\
\hline $\begin{array}{l}\text { heat of dilution, } \\
\text { pump work, and (if } \\
\text { needed) external } \\
\text { heat exchanger }\end{array}$ & Duration of initial heat-up (hr) & $<3$ & $\begin{array}{c}1.6 \text { (end of } \\
\text { pre-heat); } \\
1.8 \text { (start direct } \\
\text { steam injection) }\end{array}$ & $\begin{array}{l}\text { From the start of flow through the } \\
\text { UFP-T01A heat exchanger loop } \\
\text { to the noted event. }\end{array}$ \\
\hline \multirow{3}{*}{$\begin{array}{l}1^{\text {st }} \text { UFP-T01A } \\
\text { batch: } \\
\text { Final heat-up using } \\
\text { direct steam } \\
\text { injection }\end{array}$} & Target leach temperature $\left({ }^{\circ} \mathrm{C}\right)$ & $98 \pm 2$ & 98.0 & $\begin{array}{l}\text { Temperature used to define the } \\
\text { end of the heating ramp and the } \\
\text { start of the caustic-leach period } \\
\text { (elapsed time zero). }\end{array}$ \\
\hline & Duration of final heat-up (hr) & $3.8 \pm 0.5$ & 4.4 & $\begin{array}{l}\text { From the start of direct steam } \\
\text { injection in UFP-T01A until the } \\
\text { time the target leach temperature } \\
\text { was reached (elapsed time zero). }\end{array}$ \\
\hline & Level at end of heat-up (in.) & $\begin{array}{l}61 \pm 2 \text { (no } \\
\text { temperature } \\
\text { adjustment) }\end{array}$ & $\begin{array}{l}\text { i) } 62.5 \\
\text { ii) } 63.0 \\
\text { iii) } 60.2 \\
\text { iv) } \mathrm{n} / \mathrm{a}\end{array}$ & $\begin{array}{l}\text { i) Measured density corrected } \\
\text { bubbler; ii) as-is bubbler } \\
\text { (uncorrected); iii) vessel DB } \\
\text { (LT-0311); iv) laser (LT-0320) } \\
\text { was not functioning during stable } \\
\text { level measurement. }\end{array}$ \\
\hline \multirow{3}{*}{$\begin{array}{l}1^{\text {st }} \text { UFP-T01A } \\
\text { batch: } \\
\text { Caustic-leach } \\
\text { (constant } \\
\text { temperature } \\
\text { digestion) }\end{array}$} & Duration of leach (hr) & $16 \pm 0.1$ & 16.0 & $\begin{array}{l}\text { From the time the target leach } \\
\text { temperature was reached (elapsed } \\
\text { time zero) until the end of direct } \\
\text { steam injection. }\end{array}$ \\
\hline & Leach temperature $\left({ }^{\circ} \mathrm{C}\right)$ & $98 \pm 2$ & $\begin{array}{l}97.9(\text { see } \\
\text { Table } 3.18)\end{array}$ & Prototypic sensor, TTK- 0325. \\
\hline & PJM jet velocity (m/s) & $4.8 \pm 0.3$ & 5.3 & - $\quad$ PJMs tuning started in the \\
\hline
\end{tabular}


Table 3.1. Nominal Parameter Values for Integrated Test A (UFP-VSL-T01A leaching)

\begin{tabular}{|c|c|c|c|}
\hline Run Sheet Data & $\begin{array}{l}\text { Expected } \\
\text { Value } \\
\text { UFP-T01A } \\
\text { Leach }\end{array}$ & $\begin{array}{l}\text { Measured } \\
\text { Values } \\
\text { Integrated } \\
\text { Test A }\end{array}$ & Comments \\
\hline $\begin{array}{l}\text { PJM stroke, } 80 \% \text { nominal } \\
\text { (in. }\left[\mathrm{xx}^{0} \text { ]) }\right.\end{array}$ & $29 \pm 2$ & $26.6(76 \%)$ & \multirow{2}{*}{$\begin{array}{ll} & \text { first hour of leaching } \\
\text { - } & \text { Date and time: 1/31/09 20:26 } \\
-20: 55 \\
\text { - } & \text { TI step/page: } 7.1 .3 .14 .2 / \mathrm{p} 74 \\
\text { - } & \text { Mode: Simple }\end{array}$} \\
\hline PJM cycle time (s) & $35 \pm 1$ & 35.3 & \\
\hline $\begin{array}{l}\text { Steam ring purge air flow rate } \\
\left(\text { when above } 90^{\circ} \mathrm{C}\right)(\mathrm{kg} / \mathrm{min})\end{array}$ & $0.13 \pm 0.02$ & $\begin{array}{l}>0.14 \text { till } \sim 0.25 \\
\text { hr into the leach } \\
\quad \text { at } 98^{\circ} \mathrm{C} \text {; } \\
\sim 0.13 \text { till } \sim 14 \mathrm{hr} \\
\text { in the } 1 \mathrm{each} ; \\
\sim 0.10 \text { after } \sim 14 \\
\mathrm{hr} \text { in the leach }\end{array}$ & $\begin{array}{l}\text { Purge air cycles on when steam } \\
\text { flow rate is less than a setpoint } \\
\text { value (e.g., } 4 \text { to } 6 \mathrm{cfm} \text { ). Flow } \\
\text { rates shown (from FT-1981) are } \\
\text { typical of the purge air on } \\
\text { periods. The flow rate was } \\
\text { unexpectedly reduced after } \sim 14 \mathrm{hr} \\
\text { in the leach period. }\end{array}$ \\
\hline Level at end of digestion (in.) & $\begin{array}{l}66 \pm 5 \text { (no } \\
\text { temperature } \\
\text { adjustment) }\end{array}$ & $\begin{array}{l}\text { i) } 67.2 \\
\text { ii) } 69.5 \\
\text { iii) } 65.2 \\
\text { iv) } \mathrm{n} / \mathrm{a}\end{array}$ & $\begin{array}{l}\text { i) Measured density corrected } \\
\text { bubbler; ii) as-is bubbler } \\
\text { (uncorrected); iii) vessel DB } \\
\text { (LT-0311); iv) laser (LT-0320) } \\
\text { was not functioning during the } \\
\text { stable level measurement. }\end{array}$ \\
\hline
\end{tabular}

The caustic slurry in UFP-T02A was heated to about $71^{\circ} \mathrm{C}$ using the heat of dilution of the concentrated $\mathrm{NaOH}$ and mechanical heat from the filter-loop recirculation pumps. This initial heating was accomplished without direct steam injection, unlike the PTF, but this deviation from prototypic operation was necessary to avoid excessive steam condensate accumulation. Because boehmite dissolution is negligible at lower temperatures, the non-prototypic initial heating should have no impact on this scale-up study. The filter-loop pumps were then turned off, and a portion of the concentrated slurry in the filter-loop was flushed back into UFP-T02A before the loop was closed off from the vessel. Because the total loop volume ( 82 gal excluding dead-legs) was significantly greater than the flush volume ( $\sim 20 \mathrm{gal})$, none of the flush solution $(0.01 \mathrm{M} \mathrm{NaOH})$ is expected to have entered the vessel. After the flush, a sample of slurry was taken from the middle-low region of vessel UFP-T02A using the CD sampler for use as feed in the laboratory-scale caustic-leach tests. 
Table 3.2. Caustic-Leach Batch Component Masses for PEP Integrated Test A Batch 1

\begin{tabular}{|c|c|c|c|}
\hline & Slurry Mixture Component & Method 1 & Method 2 \\
\hline \multicolumn{2}{|c|}{ Simulant mass in vessel, initial ${ }^{(\mathrm{a})}(\mathrm{kg})$} & 1865 & 1852 \\
\hline \multicolumn{2}{|c|}{$\begin{array}{l}\mathrm{NaOH} \text { reagent mass in vessel, } \text { initial }^{(\mathrm{a}, \mathrm{b})} \\
(\mathrm{kg})\end{array}$} & 614 & 627 \\
\hline \multicolumn{2}{|c|}{$\begin{array}{l}\text { Simulant }+\mathrm{NaOH} \text { mass in vessel, } \\
\text { initial }^{(\mathrm{a})}(\mathrm{kg})\end{array}$} & $2480^{(\mathrm{c})}$ & $2480^{(\mathrm{c})}$ \\
\hline \multicolumn{2}{|c|}{$\begin{array}{l}\text { Accumulated steam condensate mass, } \\
\text { end of } 16-\mathrm{hr} \operatorname{leach}^{(\mathrm{d})}(\mathrm{kg})\end{array}$} & 346 & 364 \\
\hline \multicolumn{2}{|r|}{ Condensate mass fraction $^{(\mathrm{e})}(\mathrm{wt} \%)$} & 12.2 & 12.8 \\
\hline & \multicolumn{3}{|c|}{$\begin{array}{l}\text { The total initial mass of simulant and } \mathrm{NaOH} \text { reagent in the vessel is determined from the } \\
\text { slurry mixture volume in the vessel before direct steam injection and a } \\
\text { temperature-corrected bulk slurry density; it is the same for methods } 1 \text { and } 2 \text { ( } 2479.5 \mathrm{~kg} \text { ). } \\
\text { For simulant and } \mathrm{NaOH} \text { reagent mass determination, methods } 1 \text { and } 2 \text { differ in the } \\
\text { calculation of } \mathrm{NaOH} / \mathrm{simulant} \text { mass fraction added to the vessel: Method } 1 \text { - the total } \\
\text { mass of simulant }+\mathrm{NaOH} \text { mixture added to the vessel is determined by assuming that the } \\
498 \text { gal volume added by flowmeter (Table } 3.1 \text { ) has a density equal to the "after NaOH" } \\
\text { value measured for a sample subsequently taken from the vessel (Table } 3.16) \text {; the mass of } \\
\text { simulant is determined by difference of the total mass and the NaOH mass ( } 636 \mathrm{~kg} \text {, } \\
\text { Table } 3.1 \text { ); and Method } 2 \text { - the volume of NaOH added is determined from the mass of } \\
\mathrm{NaOH} \text { added and the density of } \mathrm{NaOH} \text { (interpolated from literature data); the volume of } \\
\text { simulant is determined by difference of the total volume ( } 498 \text { gal) and the NaOH volume; } \\
\text { and finally, the simulant mass is calculated from the simulant volume and the "before } \\
\mathrm{NaOH"} \mathrm{simulant} \mathrm{density} \mathrm{measurement} \mathrm{(Table} \mathrm{3.16).}\end{array}$} \\
\hline \multicolumn{4}{|c|}{$\begin{array}{l}\text { (b) As noted in Table } 3.1 \text {, the run sheet target amount of } \mathrm{NaOH} \text { reagent was based on an } \\
\text { assumption that } 17.9 \mathrm{M} \mathrm{NaOH} \text { was used in the PEP test whereas actual analyses indicate } \\
\text { that } 19.2 \mathrm{M} \text { was used. }\end{array}$} \\
\hline (c) & \multicolumn{3}{|c|}{$\begin{array}{l}\text { The value is } 2479.5 \mathrm{~kg} \text {, before rounding; it is consistent with the summation of the values } \\
\text { for simulant mass and } \mathrm{NaOH} \text { mass that are given in the table. }\end{array}$} \\
\hline & \multicolumn{3}{|c|}{$\begin{array}{l}\text { The steam condensate values are discussed in Section 3.4.1.1. The two estimates are } \\
\text { volume based (Method 1) and total slurry mass based (Method 2). }\end{array}$} \\
\hline & \multicolumn{3}{|c|}{$\begin{array}{l}\text { The condensate mass fraction }=16-\mathrm{hr} \text { condensate mass } /(16-\mathrm{hr} \text { condensate mass }+ \text { total } \\
\text { initial simulant }+\mathrm{NaOH} \text { mass }) \text {. }\end{array}$} \\
\hline
\end{tabular}

The slurry-caustic mixture in UFP-T02A was further heated to about $98^{\circ} \mathrm{C}$ with direct steam injection through a steam ring. The slurry was maintained at that temperature using steam injection for about $16 \mathrm{hr}$ by cycling the steam supply on and off as is planned for the PTF. When steam was not being injected, an air purge was applied to the steam ring at a flow rate chosen to achieve power/volume mixing in the upper region of UFP-T02A. ${ }^{\text {(a) }}$ Some of the injected steam accumulated in UFP-T02A as condensate, diluting the slurry, while a significant fraction of the added steam was ultimately evaporated and vented from the vessel in air streams (see Section 3.4.1). The leach was terminated by turning off the steam and cooling the slurry at a prototypic rate using the integral UFP-T02A vessel cooling jacket.

The target caustic-leach parameters, as set in the run sheet for Integrated Test B, batch 2, and actual values can be found in Table 3.3. The masses of caustic-leach batch components in the UFP-T02A vessel

(a) GB Josephson, OP Bredt, JK Young, and DE Kurath. 2009. Test Plan for Pretreatment Engineering Platform (PEP) Testing (Phase I). TP-RPP-WTP-506, Rev. 0.4, Pacific Northwest National Laboratory, Richland, Washington. 
(i.e., initial solids-concentrated simulant, added caustic, and accumulated steam condensate at the end of the 16-hr leach) are summarized in Table 3.4.

The leach batch was processed in UFP-T02A on March 15-16, 2009. A simplified timeline for the batch is provided below. All times are given in local clock time (Pacific Daylight Time) using the military convention.

\begin{tabular}{|c|c|c|}
\hline $3 / 13 / 09$ & $11: 33-12: 20$ & $\begin{array}{l}\text { Transfer of simulant from HLP-T } 22 \text { to UFP-T01A (for later transfer } \\
\text { to UFP-T02A). }\end{array}$ \\
\hline • & $12: 45$ & Add AFA to UFP-T01A, in preparation for transfer to UFP-T02A. \\
\hline $3 / 14 / 09$ & $11: 03$ & $\begin{array}{l}\text { Completed transfer of first caustic-leached batch from UFP-T02A to } \\
\text { storage in UFP-T01B. }\end{array}$ \\
\hline$\bullet$ & $12: 19-12: 52$ & $\begin{array}{l}\text { Transfer of initial batch of simulant from UFP-T01A to UFP-T02A } \\
\text { in preparation for second caustic-leached batch. }\end{array}$ \\
\hline - & $16: 37$ & Start dewatering with five filters. \\
\hline $3 / 15 / 09$ & $13: 32$ & Dewatering complete. \\
\hline$\bullet$ & $14: 11-15: 19$ & Addition of $\mathrm{NaOH}$ reagent into filter-loop. \\
\hline$\bullet$ & $16: 55$ & $\begin{array}{l}\text { Filter-loop pumps off; at this time the temperature was } 71.8^{\circ} \mathrm{C} \text { at the } \\
\text { prototypic vessel temperature sensor (TTK-0619). }\end{array}$ \\
\hline$\bullet$ & $16: 57-16: 58$ & Filter-loop flush into UFP-T02A. \\
\hline$\bullet$ & $17: 15$ & $\begin{array}{l}\text { Two 1-L samples taken from middle-lower CD port of UFP-T02A to } \\
\text { provide feed for laboratory-scale Tests B-1 and B- } 2 \text {. }\end{array}$ \\
\hline$\bullet$ & $17: 24$ & Begin direct steam injection into UFP-T02A. \\
\hline$\bullet$ & $19: 51$ & $\begin{array}{l}98^{\circ} \mathrm{C} \text { reached in UFP-T02A at prototypic temperature sensor } \\
(\mathrm{TTK}-0325) \text {. }\end{array}$ \\
\hline $3 / 16 / 09$ & $11: 50$ & End steam injection into UFP-T02A (leach is complete). \\
\hline
\end{tabular}


Table 3.3. Nominal Parameter Values for Integrated Test B (UFP-VSL-T02A leaching)

\begin{tabular}{|c|c|c|c|c|}
\hline \multicolumn{2}{|c|}{ Run Sheet Data } & $\begin{array}{c}\text { Expected } \\
\text { Value } \\
\text { UFP-T02A } \\
\text { Leach }\end{array}$ & $\begin{array}{l}\text { Measured } \\
\text { Values } \\
\text { Integrated } \\
\text { Test B }\end{array}$ & Comments \\
\hline \multirow{2}{*}{$\begin{array}{c}2^{\text {nd }} \text { UFP-T02A batch: } \\
\text { Initial transfer from } \\
\text { UFP-T01A to } \\
\text { UFP-T02A }\end{array}$} & $\begin{array}{l}\text { Total transfer volume of } \\
\text { simulant (gal) }\end{array}$ & $220 \pm 3$ & 219 & $\begin{array}{l}\text { FT }-0331 ; \pm 2 \text { gal. based on } \\
0.5 \% \text { of span. }\end{array}$ \\
\hline & $\begin{array}{l}\text { Time-averaged transfer rate of } \\
\text { simulant }(\mathrm{gpm})\end{array}$ & $6.9 \pm 1$ & 7.0 & $\begin{array}{l}\text { s.d. of flow rate - } \\
0.07 \text { gpm; } 31.25 \mathrm{~min} \\
\text { addition period. }\end{array}$ \\
\hline \multirow{2}{*}{$\begin{array}{l}2^{\text {nd }} \text { UFP-T02A batch: } \\
\text { Solids concentration } \\
\text { in UFP-T02A }\end{array}$} & $\begin{array}{l}\text { Permeate removed during } \\
\text { concentration }(\mathrm{kg})\end{array}$ & $\begin{array}{l}\text { not provided in } \\
\text { approved run } \\
\text { sheet }\end{array}$ & 2629 & FT-0720, $\pm 0.1 \%$ \\
\hline & $\begin{array}{l}\text { Total feed slurry volume added } \\
\text { as make-up from UFP-T01A } \\
\text { during concentration (gal) }\end{array}$ & $\begin{array}{c}517(=47 \\
\text { transfers } \mathrm{x} \\
11 \mathrm{gal})\end{array}$ & 519 & $\begin{array}{l}\text { FT-0331 (flowmeter); } \\
\text { SV-0351 (solenoid valve } \\
\text { setting). }\end{array}$ \\
\hline \multirow{6}{*}{$\begin{array}{l}2^{\text {nd }} \text { UFP-T02A batch: } \\
\text { Caustic addition to } \\
\text { filter-loop }\end{array}$} & $\begin{array}{l}\text { Concentration of } \mathrm{NaOH} \text { reagent } \\
\text { (M) }\end{array}$ & $\begin{array}{l}19 \text { nominal; } \\
18.6 \text { specific }\end{array}$ & 18.7 & $\begin{array}{l}\text { A preliminary caustic } \\
\text { analysis of } 18.6 \mathrm{M} \text { was } \\
\text { used to develop the run } \\
\text { sheet batch quantities. } \\
\text { The actual result is the } \\
\text { average of two } 2 / 13 / 09 \\
\text { caustic samples, } 1^{\text {st }} \\
\text { replicates only (analyzed } \\
\text { by ASO). }\end{array}$ \\
\hline & Caustic added to vessel ( $\mathrm{kg})$ & $720 \pm 5$ & $\begin{array}{l}721 \\
674\end{array}$ & $\begin{array}{l}\text { FT-0605 and FT-1421, } \\
\text { respectively. }\end{array}$ \\
\hline & $\begin{array}{l}\text { Time-average caustic addition } \\
\text { flow rate }(\mathrm{kg} / \mathrm{min})\end{array}$ & $10.7 \pm 0.5$ & $\begin{array}{c}10.5 \\
9.8\end{array}$ & $\begin{array}{l}68.67 \text { and } 68.98 \mathrm{~min} \\
\text { addition period as } \\
\text { measured on FT-0605, } \\
\text { and FT-1421, } \\
\text { respectively. }\end{array}$ \\
\hline & $\begin{array}{l}\text { Tank level after caustic addition } \\
\text { (in.) }\end{array}$ & $\begin{array}{c}49.5 \pm 2 \\
\text { (no temperature } \\
\text { adjustment) }\end{array}$ & $\begin{array}{l}\text { i) } 50.5 \\
\text { ii) } 54.0 \\
\text { iii) } 54.3 \\
\text { iv) } 52.9\end{array}$ & $\begin{array}{l}\text { i) Measured density } \\
\text { corrected bubbler; ii) as-is } \\
\text { bubbler (uncorrected); } \\
\text { iii) vessel DB (LT-0698); } \\
\text { iv) laser (LT-0614). For } \\
\text { (ii), the apparent bubbler } \\
\text { specific gravity } \\
\text { ( } 1.32 \mathrm{~kg} / \mathrm{L} \text { ) is much lower } \\
\text { than the } \\
\text { temperature-corrected } \\
\text { analytical value } \\
\text { (1.42 kg/L). (iv) is the } \\
\text { preferred measurement. }\end{array}$ \\
\hline & $\begin{array}{l}\text { Volume of antifoam (AFA) } \\
\text { concentrate to add (mL) }\end{array}$ & $330 \pm 10$ & 330 & $\begin{array}{l}\text { Diluted } 3: 1 \text { with water } \\
\text { before addition. }\end{array}$ \\
\hline & $\begin{array}{l}\text { Time-averaged filter-loop flow } \\
\text { rate }(\mathrm{gpm})\end{array}$ & $109 \pm 10$ & $\begin{array}{l}105 \\
101\end{array}$ & $\begin{array}{l}\text { FT-0623 and FT-0635, } \\
\text { respectively; 3/15/09 } \\
\text { between } \sim 14: 11 \text { and } \\
\sim 15: 19 \text { PDT. }\end{array}$ \\
\hline
\end{tabular}


Table 3.3. Nominal Parameter Values for Integrated Test B (UFP-VSL-T02A leaching)

\begin{tabular}{|c|c|c|c|c|}
\hline \multicolumn{2}{|c|}{ Run Sheet Data } & $\begin{array}{c}\text { Expected } \\
\text { Value } \\
\text { UFP-T02A } \\
\text { Leach }\end{array}$ & $\begin{array}{l}\text { Measured } \\
\text { Values } \\
\text { Integrated } \\
\text { Test B }\end{array}$ & Comments \\
\hline \multirow{3}{*}{$\begin{array}{l}2^{\text {nd }} \text { UFP-T02A batch: } \\
\text { Initial heat-up } \\
\text { provided by } \mathrm{NaOH} \\
\text { heat of dilution, } \\
\text { pump work, and (if } \\
\text { needed) external heat } \\
\text { exchanger }\end{array}$} & $\begin{array}{l}\text { Endpoint temperature for initial } \\
\text { heat-up }\left({ }^{\circ} \mathrm{C}\right)\end{array}$ & $71 \pm 1$ & $\begin{array}{l}71.8 \text { (end of } \\
\text { pre-heat); } \\
68.7 \text { (start direct } \\
\text { steam injection) }\end{array}$ & $\begin{array}{l}\text { Prototypic sensor, } \\
\text { TTK-0619. }\end{array}$ \\
\hline & Duration of initial heat-up (hr) & $\begin{array}{c}<2 \text { (batch } 1) ; \\
\text { not provided in } \\
\text { TI-066 run sheet } \\
\text { (batch } 2)\end{array}$ & $\begin{array}{c}1.6 \text { (end of } \\
\text { pre-heat); } \\
2.1 \text { (start direct } \\
\text { steam injection) }\end{array}$ & $\begin{array}{l}\text { From the end of caustic } \\
\text { addition to the noted } \\
\text { event. }\end{array}$ \\
\hline & $\begin{array}{l}\text { Time-averaged filter-loop flow } \\
\text { rate (gpm) }\end{array}$ & $109 \pm 10$ & $\begin{array}{l}106 \\
100\end{array}$ & $\begin{array}{l}\text { FT-0623 and FT-0635, } \\
\text { respectively; 3/15/09 } \\
\text { Between 15:20 and } \\
\text { 16:54 PDT, excludes } \\
\sim 9 \text { min. when the pumps } \\
\text { were turned off for a } \\
\text { stable vessel level } \\
\text { measurement. }\end{array}$ \\
\hline \multirow[b]{3}{*}{$\begin{array}{l}2^{\text {nd }} \text { UFP-T02A batch: } \\
\text { flush part of } \\
\text { filter-loop contents } \\
\text { into UFP-T02A }\end{array}$} & $\begin{array}{l}\text { Flush liquid added, endpoint } \\
\text { (kg) }\end{array}$ & $74 \pm 5$ & 77.6 & FT-1513. \\
\hline & $\begin{array}{l}\text { Time-averaged flush liquid } \\
\text { addition rate }(\mathrm{kg} / \mathrm{min})\end{array}$ & max. possible & 73 & $\begin{array}{l}\text { Average flow, FT-1513, } \\
\sim 1 \text { minute. }\end{array}$ \\
\hline & UFP-T02A level after flush (in.) & $\begin{array}{c}53.5 \pm 3 \\
\text { (no temperature } \\
\text { adjustment) }\end{array}$ & $\begin{array}{l}\text { i) } 55.2 \text {; } \\
\text { ii) } 58.5 \text {; } \\
\text { iii) } 57.6 \text {; } \\
\text { iv) } 56.3\end{array}$ & $\begin{array}{l}\text { Level measurements } \\
\text { obtained after the start of } \\
\text { direct steam injection } \\
\text { (i.e., } \sim 1 \text { gal of steam } \\
\text { condensate added } \\
\text { corresponding to } \sim 0.2 \text { to } \\
0.3 \text { in. in UFP-T02A): } \\
\text { i) measured density } \\
\text { corrected bubbler; ii) as-is } \\
\text { bubbler (uncorrected); } \\
\text { iii) vessel DB (LT-0698); } \\
\text { iv) laser (LT-0614). For } \\
\text { (ii), the apparent bubbler } \\
\text { specific gravity } \\
\text { (1.32 kg/L) is much lower } \\
\text { than the } \\
\text { temperature-corrected } \\
\text { analytical value } \\
\text { (1.41 kg/L). (iv) is the } \\
\text { preferred measurement as } \\
\text { the laser functioned and } \\
\text { was well behaved } \\
\text { throughout the test period. }\end{array}$ \\
\hline
\end{tabular}


Table 3.3. Nominal Parameter Values for Integrated Test B (UFP-VSL-T02A leaching)

\begin{tabular}{|c|c|c|c|c|}
\hline \multicolumn{2}{|c|}{ Run Sheet Data } & $\begin{array}{l}\text { Expected } \\
\text { Value } \\
\text { UFP-T02A } \\
\text { Leach }\end{array}$ & $\begin{array}{l}\text { Measured } \\
\text { Values } \\
\text { Integrated } \\
\text { Test B }\end{array}$ & Comments \\
\hline \multirow[t]{5}{*}{$\begin{array}{l}2^{\text {nd }} \text { UFP-T02A batch: } \\
\text { Final heat-up using } \\
\text { direct steam injection }\end{array}$} & Target leach temperature $\left({ }^{\circ} \mathrm{C}\right)$ & $98 \pm 2$ & 98.0 & $\begin{array}{l}\text { Temperature used to } \\
\text { define the end of the } \\
\text { heating ramp and the start } \\
\text { of the caustic-leach period } \\
\text { (elapsed time zero). }\end{array}$ \\
\hline & Duration of final heat-up (hr) & $2.6 \pm 0.5$ & 2.4 & $\begin{array}{l}\text { From the start of direct } \\
\text { steam injection in } \\
\text { UFP-T02A until the target } \\
\text { leach temperature was } \\
\text { first reached. }\end{array}$ \\
\hline & $\begin{array}{l}\text { Steam ring purge air flow rate } \\
(\mathrm{kg} / \mathrm{min})\end{array}$ & $\begin{array}{c}\text { Below } 90^{\circ} \mathrm{C}: \\
0.14 \pm 0.02 \\
\text { Above } 90^{\circ} \mathrm{C}: \\
0.09 \pm 0.02\end{array}$ & $\begin{array}{c}0.14 \text { to } 0.15 \text { up } \\
\text { to } 98^{\circ} \mathrm{C} \\
0.09 \text { during } \\
\text { leach }\end{array}$ & $\begin{array}{l}\text { Purge air cycles on when } \\
\text { steam flow rate is less } \\
\text { than a setpoint value } \\
\text { (e.g., } 4 \text { to } 6 \mathrm{cfm} \text { ). Flow } \\
\text { rate shown (from } \\
\text { FT-1995) is typical of the } \\
\text { purge air on periods. } \\
\text { Flow rate reduced } \sim 0.1 \mathrm{hr} \\
\text { into the leach period at } \\
98^{\circ} \mathrm{C} \text {. }\end{array}$ \\
\hline & $\begin{array}{l}\text { Total lower air sparger flow rate } \\
(\mathrm{kg} / \mathrm{min})\end{array}$ & $\begin{array}{c}\text { Below } 90^{\circ} \mathrm{C} \text { : } \\
0.40 \pm 0.05 \\
\quad \text { (batch } 1) ; \\
0.010 \pm 0.005 \\
\quad \text { (batch } 2) \\
\text { Above } 90^{\circ} \mathrm{C} \text { : } \\
0.08 \pm 0.02\end{array}$ & $\begin{array}{l}0.012 \text { below } \\
\sim 96^{\circ} \mathrm{C} \text {; } \\
0.08 \text { above } \\
\sim 96^{\circ} \mathrm{C}\end{array}$ & $\begin{array}{l}\text { First entry (from } \\
\text { FT- } 1977 \text { ) is the average } \\
\text { from } 90^{\circ} \mathrm{C} \text { up to } \sim 96^{\circ} \mathrm{C} \\
\text { when the flow rate was } \\
\text { adjusted (increased). For } \\
\text { batch } 2 \text { of Integrated } \\
\text { Test B, TI- } 066 \text { did not } \\
\text { instruct the operator to } \\
\text { reset the flow rate from } \\
\text { the "idle" value } \\
(0.010 \mathrm{~kg} / \mathrm{min}) \text { to the } \\
\text { correct } 0.40 \mathrm{~kg} / \mathrm{min} \text { after } \\
\mathrm{NaOH} \text { addition. }\end{array}$ \\
\hline & $\begin{array}{l}\text { Upper air sparger flow rate } \\
(\mathrm{kg} / \mathrm{min})\end{array}$ & $\begin{array}{c}\text { Below } 90^{\circ} \mathrm{C} \text { : } \\
0.10 \pm 0.03 \\
\text { Above } 90^{\circ} \mathrm{C} \text { : } \\
0.02 \pm 0.03\end{array}$ & $\begin{array}{l}0.10 \text { below } \\
\sim 91^{\circ} \mathrm{C} \\
0.02 \text { above } \\
\sim 91^{\circ} \mathrm{C}\end{array}$ & $\begin{array}{l}\text { First entry (from } \\
\text { FT-1901) is the average } \\
\text { from } 90^{\circ} \mathrm{C} \text { up to } \sim 91^{\circ} \mathrm{C} \\
\text { when the flow rate was } \\
\text { reduced. }\end{array}$ \\
\hline
\end{tabular}


Table 3.3. Nominal Parameter Values for Integrated Test B (UFP-VSL-T02A leaching)

\begin{tabular}{|c|c|c|c|c|}
\hline \multicolumn{2}{|c|}{ Run Sheet Data } & $\begin{array}{l}\text { Expected } \\
\text { Value } \\
\text { UFP-T02A } \\
\text { Leach }\end{array}$ & $\begin{array}{l}\text { Measured } \\
\text { Values } \\
\text { Integrated } \\
\text { Test B }\end{array}$ & \multirow[b]{2}{*}{\begin{tabular}{l}
\multicolumn{1}{c}{ Comments } \\
i) Measured density \\
corrected bubbler; ii) as-is \\
bubbler (uncorrected); \\
iii) vessel DB (LT-0698); \\
iv) laser (LT-0614). For \\
(ii), the apparent bubbler \\
specific gravity \\
( $1.29 \mathrm{~kg} / \mathrm{L}$ ) is much lower \\
than the \\
temperature-corrected \\
analytical value \\
(1.35 kg/L). (iii) is \\
inexplicably high. (iv) is \\
the preferred \\
measurement.
\end{tabular}} \\
\hline & Level at end of heat-up (in.) & $\begin{array}{c}60.4-2 /+3 \\
\text { (no temperature } \\
\text { adjustment) }\end{array}$ & $\begin{array}{l}\text { i) } 61.4 \\
\text { ii) } 64.1 \\
\text { iii) } 67.0 \\
\text { iv) } 61.9\end{array}$ & \\
\hline \multirow{6}{*}{$\begin{array}{l}2^{\text {nd }} \text { UFP-T02A batch: } \\
\text { Caustic-leach } \\
\text { (constant temperature } \\
\text { digestion) }\end{array}$} & Duration of leach (hr) & $16-0.1 /+1$ & 16.0 & $\begin{array}{l}\text { From the time the target } \\
\text { leach temperature was } \\
\text { reached (elapsed time } \\
\text { zero) till the end of direct } \\
\text { steam injection at } \sim 98^{\circ} \mathrm{C} \text {. }\end{array}$ \\
\hline & Leach temperature $\left({ }^{\circ} \mathrm{C}\right)$ & $98 \pm 2$ & $\begin{array}{c}97.7 \text { (see } \\
\text { Table 3.18) }\end{array}$ & $\begin{array}{l}\text { Prototypic sensor, } \\
\text { TTK-0619. }\end{array}$ \\
\hline & PJM jet velocity (m/s) & $7.3 \pm 0.4$ & 7.5 & \multirow{3}{*}{$\begin{array}{l}\text { - PJMs tuning started in } \\
\text { the first hour of } \\
\text { leaching. } \\
\text { - Date and time: } 3 / 15 / 09 \\
\text { 20:05 - 22:04. } \\
\text { - TI step/page: } \\
\text { 7.13.19.1/p96. } \\
\text { - Mode: Simple. }\end{array}$} \\
\hline & $\begin{array}{l}\text { PJM stroke, } 80 \% \text { nominal } \\
\text { (in. }[\mathrm{xx} \%] \text { ) }\end{array}$ & $31.5 \pm 3$ & $29.6(78 \%)$ & \\
\hline & PJM cycle time (s) & $33 \pm 1$ & 33.2 & \\
\hline & Level at end of digestion (in.) & $\begin{array}{c}65.2 \pm 5 \\
\text { (no temperature } \\
\text { adjustment) }\end{array}$ & $\begin{array}{l}\text { i) } 68.6 \text {; } \\
\text { ii) } 71.5 \text {; } \\
\text { iii) } 72.7 \text {; } \\
\text { iv) } 69.6\end{array}$ & $\begin{array}{l}\text { i) Measured density } \\
\text { corrected bubbler; ii) as-is } \\
\text { bubbler (uncorrected); } \\
\text { iii) vessel DB (LT-0698); } \\
\text { iv) laser (LT-0614). The } \\
\text { lower and upper bubblers } \\
\text { functioned for a limited } \\
\text { portion of the stable level } \\
\text { period (as shown). (iv) is } \\
\text { the preferred } \\
\text { measurement. }\end{array}$ \\
\hline
\end{tabular}

\subsubsection{Laboratory-Scale Test Process}

For the purposes of scale-up, this test was performed twice for test A conditions and twice for test B conditions: 
- Test A-1: Slurry-caustic mixture sampled from UFP-T01A 10 minutes or more after $\mathrm{NaOH}$ addition and before heat-up.

- Test A-2: Feed slurry sampled from HLP-T22 (before $\mathrm{NaOH}$ addition).

- Test B-1: Slurry-caustic mixture sampled from UFP-T02A at about $71{ }^{\circ} \mathrm{C}$ temperature after in-line $\mathrm{NaOH}$ addition was complete; the filter-loop had been partially flushed into UFP-T02A, and UFP-T02A had been isolated from the loop and mixed for at least 10 minutes.

- Test B-2: as for Test B-1.

Two 1-L bottles of sample had been drawn from PEP to supply each of the laboratory-scale feed batches. The Test A-1 sample was taken from the inner-middle region of UFP-T01A using the Coriolis densitometer (CD) sampler, while the sample for Test A-2 was a grab sample taken from the middle depth (approximately 108 inches from simulant surface) of HLP-T22. In the case of test B, the laboratory-scale samples used in Tests B-1 and B-2 were taken from separate 1-L bottles which both were collected from the middle-low region of UFP-T02A using the CD sampler.

Table 3.4. Caustic-Leach Batch Component Masses for PEP Integrated Test B Batch 2

\begin{tabular}{|c|c|c|}
\hline Slurry Mixture Component & Method 1 & Method 2 \\
\hline Simulant mass in vessel, initial ${ }^{(\mathrm{a})}(\mathrm{kg})$ & $707(706.8)$ & $728(728.2)$ \\
\hline $\begin{array}{l}\mathrm{NaOH} \text { reagent mass in vessel, initial }{ }^{(\mathrm{a}, \mathrm{b})} \\
(\mathrm{kg})\end{array}$ & $573(572.8)$ & $551(551.4)$ \\
\hline $\begin{array}{l}\text { Simulant }+\mathrm{NaOH} \text { mass in vessel, } \\
\text { initial }^{(\mathrm{a})}(\mathrm{kg})\end{array}$ & 1280 & 1280 \\
\hline $\begin{array}{l}\text { Accumulated steam condensate mass, } \\
\text { end of } 16-\mathrm{hr} \operatorname{leach}^{(\mathrm{c})}(\mathrm{kg})\end{array}$ & 221 & 242 \\
\hline Condensate mass fraction $^{(\mathrm{d})}(\mathrm{wt} \%)$ & 14.7 & 15.9 \\
\hline (a) & $\begin{array}{l}\text { gent in the ve } \\
\text { lly flushing th } \\
\text { injection) and } \\
\text { and } 2 \text { ( } 1280 \mathrm{k} \\
\text { ed was determ } \\
\text { e., } 82 \text { gal assu } \\
\text { t density (cor } \\
\text { o of } \mathrm{NaOH} \text { to } \\
\mathrm{OH} \text { added ( } \mathrm{Ta}\end{array}$ & $\begin{array}{l}\text { rmined from the } \\
\text { p into UFP-T02A, } \\
\text { ture-corrected } \\
\text { ass of } \\
\text { nming the volume } \\
\text { pumps off) and } \\
\text { yessel } \\
\text { tass based on the } \\
21 \mathrm{~kg} \text { on FT- } 0605\end{array}$ \\
\hline \multicolumn{3}{|c|}{$\begin{array}{l}\text { As noted in Table } 3.3 \text { the run sheet target amount of } \mathrm{NaOH} \text { reagent was based on an } \\
\text { assumption that } 18.6 \mathrm{M} \mathrm{NaOH} \text { was used in the PEP test whereas actual analyses indicate } \\
\text { that } 18.7 \mathrm{M} \text { was used. }\end{array}$} \\
\hline \multicolumn{3}{|c|}{$\begin{array}{l}\text { The steam condensate values are discussed in Section 3.4.1.2. The two estimates are } \\
\text { volume based (Method 1) and total slurry mass based (Method 2). }\end{array}$} \\
\hline \multicolumn{3}{|c|}{$\begin{array}{l}\text { The condensate mass fraction }=16-\mathrm{hr} \text { condensate mass } /(16-\mathrm{hr} \text { condensate mass }+ \text { total } \\
\text { initial simulant }+\mathrm{NaOH} \text { mass }) .\end{array}$} \\
\hline
\end{tabular}

The in-tank sampling system for UFP-T02A is shown in Figure 3.3. The systems for UFP-T01A and UFP-T01B were similar in essentials. Samples were obtained with the sample loop in recirculation mode 
with slurry returned to the vessel. To obtain a sample, a valve was used to divert the entire flow to the sample bottle. Before each sample the sampling valve and line was purged by recirculating slurry to ensure that there was no cross-contamination with previous sampling events.

The samples were rapidly cooled to ambient temperature ${ }^{(a)}$ to minimize any further leaching reaction. The laboratory-scale feed was stored at laboratory ambient temperature until it was used. The delay between the time when the feed was acquired from PEP and the time laboratory-scale testing started was about 9 days for Test A-1 and A-2 (from January 31, 2009 to February 9, 2009) and was about 4 days for test B (from March 15, 2009 to March 19, 2009).

The slurry feed, distilled water, and, in Test A-2, $\mathrm{NaOH}$ reagent added in the laboratory, was placed in a closed vessel and agitated by an impeller rotating at $120 \mathrm{rpm}$. The distilled water was added before the laboratory-scale leach process to simulate the net addition of condensate in the PEP vessel at the end of the 16-hr leach process. The slurry mixture was then mixed, heated to the digestion temperature, and held there. The temperature was measured with a calibrated thermocouple and controlled using a calibrated temperature controller. More information about the caustic-leach apparatus may be found in WTP-RPT-176 (Russell et al. 2009b).

Table 3.5 and Table 3.6 show the measured experimental parameters for laboratory-scale Test A and laboratory-scale Test B, respectively, together with the target values for those parameters. These data are taken from TI-WTP-PEP-075, Rev. 0, Caustic Leaching of Aluminum Solids Test \#A and TI-WTP-PEP-682, Rev. 0, Caustic Leaching of Aluminum Solids Test \#B.

(a) According to an interview with the lead sample handler, for one of the Test B laboratory-scale 1-L samples, rapid cooling proceeded only for about 1 hour before it had to be moved from the cold-water bath to make room in the bath for analytical PEP samples. Cooling of the laboratory-scale 1-L sample was continued by running it under cold water in the sink. 


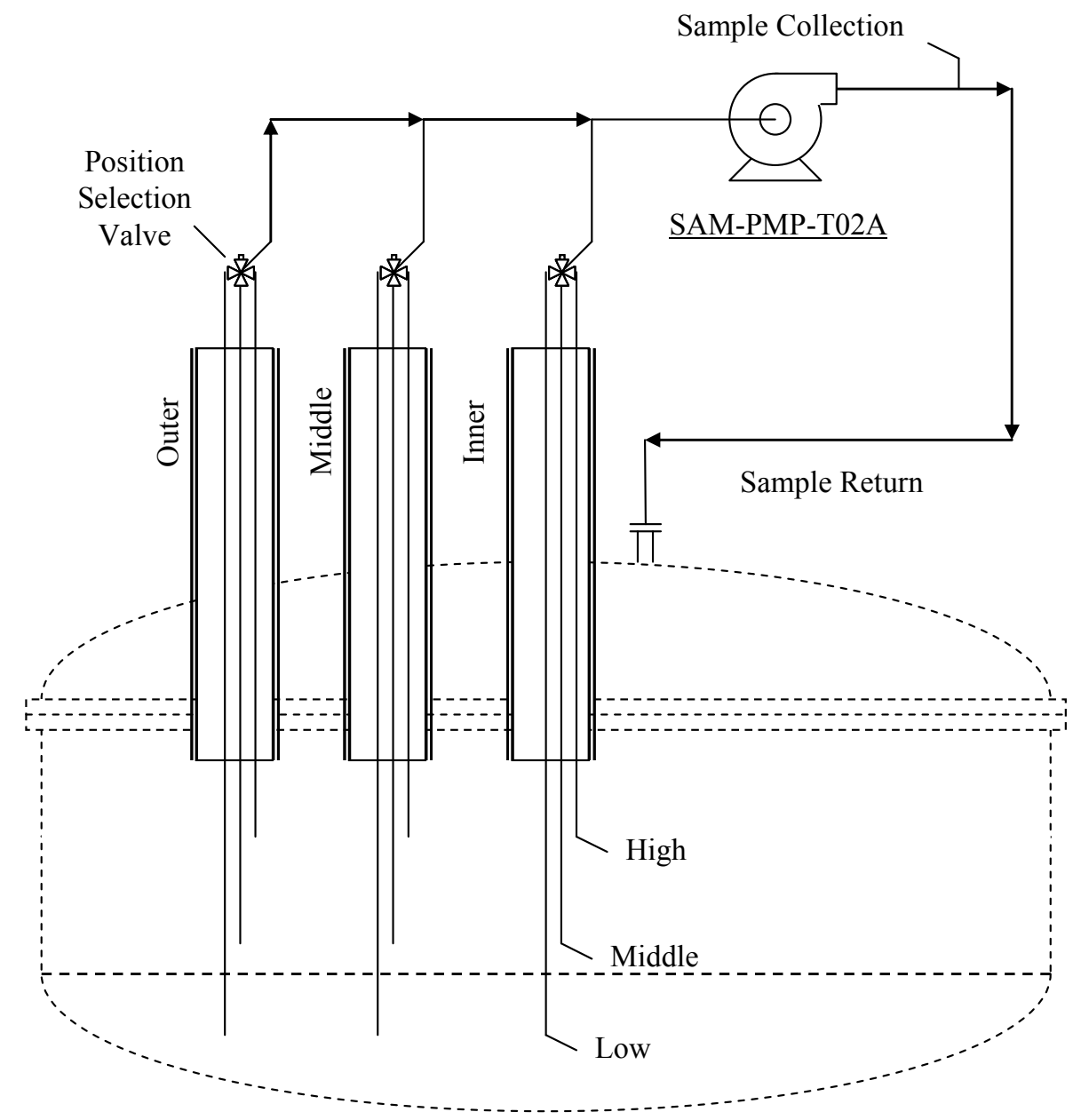

Figure 3.3. UFP-T02A In-Tank Sampling Showing the Three Radial Positions at Three Heights and Sampling Flow Loop 
Table 3.5. Experimental Parameters for Laboratory-Scale Versions of Test A

\begin{tabular}{|c|c|c|c|c|}
\hline & $\begin{array}{l}\text { Measured } \\
\text { for A-1 }\end{array}$ & Target for A-1 & $\begin{array}{l}\text { Measured } \\
\text { for A-2 }\end{array}$ & Target for A-2 \\
\hline Mass of slurry from PEP $(\mathrm{g})$ & 684.01 & 684 & 510.01 & 510 \\
\hline Mass of distilled water $(\mathrm{g})$ & 116.04 & $116^{(\mathrm{a})}$ & 124.00 & $124^{(a)}$ \\
\hline Mass of $\mathrm{NaOH}$ reagent $(\mathrm{g})$ & -- & -- & 166.01 & $166^{(\mathrm{a})}$ \\
\hline $\mathrm{NaOH}$ concentration in reagent $(\mathrm{M})$ & -- & -- & $19.2^{(\mathrm{b})}$ & $19.2^{(\mathrm{a})}$ \\
\hline Initial temperature $\left({ }^{\circ} \mathrm{C}\right)$ & 23.2 & ambient & 23.2 & ambient \\
\hline Digestion temperature $\left({ }^{\circ} \mathrm{C}\right)$ & $98.0 \pm 0.20$ & $98^{(\mathrm{a})}$ & $98.0 \pm 0.27$ & $98^{(a)}$ \\
\hline Heat-up time (hr) & $\begin{array}{l}5.3, \text { from } \\
23 \text { to } 98^{\circ} \mathrm{C}^{(\mathrm{c})}\end{array}$ & $\begin{array}{l}4.2, \text { from } \\
57 \text { to } 98^{\circ} \mathrm{C}^{(\mathrm{a})}\end{array}$ & $\begin{array}{l}5.3, \text { from } \\
23 \text { to } 98^{\circ} \mathrm{C}^{(\mathrm{c})}\end{array}$ & $\begin{array}{l}4.2, \text { from } \\
57 \text { to } 98^{\circ} \mathrm{C}^{(\mathrm{a})}\end{array}$ \\
\hline $\begin{array}{l}\text { Digestion time to the nominal 16-hr } \\
\text { sample (hr) }\end{array}$ & 16.0 & $16.1^{(\mathrm{a})}$ & 16.0 & $16.1^{(\mathrm{a})}$ \\
\hline $\begin{array}{l}\text { (a) Indicates values based on the PEP t } \\
\text { (b) Corresponds to } 50.4-\mathrm{wt} \% \mathrm{NaOH} \text { in } \\
\text { (c) The length of time between } 57^{\circ} \mathrm{C} \text { at }\end{array}$ & $\begin{array}{l}\text { est. } \\
\text { the reagent. } \\
\text { hd } 98^{\circ} \mathrm{C} \text { is not }\end{array}$ & orded in the TI. & & \\
\hline
\end{tabular}

Table 3.6. Experimental Parameters for Laboratory-Scale Versions of Test B

\begin{tabular}{lcccc}
\hline & $\begin{array}{c}\text { Measured } \\
\text { for B-1 }\end{array}$ & Target for B-1 & $\begin{array}{c}\text { Measured } \\
\text { for B-2 }\end{array}$ & Target for B-2 \\
\hline Mass of slurry from PEP $(\mathrm{g})$ & 669.02 & 669.0 & 669.01 & 669.0 \\
Mass of distilled water $(\mathrm{g})$ & 131.00 & $131.0^{(\mathrm{a})}$ & 131.02 & $131.0^{\text {(a) }}$ \\
Mass of NaOH reagent $(\mathrm{g})$ & -- & -- & -- & -- \\
$\mathrm{NaOH}$ concentration in reagent $(\mathrm{M})$ & -- & -- & -- & -- \\
Initial temperature $\left({ }^{\circ} \mathrm{C}\right)$ & 23.4 & ambient & 23.5 & ambient \\
Digestion temperature $\left({ }^{\circ} \mathrm{C}\right)$ & $98.0 \pm 0.13$ & $98^{(\text {a) }}$ & $98.0 \pm 0.11$ & $98^{(\mathrm{a})}$ \\
Heat-up time (hr) & 3.8, from & 2.6, from & 3.8, from & 2.6, from \\
& 23 to $98^{\circ} \mathrm{C}^{(\mathrm{b})}$ & 71 to $98^{\circ} \mathrm{C}^{(\mathrm{a})}$ & 23 to $98^{\circ} \mathrm{C}^{(\mathrm{b})}$ & 71 to $98^{\circ} \mathrm{C}^{(\mathrm{a})}$ \\
$\begin{array}{l}\text { Digestion time to the nominal 16-hr } \\
\text { sample (hr) }\end{array}$ & 16.0 & $16.0^{(\mathrm{a})}$ & 16.4 & $16.0^{\text {(a) }}$ \\
\hline
\end{tabular}

(a) Indicates values that were chosen to match those measured in the PEP test.

(b) The length of time between $71^{\circ} \mathrm{C}$ and $98^{\circ} \mathrm{C}$ is not recorded in the TI.

\subsection{Simulant}

PEP process testing was performed with a nonradioactive aqueous slurry of simulant waste chemicals and solids. The simulant composition and make-up recipe were provided by WTP as documented in Simulant Recommendation for Phase 1 Testing in the Pretreatment Engineering Platform. ${ }^{\text {(a) }}$ Aqueous chemical concentrations were within ranges expected for waste feeds to the PTF except for the hydroxide, oxalate, and phosphate anions. The hydroxide concentration was approximately one standard deviation from the average concentration expected in the feeds to the plant. The oxalate and phosphate components were at their respective solubility limits. The solids components and blend were selected to obtain targeted solids mass loss (aluminum and chromium leaching and oxalate washing) and treatment time. The simulant was not selected to represent any particular Hanford tank waste type.

(a) PS Sundar. 2008. Simulant Recommendation for Phase I Testing in the Pretreatment Engineering Platform. 24590-PTF-RPT-RT-08-006, Rev. 0, Bechtel National, Inc., Richland Washington. 
The simulant was blended from the components listed below. The basis for selecting the individual components and comparison to actual waste behavior is provided where applicable in the indicated references:

- Boehmite (for Al) (Russell et al. 2009a)

- Gibbsite (for Al) (Russell et al. 2009b)

- Chromium oxyhydroxide (CrOOH) slurry (Rapko et al. 2007)

- Sodium oxalate

- Filtration simulant (Russell et al. 2009c)

- Supernate.

The simulant used in Integrated Test A (and in the simulant Functional tests) was a blend of batches 0 and 1 of the simulant. It was sampled in triplicate from the HLP-T22 recirculation line port on November 25, 2008. The simulant used in Integrated Test B was all taken from batch 2 of the simulant. It was grab-sampled in triplicate from vessel FRP-T01 February 2, 2009; this sample was feed before the solids concentration step.

Table 3.7 shows the composition of the simulant fed to the caustic-leach vessel in each test. The concentrations are the means of each set of triplicate samples. The \pm values in Table 3.7 are standard deviations of the mean. They are calculated by linearized error propagation from laboratory uncertainty values (equivalent to a $95 \%$ confidence interval, or two standard deviations) that were supplied by the analytical organization for each concentration measurement. The laboratory uncertainty includes the "noise" of the analytical determination (which is related to the reporting limit) and uncertainty from instrumental techniques including aliquoting, standards, standardization, and subsampling. The error propagation equations are discussed in Section A.5.

Note that the aluminum concentrations in Integrated Test A and Integrated Test B feeds differed by about 5\%, which is consistent with the difference in UDS fractions. A number of species had measured concentrations at or below the reporting limits in one or more of the replicate samples. None of these concentrations were used in caustic-leach calculations.

The simulant make-up sheets for the Integrated Test A and Integrated Test B feeds show that boehmite and gibbsite were added in equal masses during simulant production, which would yield a value of 0.435 for the molar fraction of solid-phase $\mathrm{Al}$ present as gibbsite. The fraction of $\mathrm{Al}$ in boehmite is one minus the fraction in gibbsite, or 0.565 . 
Table 3.7. Simulant Feed Composition

\begin{tabular}{|c|c|c|c|c|c|c|}
\hline \multirow{3}{*}{ Analyte } & \multicolumn{3}{|c|}{$\begin{array}{c}\text { PEP Leach in UFP-VSL-T01A/B } \\
\text { (Integrated Test A) }\end{array}$} & \multicolumn{3}{|c|}{$\begin{array}{c}\text { PEP Leach in UFP-VSL-T02A } \\
\text { (Integrated Test B) }\end{array}$} \\
\hline & Slurry & \multicolumn{2}{|c|}{ Liquid Phase } & Slurry & \multicolumn{2}{|c|}{ Liquid Phase } \\
\hline & $\mu g / g$ & $\mu \mathrm{g} / \mathrm{g}$ & $\mathrm{m}^{(\mathrm{a})}$ & $\mu \mathrm{g} / \mathrm{g}$ & $\mu \mathrm{g} / \mathrm{g}$ & $\mathrm{m}^{(\mathrm{a})}$ \\
\hline$\overline{\mathrm{Al}}$ & $20023 \pm 344$ & $2977 \pm 52$ & $0.129 \pm 0.002$ & $18794 \pm 318$ & $3163 \pm 55$ & $0.137 \pm 0.002$ \\
\hline $\mathrm{Ca}$ & $154 \pm 4.0$ & $1^{(\mathrm{c})}$ & (c) & $155 \pm 3.0$ & $1^{(\mathrm{c})}$ & (c) \\
\hline $\mathrm{Ce}$ & $53.0 \pm 1.1$ & $0.01^{(\mathrm{c})}$ & (c) & $51.6 \pm 1.0$ & $0.013 \pm 0.001$ & $<1 \mathrm{E}-4$ \\
\hline $\mathrm{Cr}$ & $8^{(\mathrm{c})}$ & $1.32 \pm 0.03$ & $<1 \mathrm{E}-4$ & $8^{(c)}$ & $1.42 \pm 0.04$ & $<1 \mathrm{E}-4$ \\
\hline $\mathrm{Fe}$ & $4736 \pm 94$ & $3^{(\mathrm{c})}$ & (c) & $4945 \pm 98$ & $3^{(\mathrm{c})}$ & (c) \\
\hline K & $1029 \pm 17$ & $1090 \pm 20$ & $0.033 \pm 0.001$ & $999 \pm 17$ & $1063 \pm 19$ & $0.032 \pm 0.001$ \\
\hline $\mathrm{La}$ & $40.0 \pm 0.8$ & $0.010 \pm 0.001$ & $<1 \mathrm{E}-4$ & $39.5 \pm 0.8$ & $0.012 \pm 0.001$ & $<1 \mathrm{E}-4$ \\
\hline $\mathrm{Mg}$ & $105 \pm 2.9$ & $2.5^{(\mathrm{c})}$ & (c) & $94.9 \pm 1.8$ & $2^{(\mathrm{c})}$ & (c) \\
\hline $\mathrm{Mn}$ & $1027 \pm 20$ & $0.1^{(\mathrm{c})}$ & (c) & $1058 \pm 21$ & $0.1^{(\mathrm{c})}$ & (c) \\
\hline $\mathrm{Na}$ & $88920 \pm 1372$ & $91600 \pm 1587$ & $4.66 \pm 0.08$ & $90174 \pm 1400$ & $93233 \pm 1615$ & $4.73 \pm 0.08$ \\
\hline $\mathrm{Nd}$ & $108 \pm 2.1$ & $0.026 \pm 0.001$ & $<1 \mathrm{E}-4$ & $107 \pm 2.1$ & $0.031 \pm 0.001$ & $<1 \mathrm{E}-4$ \\
\hline $\mathrm{Ni}$ & $143 \pm 2.8$ & $0.12 \pm 0.029^{(\mathrm{c})}$ & (c) & $145 \pm 2.8$ & $0.1^{(\mathrm{c})}$ & (c) \\
\hline$P$ & $1784 \pm 28$ & $1873 \pm 32$ & $\begin{array}{c}0.0708 \pm \\
0.0012\end{array}$ & $1581 \pm 25$ & $1643 \pm 29$ & $0.062 \pm 0.001$ \\
\hline $\mathrm{Si}$ & $48.7 \pm 5.7$ & $3^{(\mathrm{c})}$ & (c) & $106.5 \pm 8.0$ & $19 \pm 3^{(\mathrm{c})}$ & (c) \\
\hline $\mathrm{Sr}$ & $43.8 \pm 1.3$ & $0.1^{(\mathrm{c})}$ & (c) & $44.2 \pm 0.9$ & $0.120 \pm 0.017$ & $<1 \mathrm{E}-4$ \\
\hline $\mathrm{Zr}$ & $136 \pm 2.6$ & $0.737 \pm 0.022$ & $<1 \mathrm{E}-4$ & $141 \pm 2.7$ & $0.726 \pm 0.021$ & $<1 \mathrm{E}-4$ \\
\hline Chloride $\left(\mathrm{Cl}^{-}\right)$ & $\mathrm{n} / \mathrm{m}$ & $1137 \pm 20$ & $0.038 \pm 0.001$ & $\mathrm{n} / \mathrm{m}$ & $1013 \pm 18$ & $0.033 \pm 0.001$ \\
\hline Nitrite $\left(\mathrm{NO}_{2}^{-}\right)$ & $\mathrm{n} / \mathrm{m}$ & $18267 \pm 329$ & $0.465 \pm 0.008$ & $\mathrm{n} / \mathrm{m}$ & $17867 \pm 348$ & $0.453 \pm 0.009$ \\
\hline Nitrate $\left(\mathrm{NO}_{3}^{-}\right)$ & $\mathrm{n} / \mathrm{m}$ & $79333 \pm 1380$ & $1.50 \pm 0.026$ & $\mathrm{n} / \mathrm{m}$ & $75967 \pm 1333$ & $1.43 \pm 0.025$ \\
\hline $\begin{array}{l}\text { Phosphate } \\
\left(\mathrm{PO}_{4}{ }^{3-}\right)\end{array}$ & $\mathrm{n} / \mathrm{m}$ & $5547 \pm 96$ & $0.068 \pm 0.001$ & $\mathrm{n} / \mathrm{m}$ & $4893 \pm 85$ & $0.060 \pm 0.001$ \\
\hline Sulfate $\left(\mathrm{SO}_{4}{ }^{2-}\right)$ & $\mathrm{n} / \mathrm{m}$ & $14167 \pm 247$ & $0.173 \pm 0.003$ & $\mathrm{n} / \mathrm{m}$ & $13967 \pm 247$ & $0.170 \pm 0.003$ \\
\hline Oxalate $\left(\mathrm{C}_{2} \mathrm{O}_{4}{ }^{2-}\right)$ & $\mathrm{n} / \mathrm{m}$ & $625 \pm 11$ & $0.008 \pm 0.0001$ & $\mathrm{n} / \mathrm{m}$ & $642 \pm 11$ & $0.009 \pm 0.0002$ \\
\hline Free hydroxide & $\mathrm{n} / \mathrm{m}$ & $15239 \pm 660$ & $1.05 \pm 0.045$ & $\mathrm{n} / \mathrm{m}$ & $12623 \pm 191$ & $0.866 \pm 0.013$ \\
\hline $\mathrm{TIC}^{(\mathrm{b})}$ & $1510 \pm 253$ & $6905 \pm 133$ & $0.673 \pm 0.013$ & $2023 \pm 90$ & $5577 \pm 107$ & $0.542 \pm 0.010$ \\
\hline $\mathrm{wt} \%$ UDS & $5.52 \pm 0.03$ & & & $5.20 \pm 0.03$ & & \\
\hline Density (g/cc) & $1.278 \pm 0.006$ & 1.239 & 0.001 & $1.276 \pm 0.006$ & 1.233 & 0.005 \\
\hline $\mathrm{Wt} \% \mathrm{H}_{2} \mathrm{O}$ & $\mathrm{n} / \mathrm{m}$ & 72.7 & 0.12 & $\mathrm{n} / \mathrm{m}$ & 73.4 & 0.12 \\
\hline $\begin{array}{l}\text { Mass fraction of } \\
\text { solid-phase Al } \\
\text { that is in } \\
\text { gibbsite }\end{array}$ & 0.435 & & & 0.435 & & \\
\hline
\end{tabular}

(a) $\mathrm{m}=$ molality.

(b) TIC = total inorganic carbon.

(c) Concentration measurement is at or below the reporting limit.

" $\mathrm{n} / \mathrm{m} "=$ not measured.

All concentrations are means of a triplicate set of samples. The \pm values represent 1 standard deviation; they are calculated using error propagation from the standard deviation of the mean and are derived from laboratory error. Because all samples were centrifuged before analysis, the slurry concentrations and their uncertainties were calculated from data for liquid concentration, centrifuged solids concentration, and the weight fraction of centrifuged solids in the slurry. The uncertainty assigned to the centrifuged solids weight fraction was based on the uncertainty of the weighing instrument. See Appendix C for more information.

The as-received feed compositions were reviewed as a check on whether any of the gibbsite used in simulant make-up had dissolved. The check was prompted by the observation that the dissolved concentration of Al was $0.137 \mathrm{M}$ in Integrated Test A feed and $0.145 \mathrm{M}$ in Integrated Test B feed, higher 
than the $0.125 \mathrm{M}$ supernatant liquid that had been used in simulant make-up. ${ }^{\text {(a) }}$ This apparent increase suggested some of the gibbsite had dissolved. However, the Al concentration in the solid phase of the Integrated Test $\mathrm{B}$ simulant was calculated from slurry and liquid $\mathrm{Al}$ concentrations and $\mathrm{wt} \%$ UDS and found to be 0.302 to $0.306 \mathrm{~g} \mathrm{Al} / \mathrm{g}$ solids. Because this concentration was not less than the value of 0.283 expected from the simulant recipe, and because other measurements indicated no dissolution of other major solid constituents (oxalate by TOC was at predicted levels in both supernate and solids and Fe was not found in the supernate), it was concluded that no perceptible dissolution of gibbsite had occurred. The gibbsite fraction in the solid was therefore considered to still equal the recipe value.

\subsubsection{Sample Acquisition and Handling}

During Integrated Test A, the samples of leach-vessel slurry used in caustic-leach analysis were taken from the inner CD sample loop at the middle elevation port in UFP-T01A. The samples were taken after in-line $\mathrm{NaOH}$ addition, near the end of heat-up $\left(88^{\circ} \mathrm{C}\right)$, and at a number of times during digestion. During Integrated Test B, slurry samples were taken from a low CD port in UFP-T02A before $\mathrm{NaOH}$ addition, after $\mathrm{NaOH}$ addition and flushing the loop into UFP-T02A, near the end of heat-up $\left(88^{\circ} \mathrm{C}\right)$, and at a number of times during digestion. Slurry samples taken from PEP vessels for analysis during Integrated Tests A and B were rapidly cooled to ambient temperature to make certain that any further leaching reaction was minimized and were allowed to remain at that temperature for 24 to 36 hours before the samples were centrifuged ${ }^{(\mathrm{b})}$ and the liquid decanted. The centrifuged solids were not rinsed before analysis.

Samples of diluted caustic slurry ( $\sim 30 \mathrm{~mL}$ each) were taken from the laboratory-scale vessel before heat-up began. Some of these were rinsed with three equal volumes of $0.01 \mathrm{M} \mathrm{NaOH}$ before analysis; each rinse included mixing and centrifugation. Other slurry samples were left unrinsed. After cool-down, at the end of the test, another set of slurry samples $(\sim 30 \mathrm{~mL}$ each $)$ were taken to represent final conditions. Again, some of the slurry samples were rinsed before analysis as slurry and others were analyzed without intermediate processing. Single slurry samples $(\sim 6 \mathrm{~mL})$ were taken at a number of times during the test and filtered through a $0.45-\mu \mathrm{m}$ filter to provide liquid for analysis. All samples were taken through the sample port in the top of the laboratory-scale vessel using a syringe or disposable pipette. The impeller continued to mix the contents during sampling.

\subsection{Process Conditions}

This section provides the primary analytical results used in caustic-leach and kinetics calculations. Additional auxiliary analytical data are contained in Appendix B. In this section and in Appendix B, all concentrations and properties are stated at the dilution conditions actually existing in the sample. These values have not been subjected to any adjustment for the volume "normalization" that is discussed in Section 4.

(a) These concentrations were all measured by inductively coupled plasma (ICP) at Southwest Research Institute (SwRI).

(b) According to the sample handlers' Communications Log, the centrifugation method used on Integrated Test A caustic-leach samples-10 minutes at $4500 \mathrm{G}$ - was not enough to produce phase separation for Integrated Test B caustic-leach samples. One hour at $4500 \mathrm{G}$ was used and appeared to be adequate. 
The aluminum, free hydroxide, and water concentrations that were measured in the liquid during the caustic-leach tests are given in Table 3.8 through Table 3.12. ${ }^{\text {(a) }}$ The \pm values in Table 3.8, Table 3.10, and Table 3.12 are equal to half the laboratory uncertainty values (equivalent to a $95 \%$ confidence interval, or two standard deviations) that were supplied by the analytical organization for each concentration measurement. For the sample times at which triplicate samples were taken, the concentrations are means of the set and the \pm values are standard deviations of the means, which are a factor of $1 / \sqrt{3}$ times the standard deviation for a single measurement. The laboratory uncertainty includes the "noise" of the analytical determination (which is related to the reporting limit) and uncertainty from instrumental techniques including aliquoting, standards, standardization, and subsampling. A table showing which samples were triplicate can be found in Appendix B.

Table 3.9 and Table 3.11 contain the same information as Table 3.8 and Table 3.10 , respectively, after units conversion from mass concentration to molality, or from molarity to molality, that was carried out using liquid properties in Table 3.12 and Table 3.13. The \pm values are calculated by linearized error propagation equations, which are discussed in Section A.5. The equations for the units conversion are also given there.

(a) A complete reporting of the analytical results is provided in the PEP run reports: WTP-RPT-191 (Integrated Test A run report) and WTP-RPT-192 (Integrated Test B run report). 
Table 3.8. Mass Concentration of Dissolved Aluminum During Caustic-Leach Tests

\begin{tabular}{|c|c|c|c|c|c|c|}
\hline \multirow[b]{3}{*}{$\begin{array}{l}\text { Point in } \\
\text { Process }\end{array}$} & \multicolumn{6}{|c|}{$\begin{array}{l}\text { Concentration of Aluminum }(\mu \mathrm{g} / \mathrm{g}) \text { in Liquid Phase }{ }^{(\mathrm{a})} \\
\pm 1 \text { Standard Deviation from Laboratory Analysis }\end{array}$} \\
\hline & \multirow[b]{2}{*}{$\begin{array}{c}\text { PEP } \\
\text { Integrated } \\
\text { Test } \mathrm{A}, \\
\text { Batch } 1 \text { of } \\
\text { UFP-T01A }\end{array}$} & \multicolumn{5}{|c|}{ PEP } \\
\hline & & $\begin{array}{l}\text { Laboratory- } \\
\quad \text { Scale } \\
\text { Test A-1 }\end{array}$ & $\begin{array}{l}\text { Laboratory- } \\
\text { Scale } \\
\text { Test A-2 }\end{array}$ & $\begin{array}{c}\text { Integrated } \\
\text { Test B, } \\
\text { Batch } 2 \text { of } \\
\text { UFP-T02A }\end{array}$ & $\begin{array}{l}\text { Laboratory- } \\
\text { Scale } \\
\text { Test B-1 }{ }^{(\mathrm{b}, \mathrm{c})}\end{array}$ & $\begin{array}{l}\text { Laboratory- } \\
\text { Scale } \\
\text { Test B-2 }\end{array}$ \\
\hline $\begin{array}{l}\text { Before } \\
\mathrm{NaOH}\end{array}$ & $2977 \pm 52$ & $2977 \pm 52$ & $2977 \pm 52$ & $3687 \pm 64$ & $3687 \pm 64$ & $3687 \pm 64$ \\
\hline $\begin{array}{l}\text { After } \\
\mathrm{NaOH}\end{array}$ & $4713 \pm 82$ & $4610 \pm 139$ & $2000 \pm 60$ & $16400 \pm 284$ & $12400 \pm 372$ & $12200 \pm 366$ \\
\hline At $88^{\circ} \mathrm{C}$ & $6970 \pm 210$ & $6360 \pm 192$ & $6050 \pm 182$ & $16700 \pm 500$ & $12300 \pm 369$ & $12600 \pm 378$ \\
\hline $0 \mathrm{hr}$ & $7220 \pm 125$ & $6550 \pm 197$ & $6140 \pm 185$ & $16500 \pm 286$ & $13000 \pm 390$ & $12200 \pm 366$ \\
\hline $1 \mathrm{hr}$ & $6950 \pm 210$ & $6730 \pm 203$ & $6270 \pm 189$ & $16600 \pm 498$ & $13700 \pm 411$ & $13300 \pm 399$ \\
\hline $2 \mathrm{hr}$ & $7390 \pm 223$ & $6580 \pm 198$ & $6430 \pm 194$ & $17000 \pm 510$ & $13600 \pm 408$ & $13400 \pm 402$ \\
\hline $4 \mathrm{hr}$ & $7270 \pm 219$ & $7220 \pm 217$ & $5810 \pm 175$ & $17800 \pm 535$ & $14500 \pm 435$ & $14500 \pm 435$ \\
\hline $8 \mathrm{hr}$ & $8050 \pm 242$ & $7790 \pm 235$ & $7210 \pm 217$ & $19000 \pm 570$ & $15800 \pm 474$ & $16300 \pm 489$ \\
\hline $10 \mathrm{hr}$ & $8000 \pm 241$ & $7570 \pm 228$ & $7460 \pm 225$ & $19400 \pm 580$ & $16100 \pm 483$ & $16100 \pm 483$ \\
\hline $12 \mathrm{hr}$ & $8410 \pm 253$ & $8060 \pm 243$ & $8320 \pm 251$ & $19067 \pm 330$ & $16900 \pm 507$ & $16800 \pm 504$ \\
\hline $14 \mathrm{hr}$ & $8190 \pm 247$ & $8340 \pm 251$ & $9200 \pm 277$ & $20200 \pm 605$ & $17200 \pm 516$ & $17300 \pm 519$ \\
\hline $16 \mathrm{hr}$ & $8697 \pm 151$ & $8330 \pm 251$ & $9190 \pm 277$ & $20433 \pm 353$ & $17700 \pm 531$ & $18200 \pm 546$ \\
\hline $18 \mathrm{hr}$ & $\mathrm{n} / \mathrm{m}$ & $8610 \pm 259$ & $9620 \pm 290$ & $\mathrm{n} / \mathrm{m}$ & $18200 \pm 546$ & $19000 \pm 570$ \\
\hline $20 \mathrm{hr}$ & $\mathrm{n} / \mathrm{m}$ & $8800 \pm 265$ & $9960 \pm 300$ & $\mathrm{n} / \mathrm{m}$ & $18900 \pm 567$ & $19300 \pm 579$ \\
\hline $22 \mathrm{hr}$ & $\mathrm{n} / \mathrm{m}$ & $8970 \pm 270$ & $10300 \pm 310$ & $\mathrm{n} / \mathrm{m}$ & $\mathrm{n} / \mathrm{m}$ & $\mathrm{n} / \mathrm{m}$ \\
\hline $24 \mathrm{hr}$ & $\mathrm{n} / \mathrm{m}$ & $9600 \pm 289$ & $10600 \pm 319$ & $\mathrm{n} / \mathrm{m}$ & $19800 \pm 594$ & $19800 \pm 594$ \\
\hline \multicolumn{7}{|c|}{ (a) Dissolved aluminum was measured in $\mu \mathrm{g} / \mathrm{g}$ liquid by inductively coupled plasma (ICP) at Southwest Research } \\
\hline \multirow{2}{*}{\multicolumn{7}{|c|}{$\begin{array}{l}\text { (c) Note that water was added all at once at the beginning of laboratory-scale runs, but was added gradually throughout } \\
\text { the PEP runs. } \\
\text { " } \mathrm{n} / \mathrm{m} \text { " = not measured. }\end{array}$}} \\
\hline & & & & & & \\
\hline \multicolumn{7}{|c|}{$\begin{array}{l}\text { The } \pm \text { values are equal to half the laboratory uncertainty values (equivalent to a } 95 \% \text { confidence interval, or two standard } \\
\text { deviations) that were supplied by the analytical organization for each concentration measurement. In the cases where } \\
\text { triplicate samples were taken, the concentrations are means of the set and the } \pm \text { values are standard deviations of the } \\
\text { means. }\end{array}$} \\
\hline
\end{tabular}


Table 3.9. Molal Concentration of Dissolved Aluminum During PEP Caustic-Leach Tests

\begin{tabular}{|c|c|c|}
\hline \multirow[b]{2}{*}{ Point in Process } & \multicolumn{2}{|c|}{$\begin{array}{c}\text { Concentration of Aluminum } \\
\text { (mole/kg water) in Liquid Phase }{ }^{(\mathrm{a})}\end{array}$} \\
\hline & $\begin{array}{l}\text { PEP Integrated Test A, } \\
\text { Batch } 1 \text { of UFP-T01A }\end{array}$ & $\begin{array}{c}\text { PEP Integrated Test B, Batch } 2 \\
\text { of UFP-T02A }\end{array}$ \\
\hline Before $\mathrm{NaOH}$ & $0.152 \pm 0.003$ & $0.187 \pm 0.003$ \\
\hline After $\mathrm{NaOH}$ & $0.270 \pm 0.005$ & $1.01 \pm 0.02$ \\
\hline At $88^{\circ} \mathrm{C}$ & $0.389 \pm 0.012$ & $1.00 \pm 0.03$ \\
\hline $0 \mathrm{hr}$ & $0.399 \pm 0.007$ & $0.981 \pm 0.017$ \\
\hline $1 \mathrm{hr}$ & $0.382 \pm 0.012$ & $0.980 \pm 0.030$ \\
\hline $2 \mathrm{hr}$ & $0.408 \pm 0.012$ & $0.999 \pm 0.030$ \\
\hline $4 \mathrm{hr}$ & $0.399 \pm 0.012$ & $1.04 \pm 0.03$ \\
\hline $8 \mathrm{hr}$ & $0.438 \pm 0.013$ & $1.10 \pm 0.03$ \\
\hline $10 \mathrm{hr}$ & $0.435 \pm 0.013$ & $1.12 \pm 0.03$ \\
\hline $12 \mathrm{hr}$ & $0.454 \pm 0.014$ & $1.10 \pm 0.02$ \\
\hline $14 \mathrm{hr}$ & $0.441 \pm 0.013$ & $1.16 \pm 0.04$ \\
\hline $16 \mathrm{hr}$ & $0.466 \pm 0.008$ & $1.16 \pm 0.02$ \\
\hline $\begin{array}{l}\text { (a) Dissolved alu } \\
\text { to molality us } \\
\text { The } \pm \text { values are } \mathrm{c} \\
\text { Table } 3.12 \text { supplie }\end{array}$ & $\begin{array}{l}\text { (a) Dissolved aluminum was measured in } \mu \mathrm{g} / \mathrm{g} \text { liquid by ICP at SwRI. It was converted } \\
\text { to molality using dissolved solids measurements made at SwRI. }\end{array}$ & $\begin{array}{l}\mathrm{d} \text { by ICP at SwRI. It was converted } \\
\text { made at SwRI. } \\
\text { ation methods. Table } 3.8 \text { and }\end{array}$ \\
\hline
\end{tabular}


Table 3.10. Molar Concentration of Free Hydroxide During Caustic-Leach Tests

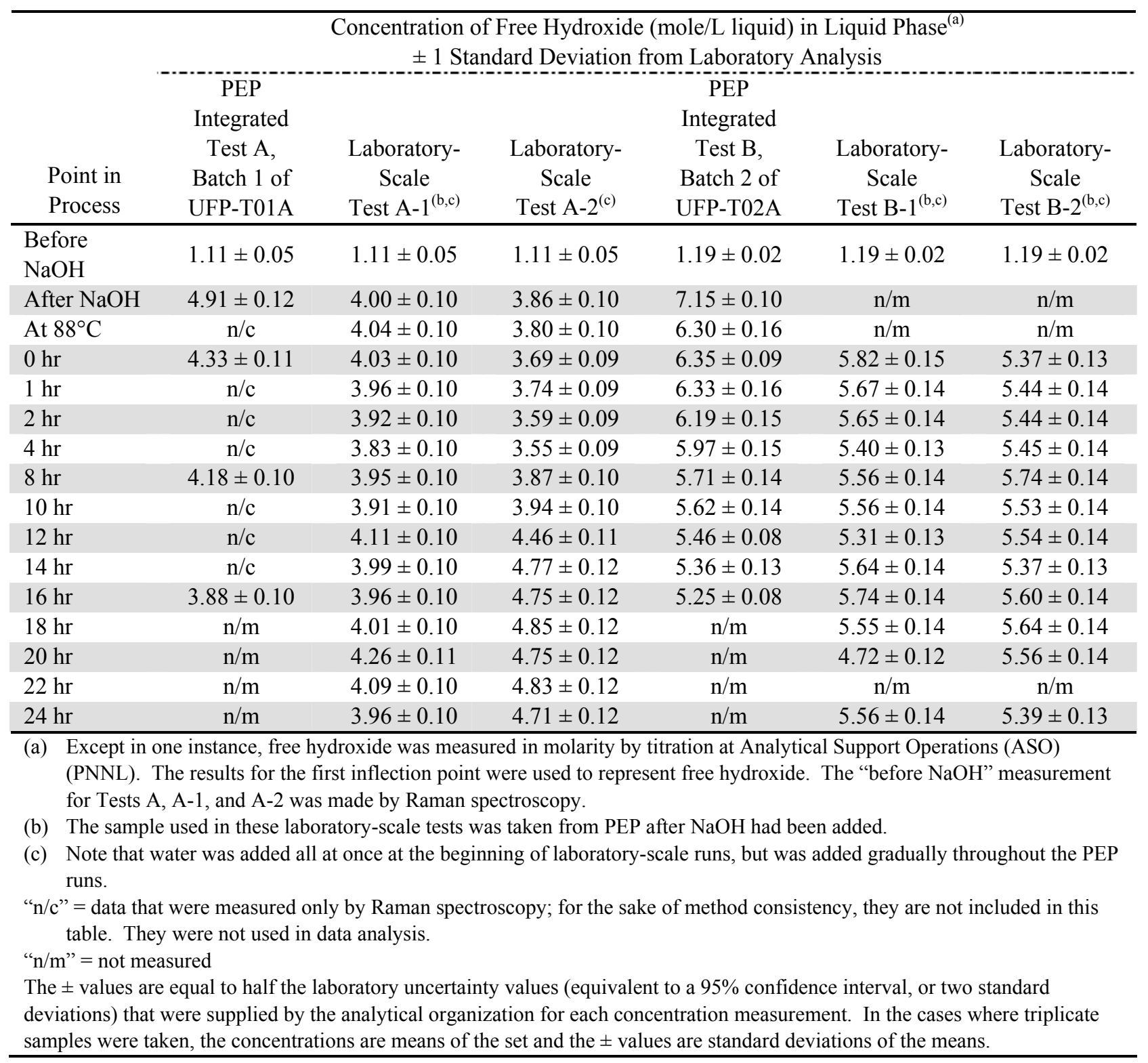


Table 3.11. Molal Concentration of Free Hydroxide During PEP Caustic-Leach Tests

\begin{tabular}{lcc}
\hline & Concentration of Free Hydroxide (mole/kg water) in Liquid Phase ${ }^{(\text {a) }}$ \\
& & Standard Deviation from Laboratory Analysis \\
Point in Process & PFP-T01A & PEP Integrated Test B, Batch 2 of \\
\hline Before $\mathrm{NaOH}$ & $1.23 \pm 0.05$ & $1.31 \pm 0.02$ \\
After NaOH & $5.72 \pm 0.15$ & $8.65 \pm 0.13$ \\
At $88^{\circ} \mathrm{C}$ & $\mathrm{n} / \mathrm{c}$ & $7.46 \pm 0.20$ \\
$0 \mathrm{hr}$ & $4.93 \pm 0.13$ & $7.52 \pm 0.12$ \\
$1 \mathrm{hr}$ & $\mathrm{n} / \mathrm{c}$ & $7.45 \pm 0.20$ \\
$2 \mathrm{hr}$ & $\mathrm{n} / \mathrm{c}$ & $7.29 \pm 0.20$ \\
$4 \mathrm{hr}$ & $\mathrm{n} / \mathrm{c}$ & $7.01 \pm 0.19$ \\
$8 \mathrm{hr}$ & $4.74 \pm 0.13$ & $6.67 \pm 0.18$ \\
$10 \mathrm{hr}$ & $\mathrm{n} / \mathrm{c}$ & $6.55 \pm 0.18$ \\
$12 \mathrm{hr}$ & $\mathrm{n} / \mathrm{c}$ & $6.33 \pm 0.10$ \\
$14 \mathrm{hr}$ & $\mathrm{n} / \mathrm{c}$ & $6.18 \pm 0.16$ \\
$16 \mathrm{hr}$ & $4.35 \pm 0.11$ & $6.07 \pm 0.09$ \\
\hline
\end{tabular}

(a) Hydroxide was measured in molarity by titration at ASO (PNNL). The results for the first inflection point were used to represent free hydroxide. It was converted to molality using dissolved solids and liquid density measurements made at SwRI.

" $\mathrm{n} / \mathrm{c} "=$ data that were measured only by Raman spectroscopy; for the sake of method consistency, they are not included in this table. They were not used in data analysis.

The \pm values are calculated by linearized error propagation methods. Table 3.10, Table 3.12, and Table 3.13 supplied the data for this table.

Table 3.12. Water in Liquid Phase During PEP Caustic-Leach Tests

\begin{tabular}{|c|c|c|}
\hline \multirow[b]{2}{*}{ Point in Process } & \multicolumn{2}{|c|}{$\begin{array}{l}\text { Concentration of } \mathrm{H}_{2} \mathrm{O}(\mathrm{wt} \%) \text { in Liquid Phase }{ }^{(\mathrm{a})} \\
\pm 1 \text { Standard Deviation from Laboratory Analysis }\end{array}$} \\
\hline & $\begin{array}{c}\text { PEP Integrated Test A, Batch } 1 \text { of } \\
\text { UFP-T01A }\end{array}$ & $\begin{array}{c}\text { PEP Integrated Test B, Batch } 2 \text { of } \\
\text { UFP-T02A }\end{array}$ \\
\hline Before $\mathrm{NaOH}$ & $72.7 \% \pm 0.1 \%$ & $73.0 \% \pm 0.1 \%$ \\
\hline After $\mathrm{NaOH}$ & $64.6 \% \pm 0.2 \%$ & $60.0 \% \pm 0.2 \%$ \\
\hline At $88^{\circ} \mathrm{C}$ & $66.4 \% \pm 0.3 \%$ & $61.8 \% \pm 0.3 \%$ \\
\hline $0 \mathrm{hr}$ & $67.1 \% \pm 0.2 \%$ & $62.3 \% \pm 0.2 \%$ \\
\hline $1 \mathrm{hr}$ & $67.4 \% \pm 0.3 \%$ & $62.8 \% \pm 0.3 \%$ \\
\hline $2 \mathrm{hr}$ & $67.2 \% \pm 0.3 \%$ & $63.1 \% \pm 0.3 \%$ \\
\hline $4 \mathrm{hr}$ & $67.6 \% \pm 0.3 \%$ & $63.4 \% \pm 0.3 \%$ \\
\hline $8 \mathrm{hr}$ & $68.1 \% \pm 0.3 \%$ & $63.9 \% \pm 0.3 \%$ \\
\hline $10 \mathrm{hr}$ & $68.2 \% \pm 0.3 \%$ & $64.0 \% \pm 0.3 \%$ \\
\hline $12 \mathrm{hr}$ & $68.7 \% \pm 0.3 \%$ & $64.5 \% \pm 0.2 \%$ \\
\hline $14 \mathrm{hr}$ & $68.9 \% \pm 0.3 \%$ & $64.8 \% \pm 0.3 \%$ \\
\hline $16 \mathrm{hr}$ & $69.2 \% \pm 0.2 \%$ & $65.1 \% \pm 0.2 \%$ \\
\hline $\begin{array}{l}\text { (a) } \mathrm{Wt} \% \text { water is (1-u } \\
\mathrm{SwRI} . \mathrm{Wt} \% \text { wate } \\
\text { The } \pm \text { values are equal } \\
\text { deviations) that were su } \\
\text { samples were taken, the }\end{array}$ & $\begin{array}{l}\text { ved solids). Dissolved solids were meas } \\
\text { vater/mass liquid. } \\
\text { laboratory uncertainty values (equivaler } \\
\text { the analytical organization for each cond } \\
\text { tions are means of the set and the } \pm \text { valu }\end{array}$ & $\begin{array}{l}\text { ing and weighing supernatant liquid at } \\
\text { confidence interval, or two standard } \\
\text { neasurement. In the cases where triplicate } \\
\text { dard deviations of the means. }\end{array}$ \\
\hline
\end{tabular}


Table 3.13. Liquid Density During PEP Caustic-Leach Tests

\begin{tabular}{|c|c|c|}
\hline \multirow[b]{2}{*}{ Point in Process } & \multicolumn{2}{|c|}{$\begin{array}{c}\text { Liquid Density }(\mathrm{g} / \mathrm{mL})^{(\mathrm{a})} \\
\pm 1 \text { Standard Deviation from Laboratory Analysis }\end{array}$} \\
\hline & $\begin{array}{l}\text { PEP Integrated Test A, Batch } 1 \text { of } \\
\text { UFP-T01A }\end{array}$ & $\begin{array}{l}\text { PEP Integrated Test B, Batch } 2 \text { of } \\
\text { UFP-T02A }\end{array}$ \\
\hline Before $\mathrm{NaOH}$ & $1.239 \pm 0.001$ & $1.235 \pm 0.005$ \\
\hline After $\mathrm{NaOH}$ & $1.330 \pm 0.006$ & $1.377 \pm 0.006$ \\
\hline At $88^{\circ} \mathrm{C}$ & $1.312 \pm 0.010$ & $1.367 \pm 0.011$ \\
\hline $0 \mathrm{hr}$ & $1.308 \pm 0.006$ & $1.355 \pm 0.006$ \\
\hline $1 \mathrm{hr}$ & $1.308 \pm 0.010$ & $1.354 \pm 0.011$ \\
\hline $2 \mathrm{hr}$ & $1.308 \pm 0.010$ & $1.346 \pm 0.011$ \\
\hline $4 \mathrm{hr}$ & $1.305 \pm 0.010$ & $1.345 \pm 0.011$ \\
\hline $8 \mathrm{hr}$ & $1.296 \pm 0.010$ & $1.339 \pm 0.011$ \\
\hline $10 \mathrm{hr}$ & $1.291 \pm 0.010$ & $1.339 \pm 0.011$ \\
\hline $12 \mathrm{hr}$ & $1.286 \pm 0.010$ & $1.338 \pm 0.006$ \\
\hline $14 \mathrm{hr}$ & $1.291 \pm 0.010$ & $1.338 \pm 0.011$ \\
\hline $16 \mathrm{hr}$ & $1.288 \pm 0.006$ & $1.330 \pm 0.006$ \\
\hline $\begin{array}{l}\text { (a) Liquid density wa } \\
\text { The } \pm \text { values are equa } \\
\text { deviations) that were } \\
\text { samples were taken, tl }\end{array}$ & $\begin{array}{l}\text { at ambient temperature by pycnometr } \\
\text { laboratory uncertainty values (equival } \\
\text { the analytical organization for each co } \\
\text { rations are means of the set, and the } \pm \mathrm{v}\end{array}$ & $\begin{array}{l}\text { confidence interval, or two standard } \\
\text { neasurement. In the cases where triplicat } \\
\text { dard deviations of the means. }\end{array}$ \\
\hline
\end{tabular}

To avoid depleting the slurry volume, the sample volume taken from the laboratory-scale system was minimized. As a result, no dissolved solids or density analyses were conducted on the laboratory-scale liquid samples. Therefore water fractions are not available for the laboratory-scale measurements and molalities are not calculated. However, liquid density values were needed to calculate unit conversions (mass concentration to molarity) in the laboratory-scale tests. The liquid density was estimated by correlating liquid density data to nitrate concentration for PEP samples taken after $\mathrm{NaOH}$ addition and then using the correlations with laboratory-scale nitrate data to estimate laboratory-scale liquid density. The nitrate concentration serves as a surrogate for the total dissolved solids. The PEP Integrated Test A and PEP Integrated Test B data were correlated separately, with the PEP Integrated Test A correlation used for laboratory-scale Tests A-1 and A-2, and the PEP Integrated Test B correlation used for laboratory-scale Tests B-1 and B-2.

Table 3.14 shows the Al concentrations in the bulk slurry for both PEP and lab tests. Only initial and end samples were taken for slurry analysis in the laboratory tests to minimize the removed volume. The concentrations in the bulk slurry are calculated from concentrations measured in centrifuged solids, the mass fraction of the slurry that was centrifuged solids, and the liquid concentrations in Table 3.8. The \pm values are standard deviations calculated by linearized error propagation methods. The error propagation equations are discussed in Section A.5. The label "rinsed sample" denotes a slurry sample that was rinsed with $0.01 \mathrm{M} \mathrm{NaOH}$ before analysis.

The solid weight fractions, slurry densities, and liquid densities that were measured are given in Table 3.15, Table 3.16, and Table 3.13, respectively. Densities are available only for the PEP Integrated tests. The \pm values are standard deviations derived from laboratory uncertainties supplied by the analytical organization. 
Table 3.15. Weight Fraction UDS During Caustic-Leach Tests

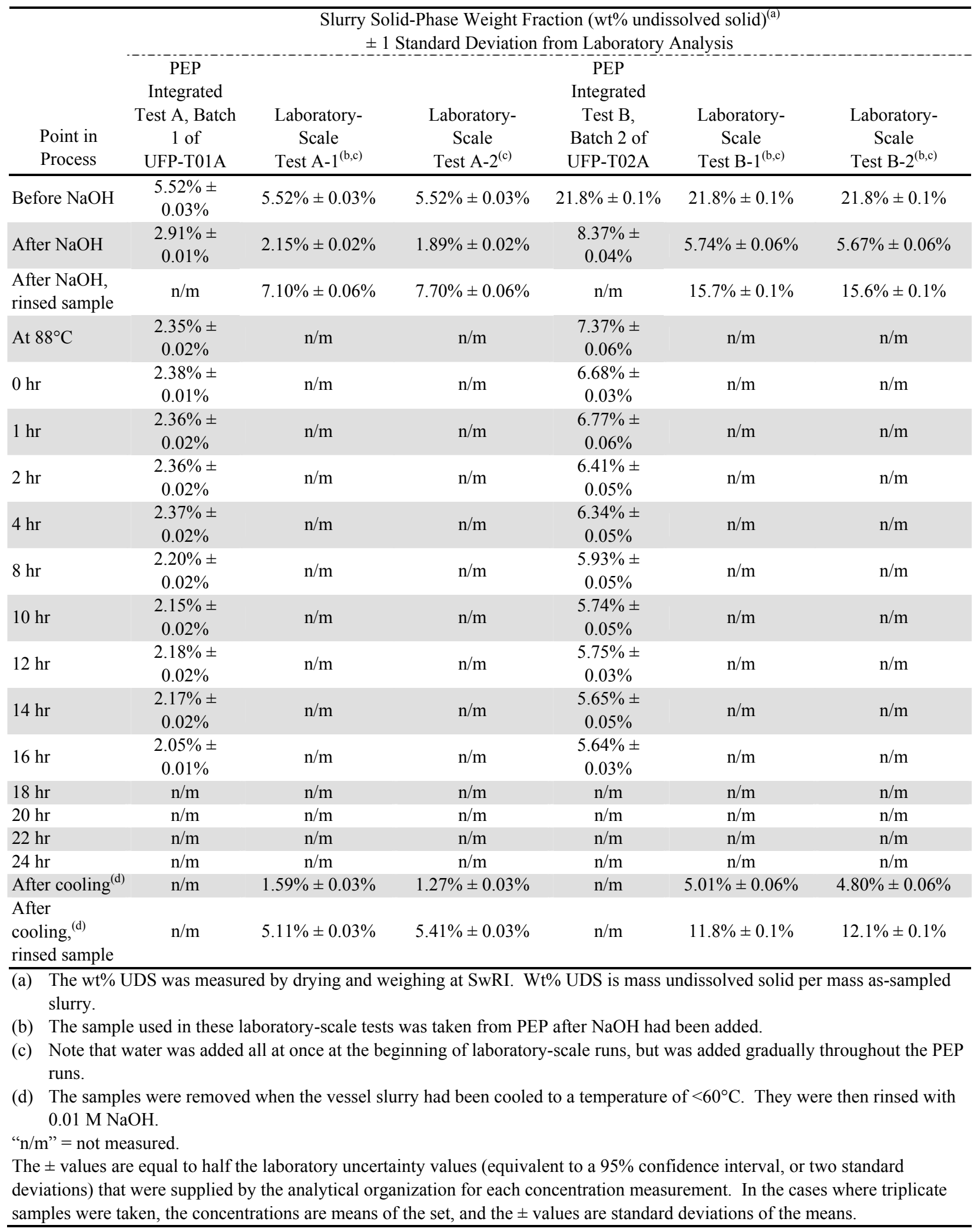


The timelines of test sampling are provided in Table 3.17. The time when $98^{\circ} \mathrm{C}$ was first reached was used as the zero time reference for assessment of condensate accumulation and the temperature profile (Sections 3.4.1 and 3.4.2). The boehmite leaching kinetic studies in Section 4.0 used the time of 0-hr sampling as the zero reference.

The ranges of temperatures during the constant-temperature digestion period are given in Table 3.18 for different subsets of temperature instruments, including all that were submerged during the tests. Table 3.19 shows the average temperatures, over all submerged instruments in the PEP tests, for each interval between samples. The data for the temperature tables were taken from data acquisition System (DAS) files; a frequency of $1 /$ minute was used.

Table 3.16. Slurry Density During PEP Caustic-Leach Tests

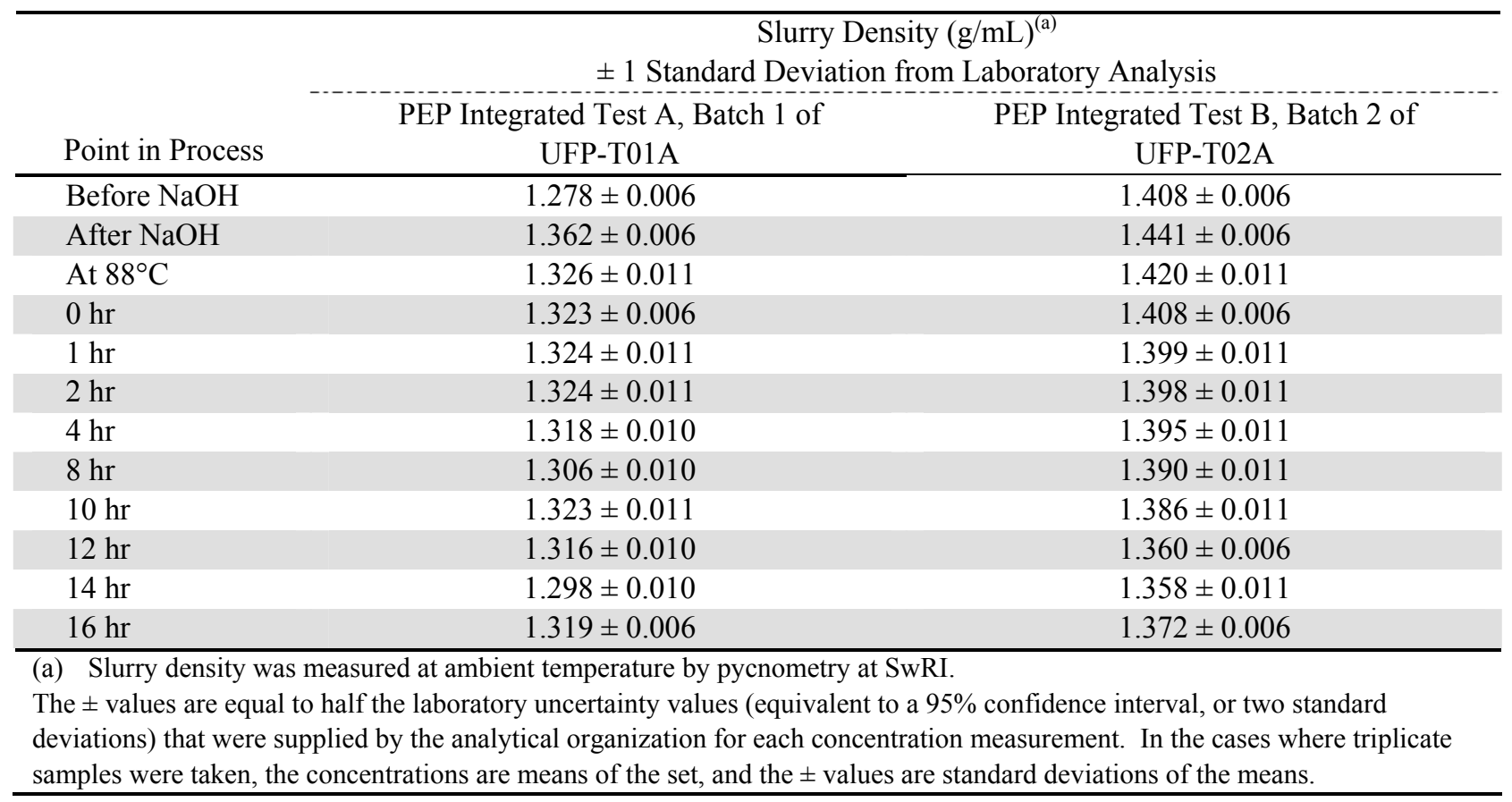


Table 3.17. Sample Timing During Caustic-Leach Tests

\begin{tabular}{|c|c|c|c|c|c|c|}
\hline \multirow[b]{2}{*}{$\begin{array}{l}\text { Point in Process } \\
\text { (Nominal Time) }\end{array}$} & \multicolumn{6}{|c|}{ Hours Before/After Reaching Temperature ${ }^{(a)}$} \\
\hline & $\begin{array}{l}\text { PEP Integrated } \\
\text { Test A, Batch } 1 \\
\text { of UFP-T01A }\end{array}$ & $\begin{array}{l}\text { Laboratory- } \\
\text { Scale } \\
\text { Test A-1 } \\
\end{array}$ & $\begin{array}{c}\text { Laboratory- } \\
\text { Scale } \\
\text { Test A-2 } \\
\end{array}$ & $\begin{array}{l}\text { PEP Integrated } \\
\text { Test B, Batch } 2 \\
\text { of UFP-T02A }\end{array}$ & $\begin{array}{l}\text { Laboratory- } \\
\text { Scale } \\
\text { Test B-1 }\end{array}$ & $\begin{array}{l}\text { Laboratory- } \\
\text { Scale } \\
\text { Test B-2 } \\
\end{array}$ \\
\hline Before $\mathrm{NaOH}$ & $\mathrm{n} / \mathrm{m}$ & $\mathrm{n} / \mathrm{m}$ & $\mathrm{n} / \mathrm{m}$ & -5.87 & $\mathrm{n} / \mathrm{m}$ & $\mathrm{n} / \mathrm{m}$ \\
\hline After $\mathrm{NaOH}$ & -6.53 & -5.27 & -5.28 & -2.71 & -3.75 & -4.08 \\
\hline At $88^{\circ} \mathrm{C}$ & -1.65 & -1.05 & -1.05 & -0.87 & -0.95 & -0.95 \\
\hline $\begin{array}{l}\text { Date/time } \\
\text { when } 98^{\circ} \mathrm{C} \\
\text { reached: start } \\
\text { digestion }\end{array}$ & $1 / 31 / 0919: 40$ & 2/9/09 13:43 & 2/9/09 13:45 & 3/15/09 19:51 & 3/19/09 12:30 & $3 / 19 / 0912: 35$ \\
\hline $\begin{array}{l}\text { Date/time of } \\
0 \text {-hr sample }\end{array}$ & 1/31/09 19:44 & 2/9/09 13:43 & 2/9/09 13:45 & 3/15/09 19:55 & $3 / 19 / 0912: 30$ & $3 / 19 / 0912: 35$ \\
\hline $0 \mathrm{hr}$ & 0.00 & 0.0 & 0.0 & 0.00 & 0.0 & 0.0 \\
\hline $1 \mathrm{hr}$ & 0.93 & 1.0 & 1.0 & 0.94 & 1.0 & 1.0 \\
\hline $2 \mathrm{hr}$ & 1.93 & 2.0 & 2.0 & 1.93 & 2.0 & 2.0 \\
\hline $4 \mathrm{hr}$ & 3.93 & 4.0 & 4.0 & 3.91 & 4.0 & 4.0 \\
\hline $8 \mathrm{hr}$ & 7.97 & 8.0 & 8.0 & 7.93 & 8.0 & 8.0 \\
\hline $10 \mathrm{hr}$ & 9.95 & 10.0 & 10.0 & 9.93 & 10.0 & 10.0 \\
\hline $12 \mathrm{hr}$ & 12.05 & 12.0 & 12.0 & 11.96 & 12.0 & 12.0 \\
\hline $14 \mathrm{hr}$ & 13.93 & 14.0 & 14.0 & 13.93 & 14.0 & 14.0 \\
\hline $16 \mathrm{hr}$ & 16.09 & 16.0 & 16.0 & 15.96 & 16.0 & 16.4 \\
\hline $18 \mathrm{hr}$ & $\mathrm{n} / \mathrm{m}$ & 18.0 & 18.0 & $\mathrm{n} / \mathrm{m}$ & 18.0 & 18.2 \\
\hline $20 \mathrm{hr}$ & $\mathrm{n} / \mathrm{m}$ & 20.0 & 20.0 & $\mathrm{n} / \mathrm{m}$ & 21.0 & 21.0 \\
\hline $22 \mathrm{hr}$ & $\mathrm{n} / \mathrm{m}$ & 22.0 & 22.0 & $\mathrm{n} / \mathrm{m}$ & $\mathrm{n} / \mathrm{m}$ & $\mathrm{n} / \mathrm{m}$ \\
\hline $24 \mathrm{hr}$ & $\mathrm{n} / \mathrm{m}$ & 24.0 & 24.0 & $\mathrm{n} / \mathrm{m}$ & 24.0 & 24.0 \\
\hline $\begin{array}{l}\text { a) Constant-temp } \\
\text { temperature se } \\
\mathrm{n} / \mathrm{m} "=\text { not measu }\end{array}$ & $\begin{array}{l}\text { oerature digestion } \\
\text { ensor (TTK- } 0325 \\
\text { red. }\end{array}$ & $\begin{array}{l}\text { sidered to } \\
\text { P-T01A, T }\end{array}$ & $\begin{array}{l}\text { the time } \\
19 \text { in UFF }\end{array}$ & e tempera & reaches $98^{\circ} \mathrm{C}$ & the prototypic \\
\hline
\end{tabular}


Table 3.18. Temperatures During Digestion Period For Caustic-Leach Tests

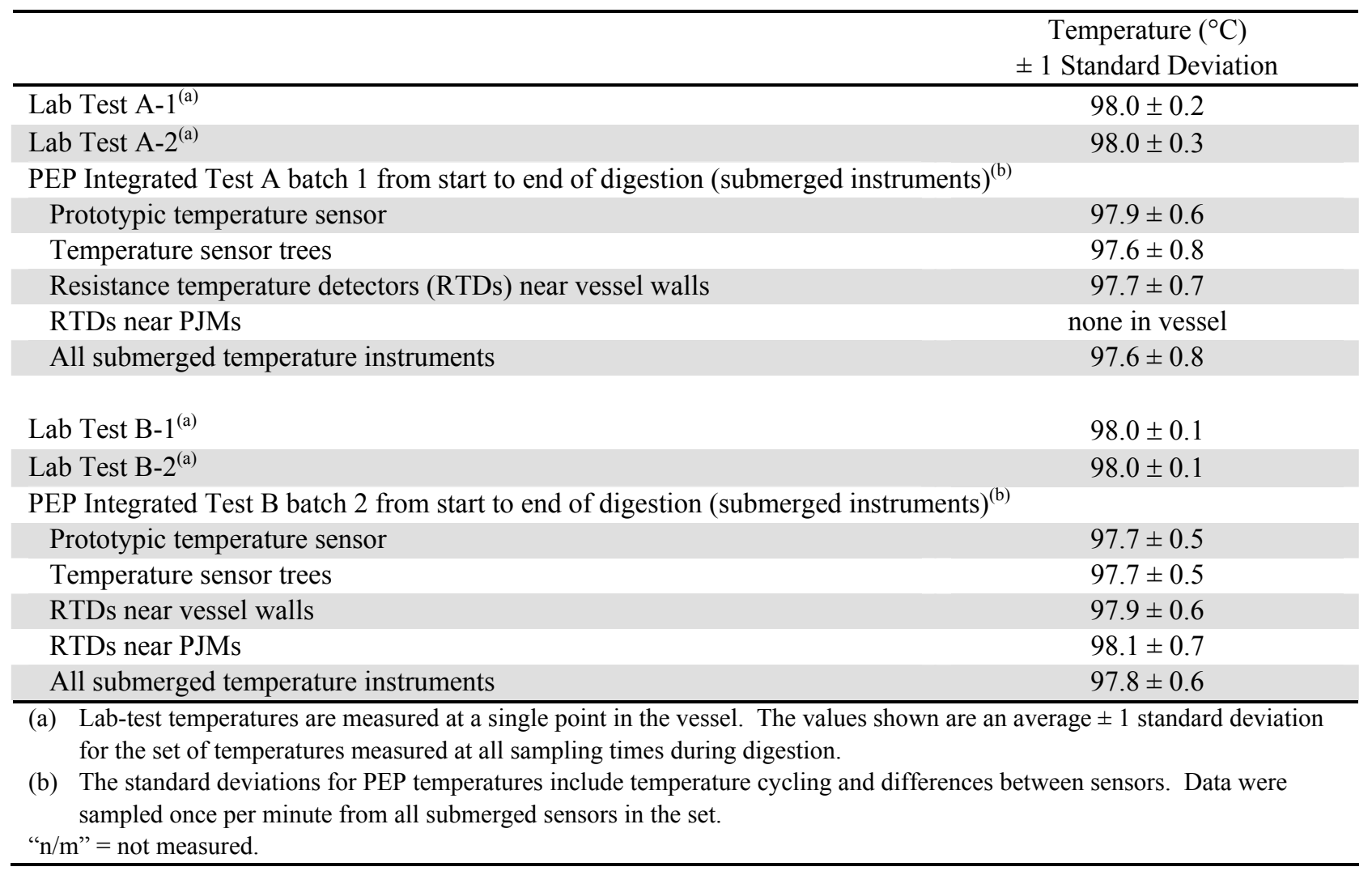


Table 3.19. Temperatures for Each Sampling Period for PEP Caustic-Leach Tests

\begin{tabular}{|c|c|}
\hline & $\begin{array}{c}\text { Temperature }\left({ }^{\circ} \mathrm{C}\right) \\
\pm 1 \text { Standard Deviation }\end{array}$ \\
\hline \multicolumn{2}{|c|}{ PEP Integrated Test $\mathrm{A}$ batch 1 from start to end of digestion, all submerged instruments } \\
\hline Start to hour 0 sample & $79.8 \pm 11.0$ \\
\hline hour 0 to hour 1 & $97.6 \pm 0.9$ \\
\hline hour 1 to hour 2 & $97.6 \pm 0.7$ \\
\hline hour 2 to hour 4 & $97.6 \pm 0.7$ \\
\hline hour 4 to hour 8 & $97.7 \pm 0.8$ \\
\hline hour 8 to hour 10 & $97.5 \pm 0.7$ \\
\hline hour 10 to hour 12 & $97.6 \pm 0.7$ \\
\hline hour 12 to hour 14 & $97.7 \pm 0.8$ \\
\hline hour 14 to hour 16 & $97.7 \pm 0.7$ \\
\hline \multicolumn{2}{|c|}{ PEP Integrated Test B batch 2 from start to end of digestion, all submerged instruments } \\
\hline Start to hour 0 sample & $78.7 \pm 10.4$ \\
\hline hour 0 to hour 1 & $97.9 \pm 0.8$ \\
\hline hour 1 to hour 2 & $97.8 \pm 0.7$ \\
\hline hour 2 to hour 4 & $97.9 \pm 0.6$ \\
\hline hour 4 to hour 8 & $97.8 \pm 0.6$ \\
\hline hour 8 to hour 10 & $97.8 \pm 0.7$ \\
\hline hour 10 to hour 12 & $97.8 \pm 0.5$ \\
\hline hour 12 to hour 14 & $97.8 \pm 0.4$ \\
\hline hour 14 to hour 16 & $97.8 \pm 0.3$ \\
\hline
\end{tabular}

\subsection{Comparison to Target Conditions}

The target conditions for the two PEP tests were set forth in the run sheets found in Test Instructions TI-WTP-PEP-065 (TI-065, Integrated Test A) and TI-WTP-PEP-066 (TI-066, Integrated Test B). The run sheet targets pertinent to added reagent masses, slurry volumes, vessel levels, temperature profiles, flow rates, and other operating parameters for batch 1 of Integrated Test A and batch 2 of Integrated Test B were given in Table 3.1 and Table 3.3, respectively. The actual measured values and comments about variations are also in these tables.

This section further compares target and measured values for some of the parameters that are key to the caustic-leach process. The masses of caustic-leach batch components (i.e., initial simulant, added caustic, and accumulated steam condensate at the end of the 16-hr leach) in the UFP-T01A vessel (Integrated Test A) and the UFP-T02A vessel (Integrated Test B) are summarized in Table 3.2 and Table 3.4, respectively. These masses were derived in part from the analysis of observed slurry volumes/levels and steam condensate accumulation during the caustic-leach batches, which is addressed in Section 3.4.1. The temperature-time profiles during batch 1 of Integrated Test A and batch 2 of Integrated Test B are discussed in Section 3.4.2. 


\subsubsection{Comparison to Target Condensate Accumulation}

In the WTP UFP vessels, direct injection of steam is to be used to heat the process slurry up to the caustic-leach temperature and maintain it. The rate of temperature increase during the heating ramp with a fixed steam addition rate, the amount of steam required to maintain a constant leach temperature, and the net amount of steam condensate accumulated in the slurry batch are dependent on a number of factors. These include the masses and specific heat capacities of the process slurry and vessel structural components, heat transfer rates from the outer vessel surfaces, heat loss due to heating of air used in PJMs, steam ring purge and spargers, and evaporation of water into the air streams. The net amount of condensate accumulated in the vessel during the leach process is the difference in the amount of steam added and the amount of water leaving the vessel with air in the PJM and vessel headspace ventilation system. A Mathcad model was developed and applied to assess the heating (and cooling) temperature profiles and the expected amount of condensate accumulation for some representative caustic-leach processes in the WTP UFP-1A/B and UFP-2 vessels (Rassat et al. 2008).

Applying similar models and considering volumetric scaling provide the basis of expected condensate accumulation in the PEP UFP vessels. Because heat transfer rates in the PEP vessels do not scale volumetrically, and to most closely mimic condensate accumulation throughout the caustic-leach process in the WTP UFP vessels, it was necessary to pre-heat the slurry in the PEP vessels before starting direct steam injection. Further, in the Integrated Test A leach batches in PEP UFP-T01A/B, liquid water was added throughout the $98^{\circ} \mathrm{C}$ leach period to maintain the expected condensate accumulation rate. In the following sections, the total slurry volume measured during the Integrated Test A, batch 1 and Integrated Test B, batch 2 caustic-leach processes using various level instruments are presented and compared to run sheet targets. Volume changes due to thermal expansion of the slurry are distinguished from changes resulting from condensate accumulation and are related to the amount of steam added. Finally, slurry volume change data are used to estimate dilution factors, and these are shown to be in good agreement with the results of liquid chemical tracer analyses.

Preliminary assessments of condensate accumulation in the two PEP test batches, using a subset of the techniques described below, were a basis for the amount of water used in the laboratory-scale caustic-leach tests (Table 3.5 and Table 3.6). The initial condensate analyses were typically completed within days of the PEP caustic-leach tests. The subsequent availability of analytical solid weight fractions (UDS, Table 3.15), slurry densities (Table 3.16), and liquid densities (Table 3.13) permitted refinement of the original volume-based analyses and incorporation of mass-based calculations, as described below.

\subsubsection{Condensate Accumulation in Integrated Test A Batch 1}

As shown in Table 3.1, the TI-065 target total volume of simulant and caustic transferred to the PEP UFP-T01A vessel in Integrated Test A, batch 1 was $501 \pm 5$ gal. This compares favorably with the total volume passing through the flowmeter supplying the vessel (498 gal) and agrees reasonably with volumes derived from in-vessel level instrumentation before starting direct steam injection (481 to $497 \mathrm{gal}$ ). Some of these volume data based on vessel levels and the run sheet target are shown as the initial values in Figure 3.4, upper. The $\mathrm{x}$-axis time scale in the figure is the elapsed time since the vessel first reached the target leach temperature of $98^{\circ} \mathrm{C}$ (time zero), and the negative elapsed time is during heat-up. The upper portion of Figure 3.4 tracks the run sheet targets and measured volumes throughout the caustic-leach process in two primary phases: heating the initial slurry volume from the pre-heated temperature $\left(\sim 57^{\circ} \mathrm{C}\right)$ specified duration of the leach $(16 \mathrm{hr})$. The y-error bars on the run sheet target volumes in Figure 3.4 


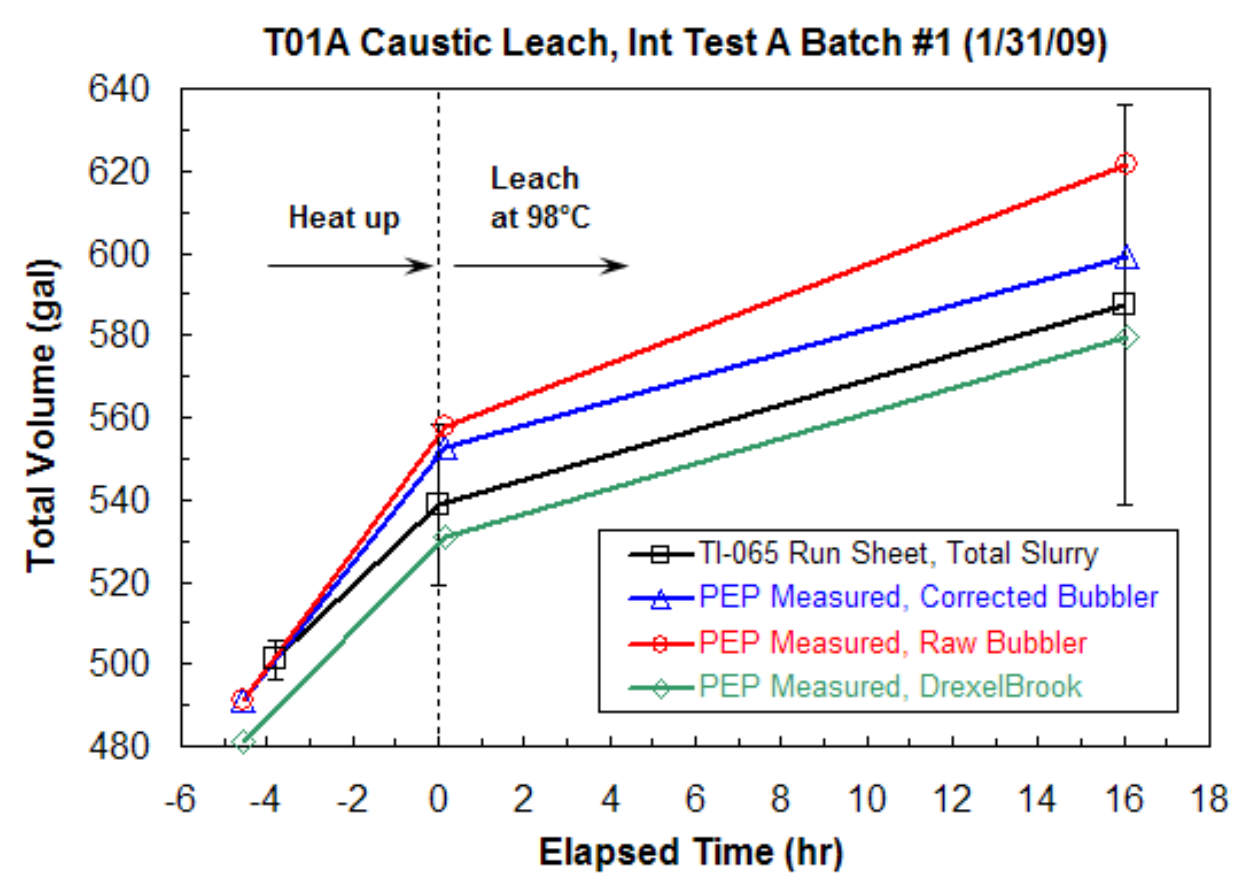

T01A Caustic Leach, Int Test A Batch \#1 (1/31/09)

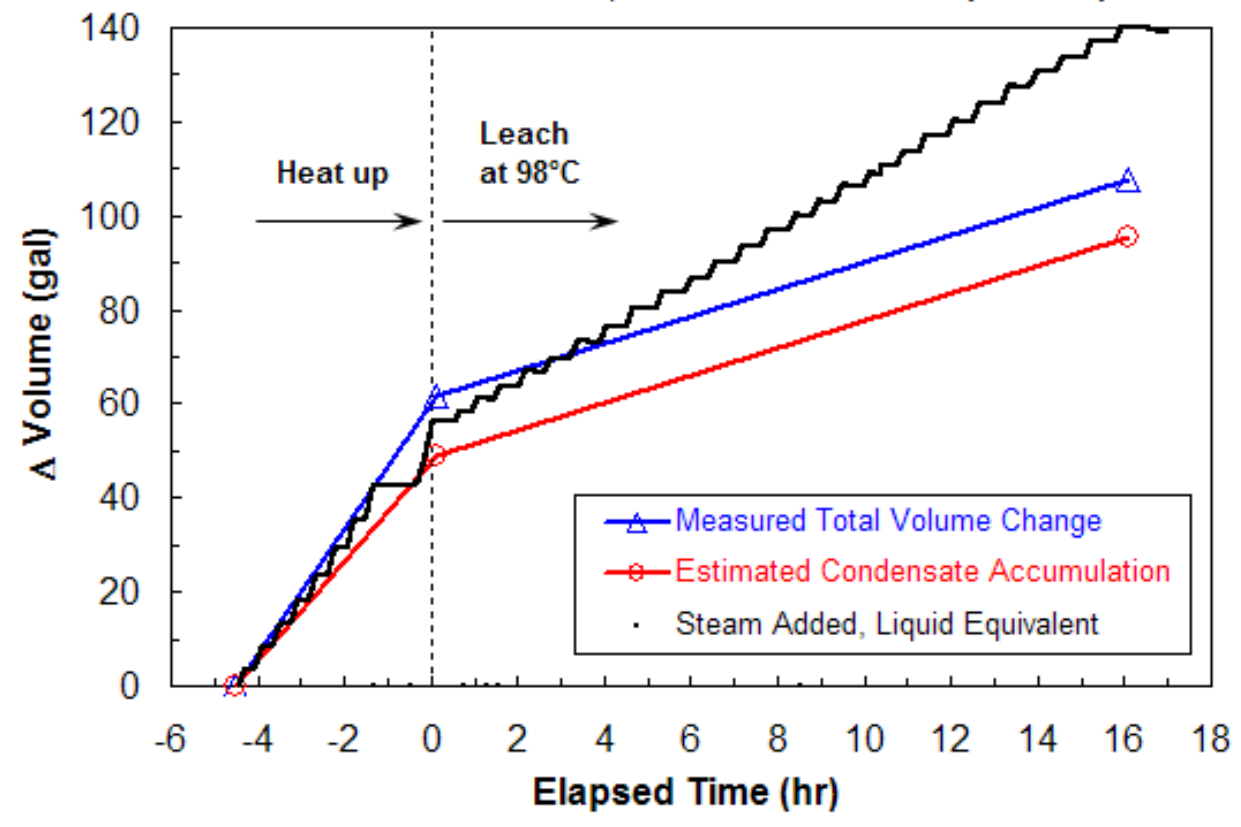

Figure 3.4. Volumes in UFP-T01A Associated with Direct Steam Injection During the Heat-Up and Caustic-Leach Periods of Integrated Test A Batch 1: Upper-Total Slurry-Condensate Mixture Volume as Determined from Multiple Level Sensors Compared to TI-065 Run Sheet Targets (with ranges shown); Lower-Slurry Component Volume Changes $(\Delta)$ (e.g., the total increase in the slurry-condensate mixture volume and the estimated volume of condensate accumulated compared to the total amount of steam added [as an equivalent liquid volume at the vessel temperature]) 
correspond to the ranges provided in Table 3.1. In cases where run sheet targets and ranges are provided as slurry level in inches, ${ }^{(a)}$ the levels were converted to volumes using an established level-volume correlation.

All reported UFP-T01A vessel levels and the corresponding volumes are based on "stable" level measurement periods when the PJMs were turned off and vented, while the steam ring purge air was left on. The purge air flow rate was $>0.14 \mathrm{~kg} / \mathrm{min}$ until after $98^{\circ} \mathrm{C}$ was reached, and it was reduced to between 0.10 and $0.13 \mathrm{~kg} / \mathrm{min}$ for the remainder of the caustic-leach period (see Table 3.1 for additional details). The measured total slurry volumes shown in Figure 3.4 (upper) are derived from three sources: 1) the vessel bubbler pressure data (i.e., both lower and upper legs) converted to slurry level using analytically measured slurry density data; 2) the as-is or "raw" vessel bubbler pressure data using the apparent slurry density (specific gravity) derived from the difference in bubbler pressures; and 3) the DrexelBrook (DB) capacitance probe located in the vessel (not in the PJMs). Unfortunately, laser level data, which gave an initial volume of 497 gal, were incomplete owing to malfunction of the instrument during the leach test; therefore, laser-based volumes are excluded from Figure 3.4. The corrected bubbler values (1) use analytical density data (shown in Table 3.16 and Table 3.13) for samples taken at the point in the process closest to the time of the stable level measurement. Further, a simple model based on the known change in water density with temperature and an assumed density of UDS ( $2.8 \mathrm{~kg} / \mathrm{L}$ average $)$ is used to estimate the bulk slurry density at the vessel temperature from reported slurry liquid density data (at $\left.25^{\circ} \mathrm{C}\right) .{ }^{(b)}$

As shown in Figure 3.4 (upper), the total slurry volume at the end of heat-up determined from the as-is bubbler data (558 gal) is close to the corrected bubbler result (553 gal), while the DB value is noticeably and suspiciously lower (531 gal). The run sheet target value at the end of heat-up is 61 in. (539 gal), but this is inconsistent with a comment in the TI-065 run sheet that indicated $\sim 62$ gal of condensate was expected during heat-up, which would give a total volume of 563 gal (= 501 gal initial +62 gal). At the end of the leach process, the bubbler based total slurry volume results diverge. This is due to the low apparent density obtained from the as-is bubbler data $(1.21 \mathrm{~kg} / \mathrm{L})$ compared to the temperature-corrected analytical slurry density $(1.25 \mathrm{~kg} / \mathrm{L})$. The corrected density is also in good agreement with $\mathrm{CD}$ readings obtained at the time the analytical sample was drawn from the vessel. For the purpose of estimating total volume change and condensate accumulation in Integrated Test A, batch 1, the corrected bubbler data are preferred over the as-is bubbler data (too high) or the DB data, which seem

(a) Note that the TI-065 runsheet target levels are nominal values and do not account for changes due to thermal expansion/contraction of the slurry.

(b) The temperature-corrected slurry liquid density $\left(\rho_{\text {liq }}\right)$ at vessel temperature $T$ for a density measured at temperature $T_{\text {ref }}(\mathrm{e}$.g., $25^{\circ} \mathrm{C}$ ) is given by:

$$
\rho_{\text {liq }}(T)=\rho_{\text {liq }}\left(T_{r e f}\right) \frac{\rho_{w}(T)}{\rho_{w}\left(T_{r e f}\right)}
$$

where $\rho_{w}$ is the density of water from literature. The temperature-corrected bulk slurry density $\left(\rho_{s l}\right)$ at the same vessel temperature is estimated from the corrected liquid density as:

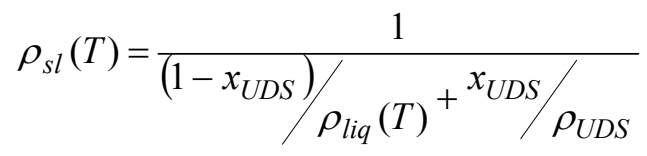

where $\rho_{U D S}$ and $x_{U D S}$ are the density and mass fraction of undissolved solids, respectively. 
generally too low. The measured total slurry volume at the end of the leach (599 gal, corrected bubbler) is slightly higher than the run sheet target of 587 gal.

The lower portion of Figure 3.4 shows the total slurry volume change in UFP-T01A in Integrated Test A, batch 1 determined from the corrected bubbler data. At the end of heat-up, the total volume change was 62 gal, and at the end of the leach process, the volume change was 108 gal. The total volume change results from thermal expansion of the slurry with increasing temperature (i.e., the slurry density decreases with increasing temperature) and a net accumulation of condensate, which includes condensed steam and water added periodically during the leach period. Approximately $2.9 \mathrm{~L}$ ( $0.77 \mathrm{gal})$ of inhibited water was added to UFP-T01A each hour of the $98^{\circ} \mathrm{C}$ hold period (starting at hour 1 and ending at hour 15) to achieve the dilution expected in equivalent WTP operations. Accounting for the thermal expansion of the liquid fraction of the slurry, as determined from UDS (Table 3.15) and liquid density (Table 3.13) data, and the change in liquid volume due to dissolution of aluminum solids, the volume change resulting from net condensate accumulation alone can be estimated. This is shown in Figure 3.4 (lower): at the end of heat-up, the estimated condensate accumulation was 49 gal, and at the end of the leach process, the condensate volume was 95 gal. This volume-derived estimate of the total condensate accumulated corresponds to the $346 \mathrm{~kg}$ value reported in Table 3.2. From the total slurry volume data and estimates of temperature-corrected bulk slurry densities, a total mass change in the vessel during the leach process of $364 \mathrm{~kg}$ is calculated. Assuming there are no other mass sources or sinks in the vessel, this provides a mass-based estimate of the total condensate accumulated (also shown in Table 3.2).

For comparison, the cumulative amount of steam added converted to an equivalent condensed water volume at the vessel temperature, is also shown in Figure 3.4 (lower). At the end of heat-up, the amount of steam added exceeds the estimated condensate accumulation by only $\sim 7$ gal, but at the end of the leach process, the total steam added ( $\sim 140$ gal) exceeds the net condensate by $\sim 45$ gal. This indicates that a large fraction of the steam added during the high-temperature leach period was evaporated and vented away from the vessel.

Table 3.20 summarizes mass dilution of the slurry liquid as a function of time in the caustic-leach process for Integrated Test A, batch 1. Results obtained from measured concentration changes in nitrate and chloride liquid tracers are compared to those determined from changes in vessel level in conjunction with analytical UDS and density data. The "total liquid dilution" values, which include aluminum dissolved in the course of the leach process, are directly comparable to the chemical tracer results. The "liquid dilution by water" entries are strictly based on change in liquid mass due to condensate accumulation and are expectedly lower. The total liquid mass dilution factors determined from volume change data are in good agreement with the results of liquid chemical tracer analyses. In this test, the nitrate results follow a steady trend whereas the chloride data tend to be inconsistent. Therefore, comparing the nitrate results to the level-based results, the total mass dilution at the end of heat-up is $8 \%$ by both methods, and at the end of the leach period, the dilution is $17 \%$ (nitrate) and $16 \%$ (level change). 
Table 3.20. Dilution of Liquid Phase During PEP Caustic-Leach Integrated Test A, Batch 1

\begin{tabular}{|c|c|c|c|c|}
\hline \multirow[b]{2}{*}{$\begin{array}{l}\text { Approximate Point } \\
\text { in Process }\end{array}$} & \multicolumn{2}{|c|}{$\begin{array}{l}\text { Total Liquid Mass Dilution from Liquid } \\
\text { Chemical Tracer Analysis }(\mathrm{wt} \%)^{(\mathrm{a})}\end{array}$} & \multicolumn{2}{|c|}{$\begin{array}{l}\text { Mass Dilution from PEP Vessel Level } \\
\text { Changes and Slurry Properties }(\mathrm{wt} \%)^{(\mathrm{b})}\end{array}$} \\
\hline & Nitrate $\left(\mathrm{NO}_{3}^{-}\right)$ & Chloride $\left(\mathrm{Cl}^{-}\right)$ & $\begin{array}{l}\text { Total Liquid } \\
\text { Dilution }^{(\mathrm{c})}\end{array}$ & $\begin{array}{l}\text { Liquid Dilution by } \\
\text { Water }^{(\mathrm{d})}\end{array}$ \\
\hline $\begin{array}{l}\text { After } \mathrm{NaOH} \text {; before } \\
\text { steam addition }\end{array}$ & $0.0 \%$ & $0.0 \%$ & $0.0 \%$ & $0.0 \%$ \\
\hline At $88^{\circ} \mathrm{C}$ & $8.1 \%$ & $9.3 \%$ & $\mathrm{n} / \mathrm{m}$ & $\mathrm{n} / \mathrm{m}$ \\
\hline $0 \mathrm{hr}$ & $8.2 \%$ & $5.0 \%$ & $8.2 \%$ & $7.3 \%$ \\
\hline $1 \mathrm{hr}$ & $11.5 \%$ & $12.0 \%$ & $\mathrm{n} / \mathrm{m}$ & $\mathrm{n} / \mathrm{m}$ \\
\hline $2 \mathrm{hr}$ & $10.4 \%$ & $9.0 \%$ & $\mathrm{n} / \mathrm{m}$ & $\mathrm{n} / \mathrm{m}$ \\
\hline $4 \mathrm{hr}$ & $11.9 \%$ & $13.3 \%$ & $\mathrm{n} / \mathrm{m}$ & $\mathrm{n} / \mathrm{m}$ \\
\hline $8 \mathrm{hr}$ & $11.7 \%$ & $9.3 \%$ & $\mathrm{n} / \mathrm{m}$ & $\mathrm{n} / \mathrm{m}$ \\
\hline $10 \mathrm{hr}$ & $15.3 \%$ & $15.4 \%$ & $\mathrm{n} / \mathrm{m}$ & $\mathrm{n} / \mathrm{m}$ \\
\hline $12 \mathrm{hr}$ & $15.3 \%$ & $10.8 \%$ & $\mathrm{n} / \mathrm{m}$ & $\mathrm{n} / \mathrm{m}$ \\
\hline $14 \mathrm{hr}$ & $18.2 \%$ & $18.0 \%$ & $\mathrm{n} / \mathrm{m}$ & $\mathrm{n} / \mathrm{m}$ \\
\hline $16 \mathrm{hr}$ & $17.4 \%$ & $13.6 \%$ & $15.7 \%$ & $14.4 \%$ \\
\hline \multicolumn{5}{|c|}{$\begin{array}{l}\text { The initial/reference state is the mass of liquid in the PEP vessel "after } \mathrm{NaOH} \text { " as determined from the stable level } \\
\text { measurement nearest to the start of direct steam injection. The liquid mass is calculated from the total slurry volume (at } \\
\text { level), the estimated volume fraction of liquid (from wt } \% \text { UDS, temperature-corrected liquid density, and the density of } \\
\text { remaining solids }[2.8 \mathrm{~kg} / \mathrm{L} \text { assumed]), and a temperature-corrected liquid density. }\end{array}$} \\
\hline \multicolumn{5}{|c|}{ Change in liquid mass/initial liquid mass. } \\
\hline \multicolumn{5}{|c|}{ Net condensate (water) mass/initial liquid mass. } \\
\hline $\mathrm{n} / \mathrm{m}$ - not measured. & & & & \\
\hline
\end{tabular}

\subsubsection{Condensate Accumulation in Integrated Test B Batch 2}

Table 3.3 shows a run sheet (TI-066) target level of $53.5 \pm 3$ inches $^{(\mathrm{a})}$ for simulant and caustic in the PEP UFP-T02A vessel in Integrated Test B, batch 2 after the filter-loop was partially flushed into the vessel and isolated. This corresponds to an expected "initial" volume of $227 \pm 14$ gal before direct steam injection into UFP-T02A. As shown in Table 3.3 and in Figure 3.5 (upper), the measured initial level and the corresponding volume, as determined with a laser (240 gal) and density-corrected bubbler (235 gal) data, are higher than the target but within the stated range. As noted in Table 3.3, the initial level was measured shortly after the start of direct steam injection, and the expected volume before the start of steam flow is approximately one gallon less than the measured values. The as-is bubbler level (using the bubbler-derived apparent slurry density) and DB capacitance probe initial levels are higher than the other two methods and are suspect. Since laser level data were available throughout the caustic-leach process, it is the preferred level instrument in this test. The vessel bubbler pressure data (i.e., both lower and upper legs), when converted to slurry level using analytically measured slurry density data, also provided reasonable results throughout the 16-hr leach period. (The 12-hr and 16-hr bubbler data suggest that air flow to the bubbler tubes was restarted during the level measurement periods or that the partially plugged tubes were cleared in the measurement periods.)

(a) Note that the TI-066 run sheet target levels are nominal values and do not account for changes due to thermal expansion/contraction of the slurry. 


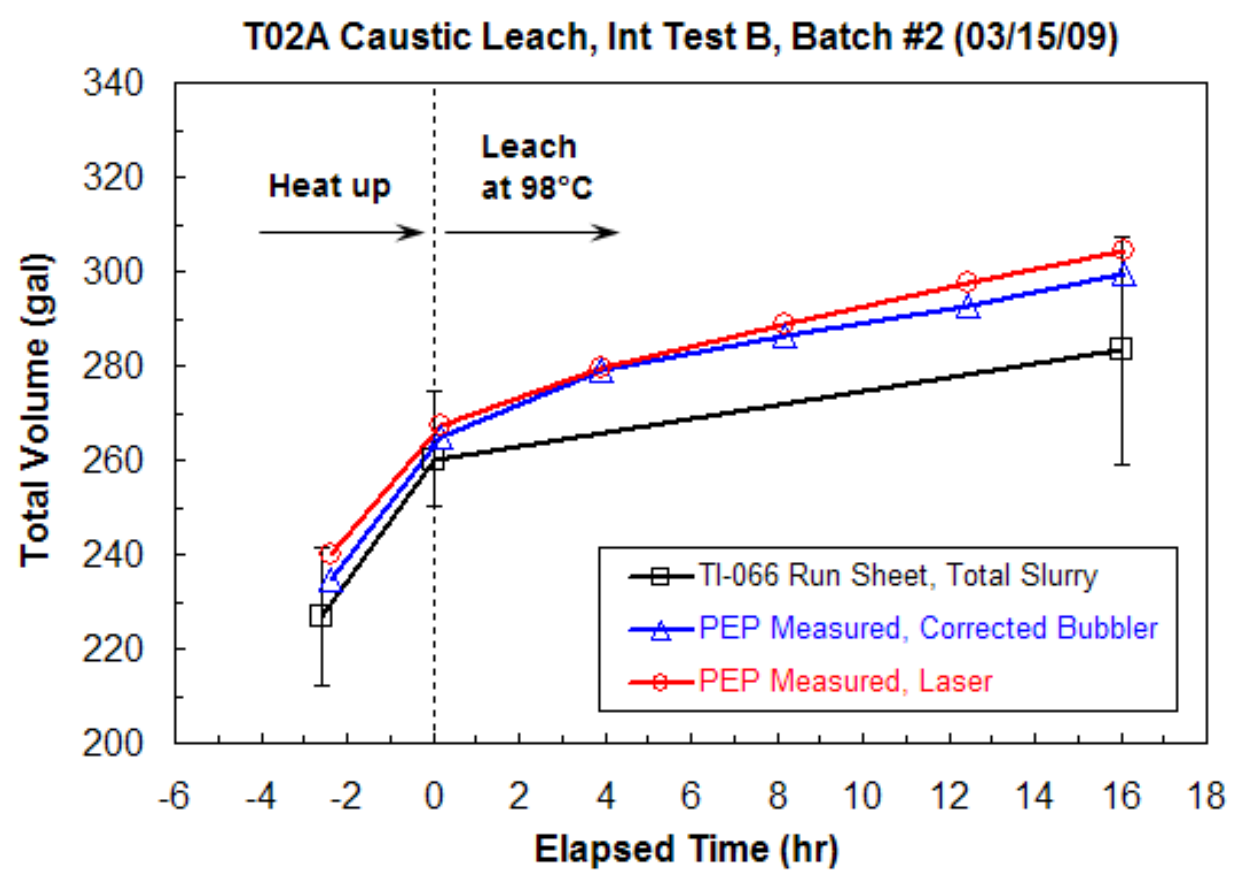

T02A Caustic Leach, Int Test B, Batch \#2 (03/15/09)

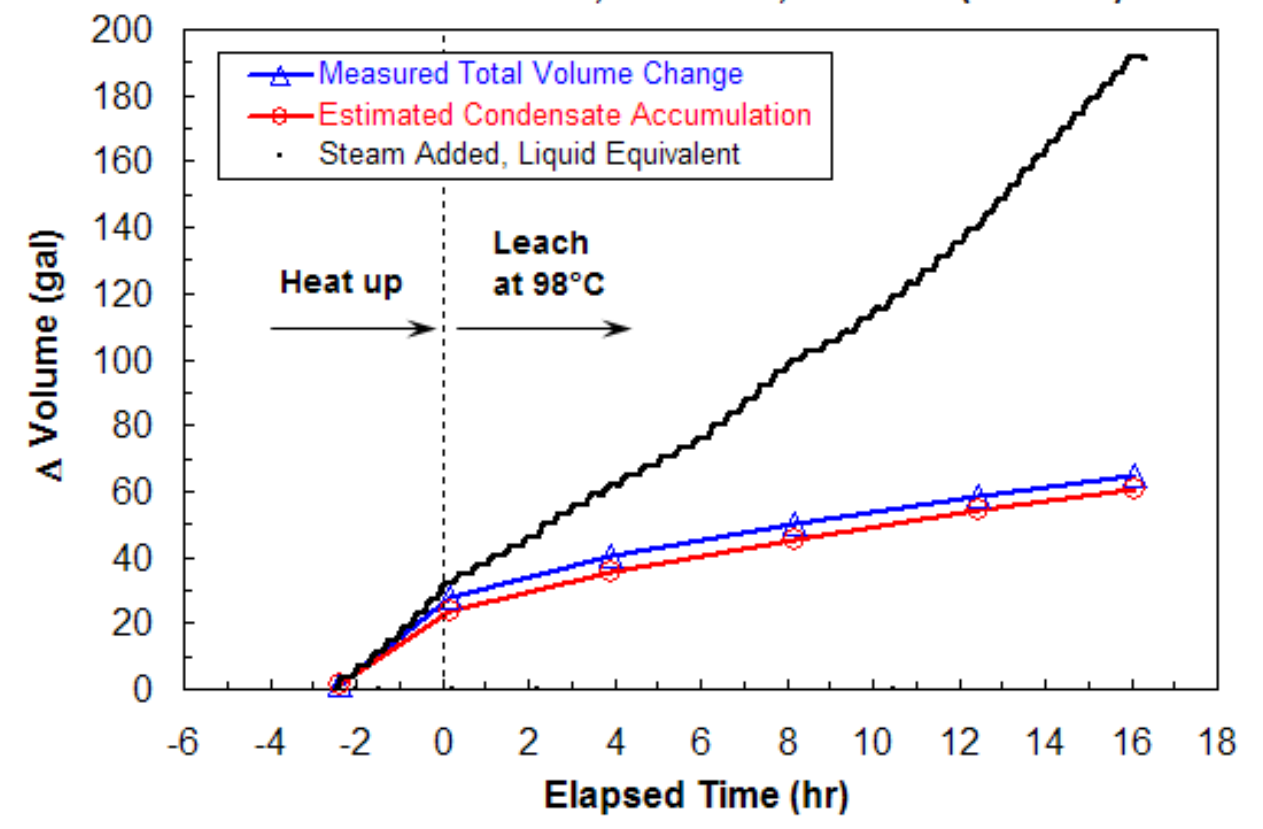

Figure 3.5. Volumes in UFP-T02A Associated with Direct Steam Injection During the Heat-Up and Caustic-Leach Periods of Integrated Test B Batch 2: Upper-Total Slurry-Condensate Mixture Volume as Determined from Two Level Sensors Compared to TI-066 Run Sheet Targets (with ranges shown); Lower-Slurry Component Volume Changes $(\Delta)$ (e.g., the total increase in the slurry-condensate mixture volume and the estimated volume of condensate accumulated from laser data compared to the total amount of steam added [as an equivalent liquid volume at the vessel temperature]) 
The $\mathrm{x}$-axis time scale in Figure 3.5 is the elapsed time since the vessel first reached the target leach temperature of $98^{\circ} \mathrm{C}$ (time zero); negative elapsed time corresponds to the heat-up period. The upper portion of Figure 3.5 tracks the run sheet target volumes (calculated from levels) and measured volumes throughout the caustic-leach process in two primary phases: heating the initial slurry volume from the pre-heated temperature $\left(\sim 69^{\circ} \mathrm{C}\right)$ to the leach temperature with direct steam injection and maintaining the leach temperature $\left(98^{\circ} \mathrm{C}\right)$ for the specified duration of the leach $(16 \mathrm{hr})$. The y-error bars on the run sheet target volumes in Figure 3.5 correspond to the level ranges provided in Table 3.3. In cases where run sheet targets and ranges are provided as slurry level in inches, the levels were converted to volumes using an established level-volume correlation for UFP-T02A.

All reported Integrated Test B, batch 2 UFP-T02A vessel levels and the corresponding volumes are based on "stable" level measurement periods when the PJMs were turned off and vented and, generally speaking, the spargers were turned off (temporarily) and the steam ring purge air was left on. The initial stable level measurement was obtained with steam flow on, rather than purge air, and the steam ring purge air flow rate was $\sim 0.09 \mathrm{~kg} / \mathrm{min}$ for the subsequent stable level measurements at $98^{\circ} \mathrm{C}$ (see Table 3.3 for additional details). The measured total slurry volumes shown in Figure 3.5 (upper) are derived from laser level data and density-corrected bubbler data. As noted in the previous section, corrected bubbler values use analytical density data (shown in Table 3.16 and Table 3.13) for samples taken at the point in the process closest to the time of the stable level measurement. Further, a simple model based on the known change in water density with temperature and an assumed density of UDS ( $2.8 \mathrm{~kg} / \mathrm{L}$ average $)$ is used to estimate the bulk slurry density at the vessel temperature from reported slurry liquid density data (at $25^{\circ} \mathrm{C}$ ).

As shown in Figure 3.5 (upper), the total slurry volume at the end of heat-up determined from the density-corrected bubbler data (265 gal) and the laser (267 gal) are slightly higher than the run sheet target value of 260 gal (60.4 in.), but well within the $-10 \mathrm{gal} /+14$ gal range. The density-corrected bubbler and laser data continue to track each other closely throughout the 16-hr caustic-leach period. The measured total slurry volume at the end of the leach (304 gal, laser; 300 gal, density-corrected bubbler) is considerably higher than the run sheet target of 283 gal, but it is within the \pm 24 -gal range.

Figure 3.5 (lower) shows the total slurry volume change and the estimated volume change due to steam condensate accumulation in UFP-T02A in Integrated Test B, batch 2 determined from the laser level data. These data are corrected to include an estimated 1.2 gal of condensate accumulated at the point the "initial" stable level measurement was taken. At the end of heat-up, the total volume change was $28 \mathrm{gal}$, and at the end of the leach process, the volume change was 65 gal. The total volume change results from thermal expansion of the slurry with increasing temperature (i.e., the slurry density decreases with increasing temperature) and a net accumulation of condensate. Accounting for the thermal expansion of the liquid fraction of the slurry, as determined from Integrated Test B, batch 2 UDS (Table 3.15) and liquid density (Table 3.13) data, and the change in liquid volume due to dissolution of aluminum solids, the volume change resulting from condensate accumulation alone can be estimated. This is shown in Figure 3.5 (lower): at the end of heat-up, the estimated condensate accumulation was $24 \mathrm{gal}$, and at the end of the leach process, the condensate volume was $61 \mathrm{gal}$. This volume-derived estimate of the total condensate accumulated corresponds to the $221 \mathrm{~kg}$ value reported in Table 3.4. From the total slurry volume data and estimates of temperature-corrected bulk slurry densities, a total mass change in the vessel during the leach process of $242 \mathrm{~kg}$ is calculated. Assuming there are no other mass sources or sinks in the vessel, this provides a mass-based estimate of the total condensate accumulated (also shown in Table 3.4). 
For comparison, the cumulative amount of steam added converted to an equivalent condensed water volume at the vessel temperature, is also shown in Figure 3.5 (lower). At the end of heat-up, the amount of steam added exceeds the estimated condensate accumulation by only $\sim 8$ gal, but at the end of the leach process, the total steam added ( $\sim 191$ gal) exceeds the net condensate by $\sim 130$ gal. This indicates that most of the steam added during the high temperature leach period was evaporated and vented away from the vessel.

Table 3.21 summarizes mass dilution of the slurry liquid as a function of time in the caustic-leach process for Integrated Test B, batch 2. Results obtained from measured concentration changes in nitrate and chloride liquid tracers are compared to those determined from changes in vessel level in conjunction with analytical UDS and density data. The "total liquid dilution" values, which include aluminum solids dissolved in the course of the leach process, are directly comparable to the chemical tracer results. The "liquid dilution by water" entries are strictly based on change in liquid mass due to condensate accumulation and are expectedly lower. The total liquid mass dilution factors determined from volume change data are in good agreement with the results of liquid chemical tracer analyses. In this test, both the nitrate and chloride results follow a steady increasing dilution trend consistent with condensate accumulation and aluminum solids dissolution. The level-based total mass dilution results follow a similar trend, although the magnitude of the dilution factor is typically a few percent less than the liquid tracer values in each time period. For example, at the end of heat-up, the tracer results indicate $12 \%$ (nitrate) and 11\% (chloride) mass dilution compared to $9 \%$ based on level change, and at the end of the leach period, the liquid mass dilution is $26 \%$ by both tracers and is $22 \%$ by level change. Overall, the two methods indicate comparable levels of liquid dilution and, by inference, condensate accumulation.

\subsubsection{Comparison to Target Temperature-Time Profile}

Figure 3.6 and Figure 3.7 depict the temperature-versus-time profile in Integrated Test A, batch 1 (UFP-T01A) and Integrated Test B, batch 2 (UFP-T02A), respectively, during the caustic-leach tests. The time axis is expressed in terms of time relative to the start of the constant-temperature leach (see Table 3.16 for the elapsed time zero clock time). The temperature is measured at the "prototypic" temperature sensor for each vessel (TTK-0325 in UFP-T01A; TTK-0619 in UFP-T02A); the sensors are located near the vessel bottoms. Each figure also shows the temperature-versus-time targets outlined in the respective Test Instructions and run sheet summary tables (Integrated Test A, batch 1, TI-065, Table 3.1; and Integrated Test B, batch 2, TI-066, Table 3.3). The $\mathrm{x}$ - and y-error bars correspond to the TI run sheet target ranges. As noted previously, the run sheet temperature profile targets in the heating and cooling regimes were derived from versions of WTP UFP vessel heat transfer models (i.e., Mathcad). 
Table 3.21. Dilution of Liquid Phase During PEP Caustic-Leach Integrated Test B, Batch 2

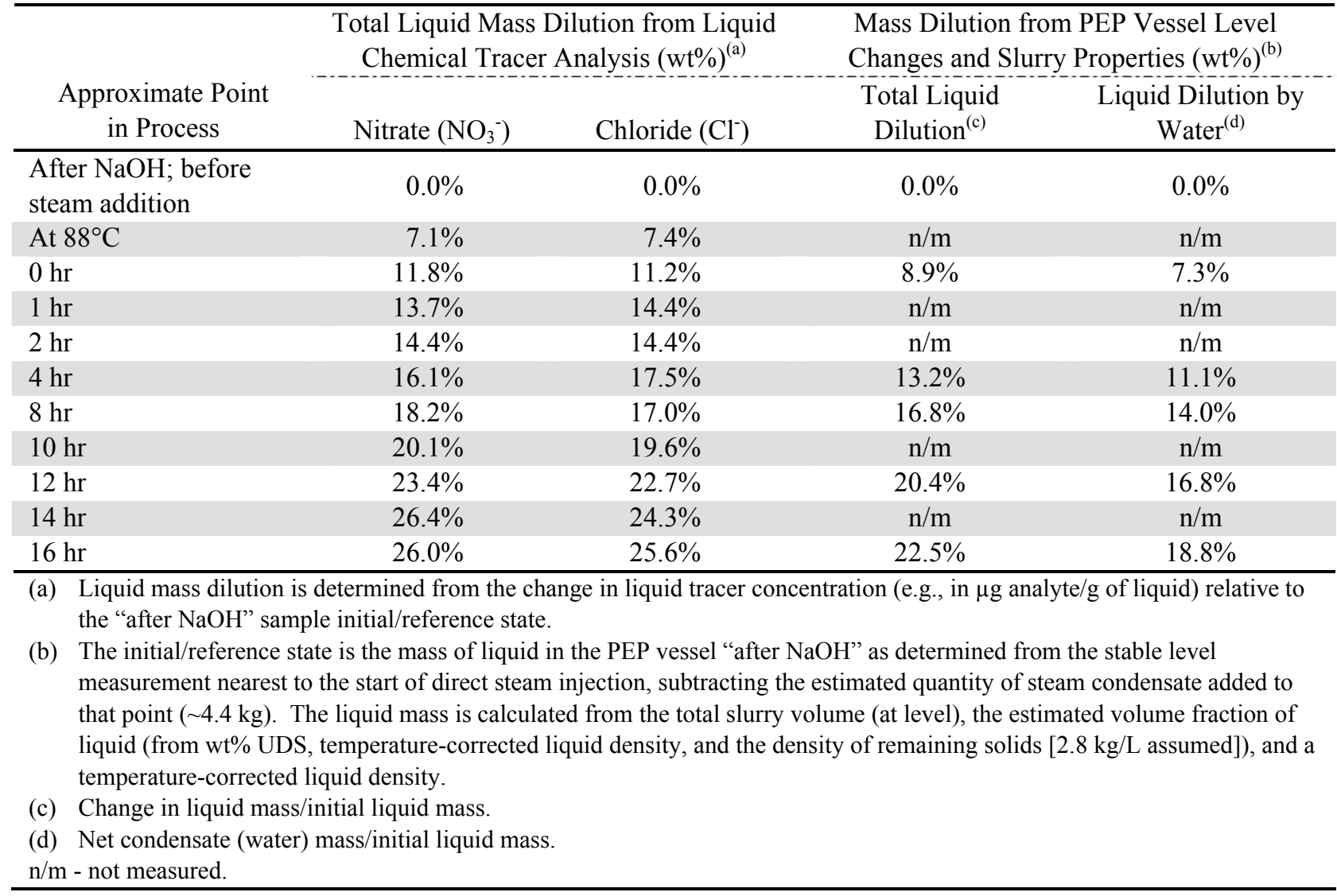

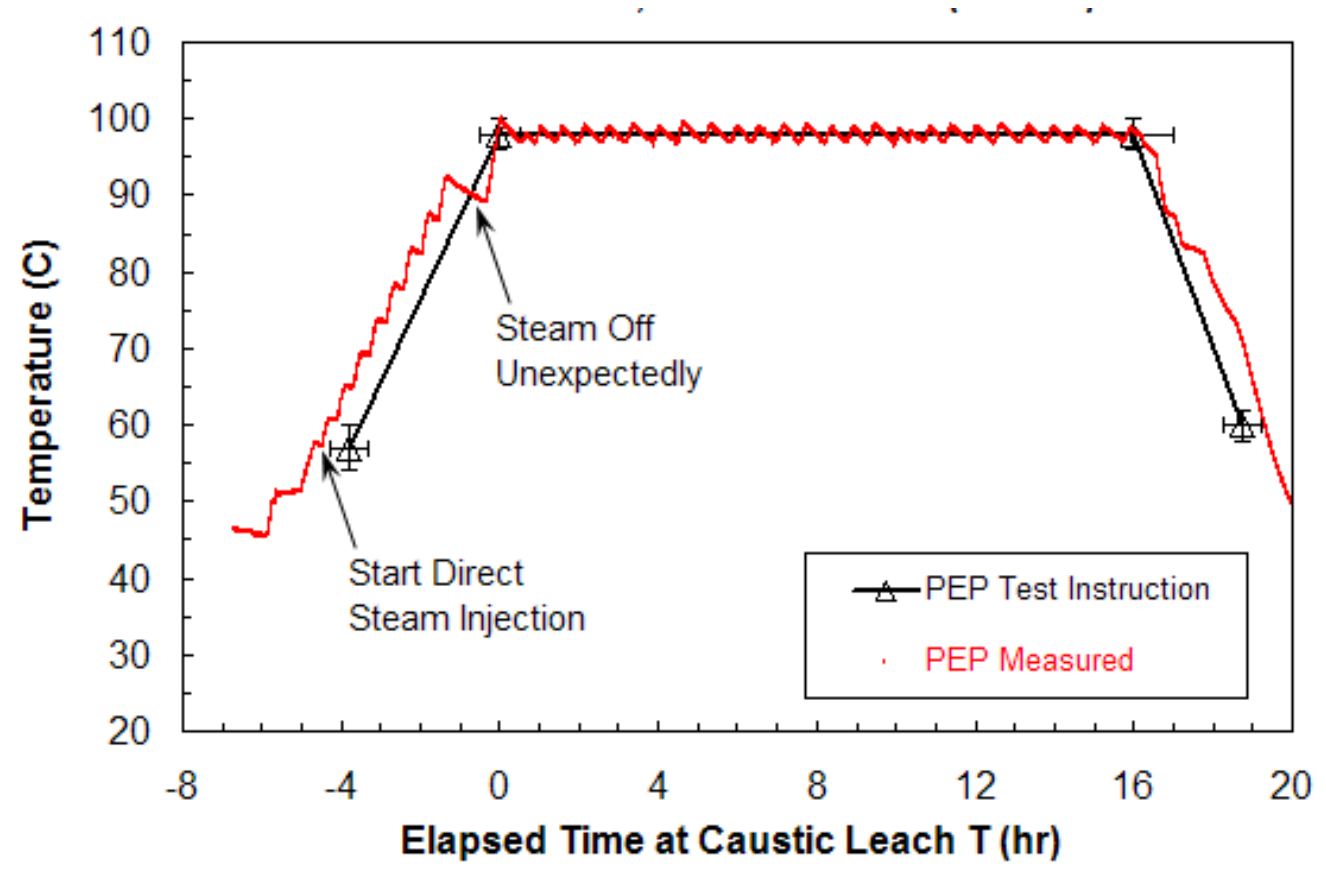

Figure 3.6. Temperature Measured at the "Prototypic" Sensor in PEP Vessel UFP-T01A During TI-065 Integrated Test A, Batch \#1 


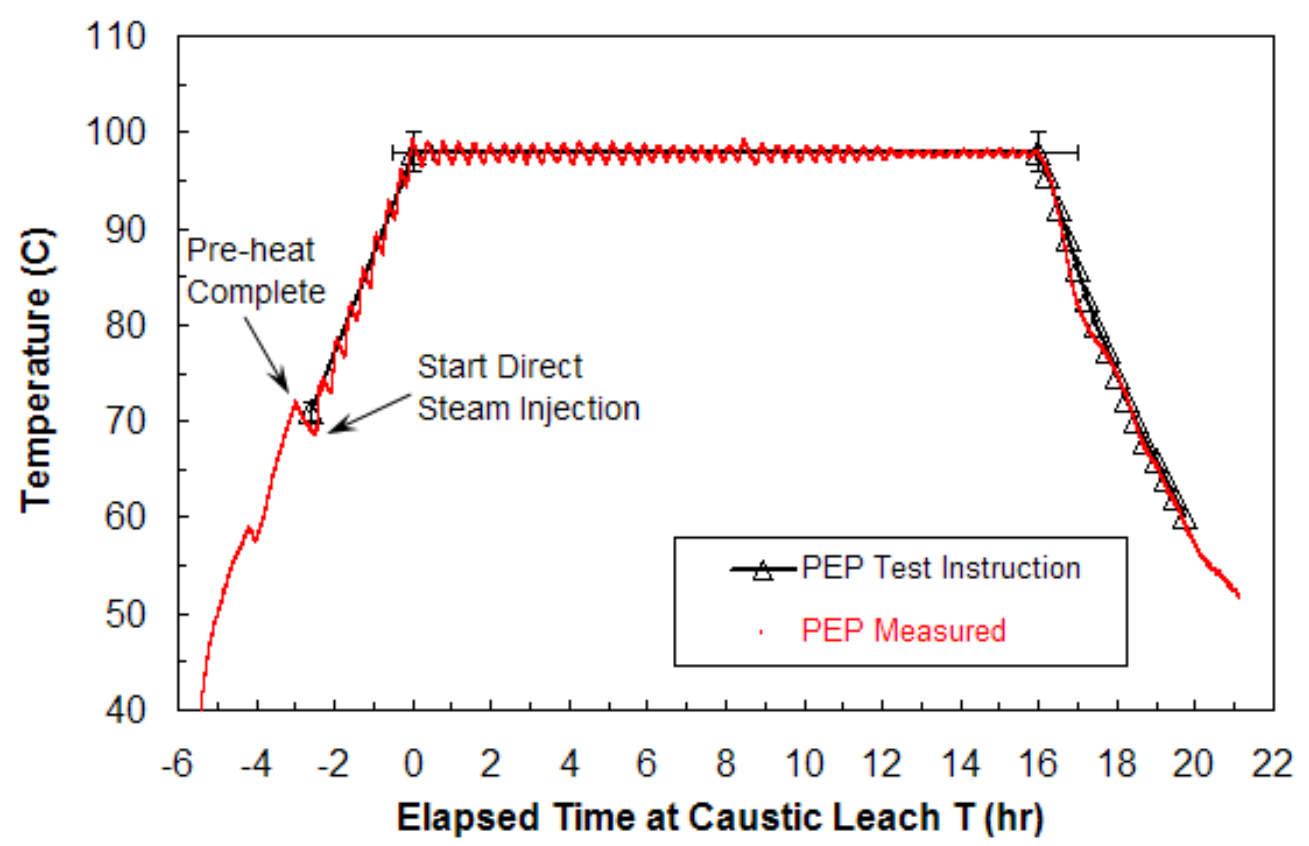

Figure 3.7. Temperature Measured at the "Prototypic" Sensor in PEP Vessel UFP-T02A During TI-066 Integrated Test B, Batch \#2

Text and arrows in Figure 3.6 highlight a few key temperature-control events in the UFP-T01A Integrated Test $\mathrm{A}$, batch 1 caustic-leach process. As noted in Table 3.1, the target pre-heat temperature was $57^{\circ} \mathrm{C}-1 /+3^{\circ} \mathrm{C}$, and the expected duration of the final heat-up to the target leach temperature $\left(98^{\circ} \mathrm{C}\right)$ was $3.8 \pm 0.5 \mathrm{hr}$. Figure 3.6 shows that the direct steam injection started at the target temperature $\left(57.3^{\circ} \mathrm{C}\right)$ at $-4.4 \mathrm{hr}$. Thus, the final heating duration was slightly longer than the target range (4.3-hr maximum). The delayed heat-up period was due to an undetected switch in steam control from automatic to manual mode between $-1.3 \mathrm{hr}\left(92.3^{\circ} \mathrm{C}\right)$ and $-0.3 \mathrm{hr}\left(89.3^{\circ} \mathrm{C}\right)$. This problem effectively resulted in an additional $0.6 \mathrm{hr}$ of caustic leaching in a temperature range of 89 to $92^{\circ} \mathrm{C}$. Otherwise, the heating-phase profile parallels the TI-065 run sheet temperature trajectory. The average temperature during the 16-hr leach period of Integrated Test A, batch 1 was $97.9^{\circ} \mathrm{C}$ (Table 3.18), and a detailed examination of the prototypic temperature sensor data shows that the temperature was maintained within the target range $98 \pm 2{ }^{\circ} \mathrm{C}$ throughout the leach. Figure 3.6 also shows the measured temperature during the initial cool-down phase after the 16-hr leach compared to the TI-065 run sheet target cooling profile $\left(2.75 \pm 0.5 \mathrm{hr}\right.$ to $60 \pm 2{ }^{\circ} \mathrm{C}$; not included in Table 3.1). As shown in the figure, cooling proceeded essentially on schedule, especially in the initial cool-down to $<85^{\circ} \mathrm{C}$ when the aluminum dissolution reaction is substantially quenched.

Figure 3.7 shows the temperature profile in the UFP-T02A Integrated Test B, batch 2 caustic-leach process. As noted in Table 3.3, the target pre-heat temperature was $71 \pm 1^{\circ} \mathrm{C}$, and the expected duration of the final heat-up to the target leach temperature $\left(98^{\circ} \mathrm{C}\right)$ was $2.6 \pm 0.5 \mathrm{hr}$. Figure 3.7 and Table 3.3 show that the batch was initially pre-heated to $72^{\circ} \mathrm{C}$, but it fell to $69^{\circ} \mathrm{C}$ at the time direct steam injection started (-2.4 hr). Although steam heating started a degree below the target range, the final heating duration was well within the period specified in TI-066. The average temperature during the 16-hr leach period of Integrated Test B, batch 2 was $97.7^{\circ} \mathrm{C}$ (Table 3.18), and a detailed examination of the prototypic temperature sensor data shows that the temperature was maintained within the target range $98 \pm 2{ }^{\circ} \mathrm{C}$ 
throughout the leach. The measured cooling trajectory shown in Figure 3.7 tracks the detailed profile outlined in TI-066 (not included in Table 3.3).

\subsection{Relationship of PEP to Plant Performance}

The PEP was designed to achieve prototypic caustic leaching performance in UFP-T01A/B by employing the following design features ${ }^{(a)}$ :

1. PEP ultrafiltration feed preparation vessels UFP-T01A/B are dimensionally prototypic, with inlet and outlet nozzles and primary internal structures (e.g., PJMs) also sized and located prototypically.

2. Mixing equipment in UFP-T01A/B is prototypic: PJMs and PJM nozzles are dimensionally scaled and located to achieve prototypic mixing.

3. In-line caustic addition inlet is prototypically located on the outlet of HLP-PMP-T21.

PEP design limitations, such as UFP-T01A/B internal support structures that were not prototypic, are assumed here to be of minor importance to prototypic performance.

Operation of the PEP to achieve prototypic caustic leaching is based on guidelines given in Technical Basis for Scaling Relationships for the Pretreatment Engineering Platform (Kuhn et al. 2008), the process description, ${ }^{(b)}$ and specific directions given in the Test Plan Pretreatment Engineering Platform (PEP) Testing (Phase I). ${ }^{(\mathrm{c})}$ Key elements are:

1. Caustic addition location and the ratio of (in-line caustic addition rate)/(slurry feed rate) should match that of the PTF. Caustic should be added to the slurry transfer line leading to UFP-T01A, after PMP-T21 to achieve similar blending to the PTF.

2. Prototypic mixing for blending of components and off-bottom suspension of particles for the Newtonian slurry during the leach is best achieved by adjusting PJM parameters to match the power/volume ratio of the PTF.

3. Prototypic air sparge mixing from the steam ring air purge should also match the power/volume ratio of the PTF. Because air sparge mixing scales differently at different heights within a vessel, and because its most important impact is to mix the upper regions of the leaching vessel, the steam ring air sparge flow rate was chosen to match the superficial gas velocity of the PTF at about 48 in., or about $73 \%$ of the normal batch depth in UFP-T01A. Regions below this will receive somewhat more mixing than in the PTF, while regions above this will receive somewhat less mixing than the PTF; however, the integrated power/volume ratio in the purge air-mixed regions of the PEP and PTF vessels should be comparable (Kuhn et al. 2008).

4. Heat-up method (i.e., direct steam injection), rate, duration, and final temperature should match those of the PTF.

5. Dilution of reactants by steam condensate accumulation should match that of the PTF.

(a) B Stiver. 2007. Functional Requirements for Pretreatment Engineering Platform (PEP). 24590-PTF-3YD-UFP-00002, Rev. 1, Bechtel National Incorporated, Richland, Washington.

(b) S Lehrman. 2008. Pretreatment Engineering Platform (PEP) Phase I Testing Process Description. 24590-WTP-RPT-PET-07-002, Rev. 1, Bechtel National Incorporated, Richland, Washington.

(c) GB Josephson, OP Bredt, JK Young, and DE Kurath. 2009. Test Plan for Pretreatment Engineering Platform (PEP) Testing (Phase I). TP-RPP-WTP-506, Rev. 0.4, Pacific Northwest National Laboratory, Richland, Washington. 
6. Slurry, caustic and steam condensate volumes should result in prototypic fluid levels throughout the leaching process. These could impact boehmite leaching because mixing can be a function of fluid depth.

As indicated in Table 3.1 and discussed in Sections 3.1, 3.3 and 3.4, each of these key elements were reasonably satisfied in Integrated Test A batch 1 and it is concluded here that, to the extent that the PEP design and operation allowed, caustic leaching was prototypic of the PTF. The non-prototypic initial heat-up of the slurry using the external heat exchanger is not expected to have a significant effect on boehmite leaching because the boehmite dissolution reaction rate is very low at the initial heat-up temperature.

Design and operational issues for prototypic caustic leaching in UFP-2A are essentially the same as those for leaching in UFP-1A/B with the exception that UFP-2A has dedicated air sparge mixers to augment PJM mixing when the slurry level is high, and the caustic is introduced upstream of PMP-T42A. The air sparge mixer flow rates were chosen, like the steam ring air purge, to match the superficial gas velocity at specific reference elevations and thereby achieve comparable integrated power/volume mixing to the PTF (Kuhn et al. 2008). As indicated in Table 3.2 and discussed in Sections 3.1, 3.3 and 3.4, the key elements for prototypic behavior were reasonably satisfied during Integrated Test B batch 2, and it is concluded here that, to the extent that the PEP design and operation allow, caustic leaching was prototypic of the PTF. 


\subsection{Results}

The purpose of the analysis in this section is to provide a scale-up factor to be used in predictions of the caustic-leach performance of the PTF. These predictions are made by the G2 model, which contains a boehmite leach submodel consisting of a kinetic equation that is based on laboratory-scale tests with actual tank waste samples. The inputs to the G2 model are initial boehmite mass, initial liquid volume and density, initial free hydroxide and aluminate concentrations in the liquid, and the temperature maintained during the constant-temperature part of leaching. The initial concentrations of aluminate and free hydroxide are based on the assumptions that

- all the condensate (whether generated during heat-up or during maintenance of constant digestion temperature) is added at once at the beginning

- all the gibbsite has been dissolved by the time boehmite leach starts and is in the form of aluminate ion at the beginning of the boehmite leach.

The G2 model steps through time, integrating an ordinary differential kinetic equation and using mass balances to account for the consumption of free hydroxide and the generation of aluminate ion as boehmite is leached at constant temperature. The leaching of boehmite during heat-up is treated as being zero. The saturated concentration of aluminate, a variable used in the kinetic equation, is calculated by G2 at the initial free hydroxide concentration. It is not recalculated as hydroxide is consumed. This is the same approach taken in performing the data correlations that provided the form of, and the constants in, the kinetic equation.

The kinetic equation in the G2 boehmite leach submodel is based on laboratory-scale experiments. The PEP test objective pertinent to this report is to determine the impact of scaling up from lab-scale to the engineering-scale process. The scale factor is applied to the boehmite leaching kinetic rate constant, and was obtained by finding the rate constants that provided the best fits of the simulant kinetic model to PEP test data and data from laboratory-scale tests that were run on slurry from the PEP vessels. The scale-up factor is the ratio of the PEP rate constant to the laboratory-scale rate constant, and is to be applied in G2 by using it as a multiplying factor for the boehmite leach rate constant that is used in G2, based on laboratory-scale experiments with tank waste.

The differential equation for kinetically controlled boehmite dissolution in the simulant is

$$
\frac{d}{d t}\left(\frac{n_{b s}}{n_{b s, i}}\right)=-k C_{O H L, i}\left(\frac{n_{b s}}{n_{b s, i}}\right)^{2 / 3}\left(1-\frac{C_{A l L, i}}{C_{A l^{*} L, i}}\right)\left(1-\frac{C_{A l L}}{C_{A l^{*} L, i}}\right) e^{\frac{E_{a}}{R}\left(\frac{1}{373}-\frac{1}{T}\right)}
$$

where $\quad n_{b s}=$ mol of solid-phase boehmite at time $t$

$$
\begin{aligned}
n_{b s, i}= & \text { mol of solid-phase boehmite at time } t=t_{i} \text { (start of constant-temperature } \\
& \text { leaching, after heat-up is complete and assumed to be before any boehmite has } \\
& \text { been leached) } \\
k= & \text { rate constant }\left(\mathrm{hr}^{-1} *[\text { mol total hydroxide } / \mathrm{L}]^{-1}\right) \\
C_{O H L, i}= & \text { mol/L of total hydroxide (free hydroxide plus } 1 \text { mol of hydroxide per mole of } \\
& \text { aluminate) in the liquid phase at time } t=t_{i}
\end{aligned}
$$




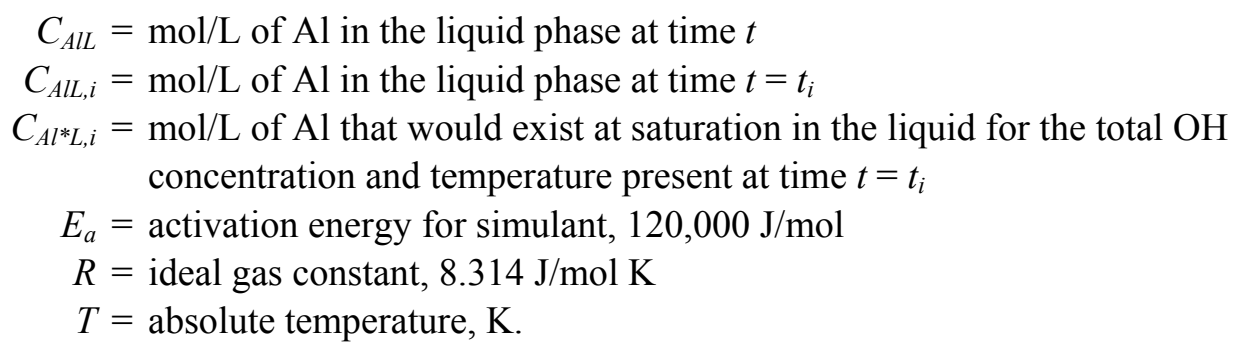

The equation is consistent with a shrinking-core model of boehmite dissolution (which gives a 2/3 power on the boehmite moles) and with a dissolution mechanism that matches the stoichiometry of reaction, giving a linear dependence of rate on total hydroxide concentration. The saturated concentration of aluminum in the liquid is a function of total hydroxide, as well as of temperature. More detail is given in Section A.4. The range of temperature and concentration data for which the kinetic equation and saturated aluminum correlation were developed were a good match to the conditions in PEP and laboratory-scale testing, except that the hydroxide concentration in the UFP-T02A tests was 40-50\% above the upper limit of concentrations used in the tests on which the saturated aluminum correlation was based. The accuracy of the correlation in this extrapolated range, and the impact of extrapolation on the kinetic model, cannot be tested because no boehmite solubility data are available at higher hydroxide concentrations. However, the correlation does behave stably in the extrapolated region, with no sudden peaks or drops, and appears to provide a plausible continuation of the known behavior. The high-hydroxide concentration was unavoidable. It was chosen to provide a reaction rate that would reach the target boehmite leach factor in the allotted run time as well as maintain leached aluminum in solution.

The kinetic equation was derived on the assumption of constant liquid volume throughout the process. The G2 model makes the same assumption of constant volume; it uses the liquid volume that is calculated at the point of maximum slurry dilution - the end of the leaching process, when all condensate has been added. This is the presently accepted treatment of the boehmite reaction in PTF modeling. In actuality, the liquid volume in the PTF will be less than the maximum-dilution volume at the beginning of the leach reaction and will increase during leaching. It will equal the maximum-dilution volume only at the end of reaction.

The first step in kinetic analysis of the data from the present series of PEP and laboratory-scale tests is the normalization of all liquid concentrations to a constant volume. The volume at maximum dilution is used in order to match the assumptions in the G2 model. The parallel laboratory-scale experiments were designed to begin with a dilution that matched that in the corresponding PEP test, according to the preliminary information available at the time of the laboratory experiment. Therefore the PEP test liquid concentrations were normalized to the volume at the end of the test. The laboratory-scale test concentrations were normalized to the volume at the beginning of the test, before any evaporation had occurred. Ratios of the concentrations of liquid tracers - species present only in the liquid phase-were used to carry out normalization, since the concentrations of liquid tracers are inversely proportional to the amount of liquid present.

As for the PTF, PEP liquid volume increased during the constant-temperature digestion. The increase was 10 to $15 \%$ (Table 3.20 and Table 3.21 ). In the laboratory-scale tests the liquid volume was greatest at the beginning of the test, when water had been added to represent condensate. From then on it decreased as a result of evaporation. The decrease was $10-20 \%$ in the laboratory-scale tests for UFP-T01A leaching and about $5 \%$ in those for UFP-T02A leaching. Because the G2 model employs a constant-volume 
(maximum-volume) assumption to model boehmite leaching in the PTF, it was necessary to employ the same assumption in kinetic data analysis to provide scale-up factors that are consistent with the G2 model approach. The constant-volume assumption is also consistent with data analysis in past laboratory-scale experiments.

Equation (4.1) was integrated over time to predict the boehmite leach factor, starting from measurement-based initial conditions. The initial condition for boehmite leaching was considered to be at $0 \mathrm{hr}, 98^{\circ} \mathrm{C}$. All gibbsite was assumed to be dissolved at this point (consistent with observations made by Russell et al. [2009c]). All aluminum remaining in the solid phase was assumed to be in the form of boehmite. The dissolved aluminum concentration was calculated from the boehmite at each modeled time step, based on mass balances, and compared to the normalized measured dissolved aluminum concentrations. The rate constant $k$ was treated as an adjustable parameter in the equation and solved for by numerically determining the best fit between predicted and measured (normalized) concentrations of dissolved aluminum. Finally, the ratio of PEP rate constant to laboratory-scale rate constant was calculated to provide the scale-up factor.

To provide a cross-check of the kinetic model predictions, total aluminum leach factors were calculated directly from aluminum and tracer concentration data, using both liquid and solid tracers to account for changes in the total slurry mass. These aluminum leach factors were then used to calculate boehmite leach factors, independent of the kinetic model. The equation for the total aluminum leach factor, based on a solid-phase tracer (a species present only in solid phase), is

$$
f_{A l s, P}=1-\left(\frac{c_{q, 0}}{c_{q, P}}\right) \frac{c_{A l, P}-\left(1-\omega_{s, P}\right) c_{A l L, P}}{c_{A l, 0}-\left(1-\omega_{s, 0}\right) c_{A l L, 0}}
$$

The equation for the total aluminum leach factor, based on a liquid-phase tracer, is

$$
f_{A I L, P}=\frac{\left(1-\omega_{s, 0}\right)\left(\frac{c_{k L, 0}}{c_{k L, P}} c_{A l L, P}-c_{A I L, 0}\right)}{c_{A l, 0}-\left(1-\omega_{s, 0}\right) c_{A I L, 0}}
$$

where $f_{A l s, P}=$ cumulative Al leach factor since the initial reference time, based on a solid tracer $f_{A L L, P}=$ cumulative Al leach factor since the initial reference time, based on a liquid tracer

$c_{q, 0}=$ concentration of solid tracer $q$ in the slurry at the initial reference time, $\mathrm{g} q / \mathrm{g}$ slurry

$c_{q, P}=$ concentration of solid tracer $q$ in the slurry at the time of sample $P, \mathrm{~g} q / \mathrm{g}$ slurry

$c_{k L, 0}=$ concentration of liquid tracer $k$ in the liquid phase at the initial reference time, $\mathrm{g} \mathrm{k} / \mathrm{g}$ liquid

$c_{k L, P}=$ concentration of liquid tracer $k$ in the liquid phase at the time of sample $P, \mathrm{~g} k / \mathrm{g}$ liquid

$c_{A l, 0}=$ concentration of $\mathrm{Al}$ in the slurry at the initial reference time, $\mathrm{g} \mathrm{Al} / \mathrm{g}$ slurry

$c_{A l, P}=$ concentration of $\mathrm{Al}$ in the slurry at the time of sample $P, \mathrm{~g} \mathrm{Al} / \mathrm{g}$ slurry

$c_{A I L, 0}=$ concentration of $\mathrm{Al}$ in the liquid phase at the initial reference time, $\mathrm{g} \mathrm{Al} / \mathrm{g}$ liquid

$c_{A l L, P}=$ concentration of $\mathrm{Al}$ in the liquid phase at the time of sample $P, \mathrm{~g} \mathrm{Al} / \mathrm{g}$ liquid 


$$
\begin{aligned}
\omega_{s, 0}= & \text { weight fraction UDS in the slurry at the initial reference time, } \mathrm{g} \text { undissolved solid } / \mathrm{g} \\
& \text { slurry } \\
\omega_{s, P}= & \text { weight fraction UDS in the slurry at the time of sample } P, \mathrm{~g} \text { undissolved solid/g slurry }
\end{aligned}
$$

The relationship between the boehmite leach factor, $f_{b}$, and the total aluminum leach factor, $f_{A l}$, at any point in time is

$$
f_{b}=\frac{f_{A l}-\phi_{A \mathrm{lg}, 0}}{1-\phi_{A \mathrm{lg}, 0}} \quad \text { for } f_{A l}>\phi_{A \mathrm{lg}, 0}
$$

where $\phi_{A l g, 0}$ is the fraction of the solid-phase $\mathrm{Al}$ that is present in gibbsite at the initial reference time. (Recall that the fraction of the solid-phase $\mathrm{Al}$ that is present in boehmite is equal to one minus the fraction in gibbsite, since solid-phase Al is present only as gibbsite or boehmite.) The boehmite leach fraction is less than zero so long as only gibbsite is being leached.

The uncertainty of the scale-up factor, and of the intermediate results of calculations leading up to it, was of crucial interest. The complexity of the data analysis made it impossible to carry through uncertainty calculations without using a stochastic computational approach. In the selected computational method, a Monte Carlo method, the full set of equations in the data analysis is solved a large number of times. Each solution is termed a "realization." In each realization every measurement value that is used has a different perturbation, representing measurement error, added to its measured value. Each perturbation is randomly chosen from a normal distribution that has a median of zero (in other words, an unbiased error) and a standard deviation equal to the known standard deviation of the measurement. The results that are calculated when all perturbations are zero (i.e., when the inputs are exactly as measured) are referred to as the "deterministic" values. More detail about the calculation of stochastic inputs is given in Appendix C.

The result of Monte Carlo calculations is a population distribution for every calculated value. In some cases the population distribution of a calculated value is symmetrical and normal and can be described by a median and standard deviation. In others, the distribution is less simple and must be described by confidence intervals around the median. A 95\% confidence interval implies that only the lowest $2.5 \%$ and the highest $2.5 \%$ of the distribution are excluded, and that there is a $95 \%$ probability that the true value lies between the upper and lower limits of the interval. In a normal distribution, a $95 \%$ confidence interval is equivalent to almost exactly two standard deviations.

Section 4.1 discusses results for the PEP tests: the evidence that liquid and solid tracers could be found that adequately represented the volume changes caused by condensate accumulation, the calculation of aluminum leach factors, and the results of kinetic modeling. Section 4.2 presents the same information for the laboratory-scale tests. The scale-up factors are presented and discussed in Section 4.3.

\subsection{PEP Modeling and Results}

As can be seen in Equations (4.1) through (4.3), the kinetic model analysis and the supporting Al leach factor analysis depend heavily on the use of tracers: liquid-phase tracers, which are species present predominantly in the liquid phase, and solid-phase tracers, species present only in the solid phase. These serve to account for changes in the total liquid mass, or total slurry mass, that occur during the test. In the 
case of the PEP tests, these changes are the result of condensate accumulation, which is discussed in Section 3.4.1.

The derivation of equations for tracer-based leach factors that is provided in Appendix A shows that the tracer-based leach factor equations, (4.2) and (4.3), depend on the following assumptions:

- All material removed from the vessel during the test (e.g., samples) contains representative proportions of solids and liquid and has a representative composition.

- The removal of material does not affect the vessel inventory or sampling representativeness in other ways, e.g., by changing the mixing energy/volume in the beaker or causing significant amounts of inventory to be left behind in a "scum" ring on the vessel wall above the slurry surface.

- The solid tracer species has a negligible concentration in the liquid phase. Examples are $\mathrm{Sr}, \mathrm{Fe}$, and $\mathrm{Nd}$, all effectively insoluble under process conditions.

- The liquid tracer species is present in the liquid. It may be present in the solid phase as well, so long as it does not move between phases (so that its liquid-phase inventory is not affected by precipitation or dissolution). The tracers used in these tests were nitrate and chloride, which are both present only in the liquid phase. Less soluble species such as sulfate, phosphate, carbonate, and oxalate were not considered suitable because of the possibility they would precipitate as sodium salts when $\mathrm{Na}$ concentration was increased and redissolve as condensate was added.

As shown in Sections A.2 and A.3, if these assumptions are not accurate, the removal of sample mass from the system can lead to distorted values for the leach factors. So long as the assumptions are true, the amount of sample mass removed can be a significant fraction of the total mass without affecting the leach factors. Since the kinetic model depends on liquid tracers to normalize liquid-phase concentrations, the first and last assumptions must be true if the evaluation of kinetic rate constants is to avoid being distorted by sample removal.

Because of the central importance of tracers, the first step in data analysis is to test which tracers best follow the trend of mass/volume changes. This test is performed by comparing the dilution factors for a number of species of interest. The dilution factor is defined as the ratio of the species mass concentration at any point in the process to its concentration at a reference condition. As condensate is added to PEP, the total system mass (and liquid mass) increases and the concentrations of tracer species decrease in inverse proportion.

Figure 4.1 shows the PEP Integrated Test A (UFP-T01A caustic-leach, batch 1) bulk concentration dilution factors for total $\mathrm{Al}$ in the slurry, total $\mathrm{Sr}$, total $\mathrm{Nd}$, total $\mathrm{Fe}$, and bulk concentrations of liquid-phase nitrate $\left(\mathrm{NO}_{3}{ }^{-}\right)$and chloride $\left(\mathrm{Cl}^{-}\right)$. All the dilution factors are referenced back to the concentration present before $\mathrm{NaOH}$ reagent was added to the UFP-T01A vessel; for Integrated Test A, the reference point is the feed simulant. Aluminum is included because it is the species of concern; its total slurry concentration should vary only with dilution from condensate, not with leaching. The species $\mathrm{Sr}$, $\mathrm{Nd}$, and $\mathrm{Fe}$ are potential solid tracers. The species $\mathrm{NO}_{3}{ }^{-}$and $\mathrm{Cl}^{-}$are potential liquid tracers; their liquid-phase concentrations (in mass per mass units) are put on a bulk-slurry-concentration basis by multiplying them by ( 1 - weight fraction UDS).

The error bars shown are for the total Al dilution factors. They represent two standard deviations, or the lower and upper bounds on a 95\% confidence interval. The error bars for the dilution factors of the 
other species would be similar in size. The standard deviations of the dilution factors were calculated from the standard deviations of measured concentrations by using simplified error propagation rules. ${ }^{\text {(a) }}$ The standard deviations of the measurements came from laboratory estimates of the expected laboratory error.

Some scatter can be seen between the various tracers, so some differences between liquid tracer and solid tracer leach factors are to be expected. Another set of data that show the performance of liquid tracers was given in Table 3.20, which showed that $\mathrm{NO}_{3}{ }^{-}$and $\mathrm{Cl}^{-}$compared well with other methods of estimating liquid dilution during leach, but that the trend in $\mathrm{Cl}^{-}$data was noisier. The species that most closely follow the trend of $\mathrm{Al}$ are generally $\mathrm{Sr}$, among solid tracers, and $\mathrm{NO}_{3}^{-}$, among liquid tracers. These species were selected for use in data analysis. Species that matched the trend of Al were used as a way of reducing any distortion of the leach factor that might result from variations in analytical method response that occurred either because of changing composition or because not all samples were analyzed in the same analytical batch and on the same date.

Figure 4.2 provides the same type of information for PEP Integrated Test B, batch 2 (caustic-leach in UFP-T02A). The scatter between liquid tracer and solid tracer trends is wider than for Integrated Test A. Table 3.21 can also be used to gauge tracer performance. Because the dilution analysis used the "after- $\mathrm{NaOH}$ " slurry concentration as a reference rather than the "before- $\mathrm{NaOH"} \mathrm{concentration,} \mathrm{the} \mathrm{offset}$ between $\mathrm{NO}_{3}{ }^{-}$and $\mathrm{Cl}^{-}$dilution trends that is seen in Figure 4.2 does not appear in Table 3.21. In the case of PEP Integrated Test B, the tracer species that were selected, as most closely following the trend in total $\mathrm{Al}$, were $\mathrm{Sr}$ for solid tracers and $\mathrm{Cl}^{-}$for liquid tracers. The solid tracers do not track Al variation as well in Integrated Test B as in Integrated Test A, though Sr is still the closest. The concentrations of the chosen solid and liquid tracers for both PEP tests are tabulated in Appendix B.

Equations (4.2) and (4.3) were used to calculate the Al leach factors, by liquid tracer and solid tracer methods, for PEP Integrated Test A and Integrated Test B. The Al leach factors are given in Table 4.1. The plus or minus values are one standard deviation, calculated by a Monte Carlo method from estimates of laboratory error in the concentrations used in the calculations. The Monte Carlo method used 5000 realizations to predict the upper and lower bounds of the $95 \%$ confidence interval around the median value. While the upper and lower bounds were not precisely the same distance from the median, they were close enough to make it reasonable to use half the difference between bound and median to represent the standard deviation from the median leach factor. For each test, there is good agreement between the two tracer methods. This agreement indicates the PEP test data are internally consistent.

The aluminum leach factors consistently equal 0.43 at the point when the digestion temperature of $98^{\circ} \mathrm{C}$ has been reached $\left(0 \mathrm{hr}\right.$ at $\left.98^{\circ} \mathrm{C}\right)$. This leach factor is consistent with the expectation that all of the gibbsite, which was $43.5 \%$ of the initial solid-phase $\mathrm{Al}$, is dissolved by the time constant-temperature digestion begins. This observation also suggests that no measurable boehmite dissolved before $98^{\circ} \mathrm{C}$.

(a) The relative standard deviation of the product or ratio of several random variables with normal error distributions equals the square root of the sum of the squares of the relative standard deviations of the individual variables. 
PEP Test A -- Concentration Change from Initial in Bulk Slurry

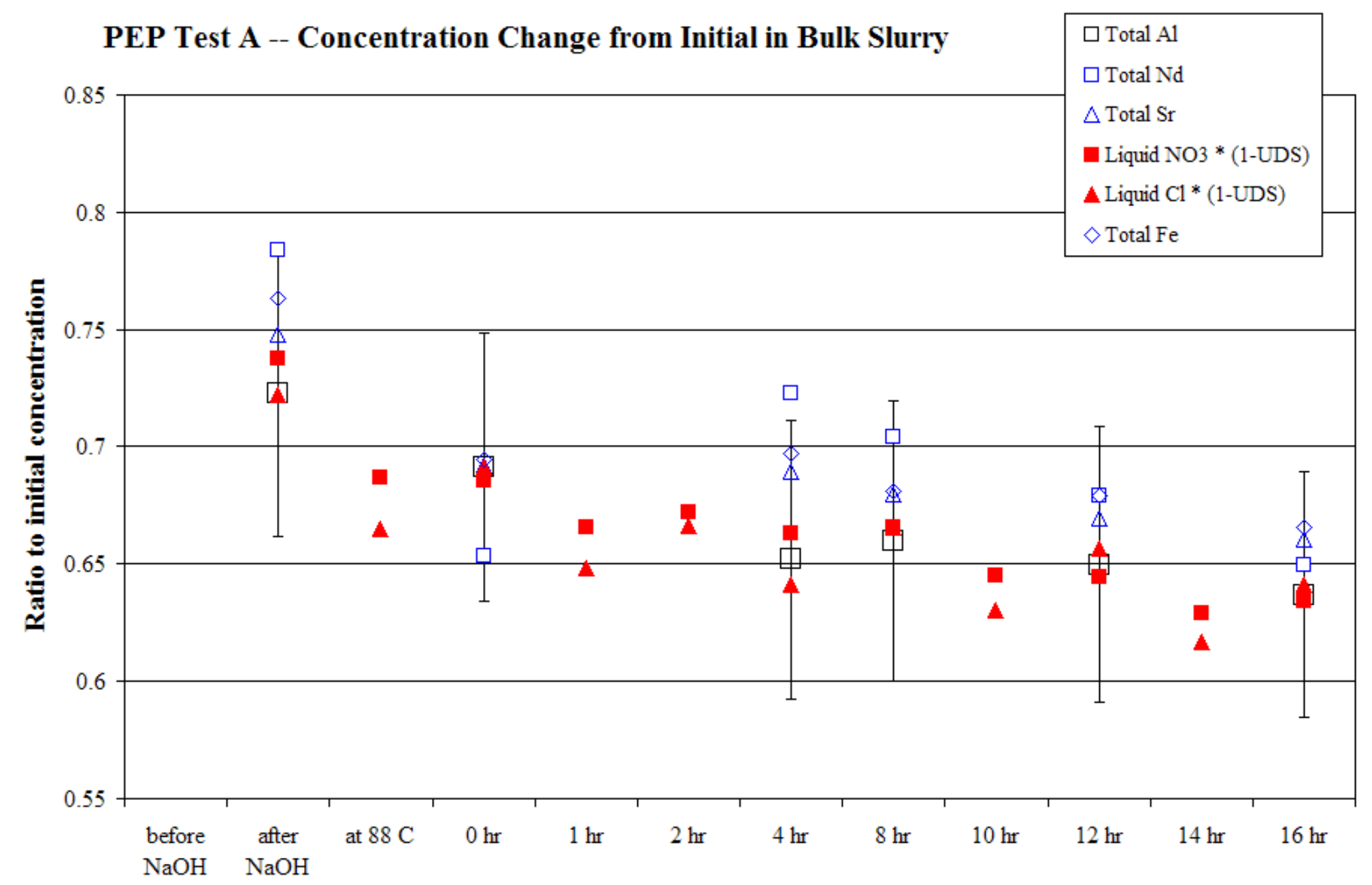

Figure 4.1. Dilution Factors with 95\% Confidence Intervals During PEP Integrated Test A (caustic leaching in UFP-T01A) 
PEP Test B -- Concentration Change from Initial in Bulk Slurry

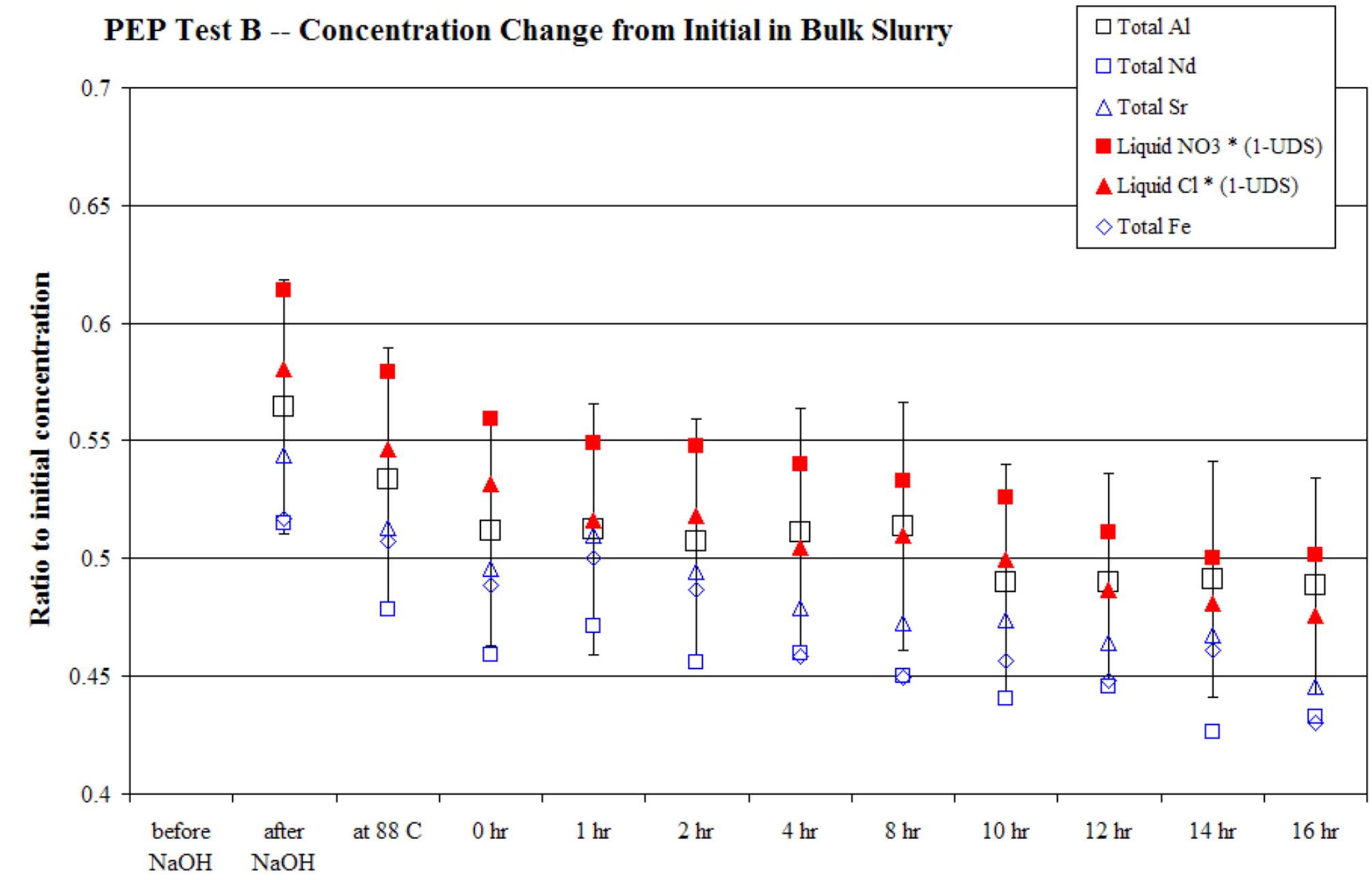

Figure 4.2. Dilution Factors with 95\% Confidence Intervals During PEP Integrated Test B (caustic leaching in UFP-T02A) 
Table 4.1. Aluminum and Boehmite Leach Factors for PEP Integrated Tests

\begin{tabular}{|c|c|c|c|c|c|c|}
\hline \multirow[b]{2}{*}{$\begin{array}{l}\text { Nominal Point in } \\
\text { Process }\end{array}$} & \multicolumn{3}{|c|}{$\begin{array}{l}\text { PEP Integrated Test A (caustic-leach in } \\
\text { UFP-T01A) }\end{array}$} & \multicolumn{3}{|c|}{$\begin{array}{l}\text { PEP Integrated Test B (caustic-leach in } \\
\text { UFP-T02A) }\end{array}$} \\
\hline & $\begin{array}{c}\text { Al Leach } \\
\text { Factor Based } \\
\text { on Solid } \\
\text { Tracer }\end{array}$ & $\begin{array}{c}\text { Al Leach } \\
\text { Factor Based } \\
\text { on Liquid } \\
\text { Tracer }\end{array}$ & $\begin{array}{l}\text { Boehmite } \\
\text { Leach Factor } \\
\text { Based on } \\
\text { Liquid Tracer }\end{array}$ & $\begin{array}{c}\text { Al Leach } \\
\text { Factor Based } \\
\text { on Solid } \\
\text { Tracer }\end{array}$ & $\begin{array}{c}\text { Al Leach } \\
\text { Factor Based } \\
\text { on Liquid } \\
\text { Tracer }\end{array}$ & $\begin{array}{c}\text { Boehmite Leach } \\
\text { Factor Based on } \\
\text { Liquid Tracer }\end{array}$ \\
\hline After adding $\mathrm{NaOH}$ & $\mathrm{n} / \mathrm{a}$ & $0.20 \pm 0.01$ & 0 & $0.37 \pm 0.025$ & $0.38 \pm 0.02$ & 0 \\
\hline At $88^{\circ} \mathrm{C}$ & $\mathrm{n} / \mathrm{a}$ & $0.41 \pm 0.03$ & $0 \pm 0.018$ & $0.41 \pm 0.035$ & $0.42 \pm 0.02$ & $0 \pm 0.018$ \\
\hline $0 \mathrm{hr}$ at $98^{\circ} \mathrm{C}$ & $0.43 \pm 0.03$ & $0.43 \pm 0.02$ & $0 \pm 0.023$ & $0.43 \pm 0.02$ & $0.43 \pm 0.02$ & $0 \pm 0.017$ \\
\hline $1 \mathrm{hr}$ at $98^{\circ} \mathrm{C}$ & $\mathrm{n} / \mathrm{a}$ & $0.43 \pm 0.03$ & $0 \pm 0.029$ & $0.45 \pm 0.03$ & $0.45 \pm 0.03$ & $0.024 \pm 0.036$ \\
\hline $2 \mathrm{hr}$ at $98^{\circ} \mathrm{C}$ & $\mathrm{n} / \mathrm{a}$ & $0.46 \pm 0.03$ & $0.045 \pm 0.046$ & $0.46 \pm 0.03$ & $0.46 \pm 0.03$ & $0.045 \pm 0.040$ \\
\hline $4 \mathrm{hr}$ at $98^{\circ} \mathrm{C}$ & $0.50 \pm 0.03$ & $0.46 \pm 0.03$ & $0.042 \pm 0.045$ & $0.46 \pm 0.03$ & $0.50 \pm 0.03$ & $0.11 \pm 0.05$ \\
\hline $8 \mathrm{hr}$ at $98^{\circ} \mathrm{C}$ & $0.54 \pm 0.03$ & $0.52 \pm 0.03$ & $0.16 \pm 0.06$ & $0.49 \pm 0.03$ & $0.53 \pm 0.03$ & $0.17 \pm 0.05$ \\
\hline $10 \mathrm{hr}$ at $98^{\circ} \mathrm{C}$ & $\mathrm{n} / \mathrm{a}$ & $0.54 \pm 0.04$ & $0.19 \pm 0.06$ & $0.56 \pm 0.03$ & $0.56 \pm 0.03$ & $0.22 \pm 0.06$ \\
\hline $12 \mathrm{hr}$ at $98^{\circ} \mathrm{C}$ & $0.58 \pm 0.03$ & $0.58 \pm 0.04$ & $0.25 \pm 0.07$ & $0.54 \pm 0.02$ & $0.56 \pm 0.02$ & $0.23 \pm 0.04$ \\
\hline $14 \mathrm{hr}$ at $98^{\circ} \mathrm{C}$ & $\mathrm{n} / \mathrm{a}$ & $0.58 \pm 0.04$ & $0.25 \pm 0.07$ & $0.57 \pm 0.03$ & $0.61 \pm 0.03$ & $0.31 \pm 0.06$ \\
\hline $16 \mathrm{hr}$ at $98^{\circ} \mathrm{C}$ & $0.63 \pm 0.02$ & $0.62 \pm 0.03$ & $0.32 \pm 0.05$ & $0.57 \pm 0.02$ & $0.62 \pm 0.03$ & $0.33 \pm 0.04$ \\
\hline
\end{tabular}


Equation (4.4) was used to calculate the boehmite leach factors based on the liquid tracer method, the method for which tracer concentration data were more available and better tracked the Al trend. These are also given in Table 4.1. In cases where the aluminum leach factor was less than 0.435 , the fraction of $\mathrm{Al}$ in gibbsite in the feed, the boehmite leach factor was set to zero. The WTP target projections ${ }^{(a)}$ for the boehmite leach factors for Integrated Test A (UFP-T01A leach) and Integrated Test B (UFP-T02A leach) were, respectively, 0.28 and 0.38. These were estimated by WTP using Equation (4.1), a rate constant of $0.015 \mathrm{hr}^{-1} *(\mathrm{~mol} \text { total } \mathrm{OH} / \mathrm{L})^{-1}$ that had been determined from preliminary lab tests, and run sheet values for simulant, condensate, and reagent volumes present. PEP Integrated Test A achieved a higher leach factor than the target while the PEP Integrated Test B was lower than the target. In each test, the variation from the target leach factor is approximately one standard deviation of the leach factor estimates.

\subsubsection{Initial Conditions for Kinetic Modeling of PEP Tests}

The integration of the kinetic model ODE depended on the initial concentrations, those present at the beginning of the constant temperature digestion (" $0 \mathrm{hr}$ at $98^{\circ} \mathrm{C}$ ")." The required initial conditions for the boehmite dissolution kinetic equation (Equation [4.1]) were 1) initial boehmite concentration ${ }^{(b)}$ in moles boehmite per volume liquid, and 2) initial total hydroxide ${ }^{(\mathrm{c})}$ and dissolved Al molarities in the liquid. Liquid tracer concentrations and liquid densities were also needed to normalize the boehmite, total hydroxide, and dissolved Al concentrations to the liquid volume at the maximum-dilution point in the test. The maximum-dilution point was the end of the test. Some points that are related to normalization and to the solution of the kinetic differential equation are discussed in Section A.5 of Appendix A.

The initial boehmite concentration could not be measured directly from samples since there is no analytical method that can quantitatively distinguish between gibbsite and boehmite. The first step in calculating the boehmite concentration is to determine the mass concentration of solid-phase Al in the slurry by subtracting the liquid-phase contribution. This concentration can then be put on a basis of liquid volume instead of slurry mass by using the weight fraction of liquid in the slurry and the liquid density. This is multiplied by the fraction of solid-phase Al that is in boehmite to obtain the mass of boehmite per liquid volume, and converted to moles boehmite per liquid volume. The equation is

$$
C_{A l b, L}=\frac{\omega_{b A l} \rho_{L}}{M_{A l}\left(1-\omega_{s}\right)}\left[c_{A l}+\left(1-\omega_{s}\right) c_{A l, L}\right]
$$

where $C_{A l b, L}=$ moles of boehmite per volume of liquid in the slurry

$\omega_{A l b, L}=$ fraction of the solid-phase Al that is in boehmite

$\rho_{L}=$ liquid density

$M_{A l}=$ molecular weight of $\mathrm{Al}$

$\omega_{s}=$ weight fraction of undissolved solid in the slurry, mass solid-phase/mass slurry

(a) The projections of boehmite leach factor were made by WTP and transmitted to D.E. Kurath and L.A. Mahoney by e-mail from J.L. Huckaby on June 15, 2009 (6:25 AM).

(b) The terminology "boehmite concentration" is used for convenience. It is not actually a concentration, but a ratio of moles of solid-phase Al to volume of liquid - in effect, it is the concentration increase in dissolved Al that would be generated if all the boehmite dissolved.

(c) The total hydroxide concentration, in molarity units, is the sum of the free hydroxide and one mole of hydroxide per mole of the aluminate ion complex, $\mathrm{Al}(\mathrm{OH})_{4}{ }^{-}$. See Equation (A.65). 


$$
\begin{aligned}
c_{A l} & =\text { mass concentration of } \mathrm{Al} \text { (solid and dissolved) in the slurry, mass } \mathrm{A} 1 / \text { mass slurry } \\
c_{A l, L} & =\text { mass concentration of dissolved } \mathrm{Al} \text { in the liquid, mass } \mathrm{A} 1 / \text { mass liquid }
\end{aligned}
$$

In the PEP tests, two data sets were available to calculate the initial boehmite concentration $\left(C_{A l b, L}\right)$.

- The data taken before $\mathrm{NaOH}$ addition (for feed, in Integrated Test $\mathrm{A}$, and for solids-concentrated feed, in Integrated Test B) could be used with the assumption that the fraction of solid Al present in boehmite was the same as in the feed, or 0.565 (Table 3.7).

- The other data set was that taken when $98^{\circ} \mathrm{C}$ was first reached ("0 hr at $98^{\circ} \mathrm{C}$ "); in this case, it was assumed that all gibbsite was dissolved, so the fraction of the solid Al that was in boehmite was unity.

The boehmite concentration in the 0 -hr sample was used as the initial boehmite concentration $\left(C_{A l b, L}\right)$, since the before- $\mathrm{NaOH}$ and $0-\mathrm{hr}$ data sets gave results within $7 \%$ of each other and since the $0-\mathrm{hr}$ concentration was the one actually measured at the start of boehmite leaching. The 0 -hr concentration of boehmite was then normalized by using liquid tracer concentrations, per Equation (A.64). The end result was the moles of boehmite per liquid volume at the maximum-dilution condition.

The initial total hydroxide molar concentration $\left(C_{O H L, i}\right)$ was calculated as the average of all the normalized total hydroxide concentrations during the digestion period ( $0 \mathrm{hr}$ through $16 \mathrm{hr})$. The averaging was intended to smooth out noise in the measurements; it was based on the fact that so long as hydroxide reacts only with $\mathrm{Al}$, the total hydroxide (which is the sum of aluminate and free hydroxide molarities) should be constant during the test. The total hydroxide molar concentration at each time was calculated using Equation (A.65) and then normalized to the maximum dilution condition to provide the set of data that were averaged to give the initial condition for the kinetic model. The standard deviation of the sets of normalized total hydroxide concentrations was less than $2 \%$ for the PEP tests. There was no consistent time trend in normalized total hydroxide concentration, indicating no reaction of hydroxide with species other than Al.

The dissolved $\mathrm{Al}$ concentration at $0 \mathrm{hr}$ was converted to molarity and then normalized to the maximum dilution condition to provide the dissolved $\mathrm{Al}$ initial condition $\left(C_{A l L, i}\right)$ for the kinetic model. The subsequent dissolved $\mathrm{Al}$ concentrations $\left(C_{A l L}\right)$ were similarly converted and normalized to provide the data set to which the model predictions are compared.

The complete kinetic equation includes an Arrhenius term to account for temperature, as shown in Equation (4.1). The temperature varies throughout the test and is not an initial condition. The 1-minute temperature data measured at the prototypic temperature sensors in vessels UFP-T01A and UFP-T02A were used as an independent variable in the Monte Carlo calculations of the kinetic model fit. Summaries of the temperature data can be found in Table 3.18 and Table 3.19 .

Table 4.2 lists the values used for the kinetic model initial conditions for the two PEP tests. The values given are the deterministic concentration ${ }^{(a)} \pm$ one standard deviation as calculated by 500 realizations of the Monte Carlo method. The Monte Carlo run used the estimates of laboratory error in measurements as the basis for estimating error in the initial conditions.

(a) The deterministic value is that calculated directly from measurements without any application of the Monte Carlo method. It is generally nearly equal to the median of the population calculated by the Monte Carlo method if a sufficient number of realizations are used. 
Table 4.2. Initial Conditions for Kinetic Modeling of PEP Integrated Tests

\begin{tabular}{lcc}
\hline $\begin{array}{l}\text { Concentrations at } 0 \mathrm{hr}, \\
\text { Normalized to Liquid Volume } \\
\text { at } 16 \mathrm{hr}:\end{array}$ & $\begin{array}{c}\text { PEP Integrated } \\
\text { Test A (caustic-leach } \\
\text { in UFP-T01A) }\end{array}$ & $\begin{array}{c}\text { PEP Integrated } \\
\text { Test B } \\
\text { (caustic-leach in } \\
\text { UFP-T02A) }\end{array}$ \\
\hline $\begin{array}{l}\text { Dissolved Al (M) } \\
\text { Boehmite (mol/L liquid) }\end{array}$ & $0.318 \pm 0.010$ & $0.720 \pm 0.023$ \\
Total hydroxide (M) & $4.29 \pm 0.11$ & $0.795 \pm 0.029$ \\
$\begin{array}{l}\text { Saturated dissolved Al }(\mathrm{M}) \\
\text { from equations in Section A.4 }\end{array}$ & $0.859 \pm 0.028$ & $1.44 \pm 0.05$ \\
\hline $\begin{array}{l}\text { Entries are deterministic estimate } \pm \text { one standard deviation calculated by 500 Monte } \\
\text { Carlo realizations. Estimates of laboratory error in measurements were the basis for } \\
\text { estimating error in the initial conditions. }\end{array}$ & \\
\hline
\end{tabular}

\subsubsection{Results of Kinetic Modeling of PEP Tests}

A total of 500 Monte Carlo realizations were used to calculate a population of values for the rate constant $k$. Each realization solved the kinetic model differential equation, finding a best fit by adjusting two parameters, the kinetic rate constant and the initial normalized dissolved Al concentration. Table 4.3 contains the lower bound of the $95 \%$ confidence interval, the median, and the upper bound of the $k$ population for each of the two PEP tests. The same population statistics are provided for the boehmite leach factor at $16 \mathrm{hr}$, as predicted by the best-fit kinetic model. The deterministic $\mathrm{R}^{2}$ for the model fit is also included in the table.

Recall, from Table 4.1, that the boehmite leach factors calculated from total $\mathrm{Al}$ leach factors were $0.32 \pm 0.049$ for Integrated Test A (UFP-T01A leach) and $0.33 \pm 0.045$ for Integrated Test B (UFP-T02A leach). These values match the boehmite leach factors calculated by the best-fit kinetic model to 0.01 .

For comparison, the WTP target projections ${ }^{(\mathrm{a})}$ for the boehmite leach factors for Integrated Test A and Integrated Test B were, respectively, 0.28 and 0.38. These were calculated using Equation (4.1) with values of $k$ that were derived from preliminary laboratory-scale tests and with run sheet projections for the initial concentrations of dissolved $\mathrm{Al}$, boehmite, and total hydroxide.

Table 4.3. Kinetic Model Results for PEP Integrated Tests

\begin{tabular}{|c|c|c|}
\hline & $\begin{array}{c}\text { PEP Integrated Test A } \\
\text { (caustic-leach in UFP-T01A) }\end{array}$ & $\begin{array}{c}\text { PEP Integrated Test B } \\
\text { (caustic-leach in UFP-T02A) }\end{array}$ \\
\hline Rate constant $k\left(\mathrm{hr}^{-1} *(\text { mol total } \mathrm{OH} / \mathrm{L})^{-1}\right)$ & $\begin{array}{c}\text { low 95\%: } 0.0128 \\
\text { median: } 0.0186 \\
\text { upper 95\%: } 0.0250\end{array}$ & $\begin{array}{c}\text { low 95\%: } 0.0182 \\
\text { median: } 0.0251 \\
\text { upper 95\%: } 0.0344\end{array}$ \\
\hline $\begin{array}{l}\text { Boehmite leach factor at } 16 \mathrm{hr} \text { as predicted } \\
\text { by the best-fit kinetic model }\end{array}$ & $\begin{array}{c}\text { low 95\%: } 0.23 \\
\text { median: } 0.33 \\
\text { upper 95\%: } 0.41\end{array}$ & $\begin{array}{c}\text { low 95\%: } 0.26 \\
\text { median: } 0.34 \\
\text { upper 95\%: } 0.43\end{array}$ \\
\hline deterministic $\mathrm{R}^{2}$ for the kinetic model fit & 0.98 & 0.98 \\
\hline
\end{tabular}

(a) The projections of boehmite leach factor were made by WTP and transmitted to D.E. Kurath and L.A. Mahoney by e-mail from J.L. Huckaby on June 15, 2009 (6:25 AM). 


\subsection{Laboratory-Scale Modeling and Results}

The discussion of tracer method assumptions that was given in the beginning of Section 4.1 is even more pertinent to the laboratory-scale tests than to the PEP tests because a larger fraction of the slurry in the beaker is taken as samples. Therefore, an assessment of which tracers were most suitable for use as dilution factors was carried out in the same way as for the PEP tests. The dilution factors trend upward in the laboratory-scale tests because dilution is decreasing during the tests as the result of evaporation.

Figure 4.3 shows the bulk concentration dilution factors for the laboratory-scale tests that parallel PEP Integrated Test A (UFP-T01A caustic-leach, batch 1). The included species are the total Al in the slurry, total $\mathrm{Sr}$, total $\mathrm{Nd}$, total $\mathrm{Fe}$, total $\mathrm{Na}$, and bulk concentrations of liquid-phase nitrate $\left(\mathrm{NO}_{3}{ }^{-}\right)$and chloride $\left(\mathrm{Cl}^{-}\right)$. The concentrations of Sr, total Na, and liquid $\mathrm{Cl}$ for the laboratory-scale tests are tabulated in Appendix B. The estimated liquid densities for the laboratory-scale tests can also be found there.

The mass dilution factors expected from the Test Instruction data (Table 3.5) are also included in the plots (they are shown as asterisks). The Test Instruction dilution factors are the ratios of simulant mass to total mass in the slurry, and serve as an accurate baseline for the initial dilution factors calculated from concentration ratios. Ideally, the dilution factors for all species would equal the Test Instruction mass dilution factor. Because of evaporation of water during the test, all concentrations increase; this is the reason for the increase in dilution factor from initial to final conditions.

Figure 4.4 shows the dilution factors for the laboratory-scale tests that parallel PEP Integrated Test B (UFP-T02A caustic-leach, batch 1). In this case, the Test Instruction mass dilution factors are based on data shown in Table 3.6. For convenience, the dilution factors for all four laboratory-scale tests are tabulated in Table 4.4 .

All the dilution factors are referenced back to the slurry concentration present in the PEP vessel at the time the 1-L bottles of feed for laboratory-scale tests were collected. In the case of Tests A-1, B-1, and B-2, where the laboratory-scale feed was collected after $\mathrm{NaOH}$ had been added, the reference concentration was the PEP "after-NaOH" sample. ${ }^{\text {(a) }}$ For Test A-2, the laboratory-scale feed was considered to be the PEP feed simulant plus the $\mathrm{NaOH}$ added in the laboratory.

Slurry samples were taken from the beaker only at the initial diluted condition and at the end of the test after $24 \mathrm{hr}$ of digestion and subsequent cooling. Therefore, only these two points appear in the plots.

It is evident from Figure 4.3 and Figure 4.4 that the dilution factors of the various species frequently do not match within two standard deviations (which can be judged from the error bar in total Al):

- The dilution of the total $\mathrm{Na}$ in the slurry at the initial diluted condition closely matches the dilution factor calculated from the diluent mass stated in the Test Instruction.

(a) For clarity in sample nomenclature: in PEP tests, "after $\mathrm{NaOH"} \mathrm{refers} \mathrm{to} \mathrm{samples} \mathrm{taken} \mathrm{from} \mathrm{the} \mathrm{vessel} 10$ minutes or more after $\mathrm{NaOH}$ addition; in laboratory-scale tests, "after $\mathrm{NaOH"} \mathrm{refers} \mathrm{to} \mathrm{samples} \mathrm{taken} \mathrm{from} \mathrm{the} \mathrm{beaker} \mathrm{after} \mathrm{all} \mathrm{diluent} \mathrm{has}$ been added and before heat-up. This latter point in laboratory-scale experiments is also referred to as "initial diluted" condition. In most of the laboratory-scale tests, $\mathrm{NaOH}$ is not added in the laboratory, the exception being Test A-2. 

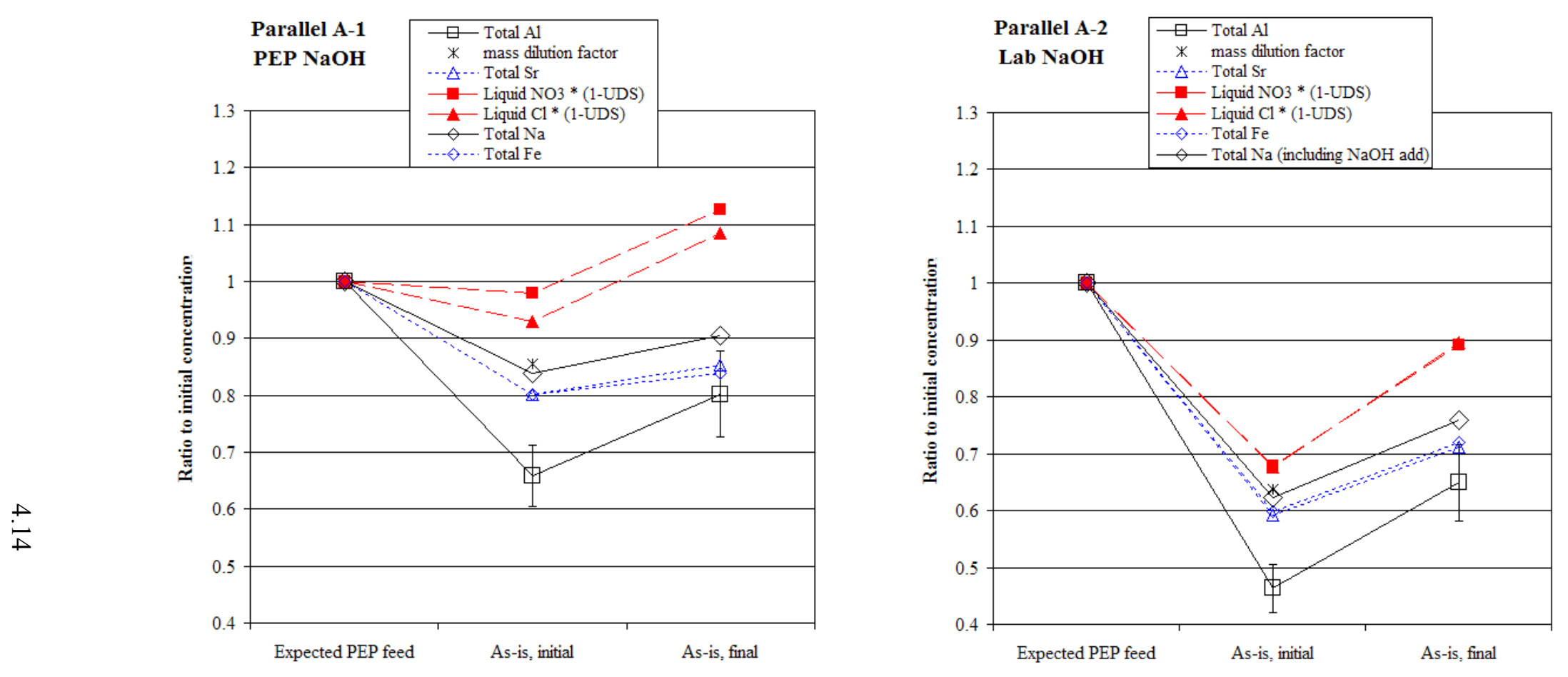

Figure 4.3. Dilution Factors with 95\% Confidence Intervals for Laboratory-Scale Tests Paralleling Test A (caustic leaching in UFP-T01A) 

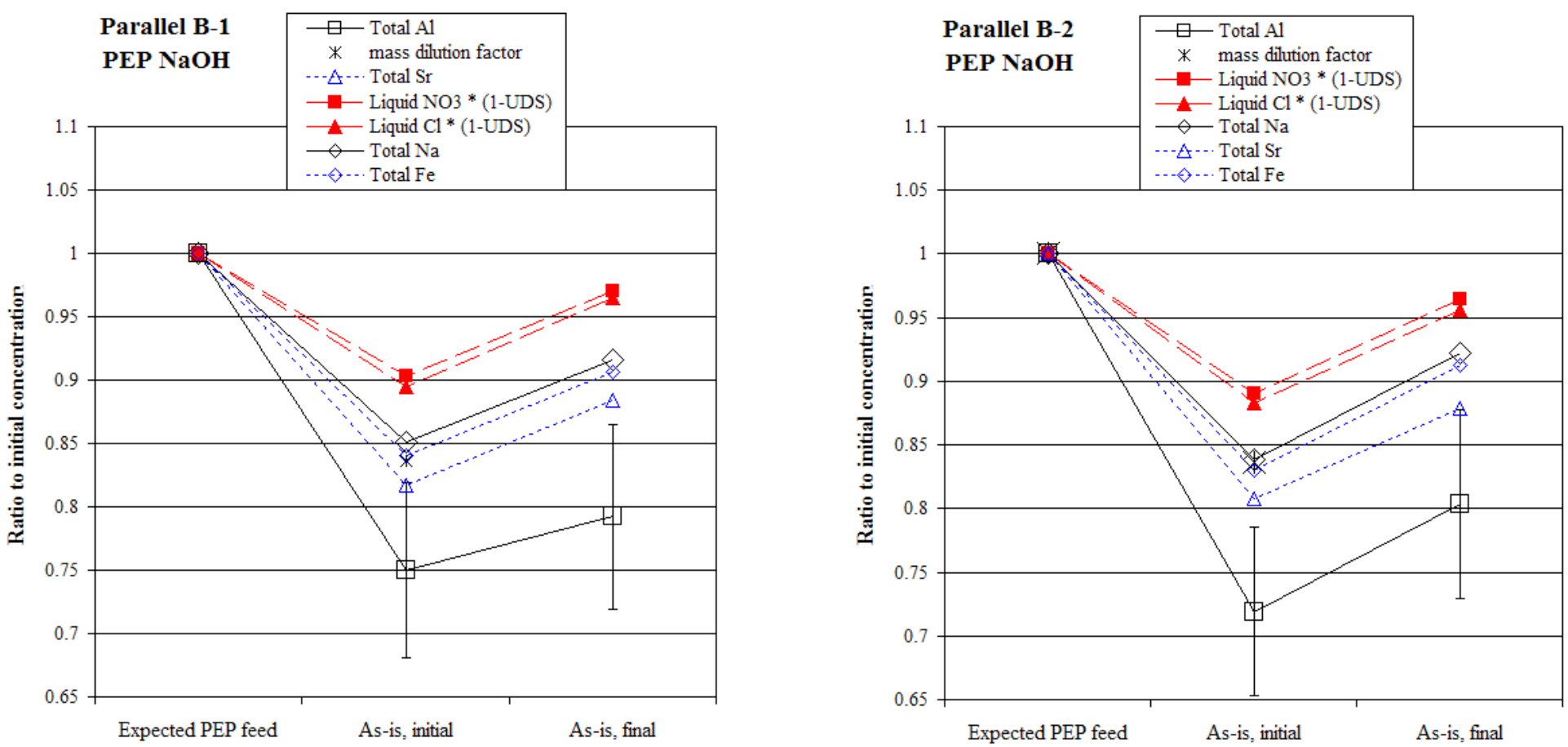

Figure 4.4. Dilution Factors with 95\% Confidence Intervals for Laboratory-Scale Tests Paralleling Test B (caustic leaching in UFP-T02A) 
Table 4.4. Dilution Factors for Laboratory-Scale Tests

\begin{tabular}{|c|c|c|c|c|}
\hline \multirow[b]{2}{*}{ Species } & \multicolumn{2}{|c|}{$\begin{array}{l}\text { Mass Dilution Factor (Ratio to } \\
\text { Concentration in the Source } \\
\text { Test A Sample) }\end{array}$} & \multicolumn{2}{|c|}{$\begin{array}{l}\text { Mass Dilution Factor (Ratio } \\
\text { to Concentration in the } \\
\text { Source Test B Sample) }\end{array}$} \\
\hline & Test A-1 & Test A-2 & Test B-1 & Test B-2 \\
\hline $\begin{array}{l}\text { Mass dilution factor from PEP } \\
\text { and diluent masses given in } \\
\text { Test Instruction }\end{array}$ & start: 0.86 & start: 0.64 & start: 0.84 & start: 0.84 \\
\hline Slurry Al & $\begin{array}{l}\text { start: } 0.66 \\
\text { end: } 0.80\end{array}$ & $\begin{array}{l}\text { start: } 0.46 \\
\text { end: } 0.65\end{array}$ & $\begin{array}{l}\text { start: } 0.75 \\
\text { end: } 0.79\end{array}$ & $\begin{array}{l}\text { start: } 0.72 \\
\text { end: } 0.80\end{array}$ \\
\hline Slurry $\mathrm{Na}$ & $\begin{array}{l}\text { start: } 0.84 \\
\text { end: } 0.90\end{array}$ & $\begin{array}{l}\text { start: } 0.62^{(a)} \\
\text { end: } 0.76^{(a)}\end{array}$ & $\begin{array}{l}\text { start: } 0.85 \\
\text { end: } 0.92\end{array}$ & $\begin{array}{l}\text { start: } 0.84 \\
\text { end: } 0.92\end{array}$ \\
\hline Slurry Sr & $\begin{array}{l}\text { start: } 0.80 \\
\text { end: } 0.85\end{array}$ & $\begin{array}{l}\text { start: } 0.59 \\
\text { end: } 0.71\end{array}$ & $\begin{array}{c}\text { start: } 0.82 \\
\text { end: } 0.88\end{array}$ & $\begin{array}{l}\text { start: } 0.81 \\
\text { end: } 0.88\end{array}$ \\
\hline Slurry Fe & $\begin{array}{l}\text { start: } 0.80 \\
\text { end: } 0.84\end{array}$ & $\begin{array}{l}\text { start: } 0.60 \\
\text { end: } 0.72\end{array}$ & $\begin{array}{l}\text { start: } 0.84 \\
\text { end: } 0.91\end{array}$ & $\begin{array}{l}\text { start: } 0.83 \\
\text { end: } 0.91\end{array}$ \\
\hline Liquid nitrate * $(1-$ UDS $)$ & $\begin{array}{c}\text { start: } 0.98 \\
\text { end: } 1.13\end{array}$ & $\begin{array}{c}\text { start: } 0.68 \\
\text { end: } 0.89\end{array}$ & $\begin{array}{l}\text { start: } 0.90 \\
\text { end: } 0.97\end{array}$ & $\begin{array}{l}\text { start: } 0.89 \\
\text { end: } 0.96\end{array}$ \\
\hline Liquid chloride * $(1-$ UDS) & $\begin{array}{ll}\text { start: } & 0.93 \\
\text { end: } & 1.08\end{array}$ & $\begin{array}{l}\text { start: } 0.68 \\
\text { end: } 0.90\end{array}$ & $\begin{array}{l}\text { start: } 0.89 \\
\text { end: } 0.96\end{array}$ & $\begin{array}{l}\text { start: } 0.88 \\
\text { end: } 0.96\end{array}$ \\
\hline $\begin{array}{l}\text { (a) In Test A-2, the dilution factor i } \\
\text { the portion that came from the } \mathrm{N} \\
\text { For all dilution factors, the } 95 \% \text { confi } \\
\text { The terminology "Liquid species * } 1 \\
\text { the liquid mass fraction of the slurry. }\end{array}$ & $\begin{array}{l}\text { based on the p } \\
\text { laOH reagent ad } \\
\text { - UDS)" indica }\end{array}$ & $\begin{array}{l}\text { of the slurry } \\
\text { in the lab is excl } \\
\text { proximately } \pm 0 . \\
\text { the liquid-phase }\end{array}$ & $\begin{array}{l}\text { lat came from } \\
\text { is concentrati }\end{array}$ & EP simulant; \\
\hline
\end{tabular}

- The liquid tracers indicate less dilution (have larger dilution factors) than the Test Instruction value at the initial diluted condition, although the amount by which their dilution factors change from initial to final condition parallels the upward trend of the total Al. This implies some difference in the measured initial and final concentrations relative to the PEP slurry, but shows that the dilution of $\mathrm{Al}$ and of liquid tracers is similar relative to the initial beaker condition.

- The solid tracers reasonably match the initial dilution factor from the Test Instruction in all four laboratory-scale tests. However, in Tests A-1 and A-2 (particularly A-1), both solid tracers and Na show less change between initial and final conditions than do $\mathrm{Al}$ and liquid tracers.

- Finally, and most importantly, the total Al trend indicates substantially less Al present in the beaker than would be expected from the composition of the PEP slurry. However, the upward trend in total Al from the initial to the final condition parallels the liquid tracers and (in Tests B-1 and B-2) the total $\mathrm{Na}$.

The reasons for these variations are unknown, but their consistency from test to test allows some conclusions to be drawn:

- The $\mathrm{Al}$ concentration in the total slurry in the laboratory-scale beakers was significantly less than would have been expected from the PEP slurry values, so the latter cannot be used to define the laboratory-scale test initial conditions. The lower concentrations of total slurry Al imply lower concentrations of solid-phase Al. 
- In Tests A-1 and A-2, solid tracer methods for calculating leach factors may be less accurate in the laboratory-scale tests because the dilution trends of the solid tracer species, from initial to final condition, differ from those of total Al.

- Liquid tracers can be used to normalize concentrations for liquid volume changes during the tests since their trends parallel those of the total Al. However, the liquid tracer concentrations do not relate back to the corresponding PEP liquid concentrations very well, judging by the difference between the initial dilution factor from the Test Instruction (and total $\mathrm{Na}$ ) and the initial dilution factor from liquid tracers. Chloride is slightly closer to the expected initial dilution than nitrate and was chosen as the liquid tracer for all four laboratory-scale tests.

Speculative explanations can be proposed for the changes in concentration from the PEP to the beaker initial condition. The liquid tracer concentrations were all measured by the same method (IC). If the IC instrument response shifted slightly between the analytical batch that included the PEP samples and that with the laboratory-scale samples, the ratios could be shifted by several percent. However, the shift in Tests A-1 and A-2 is greater than analytical variability. Some other effect is needed to explain these cases. If the measured UDS was less than the true value in the beaker or greater than the true value in the PEP, then the apparent dilution factor (which incorporates [1-UDS]) would be overestimated, as seen. This explanation seems unlikely because an error in (1-UDS) that was large enough to produce the observed offset would be unreasonably large compared to the measured UDS. The decrease in the value of (1-UDS) would need to be $5 \%$ or more of its value, implying that the true value of UDS was $7-\mathrm{wt} \%$ or more, compared to the measured and expected $2-\mathrm{wt} \%$.

Speculatively, the apparent loss of solids, preferentially of Al-containing solids, implies a difficulty in sampling from the PEP, in transferring the feed slurry from PEP into the laboratory-scale beakers or in sampling the beakers. The samples that were analyzed to provide PEP slurry concentrations were drawn from the leach vessel, through the sampling system, into a set of small vials, each of which contained about $40 \mathrm{~mL}$ of slurry. The samples that were used to feed the laboratory-scale tests were drawn from the PEP leach vessels in the same manner except that flow was maintained long enough to fill one or two 1-L bottles. One hypothesis is that the distribution of solids in the sample was affected (through an unknown mechanism) by the duration of flow, giving different solids concentration and composition for the $40 \mathrm{~mL}$ and $1 \mathrm{~L}$ samples. Another hypothesis was that the samples drawn from the PEP were representative in both cases, but that the mixing of the slurry in the 1-L bottles was not sufficient. The result would have been that a less than representative amount and composition of solids went into the subsample of slurry that was poured into the beakers. Finally, the samples taken by pipette from the beakers might not have been representative. There are not enough data to distinguish between these hypotheses and to prove one, or to develop and prove another.

The dissolved Al concentrations observed during the PEP and laboratory-scale tests, normalized to the condition of maximum dilution using a liquid tracer, are plotted in Figure 4.5 and Figure 4.6. In the tests related to caustic-leach in UFP-T01A, which are shown in Figure 4.5, the normalized dissolved Al concentrations in the laboratory-scale tests are perceptibly lower than in the PEP test, though the difference is not always outside the $95 \%$ confidence interval shown by the error bars. (The interval was calculated by error propagation from laboratory uncertainty estimates.) The difference between PEP and laboratory-scale is larger for UFP-T02A leach, seen in Figure 4.6, and was significantly more than uncertainty could account for. These observations of lower dissolved Al concentrations in the 
laboratory-scale tests, and of lower rates of increase in the leached Al, are consistent with the conclusion that the solid-phase Al concentration in the beakers was less than in the PEP slurry.

The boehmite leach factors for the laboratory-scale tests are presented in Table 4.5 and Table 4.6. The calculations required an estimate of the initial fraction of the solid-phase Al that was present in boehmite. The discussion of the way in which this fraction was calculated is deferred to Section 4.2.1. Because the boehmite leach fraction and the total Al leach fraction were based on less concentration information than for PEP, the $\mathrm{Al}$ leach factor for the laboratory-scale tests does not provide independent information and so is not tabulated.

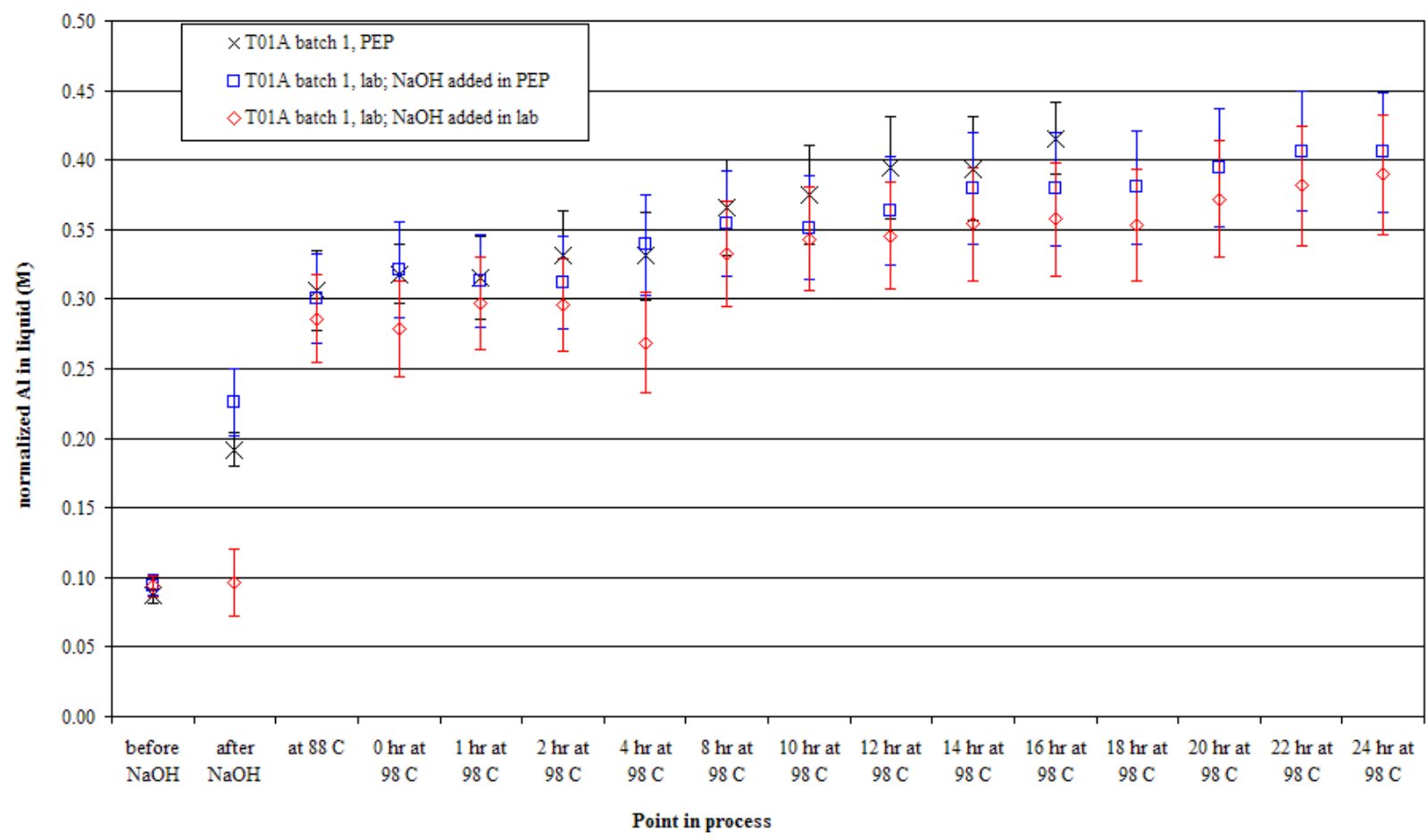

Figure 4.5. Normalized Dissolved Al with 95\% Confidence Intervals During PEP Integrated Test A and Laboratory-Scale Tests A-1 and A-2 (caustic leaching in UFP-T01A) 


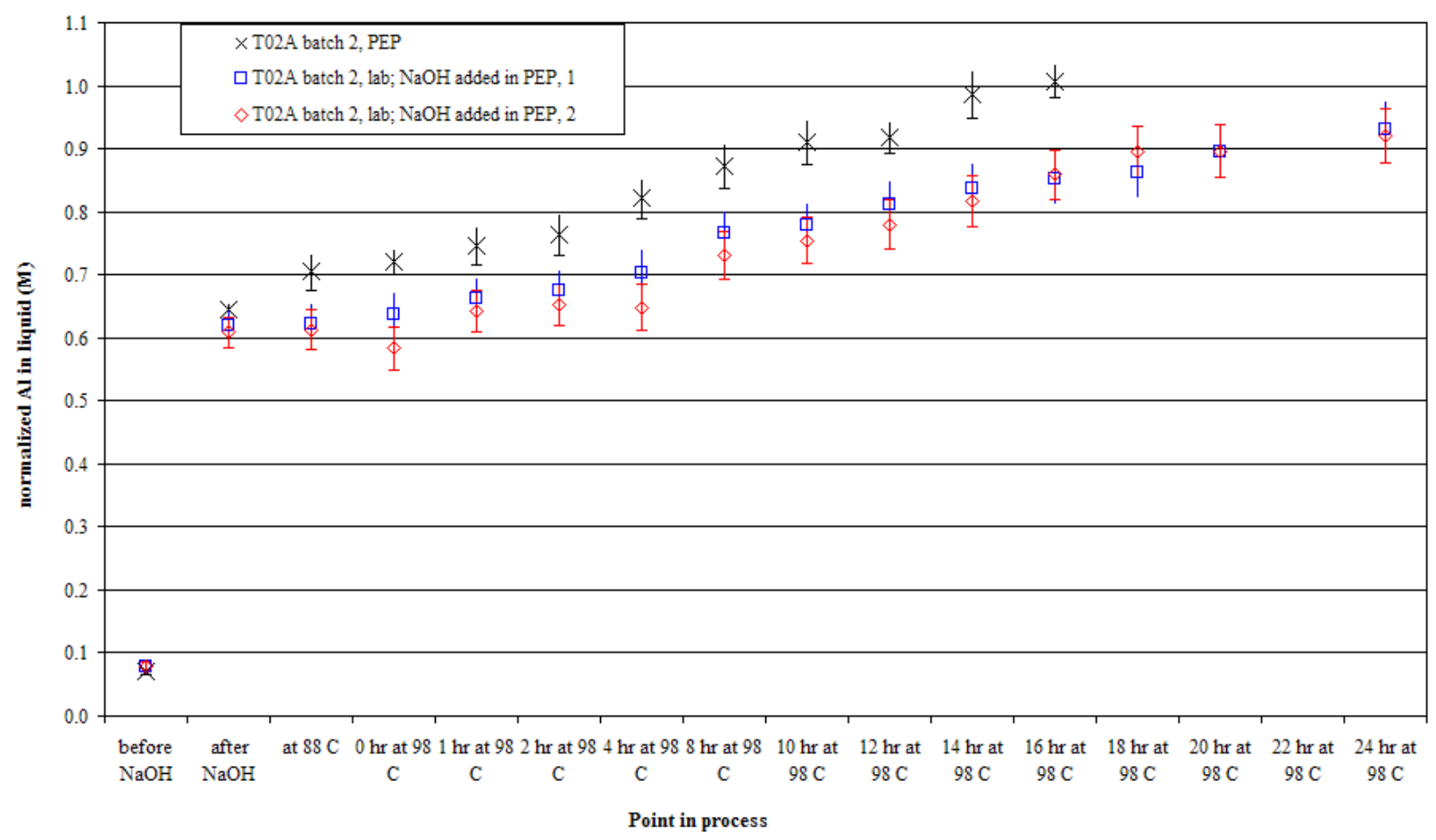

Figure 4.6. Normalized Dissolved Al with 95\% Confidence Intervals During PEP Integrated Test B and Laboratory-Scale Tests B-1 and B-2 (caustic leaching in UFP-T02A)

Table 4.5. Boehmite Leach Factors for Laboratory-Scale Tests Parallel to PEP Integrated Test A

\begin{tabular}{lcccc}
\hline \multicolumn{1}{c}{$\begin{array}{c}\text { Nominal Point in } \\
\text { Process }\end{array}$} & $\begin{array}{c}\text { Based on Solid } \\
\text { Tracer }\end{array}$ & $\begin{array}{c}\text { Based on } \\
\text { Liquid Tracer }\end{array}$ & $\begin{array}{c}\text { Test A-2 } \\
\text { Based on Solid } \\
\text { Tracer }\end{array}$ & $\begin{array}{c}\text { Based on } \\
\text { Liquid Tracer }\end{array}$ \\
\hline $0 \mathrm{hr}$ at $98^{\circ} \mathrm{C}$ & $\mathrm{n} / \mathrm{m}$ & 0 & $\mathrm{n} / \mathrm{m}$ & 0 \\
$1 \mathrm{hr}$ at $98^{\circ} \mathrm{C}$ & $\mathrm{n} / \mathrm{m}$ & $-0.04 \pm 0.11$ & $\mathrm{n} / \mathrm{m}$ & $0.07 \pm 0.07$ \\
$2 \mathrm{hr}$ at $98^{\circ} \mathrm{C}$ & $\mathrm{n} / \mathrm{m}$ & $-0.04 \pm 0.11$ & $\mathrm{n} / \mathrm{m}$ & $0.07 \pm 0.07$ \\
$4 \mathrm{hr}$ at $98^{\circ} \mathrm{C}$ & $\mathrm{n} / \mathrm{m}$ & $0.09 \pm 0.10$ & $\mathrm{n} / \mathrm{m}$ & $-0.04 \pm 0.07$ \\
$8 \mathrm{hr}$ at $98^{\circ} \mathrm{C}$ & $\mathrm{n} / \mathrm{m}$ & $0.17 \pm 0.10$ & $\mathrm{n} / \mathrm{m}$ & $0.22 \pm 0.08$ \\
$10 \mathrm{hr}$ at $98^{\circ} \mathrm{C}$ & $\mathrm{n} / \mathrm{m}$ & $0.16 \pm 0.10$ & $\mathrm{n} / \mathrm{m}$ & $0.27 \pm 0.08$ \\
$12 \mathrm{hr}$ at $98^{\circ} \mathrm{C}$ & $\mathrm{n} / \mathrm{m}$ & $0.22 \pm 0.11$ & $\mathrm{n} / \mathrm{m}$ & $0.28 \pm 0.08$ \\
$14 \mathrm{hr}$ at $98^{\circ} \mathrm{C}$ & $\mathrm{n} / \mathrm{m}$ & $0.30 \pm 0.11$ & $\mathrm{n} / \mathrm{m}$ & $0.31 \pm 0.08$ \\
$16 \mathrm{hr}$ at $98^{\circ} \mathrm{C}$ & $\mathrm{n} / \mathrm{m}$ & $0.30 \pm 0.11$ & $\mathrm{n} / \mathrm{m}$ & $0.33 \pm 0.08$ \\
$18 \mathrm{hr}$ at $98^{\circ} \mathrm{C}$ & $\mathrm{n} / \mathrm{m}$ & $0.30 \pm 0.11$ & $\mathrm{n} / \mathrm{m}$ & $0.31 \pm 0.08$ \\
$20 \mathrm{hr}$ at $98^{\circ} \mathrm{C}$ & $\mathrm{n} / \mathrm{m}$ & $0.38 \pm 0.11$ & $\mathrm{n} / \mathrm{m}$ & $0.39 \pm 0.08$ \\
$22 \mathrm{hr}$ at $98^{\circ} \mathrm{C}$ & $\mathrm{n} / \mathrm{m}$ & $0.44 \pm 0.11$ & $\mathrm{n} / \mathrm{m}$ & $0.43 \pm 0.08$ \\
$24 \mathrm{hr}$ at $98^{\circ} \mathrm{C}$ & $\mathrm{n} / \mathrm{m}$ & $0.44 \pm 0.11$ & $\mathrm{n} / \mathrm{m}$ & $0.46 \pm 0.09$ \\
\hline $\begin{array}{l}\text { After cooling } \\
\text { The } \pm \text { values are one standard deviation from the median leach factor calculated by a Monte Carlo method using }\end{array}$ \\
5000 realizations.
\end{tabular}


Table 4.6. Boehmite Leach Factors for Laboratory-Scale Tests Parallel to PEP Integrated Test B

\begin{tabular}{|c|c|c|c|c|}
\hline \multirow[b]{2}{*}{$\begin{array}{c}\text { Nominal Point in } \\
\text { Process }\end{array}$} & \multicolumn{2}{|c|}{ Test B-1 } & \multicolumn{2}{|c|}{ Test B-2 } \\
\hline & $\begin{array}{l}\text { Based on Solid } \\
\text { Tracer }\end{array}$ & $\begin{array}{c}\text { Based on } \\
\text { Liquid Tracer }\end{array}$ & $\begin{array}{c}\text { Based on Solid } \\
\text { Tracer }\end{array}$ & $\begin{array}{c}\text { Based on } \\
\text { Liquid Tracer }\end{array}$ \\
\hline $0 \mathrm{hr}$ at $98^{\circ} \mathrm{C}$ & $\mathrm{n} / \mathrm{m}$ & 0 & $\mathrm{n} / \mathrm{m}$ & 0 \\
\hline $1 \mathrm{hr}$ at $98^{\circ} \mathrm{C}$ & $\mathrm{n} / \mathrm{m}$ & $0.03 \pm 0.05$ & $\mathrm{n} / \mathrm{m}$ & $0.07 \pm 0.05$ \\
\hline $2 \mathrm{hr}$ at $98^{\circ} \mathrm{C}$ & $\mathrm{n} / \mathrm{m}$ & $0.05 \pm 0.05$ & $\mathrm{n} / \mathrm{m}$ & $0.09 \pm 0.05$ \\
\hline $4 \mathrm{hr}$ at $98^{\circ} \mathrm{C}$ & $\mathrm{n} / \mathrm{m}$ & $0.08 \pm 0.05$ & $\mathrm{n} / \mathrm{m}$ & $0.08 \pm 0.05$ \\
\hline $8 \mathrm{hr}$ at $98^{\circ} \mathrm{C}$ & $\mathrm{n} / \mathrm{m}$ & $0.16 \pm 0.05$ & $\mathrm{n} / \mathrm{m}$ & $0.18 \pm 0.05$ \\
\hline $10 \mathrm{hr}$ at $98^{\circ} \mathrm{C}$ & $\mathrm{n} / \mathrm{m}$ & $0.18 \pm 0.05$ & $\mathrm{n} / \mathrm{m}$ & $0.21 \pm 0.05$ \\
\hline $12 \mathrm{hr}$ at $98^{\circ} \mathrm{C}$ & $\mathrm{n} / \mathrm{m}$ & $0.22 \pm 0.06$ & $\mathrm{n} / \mathrm{m}$ & $0.24 \pm 0.05$ \\
\hline $14 \mathrm{hr}$ at $98^{\circ} \mathrm{C}$ & $\mathrm{n} / \mathrm{m}$ & $0.26 \pm 0.06$ & $\mathrm{n} / \mathrm{m}$ & $0.29 \pm 0.05$ \\
\hline $16 \mathrm{hr}$ at $98^{\circ} \mathrm{C}$ & $\mathrm{n} / \mathrm{m}$ & $0.28 \pm 0.06$ & $\mathrm{n} / \mathrm{m}$ & $0.34 \pm 0.06$ \\
\hline $18 \mathrm{hr}$ at $98^{\circ} \mathrm{C}$ & $\mathrm{n} / \mathrm{m}$ & $0.29 \pm 0.06$ & $\mathrm{n} / \mathrm{m}$ & $0.39 \pm 0.06$ \\
\hline $20 \mathrm{hr}$ at $98^{\circ} \mathrm{C}$ & $\mathrm{n} / \mathrm{m}$ & $0.33 \pm 0.06$ & $\mathrm{n} / \mathrm{m}$ & $0.39 \pm 0.06$ \\
\hline $22 \mathrm{hr}$ at $98^{\circ} \mathrm{C}$ & $\mathrm{n} / \mathrm{m}$ & $\mathrm{n} / \mathrm{m}$ & $\mathrm{n} / \mathrm{m}$ & $\mathrm{n} / \mathrm{m}$ \\
\hline $24 \mathrm{hr}$ at $98^{\circ} \mathrm{C}$ & $\mathrm{n} / \mathrm{m}$ & $0.37 \pm 0.06$ & $\mathrm{n} / \mathrm{m}$ & $0.42 \pm 0.06$ \\
\hline After cooling & $0.40 \pm 0.09$ & $\mathrm{n} / \mathrm{m}$ & $0.41 \pm 0.08$ & $\mathrm{n} / \mathrm{m}$ \\
\hline
\end{tabular}

The 16-hr boehmite leach factors for PEP Integrated Tests A and B, as calculated from the total Al leach factor, were $0.32 \pm 0.049$ and $0.33 \pm 0.045$, respectively. For both Integrated Test $A$ and Integrated Test B, one of the associated laboratory-scale tests had a lower 16-hr boehmite leach factor than the PEP test and one had a higher leach factor. In three out of the four cases, the 16-hr factor from the laboratory-scale test was within one standard deviation of the factor from the PEP test. The exception was the Test B-1 factor at $16 \mathrm{hr}$, which was a little more than one standard deviation low compared to the PEP Integrated Test B factor. The 16-hr boehmite leach factor for Test B-1 was consistent with the trend for that test, which was lower than for Test B-2.

\subsubsection{Initial Conditions for Kinetic Modeling of Laboratory-Scale Tests}

The same kind of kinetic model initial conditions were required for the laboratory-scale tests as for the PEP test. Because the data available were different, the approach taken was somewhat different. Details are given in Section A.7, but the method is summarized below.

The total Al concentration in the initial diluted slurry was taken to be the average of estimates based on three independent sources of data:

- The total Al measured in a sample of the initial diluted slurry in the beaker

- The total Al measured in a sample of the final slurry in the beaker, normalized to the initial-dilution condition using total $\mathrm{Na}$ concentration as a slurry tracer

- The total Al measured in a sample of the feed slurry that was left over in the 1-L bottles of sample taken from PEP to be used as laboratory-scale feed. This undiluted Al concentration was normalized to the initial-dilution condition using the dilution factor from the Test Instruction data. 
Section 4.2 included a mention of the hypothesis that the loss of Al solids from PEP slurry occurred during transfer of a subsample of slurry from the PEP $1 \mathrm{~L}$ bottles into the laboratory-scale beakers. If this was the case, the Al concentration in the leftover slurry (as listed in the third bullet above) would have been higher than the other values. In fact, it was always either the highest or second-highest of the three measured concentrations - but, except in Test A-2, it was within analytical variability of the Al concentration in the final slurry. The largest discrepancies are seen in Tests A-1 and A-2, where it is not clear whether the $\mathrm{Al}$ concentration in the leftover slurry is suspiciously high or that the $\mathrm{Al}$ concentration in the initial slurry in the beaker was suspiciously low (suggesting that the beaker slurry might not have been fully mixed at the time the initial slurry sample was taken). Given this ambiguity, it was decided to include the concentration of $\mathrm{Al}$ in the leftover slurry as part of the average to estimate the initial $\mathrm{Al}$ concentration for kinetic modeling purposes.

Table 4.7 shows each of the three independent estimates of the total $\mathrm{Al}$ concentration in the initial-diluted slurry and gives the average of the three. The expected total Al concentrations, calculated from mass dilution factors in Table 4.4 and PEP sample concentrations in Table 3.14, are also shown. The decrease from the expected total $\mathrm{Al}$ is $18 \%$ for Tests A-1 and A-2, and 12\% for Tests B- 1 and B-2.

Table 4.7. Total Al Concentration in the Initial Diluted Slurry in Laboratory-Scale Tests

\begin{tabular}{|c|c|c|c|c|}
\hline \multirow[b]{2}{*}{$\begin{array}{l}\text { Basis (concentrations } \\
\text { normalized to slurry mass } \\
\text { after initial dilution) }\end{array}$} & \multicolumn{2}{|c|}{$\begin{array}{l}\text { Test A (caustic-leach in } \\
\text { UFP-T01A) }\end{array}$} & \multicolumn{2}{|c|}{$\begin{array}{c}\text { Test B (caustic-leach in } \\
\text { UFP-T02A) }\end{array}$} \\
\hline & $\begin{array}{l}\text { Laboratory-Scale } \\
\text { Test A-1 }\end{array}$ & $\begin{array}{l}\text { Laboratory-Scale } \\
\text { Test A-2 }\end{array}$ & $\begin{array}{l}\text { Laboratory- } \\
\text { Scale } \\
\text { Test B-1 } \\
\end{array}$ & $\begin{array}{l}\text { Laboratory- } \\
\text { Scale } \\
\text { Test B-2 }\end{array}$ \\
\hline $\begin{array}{l}\text { Expected from PEP source } \\
\text { sample after in-lab dilution } \\
\text { ( } \mu \mathrm{g} \mathrm{Al} / \mathrm{g} \text { slurry) }\end{array}$ & $12370 \pm 203$ & $12765 \pm 247$ & $29877 \pm 472$ & $29876 \pm 472$ \\
\hline $\begin{array}{l}\text { Sample from initial diluted } \\
\text { slurry in beaker ( } \mu \mathrm{g} \mathrm{Al} / \mathrm{g} \\
\text { slurry) }\end{array}$ & $9528 \pm 229$ & $9288 \pm 223$ & $26814 \pm 904$ & $25713 \pm 867$ \\
\hline $\begin{array}{l}\text { Sample from final slurry in } \\
\text { beaker normalized to initial } \\
\text { dilution ( } \mu \mathrm{g} \mathrm{Al} / \mathrm{g} \text { slurry) }\end{array}$ & $10764 \pm 578$ & $10661 \pm 572$ & $26306 \pm 1551$ & $26090 \pm 1538$ \\
\hline $\begin{array}{l}\text { Sample from the leftover } \\
\text { feed that did not go into } \\
\text { beaker normalized to initial } \\
\text { dilution ( } \mu \mathrm{g} \mathrm{Al} / \mathrm{g} \text { slurry) }\end{array}$ & $10431 \pm 355$ & $11539 \pm 393$ & $26428 \pm 893$ & $26761 \pm 905$ \\
\hline Average & $10242 \pm 238$ & $10497 \pm 243$ & $26515 \pm 667$ & $26188 \pm 660$ \\
\hline
\end{tabular}

The scatter among the three estimates for the Test A laboratory-scale tests is clearly greater than would be expected from the analytical method alone. It is also worth noting that the samples taken from the Test $\mathrm{A}$ beakers at initial dilution are lower in total $\mathrm{Al}$ than concentrations based on other samples. By contrast, the total Al concentrations for Test B laboratory-scale tests are consistent both within each test and among both B-1 and B-2.

Any solid-phase Al that is still present after all the gibbsite is dissolved must be boehmite. Thus the boehmite concentration can be found by subtracting the dissolved Al present after complete gibbsite 
dissolution from the total Al. The dissolved Al concentration measured after heat-up was complete ("0 hr") was assumed to include all the gibbsite in dissolved form. This assumption was consistent with the Al leach factors observed in the PEP Integrated tests (see Section 4.1.2). This dissolved Al concentration was normalized to the volume at the initial diluted condition. It was used, with the initial UDS weight fraction measured in the slurry at that point and the initial total Al concentration, to calculate the initial solid-phase Al concentration. The equation is:

$$
C_{A l b, L, S S}=\left[c_{A l, S S}-\left(1-\omega_{s, S S}\right) c_{A l L, 0 h} \frac{c_{C l L, S S}}{c_{C l L, 0 h}}\right] \frac{1}{1-\omega_{S, S S}} \frac{\rho_{L, S S}}{1000 M_{A l}}
$$

where $\quad=$ moles of boehmite per volume of liquid in the slurry at initial diluted condition $C_{A l b, L, S S}$

$$
\begin{aligned}
c_{A l, S S}= & \text { mass concentration of } \mathrm{Al} \text { (solid and dissolved) in the slurry, mass } \mathrm{Al} / \text { mass slurry } \\
\omega_{S, S S}= & \text { weight fraction of undissolved solid in the slurry at initial diluted condition, mass } \\
& \text { solid-phase/mass slurry } \\
c_{A l L, O h}= & \text { mass concentration of dissolved } \mathrm{Al} \text { in the liquid at } 0 \mathrm{hr} \text { at temperature, mass } \mathrm{Al} / \\
& \text { mass liquid } \\
c_{C I L, S S}= & \text { mass concentration of liquid tracer } \mathrm{Cl}^{-} \text {in the liquid at initial diluted conditions, mass } \\
& \mathrm{Cl}^{-1} / \text { mass liquid } \\
c_{C I L, O h}= & \text { mass concentration of liquid tracer } \mathrm{Cl}^{-} \text {in the liquid at } 0 \mathrm{hr} \text { at temperature, mass } \\
& \mathrm{Cl}^{-} / \text {mass liquid } \\
\rho_{L, S S}= & \text { liquid density at initial diluted condition. }
\end{aligned}
$$

Assuming that the dissolved Al concentration used in the calculation was consistent with $100 \%$ gibbsite dissolution, subtracting its contribution from the total Al gave a solid-phase $\mathrm{Al}$ concentration that was equal to the mass concentration of boehmite $\mathrm{Al}$ in the initial diluted slurry. The boehmite mass concentration was converted to moles of $\mathrm{Al}$ in boehmite per liter liquid (at the initial diluted condition) to provide the boehmite initial condition $\left(C_{A l b, L, S S}\right)$.

The data were checked to find out whether the lower solid-phase Al in the laboratory-scale test slurry, compared to PEP slurry, had caused a change in the fraction of solid-phase Al that was present as boehmite. Such a change would imply a selective decrease in gibbsite or boehmite. The fraction of solid-phase Al present in boehmite was calculated by dividing the mass concentration of boehmite Al in the slurry (the term in square brackets in Equation [4.6]) by the mass concentration of all solid-phase Al in the slurry (see Equation [A.62]). The fraction of solid-phase Al present in boehmite in the laboratory-scale tests, at the initial condition, was compared to what would have been expected from the original PEP slurry. The latter was calculated from the Al leach fraction (liquid tracer method). The results are given below in terms of the expected and actual fraction of the solid-phase Al that is present in boehmite:

- Test A-1: expected (after $\mathrm{NaOH}$ addition in PEP) $=0.70$

actual $=0.67$

- Test A-2: expected (in feed simulant) $\quad=0.57$

actual $=0.57$

- Test B-1: expected (after $\mathrm{NaOH}$ addition in PEP) $=0.91$

actual $=0.98$

- Test B-2: expected (after $\mathrm{NaOH}$ addition in PEP) $=0.91$

actual $=1.03$ 
In the A-based lab tests, the difference between actual and expected fractions of solid $\mathrm{Al}$ in boehmite is within uncertainty. In the B-based tests, the higher fraction of boehmite Al actually found probably comes from dissolution of gibbsite that occurred in the four-day period between the time the slurry was removed from the PEP and the time the laboratory-scale experiment began. It is not clear whether the mechanism that demonstrably caused a decrease in total Al, and therefore in solid-phase Al, caused a selective loss in either boehmite or gibbsite.

The total hydroxide concentration $\left(C_{O H L, i}\right)$ and dissolved $\mathrm{Al}$ initial conditions $\left(C_{A L L, i}\right)$ were calculated in the same manner as for the PEP tests (see Section 4.1.1), except that the laboratory-scale maximum dilution condition is at the beginning rather than the end of the test. It was determined that the initial total hydroxide in the laboratory-scale tests was consistently less than would be expected from the total hydroxide measured in the source PEP slurry that supplied the laboratory-scale feed. A comparison is given below in terms of the expected and actual total hydroxide ${ }^{(a)}$ concentrations in the initial laboratory-scale liquid (including the $\mathrm{NaOH}$ reagent added in Test $\mathrm{A}-2$ ):

- $\quad$ Test A-1: expected $=4.34 \mathrm{M}$

$$
\begin{aligned}
& \text { actual }=4.04 \mathrm{M} \\
& \text { actual }=3.88 \mathrm{M} \\
& \text { actual }=6.07 \mathrm{M} \\
& \text { actual }=5.88 \mathrm{M}
\end{aligned}
$$

All of the actual total hydroxide concentrations at laboratory-scale conditions were within $10 \%$ of the expected values. The fact that all four were low suggests some physical reason for the loss of hydroxide. The reason is unknown. Review of the data showed that the standard deviation over each of the sets of normalized total hydroxide concentrations was $4 \%$ to $5 \%$ for the laboratory-scale tests. There was no consistent time trend in normalized total hydroxide concentration, indicating no continuing decrease in total hydroxide.

The temperature data used by the kinetic model come from the temperature data recorded in the Test Instruction at the times when samples were taken, and therefore are hourly or two-hourly data. A summary of the temperature data can be found in Table 3.18.

Table 4.8 lists the values used for the kinetic model initial conditions for the laboratory-scale tests. These are the deterministic value \pm one standard deviation as calculated by 500 realizations of the Monte Carlo method. The Monte Carlo run used the estimates of laboratory error in measurements as the basis for estimating error in the initial conditions.

(a) The total hydroxide concentration, in molarity units, is the sum of the free hydroxide and one mole of hydroxide per mole of the aluminate ion complex, $\mathrm{Al}(\mathrm{OH})_{4}^{-}$. See Equation (A.65). 
Table 4.8. Initial Conditions for Kinetic Modeling of Laboratory-Scale Tests

\begin{tabular}{|c|c|c|c|c|}
\hline \multirow[b]{2}{*}{$\begin{array}{l}\text { Concentrations at } 0 \mathrm{hr} \text {, } \\
\text { normalized to liquid volume } \\
\text { after initial dilution: }\end{array}$} & \multicolumn{2}{|c|}{ Test A (caustic-leach in UFP-T01A) } & \multicolumn{2}{|c|}{ Test B (caustic-leach in UFP-T02A) } \\
\hline & $\begin{array}{l}\text { Laboratory-Scale } \\
\text { Test A-1 (NaOH } \\
\text { added in PEP) }\end{array}$ & $\begin{array}{c}\text { Laboratory-Scale } \\
\text { Test A-2 (NaOH } \\
\text { added in lab) }\end{array}$ & $\begin{array}{l}\text { Laboratory- } \\
\text { Scale } \\
\text { Test B-1 (NaOH } \\
\text { added in PEP) }\end{array}$ & $\begin{array}{c}\text { Laboratory- } \\
\text { Scale } \\
\text { Test B-2 (NaOH } \\
\text { added in PEP) }\end{array}$ \\
\hline Dissolved Al (M) & $0.321 \pm 0.017$ & $0.279 \pm 0.016$ & $0.638 \pm 0.037$ & $0.584 \pm 0.034$ \\
\hline Boehmite (mol/L liquid) & $0.192 \pm 0.021$ & $0.239 \pm 0.019$ & $0.769 \pm 0.049$ & $0.803 \pm 0.047$ \\
\hline Total hydroxide (M) & $4.04 \pm 0.14$ & $3.88 \pm 0.13$ & $6.07 \pm 0.20$ & $5.88 \pm 0.20$ \\
\hline $\begin{array}{l}\text { Saturated dissolved } \mathrm{Al}(\mathrm{M}) \\
\text { from equations in } \\
\text { Section A.4 }\end{array}$ & $0.788 \pm 0.030$ & $0.753 \pm 0.028$ & $1.351 \pm 0.070$ & $1.285 \pm 0.065$ \\
\hline
\end{tabular}

\subsubsection{Results of Kinetic Modeling of Laboratory-Scale Tests}

Table 4.9 contains population statistics for each of the four laboratory-scale tests for $k$ and for the boehmite leach factors predicted by the best-fit kinetic model at $16 \mathrm{hr}$ and $24 \mathrm{hr}$, using 500 Monte Carlo realizations. The deterministic $\mathrm{R}^{2}$ for the model fit to the normalized dissolved data is also included in the table. For comparison, the WTP target projections ${ }^{(a)}$ for the 16-hr boehmite leach factors for PEP Integrated Test A and Integrated Test B were, respectively, 0.28 and 0.38 .

The boehmite leach factors calculated by the best-fit kinetic model for $16 \mathrm{hr}$ and $24 \mathrm{hr}$ of leach were compared with those calculated from the total Al leach factors (Table 4.5 and Table 4.6). The correspondence between the boehmite leach factors from the two types of calculations was within one standard deviation. However, it was not as close a match as for the PEP Integrated tests, suggesting greater internal inconsistency in the laboratory-scale data.

In the case of Test A-1, the 16-hr and 24-hr boehmite leach factors calculated from the total Al leach factor were low compared to the kinetic predictions: $0.30(\mathrm{Al})$ versus 0.35 (kinetic) and $0.44(\mathrm{Al})$ versus 0.48 (kinetic). The opposite trend was shown for Test A-2: 0.33 (Al) versus 0.31 (kinetic) and 0.46 (Al) versus 0.42 (kinetic). It appears that if the rate constant best-fit had been based on comparing the model-predicted boehmite leach factor to the value calculated from the total Al leach factor, rather than on comparing predicted and measured concentrations of dissolved Al, the rate constant could have been lower than the value in Table 4.9 for Test A-1 and higher for Test A-2.

Tests B-1 and B-2 showed less difference between the boehmite leach factors calculated by the best-fit kinetic model and those from the total Al leach factor. In Test B-1, the 16-hr and 24-hr boehmite leach factors calculated from the total $\mathrm{Al}$ leach factor were generally equal to or greater than the kinetic predictions: $0.28(\mathrm{Al})$ versus 0.27 (kinetic) and 0.37 (Al) versus 0.37 (kinetic). The same trend was shown for Test B-2: 0.34 (Al) versus 0.31 (kinetic) and 0.42 (Al) versus 0.41 (kinetic).

(a) The projections of boehmite leach factor were made by WTP and transmitted to D.E. Kurath and L.A. Mahoney by e-mail from J.L. Huckaby on June 15, 2009 (6:25 AM). 
Table 4.9. Kinetic Model Results for Laboratory-Scale Tests

\begin{tabular}{|c|c|c|c|c|}
\hline & \multicolumn{2}{|c|}{ Test A (caustic-leach in UFP-T01A) } & \multicolumn{2}{|c|}{ Test B (caustic-leach in UFP-T02A) } \\
\hline & $\begin{array}{l}\text { Laboratory-Scale } \\
\text { Test A-1 (NaOH } \\
\text { added in PEP) }\end{array}$ & $\begin{array}{c}\text { Laboratory-Scale } \\
\text { Test A-2 (NaOH } \\
\text { added in lab) }\end{array}$ & $\begin{array}{l}\text { Laboratory-Scale } \\
\text { Test B-1 (NaOH } \\
\text { added in PEP) }\end{array}$ & $\begin{array}{c}\text { Laboratory-Scale } \\
\text { Test B-2 (NaOH } \\
\text { added in PEP) }\end{array}$ \\
\hline $\begin{array}{l}\text { Rate constant } k \\
\left(\mathrm{hr}^{-1} *[\text { mol total OH} / \mathrm{L}]^{-1}\right)\end{array}$ & $\begin{array}{c}\text { lower 95\%: } 0.0144 \\
\text { median: } 0.0227 \\
\text { upper 95\%: } 0.0384\end{array}$ & $\begin{array}{c}\text { lower } 95 \%: \\
0.0126 \\
\text { median: } 0.0194 \\
\text { upper } 95 \% \text { : } \\
0.0298\end{array}$ & $\begin{array}{c}\text { lower 95\%: } 0.0113 \\
\text { median: } 0.0166 \\
\text { upper 95\%: } 0.0251\end{array}$ & $\begin{array}{c}\text { lower } 95 \%: \\
0.0139 \\
\text { median: } 0.0199 \\
\text { upper } 95 \% \text { : } \\
0.0290\end{array}$ \\
\hline $\begin{array}{l}\text { Boehmite leach factor at } \\
16 \mathrm{hr} \text { as predicted by the } \\
\text { best-fit kinetic model }\end{array}$ & $\begin{array}{c}\text { lower 95\%: } 0.22 \\
\text { median: } 0.35 \\
\text { upper 95\%: } 0.54\end{array}$ & $\begin{array}{c}\text { lower 95\%: } 0.20 \\
\text { median: } 0.31 \\
\text { upper 95\%: } 0.43\end{array}$ & $\begin{array}{c}\text { lower 95\%: } 0.20 \\
\text { median: } 0.27 \\
\text { upper 95\%: } 0.36\end{array}$ & $\begin{array}{c}\text { lower 95\%: } 0.24 \\
\text { median: } 0.31 \\
\text { upper 95\%: } 0.40\end{array}$ \\
\hline $\begin{array}{l}\text { Boehmite leach factor at } \\
24 \mathrm{hr} \text { as predicted by the } \\
\text { best-fit kinetic model }\end{array}$ & $\begin{array}{c}\text { lower 95\%: } 0.31 \\
\text { median: } 0.48 \\
\text { upper 95\%: } 0.69\end{array}$ & $\begin{array}{l}\text { lower 95\%: } 0.28 \\
\text { median: } 0.42 \\
\text { upper 95\%: } 0.57\end{array}$ & $\begin{array}{l}\text { lower 95\%: } 0.27 \\
\text { median: } 0.37 \\
\text { upper 95\%: } 0.47\end{array}$ & $\begin{array}{c}\text { lower 95\%: } 0.32 \\
\text { median: } 0.41 \\
\text { upper 95\%: } 0.50\end{array}$ \\
\hline $\begin{array}{l}\text { Deterministic } \mathrm{R}^{2} \text { for the } \\
\text { kinetic model fit }\end{array}$ & 0.96 & 0.97 & 1.00 & 0.98 \\
\hline
\end{tabular}

\subsection{Scale-Up Factors}

The scale-up factor needed for G2 modeling of WTP operations is an adjustment factor for the rate constant in the boehmite leach kinetic equation in the G2 model. The factor accounts for any differences between laboratory-scale and plant-scale caustic leaching performance. As discussed in Section 3.0, the PEP was designed and operated to maximize its similarity to the plant so that the caustic-leach scale factor for extending PEP results to the plant is 1. Because Integrated Test A and Integrated Test B caustic leaching processes were controlled as intended and considered to be prototypic of the plant, the bench to plant scale-up factor is considered here to be the same as the bench to PEP scale-up factor. The bench to PEP scale-up factor is obtained by dividing the rate constant determined from PEP testing by the rate constant determined by a corresponding laboratory-scale test, $k_{P E P} / k_{\text {lab }}$. These ratios, based on the population obtained by 500 Monte Carlo realizations, are given in Table 4.10 and Table 4.11 together with the initial conditions and $k$ values that produced them. Table 4.10 and Table 4.11 also show, for all six tests, the initial dissolved $\mathrm{Al}$ concentration that was measured and the one that was found from the Monte Carlo population of best fits. The difference between measurement and best fit is not significant.

The rate constants, and by extension the scale-up factors, are strongly dependent on the initial concentrations of boehmite (mol boehmite per volume liquid) and total hydroxide and on the change in dissolved $\mathrm{Al}$ concentration during digestion. Given the same change in dissolved $\mathrm{Al}$ from digestion, the rate constant is approximately inversely proportional to initial total hydroxide and boehmite. The rate constant is sensitive to total hydroxide, which appears in kinetic equation (4.1), both directly and in the saturated Al concentration in the liquid. The broad confidence intervals on the rate constants are primarily due to the uncertainty in initial conditions.

To put this in context, the uncertainty (two standard deviations) of any single measurement is relatively small. The concentrations in their as-measured units have 5 to $6 \%$ relative uncertainty, and the relative uncertainties for the UDS weight fraction and the densities are smaller. The combination of 
measurement uncertainties for unit conversions, concentration normalization, and calculation of the fraction of solid-phase $\mathrm{Al}$ present as boehmite leads to a higher propagated uncertainty in the kinetic initial conditions (Table 4.2 and Table 4.8).

Table 4.10. Scale-Up Factors and Their Basis Inputs for PEP Integrated Test A and Associated Lab Tests

\begin{tabular}{|c|c|c|c|}
\hline & $\begin{array}{c}\text { PEP Integrated } \\
\text { Test A (caustic-leach } \\
\text { in UFP-T01A) }\end{array}$ & $\begin{array}{l}\text { Laboratory-Scale } \\
\text { Test A-1 (NaOH } \\
\text { added in PEP) }\end{array}$ & $\begin{array}{l}\text { Laboratory-Scale } \\
\text { Test A-2 (NaOH } \\
\text { added in lab) }\end{array}$ \\
\hline Scale-up factor, $k_{P E P} / k_{l a b}$ & $\mathrm{n} / \mathrm{a}$ & $\begin{array}{c}\text { low 95\%: } 0.44 \\
\text { low 50\%: } 0.64 \\
\text { median: } 0.79 \\
\text { high 50\%: } 0.97 \\
\text { high 95\%: } 1.45\end{array}$ & $\begin{array}{c}\text { low 95\%: } 0.55 \\
\text { low 50\%: } 0.78 \\
\text { median: } 0.95 \\
\text { high 50\%: } 1.15 \\
\text { high 95\%: } 1.64\end{array}$ \\
\hline $\begin{array}{l}\text { Rate constant } k\left(\mathrm{hr}^{-1} *[\mathrm{~mol}\right. \\
\left.\text { total } \mathrm{OH} / \mathrm{L}]^{-1}\right)\end{array}$ & $\begin{array}{c}\text { low 95\%: } 0.0128 \\
\text { low 50\%: } 0.0165 \\
\text { median: } 0.0186 \\
\text { high 50\%: } 0.0206 \\
\text { high 95\%: } 0.0250\end{array}$ & $\begin{array}{c}\text { low 95\%: } 0.0144 \\
\text { low 50\%: } 0.0195 \\
\text { median: } 0.0227 \\
\text { high 50\%: } 0.0279 \\
\text { high 95\%: } 0.0384\end{array}$ & $\begin{array}{c}\text { low 95\%: } 0.0126 \\
\text { low 50\%: } 0.0168 \\
\text { median: } 0.0194 \\
\text { high 50\%: } 0.0224 \\
\text { high 95\%: } 0.0298\end{array}$ \\
\hline $\begin{array}{l}\text { Initial dissolved } \mathrm{Al}(\mathrm{M}) \\
\text { from the data }\end{array}$ & $0.318 \pm 0.010$ & $0.321 \pm 0.017$ & $0.279 \pm 0.016$ \\
\hline $\begin{array}{l}\text { Initial dissolved } \mathrm{Al}(\mathrm{M}) \\
\text { from the model fit }\end{array}$ & $0.312 \pm 0.008$ & $0.312 \pm 0.010$ & $0.287 \pm 0.010$ \\
\hline $\begin{array}{l}\text { Initial boehmite (mol/L } \\
\text { liquid) }\end{array}$ & $0.306 \pm 0.011$ & $0.192 \pm 0.021$ & $0.239 \pm 0.019$ \\
\hline Initial total hydroxide (M) & $4.29 \pm 0.11$ & $4.04 \pm 0.14$ & $3.88 \pm 0.13$ \\
\hline $\begin{array}{l}\text { Initial saturated dissolved } \\
\mathrm{Al}(\mathrm{M}) \text {, calculated from } \\
\text { total hydroxide using } \\
\text { equations in Section A.4 }\end{array}$ & $0.859 \pm 0.028$ & $0.788 \pm 0.030$ & $0.753 \pm 0.028$ \\
\hline $\begin{array}{l}\text { The scale-up factor and } k \text { entri } \\
\text { median, as calculated by } 500 \mathrm{~N} \\
\pm \text { a standard deviation calculat } \\
\text { measurements were the basis } \mathrm{f}\end{array}$ & $\begin{array}{l}\text { ow the } 95 \% \text { confidenc } \\
\text { te Carlo realizations. Tl } \\
\text { y } 500 \text { Monte Carlo real } \\
\text { stimating all error. }\end{array}$ & $\begin{array}{l}\text { erval and } 50 \% \text { confic } \\
\text { itial conditions cons } \\
\text { ons. Estimates of la }\end{array}$ & $\begin{array}{l}\text { terval around the } \\
\text { deterministic estimate } \\
\text { y error in }\end{array}$ \\
\hline
\end{tabular}

Because of the high uncertainty, the sources of uncertainty were assessed. The first question was the extent to which the uncertainty in the scale-up factor came from PEP data versus laboratory-scale data. Because the scale-up factor is the ratio of kinetic rate constants between a PEP run and an associated lab-scale analysis, the variance of the scale-up factor can be approximated by the following equation (p. 181, Mood et al. 1974):

$$
\sigma_{S U}^{2} \approx\left(\frac{\mu_{k P E P}}{\mu_{k l a b}}\right)^{2}\left(\frac{\sigma_{k P E P}^{2}}{\mu_{k P E P}^{2}}+\frac{\sigma_{k l a b}^{2}}{\mu_{k l a b}^{2}}\right)
$$

where $\quad \sigma_{S U}=$ the standard deviation of the scale-up factor (variance is the square of the standard deviation)

$\sigma_{k P E P}=$ standard deviation of the rate constant from the PEP test, calculated by Monte Carlo $\mu_{k P E P}=$ mean of the Monte-Carlo population of rate constants from the PEP Integrated test 
$\sigma_{k l a b}=$ standard deviation of the rate constant from the laboratory-scale test, calculated by Monte Carlo

$\mu_{k l a b}=$ mean of the Monte-Carlo population of rate constants from the laboratory-scale test.

Table 4.11. Scale-Up Factors and Their Basis Inputs for PEP Integrated Test B and Associated Lab Tests

\begin{tabular}{|c|c|c|c|}
\hline & $\begin{array}{c}\text { PEP Integrated } \\
\text { Test A (caustic-leach } \\
\text { in UFP-T02A) }\end{array}$ & $\begin{array}{l}\text { Laboratory-Scale } \\
\text { Test B-1 (NaOH } \\
\text { added in PEP) }\end{array}$ & $\begin{array}{c}\text { Laboratory-Scale } \\
\text { Test B-2 (NaOH } \\
\text { added in PEP) }\end{array}$ \\
\hline Scale-up factor, $k_{P E P} / k_{l a b}$ & $\mathrm{n} / \mathrm{a}$ & $\begin{array}{c}\text { low 95\%: } 0.89 \\
\text { low 50\%: } 1.20 \\
\text { median: } 1.51 \\
\text { high 50\%: } 1.83 \\
\text { high 95\%: } 2.63\end{array}$ & $\begin{array}{c}\text { low 95\%: } 0.77 \\
\text { low 50\%: } 1.03 \\
\text { median: } 1.26 \\
\text { high 50\%: } 1.53 \\
\text { high 95\%: } 2.14\end{array}$ \\
\hline $\begin{array}{l}\text { Rate constant } k\left(\mathrm{hr}^{-1} *[\mathrm{~mol}\right. \\
\left.\text { total } \mathrm{OH} / \mathrm{L}]^{-1}\right)\end{array}$ & $\begin{array}{c}\text { low 95\%: } 0.0182 \\
\text { low 50\%: } 0.0224 \\
\text { median: } 0.0251 \\
\text { high 50\%: } 0.0280 \\
\text { high 95\%: } 0.0344\end{array}$ & $\begin{array}{c}\text { low 95\%: } 0.0113 \\
\text { low 50\%: } 0.0147 \\
\text { median: } 0.0166 \\
\text { high 50\%: } 0.0192 \\
\text { high 95\%: } 0.0251\end{array}$ & $\begin{array}{c}\text { low 95\%: } 0.0139 \\
\text { low 50\%: } 0.0176 \\
\text { median: } 0.0199 \\
\text { high 50\%: } 0.0227 \\
\text { high 95\%: } 0.0290\end{array}$ \\
\hline $\begin{array}{l}\text { Initial dissolved } \mathrm{Al}(\mathrm{M}) \\
\text { from the data }\end{array}$ & $0.720 \pm 0.023$ & $0.638 \pm 0.037$ & $0.584 \pm 0.034$ \\
\hline $\begin{array}{l}\text { Initial dissolved } \mathrm{Al}(\mathrm{M}) \\
\text { from the model fit }\end{array}$ & $0.721 \pm 0.020$ & $0.641 \pm 0.021$ & $0.595 \pm 0.020$ \\
\hline $\begin{array}{l}\text { Initial boehmite (mol/L } \\
\text { liquid) }\end{array}$ & $0.795 \pm 0.029$ & $0.769 \pm 0.049$ & $0.803 \pm 0.047$ \\
\hline Initial total hydroxide (M) & $6.27 \pm 0.14$ & $6.07 \pm 0.20$ & $5.88 \pm 0.20$ \\
\hline $\begin{array}{l}\text { Initial saturated dissolved } \\
\mathrm{Al}(\mathrm{M}) \text {, calculated from } \\
\text { total hydroxide using } \\
\text { equations in Section A.4 }\end{array}$ & $1.44 \pm 0.05$ & $1.35 \pm 0.07$ & $1.29 \pm 0.07$ \\
\hline \multicolumn{4}{|c|}{$\begin{array}{l}\text { The scale-up factor and } k \text { entries show the } 95 \% \text { confidence interval and } 50 \% \text { confidence interval around the } \\
\text { median, as calculated by } 500 \text { Monte Carlo realizations. The initial conditions consist of a deterministic estimate } \\
\pm \text { a standard deviation calculated by } 500 \text { Monte Carlo realizations. Estimates of laboratory error in } \\
\text { measurements were the basis for estimating all error. }\end{array}$} \\
\hline
\end{tabular}

This form of the equation is based on the assumption that measurement uncertainty in the PEP data is statistically independent of the measurement uncertainty for the laboratory-scale data, allowing covariance terms to be omitted. This equation was not used to calculate the statistical results provided elsewhere in this document, but it illustrates how the uncertainty of the scale-up factor can be apportioned among the two individual contributions.

Calculating the standard deviation of the scale-up factor using Equation (4.7) requires the following four quantities: $\mu_{k P E P}=0.0186, \mu_{k L a b}=0.0240, \sigma_{k P E P}^{2}=1.003 \mathrm{E}-5$, and $\sigma_{k l a b}^{2}=4.205 \mathrm{E}-5$. Using these values, the standard deviation of the scale-up factor is 0.248 . The usefulness of the approximation is verified by noting that 0.248 is close to the standard deviation of 0.260 obtained from the full Monte Carlo analysis. 
The approximate variance equation can be used to apportion the uncertainty contributions by zeroing out one variance term or the other. Using this approach, $72 \%$ of the variance in the scale-up factor for PEP A/Lab A-1 is attributable to the variance of lab-scale results, and the other $28 \%$ is attributable to the variance of the PEP results.

Next, the uncertainty in the rate constants was assessed. A series of Monte Carlo runs were used to examine sources of uncertainty in the calculated rate constants for PEP Integrated Test A and laboratory-scale Test A-1. Each run eliminated the uncertainty of one type of measurement while not changing the uncertainties of the other measurements. For example, eliminating the uncertainty in liquid tracer concentrations in this PEP data set required setting the uncertainties for nine individual measurements to negligibly small values. Another example case, that of the initial dissolved aluminum concentration for PEP, eliminates the variance in a single measured aluminum concentration. Results are shown in Table 4.12.

Table 4.12. Sources of Uncertainty in Kinetic Rate Constants

\begin{tabular}{lcc}
\hline \multicolumn{1}{c}{$\begin{array}{c}\text { Percent of the Rate-Constant Variance That is Explained by the } \\
\text { Uncertainty in }\end{array}$} & $\begin{array}{c}\text { For PEP } \\
\text { Integrated } \\
\text { Test A }\end{array}$ & $\begin{array}{c}\text { For } \\
\text { Laboratory-Scale } \\
\text { Test A-1 }\end{array}$ \\
\hline wt\% UDS & $0.0 \%$ & $0.0 \%$ \\
Liquid density & $2.9 \%$ & $2.1 \%$ \\
Initial free hydroxide concentration & $3.9 \%$ & $0.4 \%$ \\
Liquid-tracer concentrations & $62.0 \%$ & $65.4 \%$ \\
Initial dissolved Al concentration & $1.7 \%$ & not calculated \\
All dissolved Al concentrations together & $29.9 \%$ & $30.6 \%$ \\
Initial concentration of Al in the centrifuged solids or slurry & $2.0 \%$ & $9.5 \%$ \\
Initial fraction of centrifuged solids in the slurry sample & $0.5 \%$ & not measured \\
Initial boehmite concentration & $5.4 \%$ & $40.7 \%$ \\
Combined liquid tracer and all dissolved Al concentrations & $91.2 \%$ & $89.6 \%$ \\
\hline
\end{tabular}

The Monte Carlo runs in which the variance of a single type of measurement is set to $\sim 0$ serve to identify the effect of that particular type of measurement on the variance of the rate constant. The last row of the table shows the result of a Monte Carlo run with combined effects. Here the two most significant measurement variances were eliminated: the variances of liquid tracer and dissolved $\mathrm{Al}$ concentrations. The combined runs show that uncertainty in these two types of data together accounts for about $90 \%$ of the uncertainty in the rate constant.

The run in which the variance in initial boehmite concentration was eliminated (next to last row in the table) was handled slightly differently from the other runs. The boehmite concentration is a calculated quantity, not a direct measurement like others in the table. Its variance depends on that of several measurements (including two tracer concentrations, the slurry Al concentration, the UDS, and a dissolved $\mathrm{Al}$ concentration). The Monte Carlo run for the effect of variance of boehmite concentration uses an $\sim 0$ variance value for the boehmite concentration without modifying the variances of the measurements from which the boehmite concentration was calculated. This approach allowed the effect of boehmite concentration to be pinpointed without including any side effects. It should also be noted that the combined run, in which the variances in liquid tracers and $\mathrm{Al}$ concentrations were all eliminated, necessarily reduced the variance of the boehmite concentration because it depended in part on those 
measurements. In this case, the effect on the variance of the rate constant was not that of a change in boehmite concentration variance alone.

These results identify the major sources of uncertainty in the calculated scale-up factors for the rate constants. The need to adjust for changes in liquid volume, which is done by using liquid tracer concentrations, accounts for a significant amount of uncertainty. Most of the rest of the uncertainty is attributable to the analytical uncertainty in determining the concentration of aluminum in liquid. In the case of the laboratory-scale Test A-1, there is one more source of uncertainty, the uncertainty in the initial boehmite concentration. This is an outcome of the inconsistency between slurry Al concentration measurements that was discussed in relation to Table 4.7.

Given the broad overlapping confidence intervals, the rate constants from the six PEP and laboratory-scale tests are not statistically distinguishable from each other at a $95 \%$ confidence level. It is possible that the scale-up factor is unity or greater both for caustic leaching in UFP-T01A and in UFP-T02A. The probability of this hypothesis is about $23 \%$ for Test A/Test A-1, $42 \%$ for Test $\mathrm{A} /$ Test $\mathrm{A}-2,90 \%$ for Test $\mathrm{B} /$ Test $\mathrm{B}-1$, and $77 \%$ for Test $\mathrm{B} /$ Test $\mathrm{B}-2$. These probabilities were calculated on the assumption that no systematic biases were introduced by experimental, sampling, or analytical laboratory methods.

The results suggest that the scale-up factor is less for caustic leaching in UFP-T01A than in UFP-T02A and raise the possibility that a scale-up factor of greater than one might be obtained from leaching in UFP-T02A. The reasons for scale-up factors significantly less than or greater than one are not completely clear.

In interpreting the scale-up factors, the possibility of systematic bias in the experiments should be considered. As noted in Section 4.2, the laboratory-scale experiments related to UFP-1 leach (Tests A-1 and A-2) showed differences in dilution trends between solid tracers and total $\mathrm{Na}$, on the one hand, and liquid tracers and Al, on the other. These discrepancies suggest some kind of internal inconsistency in the laboratory-scale data for these tests. However, the UFP-2 laboratory-scale tests (B-1 and B-2) did not show the same discrepancies.

There are, potentially, physical causes for differences in scale-up factors. Kuhn et al. (2008) discussed the ways in which imperfect mixing that allowed spatial variations in temperature and solids distribution could affect the extent of leaching. The authors treated the boehmite leaching reaction as depending on temperature, the concentration of boehmite in the slurry, and the dissolved concentrations of the reagent and the dissolved Al. They did not quantify the effects of spatial variation, but found (p. 3.11 of the reference) that for a given average temperature non-uniformity caused conversion to be greater than for a uniform temperature, and for a given average initial concentration of boehmite non-uniformity caused conversion to be less than for a uniform boehmite concentration. Note that these are the results of physical variability in the process conditions within a vessel, as distinct from the measurement uncertainties that have been shown in the tables and plots in this report.

Spatial variability might explain the apparent differences in scale-up factor. For example, if the boehmite concentration was less uniform in UFP-1 leaching in PEP than in the laboratory-scale beaker, the conversion would be lower in the PEP test and a kinetic rate constant that was fit to the PEP data would appear to be lower. The scale-up factor would be less than unity. Similarly, if the temperature was less uniform in UFP-2 leaching in PEP than in the beaker, the conversion would be higher in the PEP test, yielding an apparently higher rate constant and a scale-up factor greater than unity. If the effective 
boehmite particle surface area was not the same in PEP leaching as in laboratory-scale leaching, perhaps because different local shear forces led to different degrees of aggregation, this could also cause differences in the apparent kinetic rate constant and so in the scale-up factor. These explanations are speculative, however, considering the discrepancies within some tests and the broad confidence intervals produced by propagation of measurement uncertainty.

For completeness, though not for use in deriving scale-up factors, Table 4.13 shows the 16-hr boehmite leach factors calculated from total $\mathrm{Al}$ leach factors (liquid tracer method) and from the best-fit kinetic model for all six tests. The WTP-projected 16-hr boehmite leach factors are also shown. Note that the direct comparison of PEP and laboratory-scale leach factors can give a misleading impression about the relative rate constants and rates of reaction. For example, the PEP Integrated Test A leach factors are comparable to the laboratory-scale Test A-1 and A-2 leach factors, apparently supporting the possibility that the scale-up factor was 1 . However, Tests A-1 and A-2 have substantially lower initial boehmite concentrations and somewhat lower initial hydroxide concentration than PEP Integrated Test A (Table 4.10). Since Equation (4.1) shows that the leach rate depends on these initial reactant concentrations, the fact that the leach factors in the laboratory-scale tests are comparable to PEP Integrated Test A indicates not that reaction rate was comparable, but that it must have been higher in the lab tests to overcome the relative deficit in initial concentration. Because the G2 model's calculation of leach effectiveness depends on a kinetic rate constant rather than on leach factors, the scale-up factor must be based on the test results for rate constants.

Table 4.13. Comparison of Boehmite Leach Factors ${ }^{(a)}$

\begin{tabular}{|c|c|c|c|}
\hline & $\begin{array}{c}\text { Boehmite Leach Factor } \\
(16 \mathrm{hr}) \text { Based on Liquid } \\
\text { Tracer Leach Factor for Al }\end{array}$ & $\begin{array}{c}\text { Boehmite Leach } \\
\text { Factor (16 hr) Based } \\
\text { on Kinetic Model Fit }\end{array}$ & $\begin{array}{c}\text { WTP Projected } \\
\text { Boehmite Leach } \\
\text { Factor }(16 \mathrm{hr})\end{array}$ \\
\hline $\begin{array}{l}\text { PEP Integrated Test A } \\
\text { (UFP-T01A leaching) }\end{array}$ & $\begin{array}{c}\text { Low 95\%: } 0.28 \\
\text { Median: } 0.34 \\
\text { Upper 95\%: } 0.40\end{array}$ & $\begin{array}{c}\text { Low 95\%: } 0.23 \\
\text { Median: } 0.33 \\
\text { Upper 95\%: } 0.41\end{array}$ & 0.28 \\
\hline $\begin{array}{l}\text { Laboratory-Scale Test A-1 } \\
(\mathrm{NaOH} \text { added in PEP) }\end{array}$ & $\begin{array}{l}\text { Low 95\%: } 0.090 \\
\text { Median: } 0.30 \\
\text { Upper 95\%: } 0.51\end{array}$ & $\begin{array}{l}\text { Low 95\%: } 0.22 \\
\text { Median: } 0.35 \\
\text { Upper 95\%: } 0.54\end{array}$ & \\
\hline $\begin{array}{l}\text { Laboratory-Scale Test A-2 } \\
(\mathrm{NaOH} \text { added in lab) }\end{array}$ & $\begin{array}{l}\text { Low 95\%: } 0.18 \\
\text { Median: } 0.33 \\
\text { Upper 95\%: } 0.49\end{array}$ & $\begin{array}{l}\text { Low 95\%: } 0.20 \\
\text { Median: } 0.31 \\
\text { Upper 95\%: } 0.43\end{array}$ & \\
\hline $\begin{array}{l}\text { PEP Integrated Test B } \\
\text { (UFP-T02A leaching) }\end{array}$ & $\begin{array}{l}\text { Low 95\%: } 0.25 \\
\text { Median: } 0.33 \\
\text { Upper 95\%: } 0.42\end{array}$ & $\begin{array}{l}\text { Low 95\%: } 0.26 \\
\text { Median: } 0.34 \\
\text { Upper 95\%: } 0.43\end{array}$ & 0.38 \\
\hline $\begin{array}{l}\text { Laboratory-Scale Test B-1 } \\
(\mathrm{NaOH} \text { added in PEP) }\end{array}$ & $\begin{array}{c}\text { Low 95\%: } 0.17 \\
\text { Median: } 0.28 \\
\text { Upper 95\%: } 0.40\end{array}$ & $\begin{array}{c}\text { Low 95\%: } 0.20 \\
\text { Median: } 0.27 \\
\text { Upper 95\%: } 0.36\end{array}$ & \\
\hline $\begin{array}{l}\text { Laboratory-Scale Test B-2 } \\
(\mathrm{NaOH} \text { added in PEP) }\end{array}$ & $\begin{array}{l}\text { Low 95\%: } 0.24 \\
\text { Median: } 0.34 \\
\text { Upper 95\%: } 0.46\end{array}$ & $\begin{array}{l}\text { Low 95\%: } 0.24 \\
\text { Median: } 0.31 \\
\text { Upper 95\%: } 0.40\end{array}$ & \\
\hline
\end{tabular}

(a) The projections of boehmite leach factor were made by WTP and transmitted to DE Kurath and LA Mahoney by e-mail from JL Huckaby on June 15, 2009 (6:25 AM). 


\subsection{Conclusions and Recommendations}

Caustic-leach scale-up factors for use in the G2 model were developed from experimental rate constants for boehmite dissolution. A kinetic model (Equation [4.1]) was fitted to the time history of dissolved aluminum concentrations measured in samples taken over the course of leaching. The rate constants were developed from two PEP tests, Integrated Test A (caustic-leach in vessel UFP-T01A) and Integrated Test B (caustic-leach in vessel UFP-T02A) and from four laboratory-scale tests. Two of the lab tests (A-1 and A-2) were carried out on slurry taken from PEP Integrated Test A samples and two (B-1 and B-2) on slurry from PEP Integrated Test B. The rate constants from the PEP and the laboratory-scale tests were ratioed to give PEP/lab scale-up factors. Because the PEP was designed and operated to be prototypic of the $\mathrm{PTF}$, and its operation reasonably satisfied prototypic operational criteria, the PEP/lab scale-up factor is assumed to be the same as the plant/lab scale-up factor, and the former can be used directly in the G2 model.

The uncertainty in measured concentrations and temperatures was accounted for, in data analysis, by using a Monte Carlo approach. Each equation required for data analysis was solved a number of times, each time varying all the data within normal distributions defined by the uncertainty of the laboratory analytical method (assuming a normal distribution of uncertainty around a mean of zero). The resulting populations of parameters could be defined in terms of a median and standard deviation, in some cases, or in terms of a median and the lower and upper bounds of a $95 \%$ confidence interval around the median. Table 5.1 shows the results of the stochastic kinetic model. Much of the uncertainty comes from uncertainty in the initial-condition concentrations used as inputs to the kinetic model.

To put this in context, the uncertainty of any single measurement is generally $6 \%$ or less. The combination of measurement uncertainties for unit conversions, concentration normalization, and calculation of the fraction of solid-phase Al present as boehmite leads to a higher propagated uncertainty in the kinetic initial conditions. The need to adjust for changes in liquid volume, which is done by using liquid tracer concentrations, accounts for a significant amount of uncertainty. Most of the rest of the uncertainty is attributable to the analytical uncertainty in determining the concentration of aluminum in liquid. In the case of the laboratory-scale tests, there is one more source of uncertainty, the uncertainty in the initial boehmite concentration that results from uncertainty in the initial slurry Al concentration.

The laboratory-scale tests evinced higher uncertainty than the PEP tests and some inconsistencies in measured concentrations of aluminum and other predominantly solid-phase species. Inconsistencies were seen between in-PEP and in-beaker concentrations as well as between in-beaker concentrations at the beginning and end of the test. The possible causes were non-representative sampling from PEP vessels or from the beaker, or non-representative transfer of the PEP feed slurry into the beaker as a result of settling. To address these concerns in any future work, the following changes in approach are recommended:

1. Take more slurry samples from the beaker, particularly at the start of constant-temperature leaching $(0 \mathrm{hr})$ and at the end of the PEP leach time if it differs from the end time of the laboratory-scale run (as it did for Tests A and B). These samples — analyzed for UDS, densities, and composition — will provide direct data for the kinetic initial condition and for the PEP endpoint.

2. Analyze a 0 -hr slurry sample by XRD or other phase-identifying methods to confirm the absence of gibbsite. 
3. Conduct more than two parallel laboratory-scale runs for each PEP run to reduce uncertainty.

4. Take only as much slurry from PEP as is needed to provide feed for the laboratory-scale tests. Leaving an excess behind in the bottle may induce a disproportionate fraction of solids to be left behind because of settling. If there is an excess, take a sample of the slurry to check for a change in composition and UDS.

5. While sampling slurry from the beaker, temporarily increase the agitator speed to enhance mixing and ensure a homogeneous slurry.

Given the broad overlapping confidence intervals, the rate constants from the six PEP and laboratory-scale tests are not statistically distinguishable from each other at a $95 \%$ confidence level. It is possible that the scale-up factor is unity or greater both for caustic leaching in UFP-T01A and in UFP-T02A. The probability of this hypothesis is about $21 \%$ for Test A/Test A-1, $43 \%$ for Test $\mathrm{A} /$ Test $\mathrm{A}-2,93 \%$ for Test $\mathrm{B} /$ Test $\mathrm{B}-1$, and $77 \%$ for Test $\mathrm{B} /$ Test $\mathrm{B}-2$. These probabilities were calculated on the assumption that no systematic biases were introduced by experimental, sampling, or analytical laboratory methods.

The results suggest that the scale-up factor is less for caustic leaching in UFP-T01A than in UFP-T02A and raise the possibility that a scale-up factor of greater than one might be obtained from leaching in UFP-T02A. The reasons for scale-up factors significantly less than or greater than one are not completely clear.

Table 5.1. Scale-Up Factors and Kinetic Rate Constants for PEP Integrated and Laboratory-Scale Tests

\begin{tabular}{|c|c|c|}
\hline & $\begin{array}{l}\text { Rate Constant } k \\
\left(\mathrm{hr}^{-1} *[\mathrm{~mol} \text { total }\right. \\
\left.\mathrm{OH} / \mathrm{L}]^{-1}\right)\end{array}$ & $\begin{array}{l}\text { Scale-Up Factor, } \\
k_{P E P} / k_{l a b}\end{array}$ \\
\hline $\begin{array}{l}\text { PEP Integrated Test A } \\
\text { (caustic-leach in UFP-T01A) }\end{array}$ & $\begin{array}{c}\text { low 95\%: } 0.0128 \\
\text { median: } 0.0186 \\
\text { upper 95\%: } 0.0250\end{array}$ & --- \\
\hline $\begin{array}{l}\text { Laboratory-Scale Test A-1 } \\
(\mathrm{NaOH} \text { added in PEP) }\end{array}$ & $\begin{array}{c}\text { low 95\%: } 0.0144 \\
\text { median: } 0.0227 \\
\text { upper 95\%: } 0.0384\end{array}$ & $\begin{array}{c}\text { low 95\%: } 0.44 \\
\text { median: } 0.79 \\
\text { upper 95\%: } 1.45\end{array}$ \\
\hline $\begin{array}{l}\text { Laboratory-Scale Test A-2 } \\
(\mathrm{NaOH} \text { added in lab) }\end{array}$ & $\begin{array}{c}\text { low 95\%: } 0.0126 \\
\text { median: } 0.0194 \\
\text { upper 95\%: } 0.0298\end{array}$ & $\begin{array}{c}\text { low 95\%: } 0.55 \\
\text { median: } 0.95 \\
\text { upper } 95 \%: 1.64\end{array}$ \\
\hline $\begin{array}{l}\text { PEP Integrated Test B } \\
\text { (caustic-leach in UFP-T02A) }\end{array}$ & $\begin{array}{c}\text { low 95\%: } 0.0182 \\
\text { median: } 0.0251 \\
\text { upper 95\%: } 0.0344\end{array}$ & --- \\
\hline $\begin{array}{l}\text { Laboratory-Scale Test B-1 } \\
(\mathrm{NaOH} \text { added in PEP) }\end{array}$ & $\begin{array}{c}\text { low 95\%: } 0.0113 \\
\text { median: } 0.0166 \\
\text { upper 95\%: } 0.0251\end{array}$ & $\begin{array}{c}\text { low 95\%: } 0.89 \\
\text { median: } 1.51 \\
\text { upper: } 2.63\end{array}$ \\
\hline $\begin{array}{l}\text { Laboratory-Scale Test B-2 } \\
(\mathrm{NaOH} \text { added in PEP) }\end{array}$ & $\begin{array}{c}\text { low 95\%: } 0.0139 \\
\text { median: } 0.0199 \\
\text { upper 95\%: } 0.0290\end{array}$ & $\begin{array}{c}\text { low } 95 \%: 0.77 \\
\text { median: } 1.26 \\
\text { upper: } 2.14\end{array}$ \\
\hline
\end{tabular}




\subsection{References}

Kuhn WL, ST Arm, JL Huckaby, DE Kurath, and SD Rassat. 2008. Technical Basis for Scaling Relationships for the Pretreatment Engineering Platform. WTP-RPT-160, PNNL-16948, Pacific Northwest National Laboratory, Richland, Washington.

Mood AM, FA Graybill, and DC Boes. 1974. Introduction to the Theory of Statistics, Third Edition. McGraw-Hill Book Co., New York.

Rapko BM, JR Deschane, GJ Lumetta, and RA Peterson. 2007. Process Development for Permanganate Addition During Oxidative Leaching of Hanford Tank Sludge Simulants. WTP-RPT-164, PNNL-16794, Pacific Northwest National Laboratory, Richland Washington.

Rassat SD, RP Pires, and DE Kurath. 2008. Analysis of Transient Heat Transfer in the Waste Treatment Plant (WTP) Ultrafiltration Feed Preparation and Process (UFP) Vessels - Modeling Approach, Assumptions, and Results. WTP-RPT-159, PNNL-17835, Pacific Northwest National Laboratory, Richland, Washington.

Russell RL, PA Aker, EC Buck, RA Peterson, DE Rinehart, and HD Smith. 2009a. Development and Characterization of Boehmite Component Simulant. WTP-RPT-184, PNNL-18176, Pacific Northwest National Laboratory, Richland Washington.

Russell RL, RA Peterson, DE Rinehart, and HD Smith. 2009b. Development and Characterization of Gibbsite Component Simulant. WTP-RPT-176, PNNL-18013, Pacific Northwest National Laboratory, Richland Washington.

Russell RL, RA Peterson, DE Rinehart, and HD Smith. 2009c. Development and Demonstration of Ultrafiltration Simulants. WTP-RPT-183, PNNL-18090, Pacific Northwest National Laboratory, Richland Washington. 



\section{Appendix A}

Derivation of Equations Used in Leach Calculations 



\section{Appendix A}

\section{Derivation of Equations Used in Leach Calculations}

Sections A.1 through A.3 contain a general mass-balance derivation to support calculation of the caustic-leach factor of aluminum. Sections A.4, A.6, and A.7 contain derivations related to the kinetic equation, its solution and its initial conditions. Section A.5 shows units conversions and associated error propagation equations used in tabulating concentration data in Section 3.

\section{A.1 General Mass Balances}

The mass-balance derivation considers the possibilities that a reaction occurs that moves at least one species from the liquid phase to the solid phase, that slurry is removed, that liquid alone is removed, that water is added, and/or that reagent is added. The weight fraction UDS (i.e., solid phase) is a needed measurement, as well as the concentrations of species in the liquid phase and in the bulk slurry. ${ }^{(a)}$ It is assumed the samples are representative.

At initial time $t_{0}$, before any processing has begun, the various concentrations in the slurry and liquid are denoted by

$c_{q, 0}=$ tracer concentration in the system slurry at time 0 , mass $q$ per mass bulk; it is a tracer because it is always present entirely in the solid phase or entirely in the liquid phase and is not added as part of the reagent

$c_{q L, 0}=$ tracer concentration in the liquid portion of the system slurry at time 0 , mass $q$ per mass liquid

$c_{j, 0}=$ reactant concentration in the system slurry at time 0 , mass $j$ per mass bulk; $j$ is present in the initial slurry and changes phase as the result of the reaction

$c_{j L, 0}=$ reactant concentration in the liquid portion of the system slurry at time 0 , mass $j$ per mass liquid sample, mass $j$ per mass liquid

$\omega_{s, 0}=$ weight fraction UDS in the system slurry at time 0 , mass solid phase per mass bulk

$m_{L, 0}=$ mass of the liquid phase in the slurry inventory at time 0

$m_{0}=$ mass of the slurry inventory at time 0

$m_{j s, 0}=$ mass of $j$ in the solid phase in the slurry inventory at time 0

$m_{j L, 0}=$ mass of $j$ in the liquid phase in the slurry inventory at time 0

$m_{j, 0}=$ mass of $j$ in both phases in the slurry inventory at time 0

$m_{q s, 0}=$ mass of $q$ in the solid phase in the slurry inventory at time 0

$m_{q L, 0}=$ mass of $q$ in the liquid phase in the slurry inventory at time 0

$m_{q, 0}=$ mass of $q$ in both phases in the slurry inventory at time 0 .

Similar nomenclature is used for variables at times other than 0 , with 1 in the subscript for time $=t_{l}$, etc. In the caustic-leach process, $j$ refers to Al.

(a) The units of mass concentrations in the body of the report are typically $\mathrm{mg} / \mathrm{kg}(\mu \mathrm{g} / \mathrm{g})$, as reported by analytical laboratories. Units in this appendix are gram/gram; this choice avoids having to carry units-conversion constants through the derivation. 
A general derivation is needed to explore which of the conditions and operations during leaching complicate the use of phase tracers and which do not. Consider the following initial system inventories at time $t_{0}$, which for caustic-leach is the time when preparation for leach is complete, just before caustic reagent is added:

$$
\begin{gathered}
m_{j s, 0}=m_{0}\left(c_{j, 0}-\left(1-\omega_{s, 0}\right) c_{j L, 0}\right) \\
m_{j L, 0}=m_{0}\left(1-\omega_{s, 0}\right) c_{j L, 0} \\
m_{j, 0}=m_{0} c_{j, 0} \\
m_{q s, 0}=m_{0}\left(c_{q, 0}-\left(1-\omega_{s, 0}\right) c_{q L, 0}\right) \\
m_{q L, 0}=m_{0}\left(1-\omega_{s, 0}\right) c_{q L, 0} \\
m_{q, 0}=m_{0} c_{q, 0} \\
m_{L, 0}=m_{0}\left(1-\omega_{s, 0}\right)
\end{gathered}
$$

Just after time $t_{0}$, a slurry sample of mass $m_{x, 0}$ is removed; immediately afterward, the liquid of mass $m_{L x, 0}$ is removed selectively without any solids being removed together with it. This sequence contains the implicit assumption that the solids fraction in the slurry sample is not affected by any removal of liquid alone. If the value is positive, the variable $m_{L x, 0}$ can represent a separate liquid sample or liquid that is present in the slurry in excess of the representative concentration (i.e., sample is deficient in solids). If the value is negative, $m_{L x, 0}$ can represent a deficiency in the sample liquid (i.e., the sample is too high in solids to match the average solids fraction in the slurry). It is also assumed that no significant amount of reaction, evaporation, or dilution occurs during sampling.

After that, a mass $m_{w, 1}$ of water is added (or alternatively removed by evaporation); a mass, $m_{R}$, of reagent containing $c_{R z}$ of $z$ in liquid phase is added; and reaction occurs that causes a fraction $\eta_{1}$ of the mass of solid species $j$ present after the $t_{0}$ sampling event to move from solid phase to liquid. Species $q$ does not change phase. It is assumed that neither $j$ nor the reagent reactant is ever completely consumed in either phase. It is also assumed that the reactant in the reagent enters in the liquid phase and does not undergo any reaction except the one involved in leaching.

The leach factor is expressed in terms of the unleached solid-phase $j$ in the system before the reaction occurred. This solid $j$ mass is not $m_{j s, 0}$ because the sample was removed at $t_{0}$ before the reaction occurred. The mass of solid $j$ remaining after sampling is $\left(m_{0}-m_{x, 0}\right)\left(c_{j, 0}-\left(1-\omega_{s, 0}\right) c_{j L, 0}\right)$. 
The total inventories are now

$$
\begin{gathered}
m_{j s, 1}=\left(m_{0}-m_{x, 0}\right)\left(c_{j, 0}-\left(1-\omega_{s, 0}\right) c_{j L, 0}\right)\left(1-\eta_{1}\right) \\
\left.m_{j L, 1}=\left(m_{0}-m_{x, 0}\right)\left(1-\omega_{s, 0}\right)\left(1-\eta_{1}\right) c_{j L, 0}+c_{j, 0} \eta_{1}\right\rfloor-m_{L x, 0} c_{j L, 0} \\
m_{j, 1}=\left(m_{0}-m_{x, 0}\right) c_{j, 0}-m_{L x, 0} c_{j L, 0} \\
m_{q s, 1}=\left(m_{0}-m_{x, 0}\right)\left(c_{q, 0}-\left(1-\omega_{s, 0}\right) c_{q L, 0}\right) \\
m_{q L, 1}=\left(m_{0}-m_{x, 0}\right)\left(1-\omega_{s, 0}\right) c_{q L, 0}-m_{L x, 0} c_{q L, 0} \\
m_{q, 1}=\left(m_{0}-m_{x, 0}\right) c_{q, 0}-m_{L x, 0} c_{q L, 0} \\
m_{1}=m_{0}-m_{x, 0}-m_{L x, 0}+m_{w, 1}+m_{R}
\end{gathered}
$$

Equations (A.12) through (A.14), like the similar equations which follow, implicitly assume that the species $q$ does not move from one phase to the other as a result of dilution or reaction. Any change in phase would require the presence of a transfer term, which has been omitted from the equations above.

The samples taken at $t_{l}$ remove material that is at the following liquid-phase and bulk concentrations:

$$
\begin{gathered}
c_{j L, 1}=\frac{\left.\left(m_{0}-m_{x, 0}\right)\left(1-\omega_{s, 0}\right)\left(1-\eta_{1}\right) c_{j L, 0}+c_{j, 0} \eta_{1}\right\rfloor-m_{L x, 0} c_{j L, 0}}{m_{1}\left(1-\omega_{s, 1}\right)} \\
c_{q L, 1}=\frac{\left(m_{0}-m_{x, 0}\right)\left(1-\omega_{s, 0}\right) c_{q L, 0}-m_{L x, 0} c_{q L, 0}}{m_{1}\left(1-\omega_{s, 1}\right)} \\
c_{j, 1}=\frac{\left(m_{0}-m_{x, 0}\right) c_{j, 0}-m_{L x, 0} c_{j L, 0}}{m_{1}} \\
c_{q, 1}=\frac{\left(m_{0}-m_{x, 0}\right) c_{q, 0}-m_{L x, 0} c_{q L, 0}}{m_{1}}
\end{gathered}
$$

In the above equations, $\omega_{s, l}$ must be a measurement, not a calculated quantity, because there could be dissolution, precipitation, or possible other reactions in the system that involve species other than the ones explicitly identified in the equations. For example, the solids fraction in caustic-leach could be affected not only by aluminum dissolution but by oxalate precipitation or dissolution. 
A slurry sample of mass $m_{x, 1}$ is removed just after $t_{1}$, and after that a liquid mass $m_{L x, l}$ is removed. As before, sampling is assumed to occur quickly enough that no significant reaction, dilution, or evaporation occurs during the sampling process. During the remainder of the time between $t_{1}$ and $t_{2}$, there is further reaction of $j$ (to a fraction $\eta_{2}$ of the unleached-basis solid $j$ inventory that accounts for $t_{1}$ sampling); concurrently with the reaction, an $m_{w, 2}$ mass of water is added or removed.

At this point, "the unleached-basis solid $j$ inventory that accounts for $t_{1}$ sampling" must be defined. The mass of solid $j$ present after $t_{l}$ sampling, and before the reaction that occurs between times $t_{l}$ and $t_{2}$, is

$=\left(m_{0}-m_{x, 0}\right)\left(c_{j, 0}-\left(1-\omega_{s, 0}\right) c_{j L, 0}\right)\left(1-\eta_{1}\right)-m_{x, 1}\left\{\frac{\left(m_{0}-m_{x, 0}\right)\left[c_{j, 0}-\left(1-\omega_{s, 0}\right) c_{j L, 0}\right]\left(1-\eta_{1}\right)}{m_{1}}\right\}$

where the ratio in parentheses is the concentration of solid-phase $j$ in the slurry at $t_{l}$. This can be simplified to

$$
=\left(m_{1}-m_{x, 1}\right) \frac{\left(m_{0}-m_{x, 0}\right)}{m_{1}}\left[c_{j, 0}-\left(1-\omega_{s, 0}\right) c_{j L, 0}\right]\left(1-\eta_{1}\right)
$$

This is the mass of solid $j$ left after the reaction that occurred between times $t_{1}$ and $t_{2}$. If no reaction had occurred, the mass would have been

$$
=\left(m_{1}-m_{x, 1}\right) \frac{\left(m_{0}-m_{x, 0}\right)}{m_{1}}\left[c_{j, 0}-\left(1-\omega_{s, 0}\right) c_{j L, 0}\right]
$$

This is the unleached-basis solid $j$ inventory that accounts for the decrease in available leachable solids that has been caused by $t_{1}$ sampling. Multiplying it by $\eta_{2}$ gives the amount of $j$ reacted between times $t_{1}$ and $t_{2}$.

The $t_{2}$ inventories are

$$
\begin{gathered}
m_{j s, 2}=\frac{m_{1}-m_{x, 1}}{m_{1}}\left(m_{0}-m_{x, 0}\right)\left[c_{j, 0}-\left(1-\omega_{s, 0}\right) c_{j L, 0}\right]\left(1-\eta_{1}-\eta_{2}\right) \\
m_{j L, 2}=\frac{m_{1}-m_{x, 1}}{m_{1}}\left\{\begin{array}{l}
\left(m_{0}-m_{x, 0}\right)\left[\left(1-\omega_{s, 0}\right)\left(1-\eta_{1}-\eta_{2}\right) c_{j L, 0}+c_{j, 0}\left(\eta_{1}+\eta_{2}\right)\right] \\
-m_{L x, 0} c_{j L, 0}
\end{array}\right\}-m_{L x, 1} c_{j L, 1} \\
m_{j, 2}=\frac{m_{1}-m_{x, 1}}{m_{1}}\left[\left(m_{0}-m_{x, 0}\right) c_{j, 0}-m_{L x, 0} c_{j L, 0}\right]-m_{L x, 1} c_{j L, 1} \\
m_{q s, 2}=\left(m_{1}-m_{x, 1}\right)\left[c_{q, 1}-\left(1-\omega_{s, 1}\right) c_{q L, 1}\right]
\end{gathered}
$$




$$
\begin{gathered}
m_{q L, 2}=\left(m_{1}-m_{x, 1}\right)\left(1-\omega_{s, 1}\right) c_{q L, 1}-m_{L x, 1} c_{q L, 1} \\
m_{q, 2}=\left(m_{1}-m_{x, 1}\right) c_{q, 1}-m_{L x, 1} c_{q L, 1} \\
m_{2}=m_{1}-m_{x, 1}-m_{L x, 1}+m_{w, 2}
\end{gathered}
$$

The samples taken at $t_{2}$ remove material that is at the following liquid-phase and bulk concentrations:

$$
\begin{gathered}
c_{j L, 2}=\frac{m_{1}-m_{x, 1}}{m_{1} m_{2}\left(1-\omega_{s, 2}\right)}\left\{\begin{array}{l}
\left(m_{0}-m_{x, 0}\right)\left[\left(1-\omega_{s, 0}\right)\left(1-\eta_{1}-\eta_{2}\right) c_{j L, 0}+c_{j, 0}\left(\eta_{1}+\eta_{2}\right)\right] \\
-m_{L x, 0} c_{j L, 0}
\end{array}\right\}-\frac{m_{L x, 1} c_{j L, 1}}{m_{2}\left(1-\omega_{s, 2}\right)} \\
c_{q L, 2}=\frac{\left(m_{1}-m_{x, 1}\right)\left(1-\omega_{s, 1}\right) c_{q L, 1}-m_{L x, 1} c_{q L, 1}}{m_{2}\left(1-\omega_{s, 2}\right)} \\
c_{j, 2}=\frac{m_{1}-m_{x, 1}\left[\left(m_{0}-m_{x, 0}\right) c_{j, 0}-m_{L x, 0} c_{j L, 0}\right]-\frac{m_{L x, 1} c_{j L, 1}}{m_{2} m_{2}}}{m_{2}} \\
c_{q, 2}=\frac{\left(m_{1}-m_{x, 1}\right) c_{q, 1}-m_{L x, 1} c_{q L, 1}}{m_{2}}
\end{gathered}
$$

Clearly, $\left(\eta_{1}+\eta_{2}\right)$ is the cumulative leach factor at time $t_{2}$, and this cumulative factor is the quantity that needs to be determined. This sum of the stepwise incremental leach factors is the factor that determines the amount of original solid-phase $j$ removed by leaching.

Sampling steps at $t_{3}, t_{4}$, and so forth, will each produce concentrations that are related to those in the previous sample in the series in the same way that concentrations at the $t_{2}$ sampling step were related to those at $t_{1}$. This makes it possible to solve for the cumulative leach factor in terms of known input variables and then extrapolate to any number of sampling steps. The aim is to use tracer-based calculations that require only the sample concentration data, but not variables such as the mass inventory, sample masses, reagent mass, and permeate mass.

\section{A.2 Leach Factor in Terms of Solid-Phase Reactant and Tracer Concentrations}

This section derives the equation for leach factor in terms of the solid-phase concentrations of $j$ and $q$. Initially, treat $q$ as a species that can be present in both phases but does not transfer between them; this allows for a general derivation. The specific assumption that $q$ is not present in the liquid phase will be made later in this section. Based on the mass-balance equations and assumptions, and their extension to more sample steps, the cumulative leach factor can be expressed in terms of the solid-phase $j$ inventories at times $t_{0}$ and $t_{P}($ sample step $P$ ): 


$$
\sum_{p=1}^{P} \eta_{p}=1-\frac{m_{P}\left[c_{j, P}-\left(1-\omega_{s, P}\right) c_{j L, P}\right]}{\left(m_{0}-m_{x, 0}\right)\left[c_{j, 0}-\left(1-\omega_{s, 0}\right) c_{j L, 0}\right]} \prod_{p=1}^{P-1} \frac{m_{p}}{m_{p}-m_{x, p}}
$$

All the ratios of mass inventories that are present in Equation (A.33) can be expressed in terms of slurry concentrations of $q$ by rearranging mass-balance equations (A.18), (A.32), and similar equations for later sampling steps. When the new expressions for the ratios are substituted into Equation (A.33), the result is

$$
\sum_{p=1}^{P} \eta_{p}=1-\frac{\left[c_{j, P}-\left(1-\omega_{s, P}\right) c_{j L, P}\right]}{\left[c_{j, 0}-\left(1-\omega_{s, 0}\right) c_{j L, 0}\right]} \prod_{p=1}^{P}\left[\frac{c_{q, p-1}}{c_{q, p}+\left(m_{L x, p-1} / m_{p}\right) c_{q L, p-1}}\right]
$$

This equation shows that removing samples of slurry has no effect on the leach factor calculated from $q$. However, any removal of significant amounts of liquid alone $\left(m_{L x, p}\right)$ must be accounted for if $q$ is present in the liquid phase. Note that a species can be present in both solid and liquid phases and still be used as a tracer in Equation (A.34) so long as it does not change phase, and liquid-alone removal is accounted for. Also note that if slurry samples are not representative of the slurry because of sampling issues, the net effect will be either to remove excess liquid or excess solid. In the first case, $m_{L x, p}$ is non-zero and positive; in the second case, $m_{L x, p}$ is non-zero and effectively negative. Thus, non-representative sampling has a double effect: the non-representative samples themselves are inaccurate, of course, and any representative samples that are taken during the test will also give distorted leach factor results because of the net impact of change in the liquid/solid ratio.

If $q$ is a solid-phase tracer species (if it has a negligible concentration in the liquid), then

$$
\sum_{p=1}^{P} \eta_{p}=1-\frac{c_{q, 0}}{c_{q, P}} \frac{\left[c_{j, P}-\left(1-\omega_{s, P}\right) c_{j L, P}\right]}{\left[c_{j, 0}-\left(1-\omega_{s, 0}\right) c_{j L, 0}\right]}
$$

The effects of sampling cancel out even when the mass removed in slurry and liquid samples is not negligible so long as the solid tracer species is substantially absent from the liquid phase. In this case, if sampling includes both representative and non-representative samples, only the non-representative ones will give inaccurate leach factors by the solid tracer method.

\section{A.3 Leach Factor in Terms of Liquid-Phase Reactant and Tracer Concentrations}

This section derives the equation for leach factor in terms of the liquid-phase concentrations of $j$ and $q$. Initially, treat $q$ as a species that can be present in both phases but does not change phase during the leach; this allows for a general derivation. The specific assumption that $q$ is not present in the solid phase will be made later in the derivation. Based on the mass-balance equations and assumptions as well as their extension to more sample steps, the cumulative leach factor can be expressed in terms of the liquid-phase $j$ inventories at times $t_{0}$ and $t_{P}$ (sample step $P$ ): 


$$
\begin{aligned}
& \sum_{p=1}^{P} \eta_{p}=\frac{1}{\left(m_{0}-m_{x, 0}\right)\left[c_{j, 0}-\left(1-\omega_{s, 0}\right) c_{j L, 0}\right]}\left\{m_{P}\left(1-\omega_{s, P}\right) c_{j L, P} \prod_{p=1}^{P-1}\left(\frac{m_{p}}{m_{p}-m_{x, p}}\right)\right. \\
& \left.+m_{L x, 0} c_{j L, 0}+\sum_{p=1}^{P-1}\left[m_{L x, p} c_{j L, p} \prod_{b=1}^{p}\left(\frac{m_{b}}{m_{b}-m_{x, b}}\right)\right]\right\} \\
& -\left[\frac{c_{j L, 0}\left(1-\omega_{s, 0}\right)}{c_{j, 0}-\left(1-\omega_{s, 0}\right) c_{j L, 0}}\right]
\end{aligned}
$$

All the ratios of mass inventories that are present in Equation (A.36) can be expressed in terms of liquid-phase concentrations of $q$ by rearranging mass-balance equations (A.16), (A.30), and similar equations for later sampling steps. When the new expressions for the ratios are substituted into Equation (A.36), the result is

$$
\begin{aligned}
& \sum_{p=1}^{P} \eta_{p}=\frac{c_{q L, 0}}{c_{q L, P}} \frac{\left(1-\omega_{s, P}\right) c_{j L, P}}{\left[c_{j, 0}-\left(1-\omega_{s, 0}\right) c_{j L, 0}\right]}\left\{\prod_{p=1}^{P}\left[\frac{\left(1-\omega_{s, p-1}\right)}{\left(1-\omega_{s, p}\right)}-\frac{m_{L x, p-1}}{\left(m_{p-1}-m_{x, p-1}\right)\left(1-\omega_{s, p}\right)}\right]\right\} \\
& -\left[\frac{c_{j L, 0}\left(1-\omega_{s, 0}\right)}{c_{j, 0}-\left(1-\omega_{s, 0}\right) c_{j L, 0}}\right]+\frac{1}{\left(m_{0}-m_{x, 0}\right)\left[c_{j, 0}-\left(1-\omega_{s, 0}\right) c_{j L, 0}\right]}\left\{m_{L x, 0} c_{j L, 0}+\sum_{p=1}^{P-1}\left[m_{L x, p} c_{j L, p} \prod_{b=1}^{p}\left(\frac{m_{b}}{\left.m_{b}-m_{x, b}\right)}\right)\right]\right.
\end{aligned}
$$

For this equation to be applicable, species $q$ must be present in the liquid phase, and its liquid-phase inventory must not have been either increased by dissolution or decreased by precipitation. Two conditions must be met for the removal of liquid-alone mass to be negligible. First, at each sample step $p$ the mass of liquid removed as liquid alone, $m_{L x, p}$, must be negligible compared to the total mass of slurry present at that time. Second, the total of all $m_{L x, p}$ removals must be small compared to the initial slurry mass. If these conditions are met, then

$$
\sum_{p=1}^{P} \eta_{p}=\frac{c_{q L, 0}}{c_{q L, P}} \frac{\left(1-\omega_{s, 0}\right) c_{j L, P}}{\left[c_{j, 0}-\left(1-\omega_{s, 0}\right) c_{j L, 0}\right]}-\frac{c_{j L, 0}\left(1-\omega_{s, 0}\right)}{c_{j, 0}-\left(1-\omega_{s, 0}\right) c_{j L, 0}}
$$

Note that as long as the removal of liquid alone is negligible, the removal of slurry has no effect. Also note that $q$ can be present in both phases so long as it does not change phase.

Non-representative sampling has a double effect for the liquid tracer method: the non-representative samples themselves are inaccurate, and any representative samples that are taken during the test will also give distorted leach-factor results because of the net impact of change in the liquid/solid ratio.

\section{A.4 Caustic-Leach Kinetic Model}

The differential equation for kinetically controlled boehmite dissolution in the simulant is ${ }^{(a)}$

(a) The form of the kinetic equation and the value of the activation energy to be used for this simulant are documented in CCP-WTPSP-711. 


$$
\frac{d}{d t}\left(\frac{n_{b s}}{n_{b s, i}}\right)=-k C_{O H L, i}\left(\frac{n_{b s}}{n_{b s, i}}\right)^{2 / 3}\left(1-\frac{C_{A l L, i}}{C_{A l^{*} L, i}}\right)\left(1-\frac{C_{A l L}}{C_{A l^{*} L, i}}\right) e^{\frac{E_{a}}{R}\left(\frac{1}{373}-\frac{1}{T}\right)}
$$

where $=$ mol of solid-phase boehmite at time $t$

$$
\begin{aligned}
n_{b s} & \\
n_{b s, i}= & \text { mol of solid-phase boehmite at time } t=t_{i} \text { (start of constant-temperature leaching, after } \\
& \text { heat-up is complete and assumed to be before any boehmite has been leached; it is not } \\
& \text { the same as } t_{0}, \text { the time just before caustic is added) } \\
k= & \text { rate constant }\left(\mathrm{hr}^{-1} *(\text { mol total hydroxide } / \mathrm{L})^{-1}\right) \\
C_{O H L, i}= & \mathrm{mol} / \mathrm{L} \text { of total hydroxide in the liquid phase at time } t=t_{i} \\
C_{A l L}= & \mathrm{mol} / \mathrm{L} \text { of } \mathrm{Al} \text { in the liquid phase at time } t \\
C_{A l L, i}= & \mathrm{mol} / \mathrm{L} \text { of } \mathrm{Al} \text { in the liquid phase at time } t=t_{i} \\
C_{A l^{*} L, i}= & \mathrm{mol} / \mathrm{L} \text { of } \mathrm{Al} \text { that would exist at saturation in the liquid for the total } \mathrm{OH} \text { concentration and } \\
& \text { temperature present at time } t=t_{i} \\
E_{a}= & \text { activation energy for simulant, } 120 \mathrm{~kJ} / \mathrm{mol} \text { (accurate to the nearest } 10 \mathrm{~kJ} / \mathrm{mol}) \\
R= & \text { ideal gas constant, } 8.314 \mathrm{~J} / \mathrm{mol} \mathrm{K} \\
T= & \text { absolute temperature, } \mathrm{K} .
\end{aligned}
$$

This kinetic model was developed from tests of leaching of pure boehmite at temperatures of $85^{\circ} \mathrm{C}$ and $100^{\circ} \mathrm{C}$ in a solution of $5 \mathrm{M}$ total hydroxide. At each temperature tests were carried out for a range of different initial concentration of dissolved $\mathrm{Al}$, from a minimum of $0 \%$ of the saturated concentration to a maximum of $80 \%$ of saturation. The model so developed was then tested with mixtures of PEP simulant, $19 \mathrm{M} \mathrm{NaOH}$, and water at temperatures ranging from $80^{\circ} \mathrm{C}$ to $100^{\circ} \mathrm{C}$. The model was found to provide good predictions of the leaching reaction in these more complex liquid compositions.

The tests with PEP simulant were designed to be comparable to either UFP-1 or UFP-2 conditions. UFP-1 conditions were represented by an initial boehmite Al concentration of $\sim 7000-\mu \mathrm{g} / \mathrm{g}$ slurry and an initial total $\mathrm{OH}$ concentration of 3.3 M. UFP-2 conditions were represented by an initial boehmite $\mathrm{Al}$ concentration of $\sim 15000-\mu \mathrm{g} / \mathrm{g}$ slurry and an initial total $\mathrm{OH}$ concentration of $5.7 \mathrm{M}$. These preliminary test conditions matched the conditions in the actual PEP and laboratory-scale tests to within $20-25 \%$.

Equation (A.39) assumes that the liquid volume remains constant during the test. Total hydroxide is defined as the measured free hydroxide plus one mole of hydroxide per mole of the measured aluminate in solution; this accounts for the hydroxide complexed in $\mathrm{Al}(\mathrm{OH})_{4}{ }^{-}$.

Equation (A.39) can be expressed in terms of the leach factor of boehmite, $f_{b}$ :

$$
\frac{d}{d t}\left(1-f_{b}\right)=-k C_{O H L, i}\left(1-f_{b}\right)^{2 / 3}\left(1-\frac{C_{A L L, i}}{C_{A l^{*} L, i}}\right)\left(1-\frac{C_{A l L}}{C_{A l^{*} L, i}}\right) e^{\frac{E_{a}}{R}\left(\frac{1}{373}-\frac{1}{T}\right)}
$$

The relationship between the boehmite leach factor and the aluminum leach factor, $\eta$, at any point in time is

$$
f_{b}=\frac{\eta-\phi_{A \mathrm{lg}, 0}}{1-\phi_{A \lg , 0}}
$$


where $\phi_{A l g, 0}$ is the fraction of the solid-phase $\mathrm{Al}$ (either moles or mass) that was present in the compound gibbsite in the original simulant feed (at $t=t_{0}$ ). This relation holds only when all the gibbsite has dissolved, and assumes that all the gibbsite has dissolved before boehmite begins to dissolve. Substituting (A.41) into (A.40) gives

$$
\frac{d}{d t}\left(\frac{1-\eta}{1-\phi_{A \mathrm{lg}, 0}}\right)=-k C_{O H L, i}\left(\frac{1-\eta}{1-\phi_{A \mathrm{lg}, 0}}\right)^{2 / 3}\left(1-\frac{C_{A l L, i}}{C_{A l^{*} L, i}}\right)\left(1-\frac{C_{A l L}}{C_{A l^{*} L, i}}\right) e^{\frac{E_{a}}{R}\left(\frac{1}{373}-\frac{1}{T}\right)}
$$

This ordinary differential equation is solved numerically. The mass-balance equation that must be solved together with Equation (A.42), to provide the needed values of $C_{A I L}$ at each time step, is

$$
C_{A l L}=C_{A l L, i}+\frac{n_{b s, i}}{V_{L, i}} f_{b}=C_{A l L, i}+\frac{n_{b s, i}}{V_{L, i}} \frac{\eta-\phi_{A \mathrm{lg}, 0}}{1-\phi_{A \mathrm{lg}, 0}}
$$

Here $V_{L, i}$ is the initial liquid volume. Equations (A.42) and (A.43) are solved under the idealizing assumptions that the concentrations are not affected by sampling, density change, or change in the liquid volume. The ODE solution is compared to aluminate concentration data to find a value of the rate-constant $k$. The aluminate data include the effects of sampling, density change, and liquid volume change, and these effects must be removed from the data also before they can be compared correctly to the kinetic model predictions.

The initial saturated concentration of aluminum in the liquid, an input needed by the ODE, can be found from

$$
\begin{gathered}
C_{A l^{*} L, i}=\frac{2}{M_{A l 2 O 3}}\left[1 E-06 A_{1} \theta^{3}+1 E-03 A_{2} \theta^{2}+1 E-02 A_{3} \theta+A_{4}\right] \\
A_{1}=-0.0618925 x_{N L, i}+1.36953 \\
A_{2}=0.02301 x_{N L, i}+0.1707 \\
A_{3}=2.498 E-06 x_{N L, i}^{3}-3.106 E-04 x_{N L, i}^{2}+5.483 E-02 x_{N L, i}-1.332 \\
A_{4}=3.236 E-06 x_{N L, i}^{3}-7.887 E-04 x_{N L, i}^{2}+1.584 E-01 x_{N L, i}-2.518
\end{gathered}
$$

where $M_{A l 2 O 3}=\mathrm{g} / \mathrm{mol}$ molecular weight of $\mathrm{Al}_{2} \mathrm{O}_{3}$

$\theta=$ temperature, ${ }^{\circ} \mathrm{C}$

$A_{1}=3^{\text {rd }}$-order coefficient of $\mathrm{Al}$ solubility in caustic, $\mathrm{g} \mathrm{Al}_{2} \mathrm{O}_{3} / \mathrm{L} /{ }^{\circ} \mathrm{C}^{3}$

$A_{2}=2^{\text {nd }}$-order coefficient of $\mathrm{Al}$ solubility in caustic, $\mathrm{g} \mathrm{Al}_{2} \mathrm{O}_{3} / \mathrm{L} /{ }^{\circ} \mathrm{C}^{2}$ 


$$
\begin{aligned}
A_{3}= & 1^{\text {st }} \text {-order coefficient of } \mathrm{Al} \text { solubility in caustic, } \mathrm{g} \mathrm{Al}_{2} \mathrm{O}_{3} / \mathrm{L} /{ }^{\circ} \mathrm{C} \\
A_{4}= & 0^{\text {th }} \text {-order coefficient of } \mathrm{Al} \text { solubility in caustic, } \mathrm{g} \mathrm{Al}_{2} \mathrm{O}_{3} / \mathrm{L} \\
x_{N L, i}= & \mathrm{g} / \mathrm{L} \text { of total hydroxide in the liquid phase at } t=0 \text {, where total } \mathrm{OH} \text { is expressed } \\
& \text { in terms of the equivalent mass of } \mathrm{Na}_{2} \mathrm{O} .
\end{aligned}
$$

These Al solubility expressions are taken from a paper written by D Panias, P Asimidis, and I Paspaliaris, "Solubility of Boehmite in Concentrated Sodium Hydroxide Solutions: Model Development and Assessment," Hydrometallurgy 59 (2001): pp. 15-29.

$$
x_{N L, i}=\frac{M_{N a 2 O}}{2} C_{O H L, i}
$$

where $M_{\mathrm{Na2O}}$ is the molecular weight $(\mathrm{g} / \mathrm{mol})$ of $\mathrm{Na}_{2} \mathrm{O}$. The boehmite solubility expression was stated by its developers to be valid for initial sodium hydroxide concentration between 60-140 $\mathrm{g} \mathrm{Na}_{2} \mathrm{O} / \mathrm{L}$ liquid (the total hydroxide is expressed in terms of equivalent $\mathrm{Na}_{2} \mathrm{O}$ ) and for temperature between $30-150^{\circ} \mathrm{C}$. The PEP and laboratory-scale tests conditions lie within the temperature range of applicability. The Test A total hydroxide concentration was within the range, while the Test $\mathrm{B}$ total hydroxide concentration was at about $140 \%$ of the upper limit.

Next, equations are derived to account for the effect of sampling on the measured $\mathrm{Al}$ concentration. On the assumption that no significant amount of liquid is removed from the system (except as part of representative slurry samples), the dissolved $\mathrm{Al}$ (aluminate) concentration at each sampling event $P$ can be obtained by solving Equation (A.38) for $c_{j L, P}$, assuming that species $j$ is $\mathrm{Al}$ :

$$
c_{A L L, P}=\frac{c_{q L, P}}{c_{q L, 0}}\left\{c_{A l L, 0}+\left(\sum_{p=1}^{P} \eta_{p}\right) \frac{\left[c_{A l, 0}-\left(1-\omega_{s, 0}\right) c_{A l L, 0}\right]}{\left(1-\omega_{s, 0}\right)}\right\}
$$

The assumption of no removal of supernatant liquid (except as part of slurry samples) is consistent with laboratory-scale and PEP practices.

Convert the requisite $\mathrm{Al}$ concentrations to units of molarity using the appropriate liquid density, where $M_{A l}$ is the molecular weight of Al.

$$
\begin{aligned}
& C_{A l L, P}=\frac{c_{q L, P}}{c_{q L, 0}} \frac{\rho_{L, P}}{\rho_{L, 0}}\left\{C_{A l L, 0}+\frac{\rho_{L, 0}}{M_{A l}}\left(\sum_{p=1}^{P} \eta_{p}\right) \frac{\left[c_{A l, 0}-\left(1-\omega_{s, 0}\right) c_{A l L, 0}\right]}{\left(1-\omega_{s, 0}\right)}\right\} \\
& =\frac{C_{q L, P}}{C_{q L, 0}}\left\{C_{A l L, 0}+\frac{\rho_{L, 0}}{M_{A l}}\left(\sum_{p=1}^{P} \eta_{p}\right) \frac{\left[c_{A l, 0}-\left(1-\omega_{s, 0}\right) c_{A l L, 0}\right]}{\left(1-\omega_{s, 0}\right)}\right\}
\end{aligned}
$$

The multiplier in front of the brackets is the dilution factor $F_{A L L, P}$, which converts the concentrations measured in a varying-density, varying-volume system into the constant-volume terms required for comparison with the kinetic model in Equations (A.42) and (A.43). In this case, the volume and density at $t_{0}$ are the basis conditions. 
Note that a term in Equation (A.48) can be expressed in terms of the same variables used in the kinetic model:

$$
\frac{\rho_{L, 0}}{M_{A l}} \frac{\left[c_{A l, 0}-\left(1-\omega_{s, 0}\right) c_{A l L, 0}\right]}{\left(1-\omega_{s, 0}\right)}=\frac{1}{\left(1-\phi_{A \lg , 0}\right)} \frac{n_{b s, 0}}{V_{L, 0}}=\frac{V_{L, i}}{V_{L, 0}} \frac{1}{\left(1-\phi_{A \lg , 0}\right)} \frac{n_{b s, i}}{V_{L, i}} \equiv C_{A l s, 0}
$$

$C_{A l s, 0}$ is the moles of solid-phase Al per volume of liquid that is present in the feed simulant. Equation (A.49) requires the assumption that the mole amount of boehmite at the time heat-up is complete $\left(n_{b s, i}\right)$ is equal to that in the feed $\left(n_{b s, 0}\right)$.

The boehmite leaching rate constant $\mathrm{k}$ is determined as follows.

1) Dilution factors are calculated for all the samples. The conditions at maximum dilution are treated as the basis condition. This is the volume basis used in the G2 model, which will be employing the kinetic rate constants. In PEP tests, the maximum dilution occurs at the end of the run because of condensate addition through the leach. In laboratory-scale tests, the maximum dilution is at the beginning of the run (before heat-up) because of evaporation over the course of the test.

2) The measured aluminate molar concentrations for samples $i$ through $f$ are multiplied by $F_{\text {AlL,basis }} / F_{A L L, P}$ to put them in terms of the volume basis. Here $i$ refers to the 0 -hour sample, $f$ to the sample at the end of digestion, and $F_{A l, P}$ to the dilution factor for any sample $P$ between and including $i$ and $f$-in other words, all the samples taken during constant-temperature digestion. These maximum-dilution-basis aluminate concentrations are on the correct basis for comparison to aluminate concentrations predicted by the kinetic model.

3) Two of the kinetic model input concentrations $\left(C_{O H L, i}\right.$ and $\left.C_{A L L, i}\right)$ come from measurements made at sample point $i$ ( $0 \mathrm{hr}$ of digestion). The third model input concentration $\left(n_{b s, i} / V_{L, i}\right)$, the initial molar boehmite concentration, comes from slurry and liquid $\mathrm{Al}$ concentrations measured either at time $t_{0}$ (the simulant before any dilution or reagent addition) or at sample point $i$. To put the three input concentrations on the correct volume basis, they are multiplied either by $\left(F_{A L L, b a s i s} / F_{A L L, i}\right)$, for $i$ data, or by $F_{A l L, b a s i s}$ for $t_{0}$ data.

4) The kinetic model is solved, using a given value of rate constant $k$, to obtain a set of predictions of true leach factors, $\eta$, at each time step. The predicted true leach factors at the times during digestion when samples were taken are used to predict maximum-dilution-basis aluminate concentrations in molarity units. One of the two following equations, which are based on Equation (A.48), is used:

$$
\begin{aligned}
& \text { pred. Al at } P=C_{A I L, i} \frac{F_{A L L, b a s i s}}{F_{A L L, i}}+F_{A l L, b a s i s} \frac{n_{b s, 0}}{V_{L, 0}}\left[\frac{(\text { pred. } \eta \text { at } P)-\phi_{A \mathrm{lg}, 0}}{\left(1-\phi_{A \mathrm{lg}, 0}\right)}\right] \\
& \text { pred. Al at } P=C_{A I L, i} \frac{F_{A l L, b a s i s}}{F_{A L L, i}}+\frac{F_{A l L, b a s i s}}{F_{A L L, i}} \frac{n_{b s, i}}{V_{L, i}}\left[\frac{(\text { pred. } \eta \text { at } P)-\phi_{A \mid \mathrm{g}, 0}}{\left(1-\phi_{A \mathrm{lg}, 0}\right)}\right]
\end{aligned}
$$


The choice of equation depends on whether the initial boehmite concentration was derived from feed conditions, in which case Equation (A.49a) is used, or from 0-hr conditions, in which case Equation (A.49b) is used.

5) The predicted aluminate concentrations from Step 4 are compared to the measured aluminate concentrations from Step 2. The rate constant $k$ is adjusted to obtain a best fit of prediction to measurement.

The boehmite dissolution model described in equations (A.40) through (A.44) can be solved analytically, if temperature is assumed constant; however, to allow for temperature variation in PEP it is solved numerically in Mathcad version 14.0 ${ }^{(a)}$ The solution technique for the differential equation, given a specific value for $k$ and the initial concentration of aluminum in the liquid phase, is an Euler method based on a 1-minute time step. Then, values for $k$ and the initial concentration of aluminum in the liquid phase are chosen to minimize an objective function using the conjugate-gradient method. The objective function is defined to be the sum of squared differences between the sampled concentrations of aluminum in the liquid phase (adjusted to units of $\mathrm{mol} / \mathrm{L}$ ) and the model predictions of the concentration of aluminum in the liquid phase at the same times as the sampled data were taken. The same general approach is used in the Monte Carlo uncertainty analysis. However, multiple sets of plausible sampled data are used in the Monte Carlo uncertainty analysis. The "plausible" sets are developed using statements of analytical uncertainty for all measured values and assuming the uncertainty on the measured values can be described using a normal distribution around a mean of zero uncertainty.

\section{A.5 Unit Conversions for Section 3 Tables}

A number of unit conversions were performed to supply data for tables of concentrations in Section 3 of the document. The equations for the conversions, and associated error propagation equations, are given below. The error propagation expressions used for the tables are approximate. They are based on a truncated expansion of the error estimate that leaves out second-order terms and therefore may be biased. The bias is expected to be small.

\section{Mass-based liquid to molar liquid concentration}

$$
\begin{gathered}
C_{j, L}=\frac{c_{j, L} \rho_{L}}{M_{j}} \\
\delta C_{j, L}=\frac{c_{j, L} \rho_{L}}{M_{j}} \sqrt{\left(\frac{\delta c_{j, L}}{c_{j, L}}\right)^{2}+\left(\frac{\delta \rho_{L}}{\rho_{L}}\right)^{2}}
\end{gathered}
$$

where $\quad c_{j, L}=$ mass concentration of species $j$ in $\mathrm{g} j / \mathrm{g}$ liquid

$\delta c_{j, L}=$ standard deviation of mass concentration of $j$

$C_{j, L}=$ molar concentration of species $j$ in moles $j / \mathrm{L}$ liquid

$\delta C_{j, L}=$ standard deviation of molar concentration of $j$

$\rho_{L}=$ liquid density in $\mathrm{g} / \mathrm{L}$ liquid

(a) Parametric Technology Corporation, 140 Kendrick Street, Needham, MA 02494. 


$$
\begin{aligned}
\delta \rho_{L} & =\text { standard deviation of liquid density } \\
M_{j} & =\text { molecular weight of } j, \mathrm{~g} / \mathrm{mol} .
\end{aligned}
$$

Molar liquid concentration to mass-based liquid concentration

$$
\begin{gathered}
c_{j, L}=\frac{C_{j, L} M_{j}}{\rho_{L}} \\
\delta c_{j, L}=\frac{C_{j, L} M_{j}}{\rho_{L}} \sqrt{\left(\frac{\delta C_{j, L}}{C_{j, L}}\right)^{2}+\left(\frac{\delta \rho_{L}}{\rho_{L}}\right)^{2}}
\end{gathered}
$$

Mass-based liquid to molal liquid concentration

$$
\begin{gathered}
{\text { molal conc } ._{j, L}}=\frac{1000 c_{j, L}}{M_{j}\left(1-\omega_{d}\right)}, \quad \text { mol } / \mathrm{kg} \text { water } \\
\text { st. dev. molal conc. }{ }_{j, L}=\frac{1000 c_{j, L}}{M_{j}\left(1-\omega_{d}\right)} \sqrt{\left(\frac{\delta c_{j, L}}{c_{j, L}}\right)^{2}+\left(\frac{\delta \omega_{d}}{1-\omega_{d}}\right)^{2}}
\end{gathered}
$$

where $\omega_{d}$ is the mass fraction of dissolved solid in liquid, g dissolved solid/g liquid, and $\delta \omega_{d}$ is the standard deviation of mass fraction of dissolved solid.

Molar liquid concentration to molal liquid concentration

$$
\begin{gathered}
\text { molal conc. }_{j, L}=\frac{1000 C_{j, L}}{\rho_{L}\left(1-\omega_{d}\right)}, \quad \text { mol / kg water } \\
\text { st. dev. molal conc } ._{j, L}=\frac{1000 C_{j, L}}{\rho_{L}\left(1-\omega_{d}\right)} \sqrt{\left(\frac{\delta c_{j, L}}{c_{j, L}}\right)^{2}+\left(\frac{\delta \rho_{L}}{\rho_{L}}\right)^{2}+\left(\frac{\delta \omega_{d}}{1-\omega_{d}}\right)^{2}}
\end{gathered}
$$

The tables in Section 3 also contain calculated bulk slurry concentrations of Al and certain other metals. Because the samples taken during the PEP test were centrifuged before analysis, the slurry concentrations were not directly measured and must be calculated from concentrations separately measured in the centrifuged solids and the liquid. This was not the case for the washed-slurry measurements on laboratory-scale samples; these samples were not phase-separated before analysis, so no error propagation calculation was needed.

The equations for calculating the bulk slurry concentration and its propagated standard deviation from data for centrifuged solids and separated liquid are 


$$
\begin{gathered}
c_{j}=\phi c_{j, c s}+(1-\phi) c_{j, L} \\
\delta c_{j}=\sqrt{\left(c_{j, c s}-c_{j, L}\right)^{2}(\delta \phi)^{2}+\phi^{2}\left(\delta c_{j, c s}\right)^{2}+(1-\phi)^{2}\left(\delta c_{j, L}\right)^{2}}
\end{gathered}
$$

where $\quad c_{j}=$ slurry mass concentration of species $j$ in g $j / \mathrm{g}$ slurry

$$
\begin{aligned}
\delta c_{j}= & \text { standard deviation of slurry mass concentration of } j \\
c_{j, c s}= & \text { mass concentration of species } j \text { in centrifuged solids, g } j / \mathrm{g} \text { centrifuged } \\
& \text { solids } \\
\delta c_{j, c s}= & \text { standard deviation of mass concentration of } j \text { in centrifuged solids } \\
\phi= & \text { mass centrifuged solids per mass original slurry sample } \\
\delta \phi= & \text { standard deviation of the centrifuged solids mass fraction. }
\end{aligned}
$$

The two equations above can be simplified for solid tracer species, for which the species concentration in the liquid is effectively zero:

$$
\begin{gathered}
c_{j}=\phi c_{j, c s} \\
\delta c_{j}=\sqrt{c_{j, c s}^{2}(\delta \phi)^{2}+\phi^{2}\left(\delta c_{j, c s}\right)^{2}}
\end{gathered}
$$

Equations (A.60) and (A.61) also apply to rinsed (washed) solids because washing reduces the dissolved concentrations in the wet washed solids to zero.

\section{A.6 Equations Supporting Leach Factor and Boehmite Kinetics Analyses}

Section 4 describes the analysis conducted to determine the boehmite kinetic rate constant and the aluminum leach factors that are used to cross-check the kinetic model predictions. A full stochastic Monte Carlo analysis, rather than the truncated error propagation equations in Section A.5, is used to calculate the standard deviations of the initial-condition concentrations and normalized aluminate concentrations that appear in the Section 4 tables. This section supplies the equations that were used to calculate these variables.

The initial boehmite concentration was calculated in two independent ways, when data were available.

1) The concentration of solid-phase $\mathrm{Al}$ in the pre- $\mathrm{NaOH}$-addition slurry was calculated based on total $\mathrm{Al}$ concentration in the slurry, dissolved Al concentration, and weight fraction UDS. The solid-phase Al concentration in feed was assumed to be partly in the form of boehmite, as shown in Table 3.7. The feed concentration of boehmite was then normalized to the maximum-dilution condition.

2) The normalized solid-phase $\mathrm{Al}$ in the 0 -hr sample was calculated and assumed to be $100 \%$ in the form of boehmite. Data for this calculation were available for PEP tests but not for laboratory-scale tests. The 0 -hr concentration of boehmite was then normalized to the maximum-dilution condition. 
The mass concentration of solid-phase $\mathrm{Al}$ in the slurry is

$$
c_{s A l}=\phi c_{A l, c s}+\left(\omega_{s}-\phi\right) c_{A l, L}
$$

The units of Equation (A.62) are mass solid-phase Al per mass slurry. The required initial condition is moles of boehmite aluminum per liter liquid. This concentration is

$$
C_{A l b, L}=\frac{\omega_{b A l} \rho_{L}}{M_{A l}\left(1-\omega_{s}\right)}\left[\phi c_{A l, c s}+\left(\omega_{s}-\phi\right) c_{A l, L}\right]
$$

where $C_{A l b, L}=$ moles of $\mathrm{Al}$ present as boehmite per liter liquid

$\omega_{b A l}=$ mass of $\mathrm{Al}$ in boehmite divided by total mass $\mathrm{Al}$ in solid phase

$M_{A l}=$ molecular weight of aluminum, $\mathrm{g} / \mathrm{mol}$

$c_{A l, c s}=$ mass concentration of $\mathrm{Al}$ in centrifuged solids, $\mathrm{g} \mathrm{Al} / \mathrm{g}$ cent. solids

$c_{A l, L}=$ mass concentration of $\mathrm{Al}$ in liquid, $\mathrm{g} \mathrm{Al} / \mathrm{g}$ liquid.

The normalization of the boehmite molar concentration at one dilution condition to another dilution condition is carried out by the equation

$$
\left(C_{A l b, L}\right)_{N E W}=\left\{\frac{\omega_{b A l} \rho_{L}}{M_{A l}\left(1-\omega_{s}\right)}\left[\phi c_{A l, c s}+\left(\omega_{s}-\phi\right) c_{A l, L}\right]\right\}_{O L D}\left(\frac{C_{k, N E W}}{C_{k, O L D}}\right)
$$

This same type of normalization, using new and old molar concentrations of liquid tracer $k$, is also used for aluminate and total hydroxide concentrations. Molar tracer concentrations are obtained from tracer mass concentrations via Equation (A.50).

Hydroxide concentration data are obtained in the form of free (uncomplexed) hydroxide. The total hydroxide also includes the excess hydroxide that is complexed as aluminate, one mole excess hydroxide per mole aluminate. Therefore, the molar concentrations of total hydroxide, free hydroxide, and aluminum are related by

$$
C_{O H, L}=C_{F O H, L}+C_{A l}
$$

\section{A.7 Initial Conditions for Laboratory-Scale Tests}

Because of the discrepancies discussed in Section 4.2, it is necessary to interpret the laboratory-scale data in a way that relies on PEP sample analysis data as little as possible. For example, the leaching in the laboratory-scale tests must be calculated relative to the solid-phase Al actually present in the slurry used in the laboratory-scale test, as calculated from samples taken from the beaker, not relative to the beaker contents if the slurry composition had been the same as in the corresponding PEP samples. A crucial step in data interpretation is the determination of the actual slurry composition that was tested--the total Al, solid-phase Al, and liquid tracer concentration in the slurry in the laboratory-scale beaker. 
The need to rely only on beaker data precludes carrying out Al leach-factor analyses that trace back to the original PEP inventory. The leach factor can be calculated for the laboratory-scale tests, but only with reference to the material initially in the beaker, which is not the same as the PEP reference point.

The input variables are defined below.

\begin{tabular}{|c|c|}
\hline$c_{A l, X S}$ & $\begin{array}{l}\mu \mathrm{g} \mathrm{Al} / \mathrm{g} \text { slurry in the portion of the } 1 \mathrm{~L} \text { sample taken from PEP and not used in the } \\
\text { laboratory-scale test (the leftover feed) }\end{array}$ \\
\hline$c_{A l, S S}$ & $\begin{array}{l}\mu \mathrm{g} \mathrm{Al} / \mathrm{g} \text { slurry in the beaker sample after deionized water (DIW) (and } \mathrm{NaOH} \text {, in Test A-2) } \\
\text { have been added to the as-fed slurry, and before heating has begun }\end{array}$ \\
\hline$c_{A l, F S}$ & $\mu \mathrm{g} \mathrm{Al} / \mathrm{g}$ slurry in beaker sample at end of test \\
\hline$f_{D}$ & $\begin{array}{l}\text { dilution factor for the laboratory-scale test: mass of as-fed slurry divided by total mass after } \\
\text { DIW (and } \mathrm{NaOH} \text {, in Test A-2) have been added }\end{array}$ \\
\hline$c_{N a, S S}$ & $\begin{array}{l}\text { concentration data for a slurry tracer, total } \mathrm{Na} \text {, in the beaker sample after } \mathrm{DIW} \text { (and } \mathrm{NaOH} \text {, } \\
\text { in Test } \mathrm{A}-2 \text { ) have been added to the as-fed, and before heating has begun }\end{array}$ \\
\hline$c_{N a, F S}$ & concentration data for a slurry tracer, total $\mathrm{Na}$, in beaker sample at end of test \\
\hline$\omega_{s, S S}$ & $\begin{array}{l}\mathrm{g} \text { UDS/g slurry in beaker sample after DIW, and in } \mathrm{A}-2 \mathrm{NaOH} \text {, have been added to the } \\
\text { as-fed, and before heating has begun }\end{array}$ \\
\hline$c_{C I L, S S}$ & $\begin{array}{l}\mu \mathrm{g} \mathrm{Cl} / \mathrm{g} \text { liquid in beaker sample after DIW, and in } \mathrm{A}-2 \mathrm{NaOH} \text {, have been added to the } \\
\text { as-fed, and before heating has begun }\end{array}$ \\
\hline$\rho_{L, S S}$ & $\begin{array}{l}\mathrm{g} / \mathrm{mL} \text { liquid density in beaker sample after } \mathrm{DIW} \text {, and in } \mathrm{A}-2 \mathrm{NaOH} \text {, have been added to the } \\
\text { as-fed, and before heating has begun }\end{array}$ \\
\hline$c_{A l L, 0 h}$ & $\mu \mathrm{g}$ liquid $\mathrm{Al} / \mathrm{g}$ liquid in beaker sample at $0 \mathrm{hr}$ at temperature \\
\hline$c_{C l L, 0 h}$ & $\mu \mathrm{g} \mathrm{Cl} / \mathrm{g}$ liquid in beaker sample at $0 \mathrm{hr}$ at temperature \\
\hline
\end{tabular}

The total Al concentration in the initial diluted slurry is estimated using three different data sources, and then they are averaged together to give the value that will be used in subsequent calculations. The first estimate, $c_{A l, S S, l}$, is calculated from the $\mathrm{Al}$ concentration in the excess portion of the feed, applying the dilution expected from the masses of as-fed slurry and diluent given in the laboratory-scale Test Instructions.

$$
c_{A l, S S, 1}=f_{D} c_{A l, X S}
$$

The second estimate, $c_{A l, S S, 2}$, is equal to the concentration measured in beaker samples taken from the initial diluted slurry in the beaker.

$$
c_{A l, S S, 2}=c_{A l, S S}
$$

The third estimate, $c_{A l, S S, 3}$, is equal to the concentration measured in beaker samples taken at the end of the test, normalized to the initial diluted condition with a slurry tracer. In all four laboratory-scale tests, the slurry concentration of $\mathrm{Na}$ is used as the slurry tracer.

$$
c_{A l, S S, 3}=c_{A l, F S} \frac{c_{N a, S S}}{c_{N a, F S}}
$$


The three estimates of the total $\mathrm{Al}$ concentration in the initial diluted slurry are averaged to give

$$
c_{A l, S S}=\frac{c_{A l, S S, 1}+c_{A l, S S, 2}+c_{A l, S S, 3}}{3}
$$

The next step is to determine the boehmite present. Considering that there is less total $\mathrm{Al}$ in the beaker slurry than in the PEP slurry, and therefore that there is less solid-phase Al, it cannot be assumed that the solid Al that was "lost" contained the same proportions of gibbsite and boehmite as the solid Al in the PEP slurry. A preferential loss of gibbsite, or of boehmite, could have occurred. Thus, the gibbsite/boehmite ratio in the PEP slurry may not describe the beaker slurry.

Assume that all the gibbsite initially present in the beaker slurry has dissolved by $0 \mathrm{hr}$ at temperature. Then the boehmite concentration can be estimated by subtracting the dissolved $\mathrm{Al}$ at $0 \mathrm{hr}$ from the total Al to give solid-phase Al under conditions of complete gibbsite dissolution. By definition, the solid-phase $\mathrm{Al}$ must all be boehmite under these conditions. The boehmite concentration equation, which accounts for normalizing the 0 -hr dissolved $\mathrm{Al}$ to the liquid volume present after $\mathrm{DIW} / \mathrm{NaOH}$ have been added, is

$$
C_{A l b, L, S S}=\left[c_{A l, S S}-\left(1-\omega_{s, S S}\right) c_{A l L, 0 h} \frac{c_{C l L, S S}}{c_{C l L, 0 h}}\right] \frac{1}{1-\omega_{s, S S}} \frac{\rho_{L, S S}}{1000 M_{A l}}
$$

Units of $C_{A l b, L, S S}$ are moles of $\mathrm{Al}$ in boehmite per liter of liquid present in the slurry after DIW/NaOH have been added. The UDS fraction used in Equation (A.68) is the measured value, with some gibbsite still present. It is an approximation for the UDS that would be present after DIW/NaOH addition if all the gibbsite were dissolved, but the approximation should have little effect on the (1 minus UDS) term. 

Appendix B

\section{Auxiliary Data Used in Leach Calculations}





\section{Appendix B}

\section{Auxiliary Data Used in Leach Calculations}

This appendix provides auxiliary analytical data. In this appendix, all concentrations and properties are stated at the dilution conditions actually existing in the sample. These values have not been subjected to any adjustment for the volume "normalization" that was discussed in Section 4.

Table B.1. Number of Samples Taken at Each Point During Caustic-Leach Tests

\begin{tabular}{|c|c|c|c|c|c|c|}
\hline \multirow[b]{2}{*}{$\begin{array}{l}\text { Point in } \\
\text { Process }\end{array}$} & \multicolumn{6}{|c|}{ Number of Samples Taken } \\
\hline & $\begin{array}{c}\text { PEP Integrated } \\
\text { Test A, Batch } 1 \text { of } \\
\text { UFP-T01A }\end{array}$ & $\begin{array}{c}\text { Laboratory- } \\
\text { Scale } \\
\text { Test A-1 } \\
\end{array}$ & $\begin{array}{l}\text { Laboratory- } \\
\text { Scale } \\
\text { Test A-2 } \\
\end{array}$ & $\begin{array}{c}\text { PEP Integrated } \\
\text { Test B, Batch } 2 \text { of } \\
\text { UFP-T02A }\end{array}$ & $\begin{array}{c}\text { Laboratory- } \\
\text { Scale } \\
\text { Test B-1 } \\
\end{array}$ & $\begin{array}{l}\text { Laboratory- } \\
\text { Scale } \\
\text { Test B-2 } \\
\end{array}$ \\
\hline Before $\mathrm{NaOH}$ & 3 & 3 & 3 & 3 & 3 & 3 \\
\hline After $\mathrm{NaOH}$ & 3 & 2 & 2 & 3 & 1 & 1 \\
\hline $\begin{array}{l}\text { After } \mathrm{NaOH} \text {, } \\
\text { rinsed sample }\end{array}$ & $\mathrm{n} / \mathrm{m}$ & 1 & 1 & $\mathrm{n} / \mathrm{m}$ & 2 & 2 \\
\hline At $88^{\circ} \mathrm{C}$ & 1 & 1 & 1 & 1 & 1 & 1 \\
\hline $0 \mathrm{hr}$ & 3 & 1 & 1 & 3 & 1 & 1 \\
\hline $1 \mathrm{hr}$ & 1 & 1 & 1 & 1 & 1 & 1 \\
\hline $2 \mathrm{hr}$ & 1 & 1 & 1 & 1 & 1 & 1 \\
\hline $4 \mathrm{hr}$ & 1 & 1 & 1 & 1 & 1 & 1 \\
\hline $8 \mathrm{hr}$ & 1 & 1 & 1 & 1 & 1 & 1 \\
\hline $10 \mathrm{hr}$ & 1 & 1 & 1 & 1 & 1 & 1 \\
\hline $12 \mathrm{hr}$ & 1 & 1 & 1 & 3 & 1 & 1 \\
\hline $14 \mathrm{hr}$ & 1 & 1 & 1 & 1 & 1 & 1 \\
\hline $16 \mathrm{hr}$ & 3 & 1 & 1 & 3 & 1 & 1 \\
\hline $18 \mathrm{hr}$ & $\mathrm{n} / \mathrm{m}$ & 1 & 1 & $\mathrm{n} / \mathrm{m}$ & 1 & 1 \\
\hline $20 \mathrm{hr}$ & $\mathrm{n} / \mathrm{m}$ & 1 & 1 & $\mathrm{n} / \mathrm{m}$ & 1 & 1 \\
\hline $22 \mathrm{hr}$ & $\mathrm{n} / \mathrm{m}$ & 1 & 1 & $\mathrm{n} / \mathrm{m}$ & $\mathrm{n} / \mathrm{m}$ & $\mathrm{n} / \mathrm{m}$ \\
\hline $24 \mathrm{hr}$ & $\mathrm{n} / \mathrm{m}$ & 1 & 1 & $\mathrm{n} / \mathrm{m}$ & 1 & 1 \\
\hline After cooling & $\mathrm{n} / \mathrm{m}$ & 1 & 1 & $\mathrm{n} / \mathrm{m}$ & 1 & 1 \\
\hline $\begin{array}{l}\text { After cooling, } \\
\text { rinsed sample }\end{array}$ & $\mathrm{n} / \mathrm{m}$ & 3 & 3 & $\mathrm{n} / \mathrm{m}$ & 2 & 2 \\
\hline
\end{tabular}


Table B.2. Liquid Tracer Mass Concentrations During Caustic-Leach Tests

\begin{tabular}{|c|c|c|c|c|c|c|}
\hline \multirow[b]{2}{*}{$\begin{array}{l}\text { Point in } \\
\text { Process }\end{array}$} & \multicolumn{6}{|c|}{$\begin{array}{c}\text { Concentration of Liquid Tracer ( } \mu \mathrm{g} / \mathrm{g} \text { liquid) in Liquid Phase }{ }^{(\mathrm{a})} \\
\pm 1 \text { Standard Deviation from Laboratory Analysis }\end{array}$} \\
\hline & $\begin{array}{c}\text { PEP } \\
\text { Integrated } \\
\text { Test A, Batch } \\
1 \text { of UFP- } \\
\text { T01A } \\
\mathrm{NO}_{3}^{-}\end{array}$ & $\begin{array}{l}\text { Laboratory- } \\
\text { Scale } \\
\text { Test A-1 } 1^{(\mathrm{b}, \mathrm{c})} \\
\mathrm{Cl}^{-}\end{array}$ & $\begin{array}{l}\text { Laboratory- } \\
\text { Scale } \\
\text { Test A-2 } 2^{(\mathrm{c})} \\
\mathrm{Cl}^{-}\end{array}$ & $\begin{array}{c}\text { PEP } \\
\text { Integrated } \\
\text { Test } \mathrm{B}, \\
\text { Batch 2 of } \\
\text { UFP-T02A } \\
\mathrm{Cl}^{-}\end{array}$ & $\begin{array}{l}\text { Laboratory- } \\
\text { Scale } \\
\text { Test B-1 } 1^{(b, c)} \\
\text { Cl }^{-}\end{array}$ & $\begin{array}{c}\text { Laboratory- } \\
\text { Scale } \\
\text { Test B-2 } 2^{(\mathrm{b}, \mathrm{c})} \\
\mathrm{Cl}^{-}\end{array}$ \\
\hline $\begin{array}{l}\text { Before } \\
\mathrm{NaOH}\end{array}$ & $79333 \pm 1380$ & $1137 \pm 20$ & $1137 \pm 20$ & $961 \pm 17$ & $961 \pm 17$ & $961 \pm 17$ \\
\hline After $\mathrm{NaOH}$ & $56967 \pm 1016$ & $736 \pm 22$ & $741 \pm 23$ & $476 \pm 9$ & $414 \pm 13$ & $408 \pm 12$ \\
\hline At $88^{\circ} \mathrm{C}$ & $52700 \pm 1636$ & $763 \pm 23$ & $758 \pm 23$ & $443 \pm 14$ & $409 \pm 13$ & $419 \pm 13$ \\
\hline $0 \mathrm{hr}$ & $52650 \pm 1132$ & $736 \pm 22$ & $789 \pm 24$ & $428 \pm 8$ & $422 \pm 13$ & $426 \pm 13$ \\
\hline $1 \mathrm{hr}$ & $51100 \pm 1593$ & $775 \pm 24$ & $756 \pm 23$ & $416 \pm 13$ & $429 \pm 13$ & $422 \pm 13$ \\
\hline $2 \mathrm{hr}$ & $51600 \pm 1602$ & $760 \pm 23$ & $778 \pm 24$ & $416 \pm 13$ & $418 \pm 13$ & $418 \pm 13$ \\
\hline $4 \mathrm{hr}$ & $50900 \pm 1584$ & $768 \pm 23$ & $775 \pm 24$ & $405 \pm 13$ & $427 \pm 13$ & $456 \pm 14$ \\
\hline $8 \mathrm{hr}$ & $51000 \pm 1561$ & $794 \pm 24$ & $778 \pm 24$ & $407 \pm 13$ & $428 \pm 13$ & $455 \pm 14$ \\
\hline $10 \mathrm{hr}$ & $49400 \pm 1541$ & $778 \pm 24$ & $779 \pm 24$ & $398 \pm 13$ & $429 \pm 13$ & $435 \pm 13$ \\
\hline $12 \mathrm{hr}$ & $49400 \pm 1534$ & $800 \pm 24$ & $863 \pm 26$ & $388 \pm 7$ & $432 \pm 13$ & $439 \pm 13$ \\
\hline $14 \mathrm{hr}$ & $48200 \pm 1511$ & $793 \pm 24$ & $932 \pm 28$ & $383 \pm 12$ & $426 \pm 13$ & $432 \pm 13$ \\
\hline $16 \mathrm{hr}$ & $48533 \pm 866$ & $793 \pm 24$ & $922 \pm 28$ & $379 \pm 7$ & $430 \pm 13$ & $432 \pm 13$ \\
\hline $18 \mathrm{hr}$ & $\mathrm{n} / \mathrm{m}$ & $817 \pm 25$ & $976 \pm 30$ & $\mathrm{n} / \mathrm{m}$ & $438 \pm 13$ & $433 \pm 13$ \\
\hline $20 \mathrm{hr}$ & $\mathrm{n} / \mathrm{m}$ & $805 \pm 25$ & $960 \pm 29$ & $\mathrm{n} / \mathrm{m}$ & $438 \pm 13$ & $439 \pm 13$ \\
\hline $22 \mathrm{hr}$ & $\mathrm{n} / \mathrm{m}$ & $797 \pm 24$ & $968 \pm 30$ & $\mathrm{n} / \mathrm{m}$ & $\mathrm{n} / \mathrm{m}$ & $\mathrm{n} / \mathrm{m}$ \\
\hline $24 \mathrm{hr}$ & $\mathrm{n} / \mathrm{m}$ & $854 \pm 26$ & $975 \pm 30$ & $\mathrm{n} / \mathrm{m}$ & $443 \pm 14$ & $438 \pm 13$ \\
\hline $\begin{array}{l}\text { (a) } \mathrm{NO}_{3}{ }^{-} \text {and } \\
\text { (b) The sampl } \\
\text { (c) Note that } \\
\text { PEP runs. } \\
\text { " } \mathrm{n} / \mathrm{m} \text { " = not me }\end{array}$ & $\begin{array}{l}\text { were measured in } \\
\text { sed in these labor } \\
\text { er was added all } \\
\text { red. }\end{array}$ & $\begin{array}{l}\mathrm{g} / \mathrm{g} \text { liquid by IC } \\
\text { ory-scale tests } \mathrm{u} \\
\text { once at the begi }\end{array}$ & $\begin{array}{l}\text { SwRI. } \\
\text { aken from PI } \\
\text { g of laborato }\end{array}$ & $\begin{array}{l}\text { ter } \mathrm{NaOH} \text { hac } \\
\text { ale runs, but }\end{array}$ & $\begin{array}{l}\text { n added. } \\
\text { added graduall }\end{array}$ & roughout the \\
\hline
\end{tabular}


Table B.4. Slurry Tracer Mass Concentrations During Caustic-Leach Tests

\begin{tabular}{|c|c|c|c|c|c|c|}
\hline \multirow[b]{2}{*}{ Point in Process } & \multicolumn{6}{|c|}{$\begin{array}{l}\text { Concentration of Tracer }(\mu \mathrm{g} / \mathrm{g} \text { slurry) in Bulk Slurry } \\
\pm 1 \text { Standard Deviation from Laboratory Analysis }\end{array}$} \\
\hline & $\begin{array}{c}\text { PEP Integrated Test A, } \\
\text { Batch } 1 \text { of UFP-T01A } \\
\mathrm{Na}\end{array}$ & $\begin{array}{l}\text { Laboratory- } \\
\text { Scale } \\
\text { Test A- } 1^{(\mathrm{b}, \mathrm{c})} \\
\mathrm{Na}\end{array}$ & $\begin{array}{l}\text { Laboratory- } \\
\text { Scale } \\
\text { Test A-2 } \\
\text { Na }\end{array}$ & $\begin{array}{c}\text { PEP Integrated Test B, } \\
\text { Batch } 2 \text { of UFP-T02A } \\
\mathrm{Na}\end{array}$ & $\begin{array}{l}\text { Laboratory- } \\
\text { Scale } \\
\text { Test B-1 }{ }^{(b, c)} \\
\mathrm{Na}\end{array}$ & $\begin{array}{l}\text { Laboratory- } \\
\text { Scale } \\
\text { Test B-2 } 2^{(b, c)} \\
\mathrm{Na}\end{array}$ \\
\hline Before $\mathrm{NaOH}$ & $88920 \pm 1372$ & $88920 \pm 1372$ & $88920 \pm 1372$ & $80397 \pm 1072$ & $80397 \pm 1065$ & $80397 \pm 1065$ \\
\hline After $\mathrm{NaOH}$ & $138203 \pm 2161$ & $116000 \pm 2777$ & $114000 \pm 2729$ & $155033 \pm 2208$ & $132000 \pm 4491$ & 13000 \\
\hline $\begin{array}{l}\text { After } \mathrm{NaOH} \text {, } \\
\text { rinsed sample }\end{array}$ & $\mathrm{n} / \mathrm{m}$ & $466 \pm 16$ & $626 \pm 21$ & $\mathrm{n} / \mathrm{m}$ & $2020 \pm 49$ & $1790 \pm 43$ \\
\hline At $88^{\circ} \mathrm{C}$ & $\mathrm{n} / \mathrm{m}$ & $\mathrm{n} / \mathrm{m}$ & $\mathrm{n} / \mathrm{m}$ & $161783 \pm 4141$ & $\mathrm{n} / \mathrm{m}$ & $\mathrm{n} / \mathrm{m}$ \\
\hline $0 \mathrm{hr}$ & $127008 \pm 2043$ & $\mathrm{n} / \mathrm{m}$ & $\mathrm{n} / \mathrm{m}$ & $158000 \pm 2377$ & $\mathrm{n} / \mathrm{m}$ & $11 /$ \\
\hline $1 \mathrm{hr}$ & $\mathrm{n} / \mathrm{m}$ & $\mathrm{n} / \mathrm{m}$ & $\mathrm{n} / \mathrm{m}$ & $155917 \pm 4056$ & $\mathrm{n} / \mathrm{m}$ & $\mathrm{n} / \mathrm{m}$ \\
\hline $2 \mathrm{hr}$ & $\mathrm{n} / \mathrm{m}$ & $\mathrm{n} / \mathrm{m}$ & $\mathrm{n} / \mathrm{m}$ & $155523 \pm 4053$ & $\mathrm{n} / \mathrm{m}$ & $\mathrm{n} / \mathrm{m}$ \\
\hline $4 \mathrm{hr}$ & $126565 \pm 3547$ & $\mathrm{n} / \mathrm{m}$ & $\mathrm{n} / \mathrm{m}$ & $152949 \pm 4030$ & $\mathrm{n} / \mathrm{m}$ & $\mathrm{n} / \mathrm{m}$ \\
\hline $8 \mathrm{hr}$ & $\mathrm{n} / \mathrm{m}$ & $\mathrm{n} / \mathrm{m}$ & $\mathrm{n} / \mathrm{m}$ & $148617 \pm 3974$ & $\mathrm{n} / \mathrm{m}$ & $\mathrm{n} / \mathrm{m}$ \\
\hline $10 \mathrm{hr}$ & $\mathrm{n} / \mathrm{m}$ & $\mathrm{n} / \mathrm{m}$ & $\mathrm{n} / \mathrm{m}$ & $150083 \pm 3938$ & $\mathrm{n} / \mathrm{m}$ & $\mathrm{n} / \mathrm{m}$ \\
\hline $12 \mathrm{hr}$ & $125628 \pm 3545$ & $\mathrm{n} / \mathrm{m}$ & $\mathrm{n} / \mathrm{m}$ & $148327 \pm 2255$ & $\mathrm{n} / \mathrm{m}$ & $\mathrm{n} / \mathrm{m}$ \\
\hline $14 \mathrm{hr}$ & $\mathrm{n} / \mathrm{m}$ & $\mathrm{n} / \mathrm{m}$ & $\mathrm{n} / \mathrm{m}$ & $146329 \pm 3826$ & $\mathrm{n} / \mathrm{m}$ & $\mathrm{n} / \mathrm{m}$ \\
\hline $16 \mathrm{hr}$ & $123603 \pm 2017$ & $\mathrm{n} / \mathrm{m}$ & $\mathrm{n} / \mathrm{m}$ & $144832 \pm 2217$ & $\mathrm{n} / \mathrm{m}$ & $\mathrm{n} / \mathrm{m}$ \\
\hline $18 \mathrm{hr}$ & $\mathrm{n} / \mathrm{m}$ & $\mathrm{n} / \mathrm{m}$ & $\mathrm{n} / \mathrm{m}$ & $\mathrm{n} / \mathrm{m}$ & $\mathrm{n} / \mathrm{m}$ & $\mathrm{n} / \mathrm{m}$ \\
\hline $20 \mathrm{hr}$ & $\mathrm{n} / \mathrm{m}$ & $\mathrm{n} / \mathrm{m}$ & $\mathrm{n} / \mathrm{m}$ & $\mathrm{n} / \mathrm{m}$ & $\mathrm{n} / \mathrm{m}$ & $\mathrm{n} / \mathrm{m}$ \\
\hline $22 \mathrm{hr}$ & $\mathrm{n} / \mathrm{m}$ & $\mathrm{n} / \mathrm{m}$ & $\mathrm{n} / \mathrm{m}$ & $\mathrm{n} / \mathrm{m}$ & $\mathrm{n} / \mathrm{m}$ & $\mathrm{n} / \mathrm{m}$ \\
\hline $24 \mathrm{hr}$ & $\mathrm{n} / \mathrm{m}$ & $\mathrm{n} / \mathrm{m}$ & $\mathrm{n} / \mathrm{m}$ & $\mathrm{n} / \mathrm{m}$ & $\mathrm{n} / \mathrm{m}$ & $\mathrm{n} / \mathrm{m}$ \\
\hline After cooling $^{(\mathrm{d})}$ & $\mathrm{n} / \mathrm{c}$ & $125000 \pm 4232$ & $139000 \pm 4706$ & $\mathrm{n} / \mathrm{c}$ & $142000 \pm 4831$ & $143000 \pm 486$ \\
\hline $\begin{array}{l}\text { After cooling, } \\
\text { rinsed sample }\end{array}$ & $\mathrm{n} / \mathrm{m}$ & $702 \pm 14$ & $873 \pm 17$ & $\mathrm{n} / \mathrm{m}$ & $2730 \pm 90$ & $2845 \pm 68$ \\
\hline \multicolumn{7}{|c|}{$\begin{array}{l}\text { (a) For the PEP tests, Na was measured by ICP at SwRI for centrifuged solids and for the decanted liquid in units of } \mu \mathrm{g} / \mathrm{g} \text {. The } \\
\text { Na concentrations in the bulk slurry are calculated from the liquid concentrations, the concentrations measured in } \\
\text { centrifuged solids, and the mass fraction of the slurry that was centrifuged solids. The } \pm \text { values are standard deviations } \\
\text { calculated by linearized error propagation methods. The method used to estimate the uncertainty of the centrifuged solids } \\
\text { weight fraction depends on measurements for the triplicate data sets. The different number of triplicate data sets in PEP and } \\
\text { laboratory-scale tests causes differences in centrifuged solids fraction uncertainty, and therefore in slurry concentration } \\
\text { uncertainty, for the same sample, when determined from PEP test data sets and from laboratory-scale test data sets. See } \\
\text { Appendix C for more information. }\end{array}$} \\
\hline \multicolumn{7}{|c|}{ (b) The sample used in these laboratory-scale tests was taken from PEP after $\mathrm{NaOH}$ had been added. } \\
\hline \multicolumn{7}{|c|}{$\begin{array}{l}\text { (c) Note that water was added all at once at the beginning of laboratory-scale runs, but was added gradually throughout the PEP } \\
\text { runs. }\end{array}$} \\
\hline \multicolumn{7}{|c|}{$\begin{array}{l}\text { (d) The samples were removed when the vessel slurry had been cooled to a temperature of }<60^{\circ} \mathrm{C} \text {. They were then rinsed with } \\
0.01 \mathrm{M} \mathrm{NaOH} \text {. }\end{array}$} \\
\hline
\end{tabular}


Table B.5. Estimated Liquid Densities for Laboratory-Scale Caustic-Leach Tests

\begin{tabular}{|c|c|c|c|c|}
\hline \multirow[b]{2}{*}{ Point in Process } & \multicolumn{4}{|c|}{$\begin{array}{c}\text { Density Estimated from PEP Data }{ }^{(\mathrm{a})} \\
\pm 1 \text { Standard Deviation based on PEP Laboratory Analysis }\end{array}$} \\
\hline & $\begin{array}{l}\text { Laboratory- } \\
\text { Scale Test A-1 }\end{array}$ & $\begin{array}{l}\text { Laboratory- } \\
\text { Scale Test A-2 }\end{array}$ & $\begin{array}{l}\text { Laboratory- } \\
\text { Scale Test B-1 }\end{array}$ & $\begin{array}{l}\text { Laboratory- } \\
\text { Scale Test B-2 }\end{array}$ \\
\hline Before $\mathrm{NaOH}$ & $1.239 \pm 0.001$ & $1.239 \pm 0.002$ & $1.235 \pm 0.005$ & $1.235 \pm 0.005$ \\
\hline After $\mathrm{NaOH}$ & $1.323 \pm 0.010$ & $1.305 \pm 0.010$ & $1.351 \pm 0.010$ & $1.348 \pm 0.010$ \\
\hline At $88^{\circ} \mathrm{C}$ & $1.332 \pm 0.010$ & $1.312 \pm 0.010$ & $1.351 \pm 0.010$ & $1.351 \pm 0.010$ \\
\hline $0 \mathrm{hr}$ & $1.321 \pm 0.010$ & $1.334 \pm 0.010$ & $1.354 \pm 0.010$ & $1.357 \pm 0.010$ \\
\hline $1 \mathrm{hr}$ & $1.336 \pm 0.010$ & $1.328 \pm 0.010$ & $1.357 \pm 0.010$ & $1.354 \pm 0.010$ \\
\hline $2 \mathrm{hr}$ & $1.330 \pm 0.010$ & $1.332 \pm 0.010$ & $1.354 \pm 0.010$ & $1.353 \pm 0.010$ \\
\hline $4 \mathrm{hr}$ & $1.332 \pm 0.010$ & $1.330 \pm 0.010$ & $1.356 \pm 0.010$ & $1.370 \pm 0.010$ \\
\hline $8 \mathrm{hr}$ & $1.343 \pm 0.010$ & $1.316 \pm 0.010$ & $1.355 \pm 0.010$ & $1.367 \pm 0.010$ \\
\hline $10 \mathrm{hr}$ & $1.334 \pm 0.010$ & $1.319 \pm 0.010$ & $1.359 \pm 0.010$ & $1.359 \pm 0.010$ \\
\hline $12 \mathrm{hr}$ & $1.341 \pm 0.010$ & $1.348 \pm 0.010$ & $1.359 \pm 0.010$ & $1.357 \pm 0.010$ \\
\hline $14 \mathrm{hr}$ & $1.343 \pm 0.010$ & $1.370 \pm 0.010$ & $1.356 \pm 0.010$ & $1.356 \pm 0.010$ \\
\hline $16 \mathrm{hr}$ & $1.341 \pm 0.010$ & $1.368 \pm 0.010$ & $1.361 \pm 0.010$ & $1.359 \pm 0.010$ \\
\hline $18 \mathrm{hr}$ & $1.350 \pm 0.010$ & $1.386 \pm 0.010$ & $1.361 \pm 0.010$ & $1.359 \pm 0.010$ \\
\hline $20 \mathrm{hr}$ & $1.345 \pm 0.010$ & $1.379 \pm 0.010$ & $1.364 \pm 0.010$ & $1.362 \pm 0.010$ \\
\hline $22 \mathrm{hr}$ & $1.343 \pm 0.010$ & $1.384 \pm 0.010$ & $\mathrm{n} / \mathrm{m}$ & $\mathrm{n} / \mathrm{m}$ \\
\hline $24 \mathrm{hr}$ & $1.363 \pm 0.010$ & $1.386 \pm 0.010$ & $1.363 \pm 0.010$ & $1.362 \pm 0.010$ \\
\hline
\end{tabular}

(a) The liquid density was estimated by correlating liquid density data to nitrate concentration for PEP samples taken after $\mathrm{NaOH}$ addition and then using the correlations with laboratory-scale nitrate data to estimate laboratory-scale liquid density. The nitrate concentration serves as a surrogate for dissolved solids. The PEP Integrated Test A and PEP Integrated Test B data were correlated separately, with the PEP Integrated Test A correlation used for laboratory-scale Tests A-1 and A-2, and the PEP Integrated Test B correlation used for laboratory-scale Tests B-1 and B-2. Standard deviations were set equal to $0.01 \mathrm{~g} / \mathrm{mL}$; this was the approximate value for the densities measured from PEP samples.

Correlation equations were

$\rho_{\mathrm{L}}=5.061 \mathrm{E}-06 c_{N O 3, L}+1.043$ for Tests A-1, A-2 (units $\mathrm{g} / \mathrm{mL}$ and $\mu \mathrm{g} / \mathrm{g}$ ), $\mathrm{R}^{2}=0.90$

$\rho_{\mathrm{L}}=5.641 \mathrm{E}-06 c_{N O 3, L}+1.159$ for Tests B-1, B-2 (units $\mathrm{g} / \mathrm{mL}$ and $\mu \mathrm{g} / \mathrm{g}$ ), $\mathrm{R}^{2}=0.94$ 

Appendix C

Uncertainty Inputs to Monte Carlo Calculations and Uncertainties in Tabulations 



\section{Appendix C}

\section{Uncertainty Inputs to Monte Carlo Calculations and Uncertainties in Tabulations}

In the Monte Carlo method, the complete set of deterministic equations required for leach factor and kinetic data analyses is solved a large number of times; each solution is termed a "realization." In each realization, every measurement value that is used in an equation has a different perturbation, representing random measurement error, added to its measured value. To put it differently, each realization contains a different "sampling" of measurement inputs from the possible populations that could result from preparative and analytical error around the true values.

All of the realizations, taken together, describe the propagation of measurement uncertainty through the calculations by generating the probability distributions of every calculated variable in the data analysis. The uncertainty of any calculated variable is then found by taking the standard deviation, or other statistically appropriate measure, of the variable's distribution.

The uncertainties of analytical measurements (the inputs to the deterministic equations) were generally part of the data supplied by the analytical providers. Section E.3 of Kurath et al. (2009) provides more detail on the technical basis of the uncertainties. These uncertainties represented $95 \%$ confidence bounds on the error caused by laboratory procedures and analytical methods, and so were equal, to a close approximation, to two standard deviations on either side of the measured value. The uncertainties supplied by analytical providers were therefore halved to give the standard deviations of the measurements for individual samples.

For process points where sets of triplicate or duplicate samples were taken (as listed in Table B.1), the mean standard deviation of the set of samples, $\sigma_{N}$, was calculated using the following equation:

$$
\sigma_{N}=\frac{1}{N} \sqrt{\sum_{n=1}^{n} \sigma_{n}^{2}}
$$

where $N$ is the number of samples in the set and $\sigma_{n}$ is the standard deviation of each sample. The mean of the measurements and the mean standard deviation were used to represent the set.

The only information needed to perform a Monte Carlo analysis is an identification of the variables that are direct inputs (measurements), a definition of the perturbation distribution used for each direct input variable, and the set of deterministic equations used in the data analysis. Section C. 1 lists the sequence of equations used in each type of data analysis and defines the input variables for which perturbation distributions were assigned. The only inputs that require perturbations to be assigned are those that are either directly measured or defined (e.g., molecular weights). The equations may also include inputs of calculated variables (e.g., Al leach factors); calculated inputs are not listed because their 
perturbation distributions are not assigned, but are calculated as Monte Carlo outputs. Section C.2 gives details of the perturbation distributions for each type of input used in the stochastic rate constant and leach factor calculations.

\section{C.1 Equations Used in Monte Carlo Analysis}

The sequence of calculations that supplied the Al and boehmite leach factors for PEP tests, based on the liquid tracer and solid tracer methods, was as shown below.

1. Use Equation (A.58) to obtain the total slurry concentration of $\mathrm{Al}$ at the reference point (before $\mathrm{NaOH}$ was added).

- Inputs: Reference weight fraction of centrifuged solids in the slurry, reference Al mass concentration in the sample's centrifuged solids, reference Al mass concentration in the liquid.

2. Use Equation (A.58) to obtain the total slurry concentration of $\mathrm{Al}$ at time $t$.

- Inputs: Weight fraction of centrifuged solids in the slurry at $t, \mathrm{Al}$ mass concentration in the sample's centrifuged solids at $t, \mathrm{Al}$ mass concentration in the liquid at $t$.

3. Use Equation (A.58) to obtain the total slurry concentration of solid tracer at the reference point.

- Inputs: Reference weight fraction of centrifuged solids in the slurry, reference solid tracer mass concentration in the sample's centrifuged solids.

- Note that the solid tracer concentration in the liquid is defined as zero.

4. Use Equation (A.58) to obtain the total slurry concentration of solid tracer at time $t$.

- Inputs: Weight fraction of centrifuged solids in the slurry at $t$, solid tracer mass concentration in the sample's centrifuged solids at $t$.

- Note that the solid tracer concentration in the liquid is defined as zero.

5. Use Equation (A.38) to obtain the liquid tracer Al leach factor at time $t$.

- Inputs: Reference weight fraction of UDS in the slurry, reference Al and liquid tracer mass concentrations in the liquid, $\mathrm{Al}$ and liquid tracer mass concentrations in the liquid for time $t$.

6. Use Equation (A.35) to obtain the solid tracer Al leach factor at time $t$.

- Inputs: Reference weight fraction of UDS in the slurry, weight fraction of UDS at $t$, reference Al concentration in the liquid, Al mass concentration in the liquid for time $t$, reference solid tracer mass concentration in the slurry, solid tracer mass concentration in the slurry for time $t$.

7. Use Equation (A.41) to obtain the boehmite leach factor from the Al leach factor at time $t$.

- Inputs: Fraction of solid-phase Al that is present in gibbsite at the reference point.

The sequence of calculations that supplied the Al and boehmite leach factors for laboratory-scale tests, based on the liquid tracer and solid tracer methods, was as shown below.

1. Use Equations (A.66a), (A.66b), and (A.66c) to obtain three different estimates of the Al concentration in the initial diluted slurry.

- Inputs: Weight fraction of dilution in the initial diluted slurry, Al mass concentration in the excess slurry, Al mass concentration in the initial diluted slurry, Al mass concentration in the 
final slurry, Na mass concentration in the final slurry, Na mass concentration in the initial diluted slurry.

2. Use Equation (A.67) to average the three estimates to obtain the total slurry concentration of $\mathrm{Al}$ in the initial diluted slurry.

- Inputs: None.

3. Use Equation (A.62) to calculate the concentration of solid-phase Al in the initial diluted slurry.

- Inputs: Weight fraction of UDS in the initial diluted slurry, Al mass concentration in the liquid of the initial diluted slurry.

- Because the slurry samples taken in the laboratory-scale tests were not centrifuged before analysis, the weight fraction of centrifuged solids in the slurry is defined as unity for the purpose of using Equation (A.62).

4. The term in square brackets in Equation (A.68) was used to obtain the concentration of boehmite Al in the initial diluted slurry.

- Inputs: Weight fraction of UDS in the initial diluted slurry, $\mathrm{Al}$ and liquid tracer mass concentrations in the liquid at $0 \mathrm{hr}$, liquid tracer mass concentration in the liquid of the initial diluted slurry.

5. Fraction of solid-phase Al that is present in gibbsite in the initial diluted slurry, equal to one minus the ratio of Step (4) to Step (3).

- Inputs: None.

6. Use Equation (A.38) to obtain the liquid tracer Al leach factor at time $t$.

- Inputs: Weight fraction of UDS in the initial diluted slurry, $\mathrm{Al}$ and tracer mass concentrations in the liquid in the initial diluted slurry, $\mathrm{Al}$ and tracer mass concentrations in the liquid for time $t$.

7. Use Equation (A.35) to obtain the solid tracer Al leach factor in the final slurry.

- Inputs: Weight fraction of UDS in the initial diluted slurry, weight fraction of UDS in the final slurry, Al mass concentration in the liquid in the initial diluted slurry, Al mass concentration in the liquid in the final slurry, $\mathrm{Al}$ mass concentration in the final slurry, solid tracer mass concentration in the initial diluted slurry, solid tracer mass concentration in the final slurry.

8. Use Equation (A.41) to obtain the boehmite leach factor from the Al leach factor at time $t$.

- Inputs: None.

The sequence of calculations in the kinetic data analysis for the PEP tests was as shown below.

1. Use Equation (A.64) to obtain the moles of boehmite at $0 \mathrm{hr}$ per volume of liquid at $16 \mathrm{hr}$ (initial molar concentration of boehmite normalized to maximum-volume conditions).

- Inputs: Molecular weight of Al, weight fraction UDS in the slurry at $0 \mathrm{hr}$, weight fraction of centrifuged solids in the slurry sample at $0 \mathrm{hr}, \mathrm{Al}$ mass concentration in the centrifuged solids at $0 \mathrm{hr}, \mathrm{Al}$ mass concentration in the liquid at $0 \mathrm{hr}$, liquid tracer mass concentration in the liquid at $0 \mathrm{hr}$, liquid tracer mass concentration in the liquid at $16 \mathrm{hr}$, liquid density at $16 \mathrm{hr}$.

- Because all gibbsite is assumed to have dissolved by $0 \mathrm{hr}$, the fraction of solid-phase Al that is in boehmite is defined as unity for the purpose of using Equation (A.64). Also note that the liquid 
density at $0 \mathrm{hr}$ is not needed because it cancels out of Equation (A.64), being implicit in the molar concentration of the liquid tracer (see Equation [A.50]).

2. Use Equation (A.65) to obtain the molar total hydroxide concentration at time $t$, then normalize to maximum-volume conditions at $16 \mathrm{hr}$.

- Inputs: Molar free hydroxide at $t, \mathrm{Al}$ mass concentration in the liquid at $t$, liquid density at $t$, molecular weight of $\mathrm{Al}$, liquid tracer mass concentration in the liquid at $t$, liquid tracer mass concentration in the liquid at $16 \mathrm{hr}$, liquid density at $16 \mathrm{hr}$.

3. Average all the normalized molar total hydroxide concentrations from (2).

- Inputs: None.

4. Convert all liquid $\mathrm{Al}$ concentrations to molarity and normalize to maximum-volume conditions at $16 \mathrm{hr}$

- Inputs: Al mass concentrations in the liquid at all $t$, liquid densities at all $t$, molecular weight of $\mathrm{Al}$, liquid tracer mass concentrations in the liquid at all $t$, liquid tracer mass concentration in the liquid at $16 \mathrm{hr}$, liquid density at $16 \mathrm{hr}$.

5. Assuming values for the adjustable parameters (the kinetic rate constant and the initial normalized molar Al concentration in the liquid), use Equations (A.42) through (A.46) to predict the boehmite leach factor and the $\mathrm{Al}$ concentration in the liquid at 1-min intervals, calculate the prediction error in liquid $\mathrm{Al}$ concentration for those times at which sample data are available, and solve for the values of the adjustable parameters that minimize the prediction error over all the realizations.

- Inputs: Temperature (the average over all submerged sensors) at 1-min intervals, activation energy, ideal gas constant, molecular weights of $\mathrm{Al}_{2} \mathrm{O}_{3}$ and $\mathrm{Na}_{2} \mathrm{O}$.

- Because all gibbsite is assumed to have dissolved by the time temperature is reached, the fraction of solid-phase Al that is in boehmite at $0 \mathrm{hr}$ is defined as unity.

The sequence of calculations in the kinetic data analysis for the laboratory-scale tests was as shown below.

1. Use Equations (A.66a), (A.66b), and (A.66c) to obtain three different estimates of the Al concentration in the initial diluted slurry.

- Inputs: Weight fraction of dilution in the initial diluted slurry, Al mass concentration in the excess slurry, Al mass concentration in the initial diluted slurry, Al mass concentration in the final slurry, Na mass concentration in the final slurry, Na mass concentration in the initial diluted slurry.

2. Use Equation (A.67) to average the three estimates to obtain the total slurry concentration of $\mathrm{Al}$ in the initial diluted slurry.

- Inputs: None.

3. Use Equation (A.68) to obtain the moles of boehmite at $0 \mathrm{hr}$ per volume of liquid in the initial diluted slurry (initial molar concentration of boehmite normalized to maximum-volume conditions).

- Inputs: Molecular weight of Al, weight fraction UDS in the initial diluted slurry, Al mass concentration in the initial diluted slurry, $\mathrm{Al}$ mass concentration in the liquid at $0 \mathrm{hr}$, liquid tracer mass concentration in the liquid at $0 \mathrm{hr}$, liquid tracer mass concentration in the liquid in the initial diluted slurry, liquid density in the initial diluted slurry. 
4. Use Equation (A.65) to obtain the molar total hydroxide concentration at time $t$, then normalize to maximum-volume conditions in the initial diluted slurry.

- Inputs: Molar free hydroxide at $t, \mathrm{Al}$ mass concentration in the liquid at $t$, liquid density at $t$, molecular weight of Al, liquid tracer mass concentration in the liquid at $t$, liquid tracer mass concentration in the liquid of the initial diluted slurry, liquid density in the initial diluted slurry.

5. Average all the normalized molar total hydroxide concentrations from (2).

- Inputs: None.

6. Convert all liquid $\mathrm{Al}$ concentrations to molarity and normalize to maximum-volume conditions in the initial diluted slurry.

- Inputs: Al mass concentrations in the liquid at all $t$, liquid densities at all $t$, molecular weight of $\mathrm{Al}$, liquid tracer mass concentrations in the liquid at all $t$, liquid tracer mass concentration in the liquid in the initial diluted slurry, liquid density in the initial diluted slurry.

7. Assuming values for the adjustable parameters (the kinetic rate constant and the initial normalized molar Al concentration in the liquid), use Equations (A.42) through (A.46) to predict the boehmite leach factor and the $\mathrm{Al}$ concentration in the liquid at 1-min intervals, calculate the prediction error in liquid $\mathrm{Al}$ concentration for those times at which sample data are available, and solve for the values of the adjustable parameters that minimize the prediction error over all the realizations.

- Inputs: Temperature at 1-min intervals based on the temperature measured at the most recent sample time (samples were taken 1 to $2 \mathrm{hr}$ apart), activation energy, ideal gas constant, molecular weights of $\mathrm{Al}_{2} \mathrm{O}_{3}$ and $\mathrm{Na}_{2} \mathrm{O}$.

Because all gibbsite is assumed to have dissolved by the time temperature is reached, the fraction of solid-phase $\mathrm{Al}$ that is in boehmite at $0 \mathrm{hr}$ is defined as unity.

\section{C.2 Perturbation Distributions Used in Monte Carlo Analysis}

The perturbation distributions are listed below for each type of measurement that was used.

Weight fractions undissolved solids (UDS fractions): For both PEP and laboratory-scale analyses the UDS fractions were direct measurements. The perturbations added to UDS fractions were calculated as random values from a normal distribution that had a standard deviation equal to half the uncertainty value supplied by the provider, and that was centered on zero (no bias).

Liquid densities: The liquid densities for the PEP samples were direct measurements. Stochastic calculations were carried out in the same way as for UDS fraction. No liquid densities were measured for the laboratory-scale samples. The liquid density was estimated from correlations of PEP data as described in the footnote to Table B.5. The uncertainty was assumed to be the same as for the measured densities from PEP samples. Presumably the true uncertainty was higher, but the difference between the PEP data and the correlation line drawn through them was generally less than $0.01 \mathrm{~g} / \mathrm{mL}$, relatively small. The perturbations were calculated as for the measured liquid densities.

Concentrations in the liquid: In all cases the concentrations of dissolved species were measured in mass concentration units, for $\mathrm{Al}$ and liquid tracers, and in molarity, for free hydroxide. Perturbations added to liquid-phase concentrations of species were calculated as random values from a normal 
distribution that had a standard deviation equal to half the uncertainty value supplied by the provider, and that was centered on zero.

Total concentrations in the slurry: For laboratory-scale samples, all concentrations of species in the slurry were direct measurements, for which stochastic calculations were carried out in the same way as for liquid concentrations. For PEP samples, which were centrifuged before analysis, all total slurry concentrations were calculated values. They were based on three measurements: concentration in the centrifuged solids, weight fraction of centrifuged solids in the slurry, and (except for solid tracer species) concentration in the liquid. The liquid concentrations of solid tracers were assumed to be zero with no uncertainty. See Equations (A.60) and (A.58).

The species concentrations in the centrifuged solids and in the liquid were assigned perturbations in the standard way, based on the uncertainty data supplied by the analytical provider. The weight fraction of centrifuged solids did not have a supplied uncertainty. The fraction was calculated as the ratio of the mass centrifuged solids and the mass slurry. For stochastic purposes, the standard deviation of the fraction was calculated in the following way. For every triplicate set of samples in a test, the standard deviation of the three samples' centrifuged solids weight fractions was calculated and divided by the mean of the three fractions to give a relative standard deviation. The maximum relative standard deviation over all the triplicate sets in the test was then used as the relative standard deviation for all weight fractions in the test. It was multiplied by the measured fractions to give absolute standard deviations. Because there were fewer triplicate data sets in the lab scale tests than in the PEP tests, the standard deviations assigned to the same sample in the two types of test were different. This led to small differences (10-20\%) in the standard deviation of the slurry concentration for the same sample, depending on whether the sample concentration was part of stochastic calculations for the PEP tests or the laboratory-scale tests.

The perturbations applied to temperature in the kinetic calculations had a different basis for the PEP tests than for the laboratory-scale tests. For the PEP tests, temperatures were measured simultaneously at a number of sensors. The standard deviation of the temperatures at all the submerged sensors, with 1-min time resolution, was used as the standard deviation of the perturbation distribution. For the laboratory-scale tests, a single sensor was used to measure temperature at the time each sample was taken. The standard deviation of all temperatures measured during the "constant-temperature" leach period was used as the standard deviation of the perturbation distribution. For both the PEP and laboratory-scale tests the mean of the temperature perturbation distribution was zero (no bias).

Some of the variables used in stochastic calculations had unknown uncertainty and were assigned zero uncertainty for lack of other information. These included weight fraction dilution in the initial diluted slurry in laboratory-scale tests, elapsed time, molecular weights of elements and compounds, activation energy in the kinetic equation, the fraction of solid-phase Al that was in boehmite before $\mathrm{NaOH}$ was added (in the feed simulant), and the fraction of solid-phase $\mathrm{Al}$ that was in boehmite when $98^{\circ} \mathrm{C}$ was first reached (assumed to be 100\%).

In addition, the correlation uncertainty was not considered in using the correlation of saturated $\mathrm{Al}$ concentration as a function of total hydroxide concentration (Equations [A.44] and [A.45]). The correlation was treated as an exact predictor of saturated $\mathrm{Al}$ in stochastic calculations.

Finally, it should be noted that there is a distinction between the data that appear in tables in Section 3, describing process conditions, and those used in stochastic calculations, as shown in tables in 
Section 4. The standard deviations in the Section 3 tables of calculated quantities - molal concentrations or slurry concentrations - were calculated using approximate error propagation equations (given in Section A.5). The standard deviations of calculated quantities that are shown in Section 3 were used only for tabulation purposes and were not used in stochastic calculations. The stochastic calculations depended only on the uncertainties of direct measurements.

The small difference between the uncertainties of slurry concentrations has already been mentioned in the context of stochastic calculations. It can also be seen in the standard deviations calculated by error propagation for Section 3 tables. In Table 3.14, for example, the standard deviation for the "before $\mathrm{NaOH}$ " samples is different in the PEP test than in the laboratory-scale tests. A third, slightly different

value of standard deviation of the slurry concentration is shown in Table 3.7. Again, the difference comes from a different method of calculating the standard deviation of the centrifuged solids weight fraction. For the concentrations tabulated in Table 3.7, the standard deviation of the fraction was estimated from the uncertainty of the balance instrument used to weigh the centrifuged solids mass and the slurry mass.

\section{$\underline{\text { REFERENCE }}$}

Kurath DE, BD Hanson, MJ Minette, DL Baldwin, BM Rapko, LA Mahoney, PP Schonewill, RC Daniel, PW Eslinger, JL Huckaby, JM Billing, PS Sundar, GJ Josephson, JJ Toth, ST Yokuda, EBK Baer, SM Barnes, EC Golovich, SD Rassat, CF Brown, JGH Geeting, GJ Sevigny, AJ Casella, JR Bontha, RL Aaberg, PM Aker, CE Guzman-Leong, ML Kimura, SK Sundaram, RP Pires, BE Wells, and OP Bredt. Pretreatment Engineering Platform Phase 1 Final Test Report. WTP-RPT-197, PNNL-18894, Pacific Northwest National Laboratory, Richland Washington. 



\section{Distribution}

No. of

Copies

OFFSITE
No. of

Copies

\section{ONSITE}

Pacific Northwest National Laboratory

(authors will be notified electronically)

R.L. Aaberg

K3-54

P.M. Aker

$\mathrm{K} 5-25$

P.W. Eslinger

K6-52

E.C. Golovich

$\mathrm{K} 5-25$

B.D. Hanson

P7-27

T.S. Hausmann

Sequim

J.L. Huckaby

K7-15

D.E. Kurath

K3-52

L.A. Mahoney

K7-15

P7-25

M.J. Minette

K6-28

S.D. Rassat

K6-24

S.K. Sundaram

K7-15

Information Release (pdf)

2 Bechtel National, Inc. WTP R\&T Docs

H4-02

SM Barnes

Dist. 1 


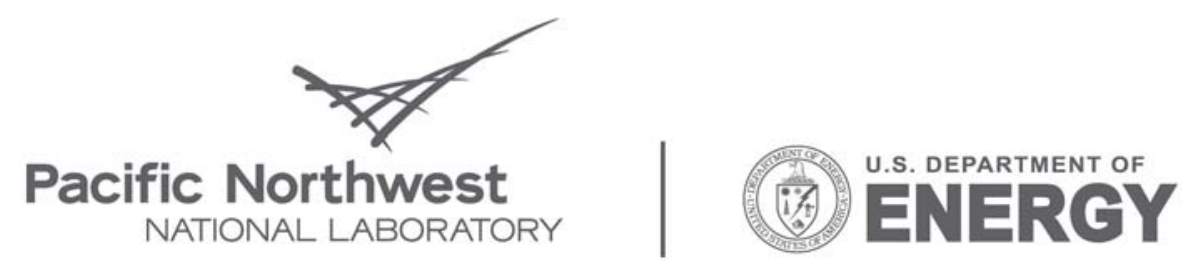

Proudly Operated by Battelle Since 1965

902 Battelle Boulevard

P.O. Box 999

Richland, WA 99352

1-888-375-PNNL (7665)

www.pnl.gov 